\title{
Towards (primary) prevention of childhood asthma in primary care : the PREVASC study
}

Citation for published version (APA):

Schonberger, H. J. A. M. (2003). Towards (primary) prevention of childhood asthma in primary care : the PREVASC study. [Doctoral Thesis, Maastricht University]. Universiteit Maastricht. https://doi.org/10.26481/dis.20040319hs

Document status and date:

Published: 01/01/2003

DOI:

10.26481/dis.20040319hs

Document Version:

Publisher's PDF, also known as Version of record

\section{Please check the document version of this publication:}

- A submitted manuscript is the version of the article upon submission and before peer-review. There can be important differences between the submitted version and the official published version of record.

People interested in the research are advised to contact the author for the final version of the publication, or visit the DOI to the publisher's website.

- The final author version and the galley proof are versions of the publication after peer review.

- The final published version features the final layout of the paper including the volume, issue and page numbers.

Link to publication

\footnotetext{
General rights rights.

- You may freely distribute the URL identifying the publication in the public portal. please follow below link for the End User Agreement:

www.umlib.nl/taverne-license

Take down policy

If you believe that this document breaches copyright please contact us at:

repository@maastrichtuniversity.nl

providing details and we will investigate your claim.
}

Copyright and moral rights for the publications made accessible in the public portal are retained by the authors and/or other copyright owners and it is a condition of accessing publications that users recognise and abide by the legal requirements associated with these

- Users may download and print one copy of any publication from the public portal for the purpose of private study or research.

- You may not further distribute the material or use it for any profit-making activity or commercial gain

If the publication is distributed under the terms of Article $25 \mathrm{fa}$ of the Dutch Copyright Act, indicated by the "Taverne" license above, 
Towards (Primary) Prevention Of Childhood Asthma The PREVASC Study 
The study presented in this thesis was performed at the institute CAPHRI, part of the Netherlands School of Primary Care Research (CaRe), acknowledged in 1995 by the Royal Netherlands Academy of Sciences (KNAW)

The PREVASC study is a joint project of the Departments of General Practice of the University Maastricht, The Netherlands and the Radboud University Nijmegen. The Netherlands.

Towards (primary) prevention of childhood asthma in primary care I Schönberger, Hubertus Jacobus Antonius Maria. Thesis Maastricht - With Ref - With summary in Dutch

(C) Copyright. H.J.A.M. Schönberger, Maastricht. 2003

ISBN 90-9017887-2

Subject headings: asthma, prevention, environmental exposure, childhood

Druk:

(C): Niets van deze uitgave mag worden vermenigvuldigd en/of openbaar gemaakt worden door middel van druk, fotocopie, microfilm of op welke andere wijze dan ook, zonder voorafgaande schriftelijke toestemming van de auteur Press:

(C): No parts of this book may be reproduced or transmitted in any form or by any means. electronic or mechanical, including photocopying, recoding or any information storage and retrieval system, without the permission in writing of the author.

Omslag: fetal felicity (foetale gelukzaligheid)"; H.J.A.M. Schönberger 2003, gemengde techniek

Printing: $\quad$ FEBOdruk BV. Enschede 
Towards (primary) prevention of childhood asthma in primary care

The PREVASC study

Een wetenschappelijke proeve op het gebied van de medische wetenschappen

\author{
Proefschrift \\ ter verkrijging van het \\ de graad van doctor \\ aan de Universiteit Maastricht \\ op gezag van de Rector Magnificus. \\ Prof. mr. G.P.M.F. Mols, \\ volgens besluit van het College van Decanen. \\ in het openbaar te verdedigen op \\ 19 maart 2004 te 16.00 uur \\ door
}

Hubertus Jacobus Antonius Maria Schönberger 
Promotores:

Prof. dr. C.P. van Schayck

Prof. dr. J.A. Knottnerus

Prof. dr. C. van Weel (Radboud Universiteit Nijmegen)

Beoordelingscommissie:

\author{
Prof. dr. E.F. Wouters (voorzitter) \\ Prof. dr. H.F.J.M. Crebolder \\ Dr. J.J. Hendriks \\ Prof. dr. D.S. Postma (Rijks Universiteit Groningen) \\ Dr. C. Thiis
}

The PREVASC study was supported by the Dutch "Praeventiefonds" (now, ZonMw 'Netherlands Organisation for Health Research and Development'). by the Dutch Asthma Foundation, and by the Royal Netherlands Academy of Sciences (KNAW).

The printing of this thesis was financially supported by a grant from the Dutch Asthma Foundation, from Claxo Wellcome BV and from Boehringer Ingelheim - Pfizer BV. 
In dankbare herinnering aan mijn ouders Jacques Schönberger en Jo Ardts.

Voor mijn kinderen, David. Titus, Hanneke en Laurens, wellicht als voorbeeld?

Voor Maria, zo vol van liefde.

Haiku voor de 19 e maart 2004

De corona vraagt.

peinst de promovendus plots

ha, bijna lente! 



\section{Content}

Preface

Chapter 1

General introduction, formulating the aims and the research questions

Chapter 2

The rationale and design of the PREVASC study

Chapter 3

The room for improvement in reducing environmental exposure

Chapter 4

The compliance with the PREVASC program and the effect of exposure reducing measures on house dust mite and pet allergens.

Chapter 5

The clinical effectiveness of the PREVASC program

Chapter 6

The timing of the prevention. Prenatal environmental exposure and $\lg _{\mathrm{g}}$ at birth

Chapter 7

Towards an early diagnosis of asthma in general practice

Chapter 8

General discussion, conclusions and recommendations

Chapter 9

Summary

Samenvatting 
Na-en dankwoord

Curriculum vitae

Appendices

1 The PREVASC prevention program

2 Excerpt of the health educational intervention protocol

3 The timing of the intervention measures and data sampling

4 Informed consent form of the intervention (a) and control group (b)

5 Registration form general practitioners

6. Registration weekly diary form parents

For reasons of consistency some terms and notions within this manuscript are standardised and may therefore differ from the used terms and notions in papers, published or submitted to different journals in different countries. 
This thesis originated as the result of scientific astonishment and curiosity, which was aroused during my work/career as a family doctor. Two things particularly drew my attention. First. the familial occurrence of numerous diseases.

For more than 25 years I had been working as a general practitioner in an isolated, rural village, hemmed in between the river Meuse and the German border. It is a place where residents stay their whole life. Most of them never leave the village in which they are born. usually finding their partners in the same village or nearby. Not surprisingly, the parents of the young couples are mostly also living there. Now through the years I got to know nearly all of the families in the village and their mutual relationships. I saw their members when I worked in the well-baby clinic and in the local nursing home. I saw them as a general practitioner during my surgery hours or during my daily visits to people ill in bed. Besides 1 met them in a social capacity as a member of the village community during social activities. Not seldom was I treating three generations of the same family at the same time. I noticed that besides the well-known familial occurrence of some diseases such as diabetes, cardiovascular diseases and allergies, there was a range of more or less minor illnesses, which appeared to me to run in families, too. Low blood pressure, varices, gall bladder and kidney stones, defaecation patterns, spastic colitis, chondropathia patellae, low back pain, inguinal hernia, gonarthrosis and anxiety disorder were examples of illnesses that showed this familial pattern. Often patients themselves would draw attention to this familial occurrence, when they consulted me.

Now it seemed to me quite simply that if certain outward resemblances such as facial expression, length, posture, general expression and gesture were so strikingly present between (grand) parents and children, it could perhaps be argued that there were similar 'biological' resemblances possible 'on the inside' of the body, at organ level. Of course I had to question whether the familial occurrence of these examples of mostly minor, but still annoying illnesses was really the result of the phenotypical expression of a (polygenetic) inheritance or might be explained by 'pseudo-inheritance', in which the familial occurrence was perhaps caused by other factors such as a shared environment, practicing the same trade or profession, or confounding factors such as increased awareness of symptoms of the disease present in other family members. All this led to some further questions: what could 
we, general practitioners, actually do with the knowledge of familial occurrences with which we were so frequently confronted? What could be the diagnostic, therapeutic or preventive value? The need for further understanding in this whole issue was born.

The other issue facing me - partly originating from the first - had to do with my experience that many of my patients, confronted with minor or major diseases in members of their family often asked me how they might prevent the development of the same disease in themselves. Mostly I had no answer. What I had learned as a general practitioner was to direct medical educational advice to sick people, not to healthy persons. I had not been trained for this at university. Rather I wanted to use my range of diagnostic tools and my authority in prescribing medication. Moreover, most health education, in my view, did not seem to be based on evidence but rather on belief and experience coupled with a modicum of common sense and laymen's ability to interpret 'biological facts'. For example, the advice to lose weight when diabetic is evidence based, but does the advice to strive to attain a normal weight prevent the development of diabetes when there is a familial occurrence of diabetes? These two issues, the wish to explore (the usefulness of the knowledge of familial occurrence of diseases in medical practice and the need to evaluate the effect of health education in preventing diseases in primary care, formed the background for this thesis.

In the course of the last 5-10 years my special interest was more and more aroused for allergic diseases, especially asthma, a disease which 'ideally' seemed to fit my specific areas of interest.

Asthmo occurs more often in the same family and seems to be influenced by environmental factors, which, if avoided, might prevent it. Moreover, asthmatic symptoms arise early in life, which makes it possible to assess the effect of preventive measures within a time span of 4 years, coinciding with the period usually given to researchers by the providers of grants to carry out their research (and complete a thesis). I decided to study the possibilities for prevention of asthma in general practice. With the expert help of professor Onno van Schayck. a framework was set up within which my studies were took shape and were developed.

These are now reported in this thesis. 


\section{CHAPTER I}

General introduction 



\section{Primary and secondary prevention of asthmo}

This thesis deals with primary and secondary prevention of childhood asthma in primary care. Primary prevention aims to prevent the development of a disease by taking away the causes of this disease and is therefore by definition directed towards healthy persons. Well-known examples of primary prevention of diseases are: health education (e.g. campaigns against smoking. promoting safe sex), vaccination, and some legislation (e.g. compulsory wearing seat belts when driving in a car).

Primary prevention might be directed towards the general population or specifically towards those who carry a high risk of developing the disease. The choice between a general and a high-risk approach depends (apart from the extent of personal and socio-economic burden) on the effectiveness and efficiency of the preventive therapy in the population at large general or the high-risk segment. Assessing the effectiveness and efficiency includes a health economical evaluation of the primary prevention, which means that the benefits of the therapy have to outweigh the costs. Important factors that affect the efficiency of the intended prevention are its prevalencelincidence within the population, the related economic consequences and the extent to which preventive therapy can implemented in daily practice. What is also important is the acceptability of the intended preventive measures for the target population. For example, a complex asthma preventive therapy may be acceptable for asthmatic families but not for the whole population. In general practice. primary prevention for a specific disease is mostly directed towards subjects who can be identified to be at high risk for the disease, as one would expect high-risk subjects to benefit most from the preventive therapy in terms of health gain. In addition, the high-risk approach has the advantage that fewer subjects are erroneously confronted with possible negative effects of a preventive therapy. Conversely, prevention aimed at the general population. such as mass screening, may result in the treatment of many subjects being treated but only few being cured.

In secondary prevention the goal is to treat the disease as early as possible. in order to prevent the disease from becoming clinically manifest. Secondary prevention is directed towards subjects who show early signs of the disease. Examples of secondary prevention in the Netherlands are early treatment of phenylketonuria and congenital hypothyroidism in newborns identified by heel prick blood at day 3-5 after birth, the periodic physical 
examination in children at school age, screening on hypercholesterolemia in adults and on cervical cancer and breast cancer in women,'

\section{Why prevention of asthma?}

Asthma is an important health problem. It is the most common chronic disease in childhood resulting in great personal and familial burden and socio-economic consequences due to direct and indirect medical costs. ${ }^{2.3}$ Figures about the prevalence of childhood asthma in general practice in the Netherlands can be derived from morbidity databases of several academic networks. Prevalence varies from 3-5\%. ${ }^{4.5}$ Asthma is the disease in childhood with the most common prevalence in general practice. ${ }^{6}$ Moreover, the last 20 years has witnessed a rising trend in the prevalence of asthma in children worldwide. This rising trend has continued up to now as reported in several recent studies. ${ }^{8-10}$ The increased prevalence has also been reported in primary care, emphasing an increase which cannot be explained by changing diagnostic labelling or increased awareness on the part of physicians and patients.

The cause of the increasing prevalence of asthma is unknown. An increase in genetic predisposition is clearly an inadequate explanation. ${ }^{12}$ Nor is it caused by changes in established risk factors such as birth weight, maternal age at birth, breast feeding, family size. maternal smoking and social class. ${ }^{13}$ As asthma is more prevalent in affluent countries than in less developed countries, it is supposed that asthma seems to be "a disease of prosperity". This is further underlined by the increase of atopy and asthma that occurred in children in East Germany after the reunion with West Germany. ${ }^{14}$ However, the why and how of this supposition has still to be clarified. The increasing prevalence of asthma with the resulting socio-economic burden has resulted in the need to investigate the possibilities for primary and secondary prevention of asthma and consequently the need to evaluate the effectiveness and efficiency of the prevention.

There are several theories that address the underlying mechanism of the increasing prevalence of asthma.

The "hygiene hypothesis" theory explains the increasing prevalence of asthma as the result of (among other things) the reduction of common infections in early childhood. This may be caused by growing up in families with fewer siblings and by vaccination against childhood 
diseases. Living in a less polluted environment with less bacterial endotoxines is also supposed to affect the increase of asthma and allergy. ${ }^{15-17}$ As a result the infont's immature immune system may not develop protective immunity against allergens and microbial pathogens.

Another explanation for the increase in the prevalence of asthma is given by the "dietary hypothesis". Changes in diet, such as less intake of vitamine E, C. niacin, zinc, copper and poly-unsaterised fatty acids together with a decline in physical activity has been put forward as the cause of the increase in prevalence. ${ }^{18.19}$

A third hypothesis is the "increased exposure hypothesis", based on studies that report on the positive association between the risk of asthma and environmental allergic exposure, such as allergens of the house dust mite and of the cat, ${ }^{20-22}$ or to food allergens, ${ }^{23}$ and non-allergic exposure such as prenatal and postnatal passive tobacco smoking. ${ }^{24}$ Investigators attribute the increase in prevalence of asthma to a heightened exposure to these environmental factors. Spending increasingly more time indoors in combination with all the changes that have affected indoor living such as the application of insulation with increased indoor humidity, inevitably results in greater exposure. ${ }^{25}$

Given the "increased exposure" hypothesis, it was a logical step to study whether reduction of exposure to known environmental risk factors might prevent the development of asthma. This was the subject on which the PREVASC study was focused. An outline of the studies with regard to primary prevention of asthma is presented below (I). followed by an outline of the studies on secondary prevention of asthma (II).

\section{Primary prevention of asthma: the PREVASC study}

In the course of the last ten years various studies have been designed and set up to elucidate the efficacy of elimination of allergic environmental risk factors, especially house dust mite allergens. Several randomised cohort studies were started to investigate whether the development of asthma could be averted by reduction/avoidance of allergenic and nonallergenic irritants. The studies varied in the kind of environmental exposure that had been manipulated. Some investigated the preventive effect of reduction of a single exposure, such as food allergens, ${ }^{26}$ mite allergens and pet allergens. ${ }^{27.28}$ Others used a dual approach of avoidance of food and mite allergens. ${ }^{29}$ combined with reduction of passive smoking. ${ }^{30}$ Some of them reported preliminary results, looking promising. ${ }^{31}$ Most of the studies directed their 
intervention towards a more or less selected population in more or less controlled circumstances. However, when interventions after proven efficacy are planned to be implemented in daily care, a prerequisite is that the effectiveness of these interventions must also be proved in the "daily care" population, recruited by practitioners working in this "daily care" setting.

From the above, the need to investigate the possibilities for primary prevention of asthma in primary care grew. For that purpose the "PREvention of ASthma in Children" (PREVASC) study, a randomised birth cohort study was designed.

\subsection{Positioning the PREVASC study}

Ideally, the assessment of the cost-effectiveness of a therapy has to be the last step in the empiric cycle before it is decided to implement the therapy in daily care. The empiric cycle starts with the formulation of the supposed (positive) effect of the therapy. Next, the efficacy of the therapy has to be proven. This is done by measurement of the effect of the therapy while controlling for confounders in a restricted population that maximally co-operates with the therapy: The next step is to establish whether the (supposedly efficacious) therapy also works in usual circumstances of daily life: i.e. the effectiveness. Finally, the health-economics effect of the therapy have to be determined which is the combined result of the clinical effectiveness, the costs and the feasibility of applying the therapy in daily life.

The PREVASC study brings together the factors that determine effectiveness and efficiency addressed in primary care. Moreover, in contrast to most primary prevention studies cited above, the comprehensive preventive effect of simultaneous reduction of environmental exposures (of mite, pet and food allergens and passive smoking) is assessed rather than the effect of a reduction of a single exposure.

The rationale, the composition of the prevention program and design of the PREVASC study are explained in chapter 2 in the paper "Prevention of asthma in genetically predisposed children in primary care - from clinical efficacy to a feasible intervention program". ${ }^{32}$

On the basis of this study, the prevention program could be composed (hereafter referred to as the PREVASC programl. The PREVASC program is shown in the box. 


\section{Box. Prevention program of asthma in the PREVASC study}

Recommended measures to reduce exposure in the high-risk infant by avoidance of:

1. Mite allergens from birth and through at least the first two years of life by:

- providing a smooth floor covering in living room, bedroom and nursery;

- cleaning thoroughly by vacuuming/damp mop;

- washing bed-clothes at 60 degrees Celsius;

- providing anti house dust mite covers for parental and crib mattresses;

- providing a new crib mattress;

- ventilating continuously and airing daily during one hour the bedrooms.

2. Cat and dog allergens from birth and through at least the first two years of life by:

- not buying pets;

- in case of pet-owning: re-housing pets and when objected to, regularly washing them and keeping them outside the house.

3. Food allergens during at least the first 6 months of life by:

- not regular formula feeding but breast-feeding and/or using hypoallergenic formula feeding;

- no intake of solid foods.

4. Passive smoking by:

- no maternal prenatal and postnatal smoking;

- no paternal postnatal smoking;

- no smoking by others inside the house.

The PREVASC program was based on a health educational instruction, which was executed by trained nurses. A more detailed reproduction of the health educational protocol is shown in Appendix 2. The nurses visited the parents twice during pregnancy lone visit at the entrance of the study, and the other at month 7-8 of pregnancy) and once directly after birth. They informed the parents about the relation of indoor environmental exposures and asthma and instructed them how and at what time the measures to reduce exposures of the PREVASC program should be applied. Smoking mothers were recommended to abstain from smoking during pregnancy and during the first year of life. Families that kept pets were recommended to dispose of their pets at least 3 months before birth, because pet-specific allergens have shown to be still present several months after the pet had been removed. ${ }^{33}$ When disposal of pets was not possible or refused, the families were asked to keep them 
outside at least 3 month before birth, and to wash them regularly. Reduction of exposure to house dust mite was also recommended to start with before birth. because some measures might take some time to execute, such as the advice to replace a textile floor with a smooth floor covering. Anti house dust mite covers (for mattresses, quilts and pillows and for infant's sleeping bag) were provided for free (Mitecare ${ }^{\circ}$, Sanalife BV. Lelystad, The Netherlands) at month 7-8 of pregnancy with the advice to cover the parental and crib mattresses before birth. During the second visit before birth, it was also recommended to exclusively breastfeed the newborn. from birth until six months of age. In case the infants were born in a hospital setting and additional bottle-feeding would be necessary, parents and caregivers were recommended to use the hypo-allergenic bottle-feeding provided by the PREVASC nurses before birth (Nutrilon Pepti. Numico, Zoetermeer. The Netherlands). A summary of the timing of the interventions and of the data sampling is shown in Appendix 3.

\subsection{Formulating the research questions}

In studying the clinical effectiveness of the PREVASC program, several issues arise that may influence the effectiveness. These issues concern the room for improvement to what extent have asthmatic families not already applied the prevailing preventive measures included in the PREVASC program?), the readiness to comply with the PREVASC program (will parents do what you ask them to do to prevent asthma and if so, are the measures effective in reducing exposure?) and the timing of the start of the PREVASC program lat what point of time does the intervention have to start: early in pregnancy or after birth?l.

\subsubsection{Primary prevention: room for improvement}

A prevention program composed of several environmental avoidance measures will have less impact when the measures recommended have already been carried out in the families involved. This might the case when these measures are applied on one's own initiative or are recommended by professionals. To date, in the Netherlands, primary prevention of asthma is not recommended in medical practice. The guidelines of the Dutch College of Ceneral Practitioners $(\mathrm{NHC})^{34}$ comprise only recommendations on reduction of (passive) smoking and house dust mite and pet allergen exposure (relating to furnishing the home, reducing air humidity, use of anti-mite encasings, avoidance of pets) when asthma has been diagnosed and additionally patients have shown to be allergic to mite and/or pet allergens. No special 
advice is given to prevent the development of asthma in high-risk newborns. Breast-feeding is recommended for all infants. Breast-feeding during the first 6 months of life or when not possible, hypo-allergenic formula feeding. and postponement of the introduction of the first solid foods until after the sixth month, are only recommended with respect to prevention of cow-milk allergy in high-risk infants (i.e. those, with other siblings seriously affected by cowmilk allergy or atopic dermatitis). Naturally, pregnant women are recommended not to smoke.

As already applied measures will affect the room for improvement for the same measures included in the PREVASC program, insight is wanted to in how far asthmatic families have already taken the prevailing preventive measures (Chapter 3 ).

The research question is:

Which measures included in the PREVASC program have asthmatic families already taken? In other words, is there still enough room for improvement in exposure reducing measures in asthmatic families?

\subsubsection{Primary prevention: compliance with measures included in the PREVASC program and their effectiveness in reducing allergen exposure.}

The preventive measures of the PREVASC program were based on published research on efficacious reductions in environmental exposure in controlled situations. Their effectiveness in real life circumstances and in daily primary care, however, has still to be proven. The effectiveness of the PREVASC program on reducing exposure depends on the willingness to comply with the PREVASC measures. Therefore insight in degree of compliance with the measures in the recommended exposure reducing measures is needed. Will parents comply with the recommended measures in the PREVASC program? Who will? And who will not? And to what extent? Which of the measures will they accept, which not? In chapter 4 these questions are dealt with. The research questions are:

How much parental compliance is there with the PREVASC program?

Are the recommended preventive measures regarding house dust mite and pet allergens effective in reducing these allergen levels? 


\subsubsection{Primary prevention: the clinical effectiveness of the PREVASC program}

The main research question in the primary prevention part of this thesis describes the clinical effectiveness of the PREVASC program. In Chapter 5 we report on the effect of the PREVASC program on several clinical outcomes when the children were two years old.

The research question is:

\section{Is the PREVASC program effective in the prevention of asthma?}

\subsubsection{Primary prevention: the timing of the intervention}

The PREVASC study was designed in 1997 and its intervention to reduce house dust mite and pet allergens exposure was intended to achieve low allergen levels at birth and during at least the first two years of life. However, after the start of the PREVASC study some studies suggested the possibility of prenatal sensitisation, reporting in vitro foetal immune responses on maternal exposure to house dust mite allergens. ${ }^{35.36}$ On the base of this knowledge. some suggested that the allergen avoidance measures should start in early pregnancy, ${ }^{36}$ although this is controversial. ${ }^{38}$ The option of starting the prevention before birth could be recommended on good grounds if a clear (dose-response) relationship between prenatal exposure and allergic morbidity and asthma could be demonstrated. Within the PREVASC study, we were able to analyse the relationship between prenatal exposure to inhalant allergens with total lgE at birth in a group high-risk neonates. This study is presented in chapter 6 . The research question is:

What is the relationship between the prenatal environmental exposure and $\mathrm{IgE}$ at birth?

\section{Why secondary prevention of asthma?}

Many children who develop asthma do not have a family history of asthma and would therefore not be a candidate for the primary prevention directed towards high-risk newborns. ${ }^{39}$ Moreover, we have to be realistic and see that. even if it is proved that primary prevention of asthma has beneficial effect. the way to implementation of primary prevention in daily practice is still long and, even if primary prevention was implemented, it is still unlikely that it would completely prevent the development of asthma. Therefore, secondary 
prevention of asthma remains important. Moreover, there is growing evidence that early treatment, especially with anti-inflammatory medication, might prevent irreversible damage of the lung ${ }^{40.41}$ with all the consequences later in life. Early treatment implies however early diagnosis of asthma and that may be a problem in general practice. However, here we have a problem. Although wheezing is the most prominent symptom of asthma in infants, ${ }^{42.43}$ is not specific enough to confirm asthma. ${ }^{43}$ Identification of children with asthma among the many that present wheezing in early life is a challenge, as before 6 years of age lung function tests and other 'diagnostic' markers are either impossible to be performed or not predictive enough to diagnose asthma. ${ }^{44}$ Therefore we investigated a birth cohort in general practice to explore the risk of asthma in wheezing children with the following research questions:

What is the risk of early childhood wheezing for asthma?

What is in early wheezing children the additional diagnostic value of familial occurrence of atopic diseases?

What is in early wheezing children the additional diagnostic value of non-wheezing respiratory and atopic morbidity for asthma?

This part of the thesis is reported in chapter 7.

Finally, in chapter 8 , a comprehensive general discussion is presented addressing the most important results of the study, methodological aspects, implications as to current knowledge, and recommendations for practice and future research. 


\section{References}

1. Eddy DM. Secondary prevention of cancer: an overview. Bull World Health Organ 1986;64(3):421-9.

2. Molken MP, Van Doorslaer EK, Rutten FF. Economic appraisal of asthma and COPD care: a literature review 1980-1991. Soc Sci Med 1992;35(2):161-75.

3. von Mutius E. The burden of childhood asthma. Arch Dis Child 2000;82(Suppl 2):II2-5.

4. Lamberts H. Morbidity in general practice. Diagnosis related information from the Monitoring Project. Utrecht : Huisartsen Pers BV. 1984.

5. Metsemakers JFM, Höppener P, Knottnerus JA, Kocken RJJ, ChBG. L. Computerized health information in the Netherlands: a registration network of family practices. Br J Gen Pract 1992;42:102-106.

6. Knottnerus JA, Metsemakers J, Hoppener P, Limonard C. Chronic illness in the community and the concept of 'social prevalence' [see comments]. Fam Pract 1992;9(1):15-21.

7. Aberg N, Sundell J, Eriksson B, Hesselmar B, Aberg B. Prevalence of allergic diseases in schoolchildren in relation to family history, upper respiratory infections, and residential characteristics. Allergy 1996;51(4):232-7.

8. Downs SH, Marks GB, Sporik R, Belosouva EG, Car NG, Peat JK. Continued increase in the prevalence of asthma and atopy. Arch Dis Child 2001;84(1):20-23.

9. Upton MN, McConnachie A, McSharry C, et al. Intergenerational 20 year trends in the prevalence of asthma and hay fever in adults: the Midspan family study surveys of parents and offspring. $B M J$ 2000;321(7253):88-92.

10. Ng Man Kwong G, Proctor A, Billings C, et al. Increasing prevalence of asthma diagnosis and symptoms in children is confined to mild symptoms. Thorax 2001;56(4):312-4.

11. Tirimanna PR, van Schayck CP, den Otter JJ, et al. Prevalence of asthma and COPD in general practice in 1992: has it changed since 1977? Br J Gen Pract 1996;46(406):277-81.

12. Devereux $G$. The increase in allergic disease: environment and susceptibility. Proceedings of a symposium held at the Royal Society of Edinburgh, 4th June 2002. Clin Exp Allergy 2003;33(3):394-406.

13. Chinn S, Rona RJ. Can the increase in body mass index explain the rising trend in asthma in children? Thorax 2001;56(11):845-50.

14. von Mutius E, Martinez FD, Fritzsch C, Nicolai T, Roell G, Thiemann HH. Prevalence of asthma and atopy in two areas of West and East Germany. Am J Respir Crit Care Med 1994;149(2 Pt 1):358-64.

15. Strachan DP. Family size, infection and atopy: the first decade of the "hygiene hypothesis". Thorax 2000;55 Suppl 1:\$2-10.

16. Wickens K, Pearce N, Crane J, Beasley R. Antibiotic use in early childhood and the development of asthma. Clin Exp Allergy 1999;29(6):766-71.

17. Von Ehrenstein OS, Von Mutius E, Illi S, Baumann L, Bohm O, von Kries R. Reduced risk of hay fever and asthma among children of farmers. Clin Exp Allergy 2000;30(2):187-93.

18. Schwartz J, Weiss ST. Dietary factors and their relation to respiratory symptoms. The Second National Health and Nutrition Examination Survey. Am J Epidemiol 1990;132(1):67-76.

19. Devereux G, Barker RN, Seaton A. Antenatal determinants of neonatal immune responses to allergens. Clin Exp Allergy 2002;32(1):43-50.

20. Sears MR, Greene JM, Willan AR, et al. Long-term relation between breastfeeding and development of atopy and asthma in children and young adults: a longitudinal study. Lancet 2002;360(9337):901-7.

21. Lanphear BP, Aligne CA, Auinger P, Weitzman M, Byrd RS. Residential exposures associated with asthma in US children. Pediatrics 2001;107(3):505-11.

22. Simpson BM, Custovic A, Simpson A, et al. NAC Manchester Asthma and Allergy Study (NACMAAS): risk factors for asthma and allergic disorders in adults. Clin Exp Allergy 2001;31(3):391-9. 
23. Gdalevich M, Mimouni D, Mimouni M. Breast-feeding and the risk of bronchial asthma in childhood: a systematic review with meta-analysis of prospective studies. $J$ Pediatr 2001;139(2):261-6.

24. Lodrup Carlsen KC, Carlsen KH. Effects of maternal and early tobacco exposure on the development of asthma and airway hyperreactivity. Curr Opin Allergy Clin Immunol 2001;1(2):139-43.

25. van Lynden van Nes AMT. Effective mite allergen avoidance in households with asthmatic children., 1999.

26. Exl BM, Deland U, Secretin MC, Preysch U, Wall M, Shmerling DH. Improved general health status in an unselected infant population following an allergen reduced dietary intervention programme. The ZUFF-study-programme. Part I: Study design and 6-month nutritional behaviour. Eur J Nutr 2000;39(3):89-102.

27. Custovic A, Simpson BM, Simpson A, Kissen P, Woodcock A. Effect of environmental manipulation in pregnancy and early life on respiratory symptoms and atopy during first year of life: a randomised trial. Lancet 2001;358(9277):188-93.

28. Koopman LP, van Strien RT, Kerkhof M, et al. Placebo-controlled trial of house dust miteimpermeable mattress covers: effect on symptoms in early childhood. Am J Respir Crit Care Med 2002;166(3):307-13.

29. Hide DW, Matthews S, Tariq S, Arshad SH. Allergen avoidance in infancy and allergy at 4 years of age [see comments]. Allergy 1996;51(2):89-93.

30. Chan-Yeung M, Manfreda J, Dimich-Ward H, Ferguson A, Watson W, Becker A. A randomized controlled study on the effectiveness of a multifaceted intervention program in the primary prevention of asthma in high-risk infants. Arch Pediatr Adolesc Med 2000;154(7):657-63.

31. Gore C, Custovic A. Preventive measures and their effects. Results from cohort studies. Paediatr Respir Rev 2002;3(3):205-18.

32. Schonberger HJ, Van Schayck CP. Prevention of asthma in genetically predisposed children in primary care--from clinical efficacy to a feasible intervention programme. Clin Exp Allergy 1998;28(11):1325-31.

33. Wood RA, Chapman MD, Adkinson NF, Jr., Eggleston PA. The effect of cat removal on allergen content in household-dust samples. J Allergy Clin Immunol 1989;83(4):730-4.

34. Dirksen WJ, Geijer RMM, de Haan M, de Koning G, Flikweert S, Kolnaar BGM. NHG-Standaard Astma bij Kinderen (eerste herziening). Huisarts Wet 1998(41(3)):130-43.

35. Heinrich J, Bolte G, Holscher B, et al. Allergens and endotoxin on mothers' mattresses and total immunoglobulin E in cord blood of neonates. Eur Respir J 2002;20(3):617-23.

36. Miller RL, Chew GL, Bell CA, et al. Prenatal exposure, maternal sensitization, and sensitization in utero to indoor allergens in an inner-city cohort. Am J Respir Crit Care Med 2001;164(6):9951001.

37. Austin JB, Kaur B, Anderson HR, et al. Hay fever, eczema, and wheeze: a nationwide UK study (ISAAC, international study of asthma and allergies in childhood) [In Process Citation]. Arch Dis Child 1999;81(3):225-30.

38. Smillie FI, Elderfield AJ, Patel F, et al. Lymphoproliferative responses in cord blood and at one year: no evidence for the effect of in utero exposure to dust mite allergens. Clin Exp Allergy 2001;31(8):1194-204.

39. Bergmann R, Woodcock A. Whole population or high-risk group? Childhood asthma. Eur Respir J Suppl 1998;27:9s-12s.

40. Barnes PJ. Efficacy of inhaled corticosteroids in asthma. J Allergy Clin Immunol 1998;102(4 Pt 1):531-8.

41. Volovitz B, Nussinovitch M, Finkelstein Y, Harel L, Varsano I. Effectiveness of inhaled corticosteroids in controlling acute asthma exacerbations in children at home. Clin Pediatr (Phila) 2001;40(2):79-86.

42. Kaur B, Anderson HR, Austin J, et al. Prevalence of asthma symptoms, diagnosis, and treatment in 12-14 year old children across Great Britain (international study of asthma and allergies in childhood, ISAAC UK). Bmj 1998;316(7125):118-24. 
43. Martinez FD, Wright AL, Taussig LM, Holberg CJ, Halonen M, Morgan WJ. Asthma and wheezing in the first six years of life. The Group Health Medical Associates [see comments]. $N$ Engl J Med 1995;332(3):133-8.

44. Pattemore PK, Asher MI, Harrison AC, Mitchell EA, Rea HH, Stewart AW. The interrelationship among bronchial hyperresponsiveness, the diagnosis of asthma, and asthma symptoms. Am Rev Respir Dis 1990;142(3):549-54. 


\section{CHAPTER 2}

The rationale and the design of the PREVASC study

Published as:

Schonberger HJ. Van Schayck CP. Knottnerus JA. Prevention of asthma in genetically predisposed children in primary care--from clinical efficacy to a feasible intervention programme. Clin Exp Allergy 1998:281711:132531. 


\begin{abstract}
On the basis of literature the possibilities for a feasible primary prevention of asthma by means of reduction of environmental exposures in primary care were discussed. The primary prevention should consist of environmental reducing measures, which have shown to be associated with asthma, can be reduced efficaciously, were supposed to be efficaciously in reducing asthma morbidity and are acceptable for the parents and child. Using these criteria, a prevention program could be composed. The prevailing measures were: 11 ) reduction of house dust mite allergens (sanitation measures and use of house dust mite impermeable covers for the parental and crib mattress, quilt, pillow and infants' sleeping bag): (2) reduction of allergens of cat and dog (not procuring pets, washing, keeping them outside); (3) food allergens lexclusive breast-feeding the infant and/or avoiding cow-milk based regular bottle feeding: postponing the first solid food until six months of age): (4) avoidance of prenatal and postnatal passive tobacco smoking.
\end{abstract}

The methodological characteristics of a planned intervention study to be executed have been outlined: recruitment of of least 400 high-risk unborn children by the general practitioner; allocation of recruited families to the intervention and control group by prerandomisation: the intervention group receives health educational advice from especially trained nurses: the control group receives usual care and remains unaware of the intervention: clinical outcomes are asthma-like symptoms, recorded by the general practitioner and parents and, total and specific lgE at age two years; compliance on the extent the advised measures will be measured. 


\section{Introduction}

Wheezing in infancy and asthma in children are growing health problems. World-wide the prevalence of asthma in children is high and it seems to be still increasing. ${ }^{1-4}$ Changes in the domestic environment might be an underlying cause. ${ }^{5.6}$ Asthma in childhood is, apart from social and economic consequences, a disruptive burden for these children and for their parents. ${ }^{5.7-11}$ Therefore, much attention is paid how asthma can be prevented. Besides secondary prevention, such as pharmacotherapy or immunotherapy, there is growing interest in the primary prevention of asthma. Primary prevention of asthma implies that the development of asthma is averted by elimination of influenceable causes of the disease. It is generally agreed that asthma is a multifactorial disease which develops when genetically predisposed children are exposed to relevant environmental irritants in very early life or even in utero. ${ }^{12.13}$ As it is (ot present) not possible to manipulate the 'asthmatic' genotype of the child, we can only try to influence the environmental factors, which are known to enhance the development of asthma. ${ }^{14}$ These factors have been repeatedly determined in observational studies ${ }^{15-21}$ and are summarised in several reviews. ${ }^{22-24}$ Male sex, birth order, birth month, size of families, pre- and dysmaturity, and age of the mother, have all proven to influence the likelihood of the development of childhood asthma. These factors, however, cannot (or not easily) be manipulated. The role of other, to a certain extent influenceable risk factors such as the intake of antioxidants (e.g. vitamin A, C. E and Selenium) ${ }^{25.26}$ is not clear yet. The same holds for air pollutants ${ }^{27.28}$ and respiratory (viral) infections. ${ }^{18.29-35}$ Respiratory infections may be stimulating or inhibiting the immune system, they can modulate the developing autoimmune mechanism of the genetically predisposed infant in the direction of either the Th2 (allergic) or the Th1 (non-allergic) phenotype. In which of the two directions the immune mechanism is driven may depend upon which period in the development of the immune mechanism of the infant a virus infection occurs, and perhaps also on the frequency of exposure and/or the dose of the viral antigen. The well-known risk factors, such as the exposure to respiratory ${ }^{36-38}$ and food allergens $s^{39-54}$ as well as environmental tobacco smoking $(E T S)^{55.57}$ seem to have more possibilities for intervention.

In this paper the possibilities for a feasible and applicable prevention of the development of asthma in a primary care setting are discussed. As the general practitioner (GP) plays a key role in family health care, the preconditions of primary prevention of asthma seem to be best 
met in primary care. The central issue is the question whether our knowledge is nowadays sufficient to implement a comprehensive prevention program for asthma in primary care on a large scale. To answer this question, the conditions, first postulated by Wilson and Jungner in 1968 for screening programs aiming on the early detection of diseases ${ }^{58}$ are used here as a guideline. The conditions are summarised in an adapted form in Table 1. The most important ones are discussed in this paper. Firstly, it has to be known whether the selection of high-risk children of asthma is possible and feasible in primary care (condition 3 and 4). Furthermore, it has to be proven whether the planned preventive measures are efficacious and cost-effective (condition 5 and 6 ). In addition, the preventive actions must be acceptable and applicable for the parents and their infants. Finally, the program has to be feasible in daily work of the caregivers, such as GPs, practice assistants, district nurses and paediatricians (condition 7 and 8 ). To what extent are these conditions fulfilled at this moment?

Table 1. Conditions which must be fulfilled before planning a primary prevention program of asthma in primary care ladapted from Wilson and Jungner $1968^{58}$,

(1) Sufficient acknowledged importance of the health problem. caused by asthma

(2) Presence of sufficient knowledge about the natural course of asthma

(3) Possibility to identify prenatally children with a high risk for asthma

(4) Acceptability and general availability of the method to identify the risk group

(5) Proven clinical efficacy of the primary prevention of asthma

(6) Positive cost-benefit effect of the prevention program

(7) Acceptability and general availability of the preventive measures

(8) Feasibility of the preventive program in primary care

Is selection of high-risk children possible and acceptable in primary care?

Because some of the interveneable risk factors are assumed to affect the high-risk children prenatally, the identification of these children has to start in early pregnancy. The only possible predictor at this moment to use prenatally is a positive family history. ${ }^{59.61}$ We have recently studied in 52 general practices with a study population of 100.000 subjects that identification of children with a high risk of asthma is feasible in general practice. ${ }^{62}$ A positive family history of asthma (defined as the presence of doctor-diagnosed asthma in first-degree 
family members of the unborn child) occurred in nearly $20 \%$ and showed a significant increased relative risk (RR, with 95\% confidence Interval (CI)), (3.8; C.I. 3.2-4.3) of asthma in the offspring. If both parents have asthma the RR increased to 6.4; C.I, 4.2-9.8. Allergic rhinitis and atopic dermatitis in the relatives did not increase the relative risk of asthma (Figure 1). This way of selection of unborn children at risk for asthma is relatively simple and cheap. In the Netherlands and in several other countries, members of the same family have the same CP. The CP has registered whether a member of the family has asthma. Because almost every pregnant woman visits her GP in early pregnancy, the GP can easily determine whether the unborn child is at risk for asthma.

Figure 1. The relative risk (RR) with $95 \% \mathrm{CI}$ (error bars) of asthma in children when having a positive family history of atopi diseases

9.8

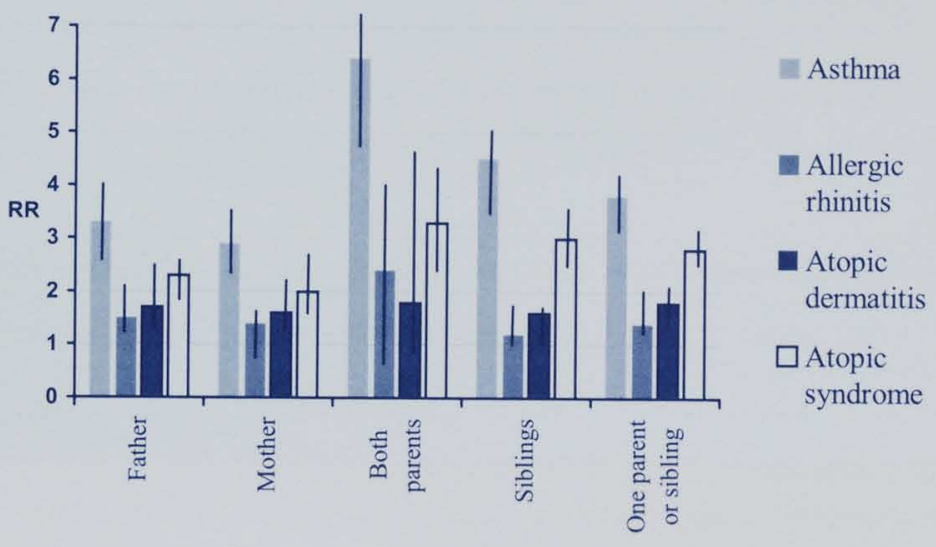

Are preventive measures efficacious and cost-effective?

Firstly, preventive measures which have proven to be clinical efficacious are reviewed. Secondly, it is important to determine, before actually carrying out a prevention program to what extent parents, who have asthma (or whose children have asthma), have taken already some of the proposed preventive measures. In that case a preventive program would have less additional value, as there is less "room for improvement". A third point to consider is that efficacy-knowledge derived from selected populations under controlled circumstances does not answer the most important questions in daily health care: is primary prevention of asthma effective and attainable in the general population in 'real life' circumstances, and are the 
costs at least compensated by the benefits? In other words: is primary prevention of asthma cost-effective? To date, this question has not been yet been answered. Because the (cost) effectiveness and efficiency of a program on prevention of childhood asthma is strongly dependent on the compliance of the parents with the recommended preventive measures. we have to gain insight to what extent parents will co-operate. It is important to know which parents will be compliant and which will be not, and with which preventive measure? These three points (efficacy, room for improvement and compliance) will be discussed in successive order below.

\section{(Clinical) efficacy of the preventive measures}

The possible measures which are suitable for (primary) prevention can roughly be divided in three groups: measures to reduce respiratory allergens produced by house dust mite and pets, measures to reduce food allergens and measures to avoid passive smoking before and after birth. They are summarised in Table 2. With respect to the first two groups of preventive measures, a variety of studies have tried to elucidate their possible beneficial role on wheezing syndromes and asthma. ${ }^{39-54}$

Concerning food allergens, there are four possible methods to prevent early exposition (Table 2). Only prolonged breast feeding and postponing solid foods have shown to be clinically efficacious ${ }^{43.45-51}$ (Table 2 , second and third column).

Concerning respiratory allergens, the (clinical) efficacy of methods to avoid these irritants is reported in several studies (Table 2 , second and third column). ${ }^{63-74}$ Controlling the house dust mite is most effectively achieved by using house dust mite impermeable covers for mattresses, pillows and duvets. 
Table 2. Possible measures and methods which are eligible for admission in a prevention program and their efficacy in reducing exposure and their clinical efficacy.

\begin{tabular}{lll}
\hline Possible preventive measures & $\begin{array}{l}\text { Methods of reduction of exposure and } \\
\text { their efficacy in reducing exposure }\end{array}$ & efficacy on \\
& wheezing \\
& syndromes \\
and/or asthma & (ref)
\end{tabular}

(1) reduction of respiratory allergens

house dust mite

pets (cat and dog) encasing the mattress, pillow, duvet

yes $(63-68)$

sanitation measures:

acaricidal treatment

no (64-68)

hot washing, cleaning, yes $(63-68)$

furnishing, carpet removal

reducing air humidity $<50 \%$

no* $(67-70)$

removal or keeping pets outside the

no* $(72-74)$

house or

sanitation measures: washing the pets

yes* $(72-74)$ (cat)

(2) reduction of food allergens

mother

maternal elimination diet during

no $(41-44)$

pregnancy

elimination diet during lactation

no (51-54)

stimulating breast feeding or hypo-

yes $(43,45-51)$

allergenic formula during at least 6

months after birth

postponing solid foods until at least 6

yes $(48-50)$

months after birth

(3) reduction of environmental tobacco

smoking (ETS)

prenatal

no maternal smoking

yes (75)

postnatal

no maternal and paternal smoking in the

yes (76)

presence of the child

\footnotetext{
* methods showing efficacy of reducing the quantity of specific allergens or irritants, but the clinical benefit of the preventive method has still to be proven.
} 
Apart from that, colonisation of the house dust mite can be combated by hot washing of the bed linens, cleaning. furnishing, carpet removal and by controlling humidity. Reduction of cat allergens by removal of the cat is efficacious. Cat washing seems to be an alternative. ${ }^{72-74}$ although the effect on the airborne level of cat allergens is temporarily. ${ }^{73.74}$ Conversely, to date, the effect of reducing pet allergens on clinical symptoms has not been proven yet. It is important to emphasise that, comparison of the clinical efficacy of studies focusing on the control of food and respiratory allergens is difficult, since most of the studies aim at controlling different environmental risk factors in different combinations and, in addition. criteria for inclusion, outcome parameters and diagnostic criteria differ. Nonetheless, these studies provide enough evidence that there are several methods to diminish food and respiratory allergen exposure with concomitant clinical efficacy on wheezing syndromes and other atopic manifestations.

The third group of preventive measures to discuss is reducing exposure to ETS prenatally and postnatally. What is known about the (clinical) efficacy of ovoidance of ETS? To date. no studies have been done to assess the clinical benefit of reducing pre- and postnatal passive smoking to prevent wheezing syndromes or asthma in children. However. observational data suggest a clear correlation between prenatal and postnatal ETS and upper and lower respiratory diseases, among which wheezing syndromes and asthma. ${ }^{55-57}$ Moreover, reducing passive smoking of the infant prenatally and postnatally seems promising in reducing infant (respiratory) morbidity. ${ }^{75.76}$ Therefore, measures to reduce prenatal and postnatal ETS should very likely to be a part of an anti-asthma prevention program.

\section{The room for improvement}

What is the room for improvement in food and respiratory allergen avoidance?

Concerning breast feeding, a study in four general practices in the Netherlands under 1347 newborns has demonstrated that nearly $40 \%$ of the infants did not receive breast milk at all. $^{77}$ The percentage was the same for infants at risk and not at risk. Only $11 \%$ breast-feed for 6 months or longer. In the UK only 19\% of the high risk babies receive breast milk longer than 4 month. $^{78}$ With respect to postponement of the first solid food until the infants are 6 month of age: $90 \%$ of the children start eating solid food before they were 4 months old. ${ }^{78}$ 
Respiratory allergen avoidance knowledge of women with asthma themselves or in their family seems limited. ${ }^{79}$ Concerning pets, they are present in approximately $40 \%$ in nonasthmatic as well as asthmatic families. ${ }^{43}$

High-risk children experienced ETS in $65 \%$, of which $20 \%$ by maternal smoking. ${ }^{44}$ Children with asthma experienced in $47 \%$ ETS of which $31 \%$ caused by the mother. ${ }^{80}$ One third of the women, who quit smoking during pregnancy start smoking again after birth within 30 days. ${ }^{81}$ Thus, these data show that there is still much room for improvement to expect in controlling exposure to respiratory and food allergens and ETS. However, it is important to study in how far asthmatic families have applied preventive measures already.

\section{Compliance with the preventive measures}

There are no studies performed which assessed to what extent parents are compliant with recommended measures to avoid respiratory and food allergens. With regard to the compliance of the parents with the advice to reduce ETS for the infant it is reported that a protocolled approach (Minimal Intervention Strategy) reduces smoking in 20\% of the pregnant women, compared to $5 \%$, which stop smoking when they received a 'simple' stopsmoking advice. . $^{82-84}$

In summary, on the base of existing data we conclude that it is possible to compose a prevention program that is based on efficacious measures to prevent wheezing syndromes and childhood asthma. In addition, it seems that parents have not taken these measures already themselves. However, data concerning compliance of the parents with the recommended measures are lacking.

In addition, a cost-benefit analysis of preventive measures has not yet been performed.

Is the planned prevention program of asthma feasible and acceptable for the child and parents?

Another important condition to discuss is whether the preventive measures are acceptable and feasible for the parents and for their child. Moreover, it must be possible to implement the preventive program in the daily practice of the health caregivers. In this respect, it has to be known which caregiver in primary care (the $C P$. the district nurse and the midwife) is the most appropriate to give which specific preventive advice, and how and when this should be 
done. Since we do not have insight in this issue, it has to be part of future research before a prevention program of asthma is actually implemented.

In conclusion, the central question in this paper whether our state of knowledge is nowadays sufficient to implement a comprehensive prevention program for childhood asthma in primary care, must be answered negatively. Before primary prevention of asthma can be implemented in primary care on a large scale, more information is needed on:

1) the (cost) effectiveness of a prevention program of asthma with measures of proven efficacy:

2) the room for improvement in and compliance with the recommended preventive measures in asthmatic families;

3) the feasibility and acceptability of the prevention program in daily care for GPs, midwives and district nurses and other caregivers and, for parents and their children.

\section{The PREVASC project}

The PREVASC (Prevention of Asthma in Children) project, which started in June 1997 in the Netherlands, is designed to elucidate several of the above-mentioned points. The project aims to study the (cost) effectiveness of a primary prevention program in daily life circumstances. A (cost) effectiveness study has always the disadvantage when compared to an efficacy study, as the real life situation in which the intervention has been studied, is relatively uncontrolled. ${ }^{85}$ The PREVASC study is a prenatally started randomised intervention study of 400 genetically predisposed children in primary care. These children are born in a 2-year period in the open registered population ( $n=140.000$ ) of $78 \mathrm{CP}$ 's. The follow-up will be at least 6 years. The CPs determine prenatally the risk of the infant for developing asthma (doctor-diagnosed asthma in either father or mother or siblings of the unborn child). The children are allocated by means of a randomised consent according to Zelen ${ }^{86}$ to an experimental group and a control group. In this design the control group receives the usual care laccording to the Cuidelines of the Dutch College of Ceneral Practitioners) and is not informed on the preventive measures, which the experimental group receives, until the end of the study, in order to avoid contamination. The informed consent letters for the intervention group and the control group are shown in Appendix $4 a$ and $b$. 
respectively. The experimental group receives a standardised prevention program. It consists of a combination of all measures displayed in Table 2. except the measures, which have not shown to be efficacious, such as acaridal treatment and food elimination during pregnancy and lactation. The prevention program will be carried out by special trained nurses (education at 4 and 8 month of pregnancy and 4 weeks after birth). The educational instructions giving in the first, second and third visit are shown in Appendix 2.

The effect parameters in both groups are:

All upper and lower respiratory morbidity and the presence of other atopic conditions during the first 6 years of life. These are prospectively and recorded by the CPs in a standardised way (Appendix 5). The diagnostic criteria are according to the International Classification of Problems in Primary Care (ICPC). Asthma-like and atopic symptoms will be assessed by a weekly report by the parents (Appendix 6) and in questionnaires when the child is six months, and one and two years old. At age six, all children in both groups will be evaluated on their asthma status, based on bronchial symptoms, lung-function, reversibility of the obstruction and bronchial hyperresponsiveness.

Atopic markers such as total and specific lgE against house dust mite (Der p l). cat (Fel d 1) and $\operatorname{dog}(C a n f 1)$, eosinophil protein $X(E P X)$ are measured every year from birth up to 6 year of age.

Compliance with preventive measures will be checked by questionnaires and by repeated measurements of concentrations of house dust mite and pet allergens in the bedroom of the child and parents and in the living room, and of air humidity.

All direct medical costs and indirect costs (e.g. working-day loss) are continuously measured.

An additional goal of the PREVASC study is to investigate whether inhaled corticosteroids. when symptoms arise, still can prevent asthma (secondary prevention). In a randomised double blind study inhaled corticosteroids (Fluticasone proprionate 2 times 2 puffs of 50 $\mathrm{mcg} /$ puft) or placebo will be administered by means of a babyhaler for 6 months, to those children which have two or more episodes of doctors diagnosed wheeze after the age of two. When the child is after this treatment not free of symptoms for at least 2 months, it will be administered the same blinded medication for another period of 6 months, and so on.

Finally, another goal of the PREVASC project is to assess whether the reduction of exposure to irritants in children with a comparable genotype is related to different phenotypes after 
the age of 6. By this, the genotype might be identified as an effect modifier of the effect of exposure and also of the effectiveness of reduction of exposure. This might open possibilities for a more targeted primary prevention in the very high-risk infonts.

The first data of the PREVASC study can be expected in 2000. 


\section{References}

1. Burney PGJ, Chinn S, Rona RJ. Has the prevalence of asthma increased in children? Evidence from the national study of health and growth 1973-1986. BMJ 1990; 300:1306-8.

2. Strachan DP, Butland BK, Anderson HR. Incidence and prognosis of asthma and wheezing illness from early childhood to age 33 in a national British cohort. BMJ 1996; 312:119 99.

3. Strachan DP, Anderson HR. Trends in hospital admissions rates for asthma in children. $B M J$ 1992; 304:819-20.

4. Robertson CF, Heycock E, Bishop J, Nolan T, Olinsky A, et al. Prevalence of asthma in Melbourne schoolchildren: change 25 years. BMJ 1991; 302: 1116-8.

5. Holgate ST (ed). The Rising Trends in Asthma. Ciba Foundation Bulletin no 206,1997.

6. Nicolai T, Bellach B, Mutius von E, Thefeld W, Hoffmeister H. Increased prevalence of sensitization against aeroallergens in adults in West compared with East Germany. Clin Exp Allergy 1997; 27:886-892.

7. Lenney W, Wells NEJ, O'Neill BA. The burden of paediatric asthma. Eur Resp Rev 1994; 18: 49-62.

8. Hill RA, Standed PJ, Tattersfield AE. Asthma, wheezing, and schoolabsence in primary schools. Arch Dis Child 1989; 63: 246-51.

9. Gustavson PA, Bjorksten B, Kjellmann NI. Family dysfunction in asthma: a prospective study of illness development. J Pediatr 1994;125:493-8

10. Wever-Hess J, Wever AMJ, Yntema JL. Mortality and morbidity from respiratory disease in childhood asthma in the Netherlands, 1980-1987. Eur Respir J 1991; 9: 429-33.

11. Anderson HR. Trends and district variations in the hospital care of childhood asthma: results of a regional study 1970-85. Thorax 1990; 45: 431-7.

12. Holgate ST. The cellular and mediator basis of asthma in relation to natural history. Lancet Conference Proceedings 1997.

13. Warner JA, Jones AC, Miles EA, Colwell BM, Warner JA. Materno-fetal interaction and allergy. Allergy 1996; 51:447-51.

14. Holt PG, Sly PD. Allergic respiratory disease: strategic targets for primary prevention in childhood. Thorax 1997; 52: 1-4.

15. Schwartz J, Gold D, Dockery DW, Weiss ST, Speizer FE. Predictors of asthma and persistent wheeze in a national sample of children in the United States. Association with social class, perinatal events and race. Am Rev Respir Dis 1990; 142:555-62.

16. Lewis S, Richards D, Bynner J, Butler N, Britton J. Prospective study of risk factors for early and persistent wheezing in childhood. Eur Respir $J$ 1995; 8:349-56

17. Aalberse RC, Nieuwenhuys EJ, Hey M, Stapel SO. 'Horoscope effect' not only for seasonal but also for non-seasonal allergens. Clin Exp Allergy 1992; 22:1003-6.

18. Bodner C, Godden D, Seaton A. Family size, childhood infections and atopic disease. Thorax 1998; 53:28-32

19. Rona RJ, Gulliford MC, Chinn S. Effects of prematurity and intrauterine growth on respiratory health and lung function in childhood. BMJ 1993; 306(6881): 817-20.

20. Mutius von E, Nicolai T, Martinez FD. Prematurity as a risk factor for asthma in preadolescent children. J Pediatr 1993; 123(2):223-9.

21. Mutius von E, Illi S, Nicolai T, Martinez FD. Relation of indoor heating with asthma, allergic senstisation, and bronchial responsiveness: survey of children in south Bavaria. $B M J$ 1996; 312:1448-50.

22. Sears M. Epidemiology of childhood asthma. Lancet 1997; 350:1015-20.

23. Mutius von E. Towards prevention. Lancet 1997; 350 (suppl II):14-17.

24. Becklave M, Ernst P. Environmental factors. Lancet 1997; 350 ( suppl II):10-13.

25. Schwartz J, Weiss ST. Relationship between dietary vitamin $\mathrm{C}$ intake and pulmonary function in the First National Health and Nutrition Examination Survey (NHANES I). Am J Clin Nutr 994; 59:110-14.

26. Hatch GE. Asthma, inhaled oxidants, and dietary antioxidants. Am J Clin Nutr 1995; 63:625S$30 \mathrm{~S}$. 
27. Brunekreef B, de Hartog J, van Vliet P, Knape M, Janssen NAH, Harssema H. Respiratory Health of children living near Dutch freeways. Epidemiology 1996; 7:T 55:S32.

28. Mutius E von, Fritzsch C, Weiland SK, Roll G, Manussen G. Prevalence of asthma and allergic disorders among children in united Germany: a descriptive comparison. Br Med J 1992; 305: 1395-99.

29. Cookson WOCM, Moffat MF. Asthma: an epidemic in the absence of infections? Science 1997; 275:41-2.

30. Schwartz J, Hamelmann E, Bradly KL, Takeda K, Gelfand EW. Respiratory syncytial virus infection results in airway hyperresponsiveness and enhanced airway sensitization to allergen. J Clin Invest 1997; 100: 226-33.

31. Holt PG. Environmental factors and priming T-cell sensitization to inhalant allergen in infancy: reappraisal of the role of infections and air pollution. Pediatr All Immunol. 1995; 6:110.

32. HusselI T, Spender LC, GeorgiouA, O'Garra A, Openshaw PJM. Th1 and Th2 cytokine induction in pulmonary $T$ cells during infection with respiratory syncytial virus. J Gen Virol $1996 ; 77: 2447-55$.

33. Martinez FO. Role of viral infections in the inception of asthma and allergies during childhood: could they be "protective"? Thorax 1994; 49:1189-91.

34. Marbury MC, Maldonado G, Waller L. Lower respiratory illness, recurrent wheezing and day care attendance. Am J Respir Crit Care Med 1997; 155:156-61.

35. Openshaw PJM, O'Donnel D. Asthma and the common cold: can viruses imitate worms? Thorax 1994; 49:101-3.

36. Sporik R, Holgate S, Platts-Mills TAE, Cogswell JJ. Exposure to house dust mite allergen (Der pl) and the development of asthma in childhood. A prospective study. N Engl J Med 1990; 323: 502-7.

37. Warner JA, Little SA, Pollock I, Longbottom JL, Warner JO. The influence of exposure to house dust mite, cat, pollen and fungal allergens in the home on primary sensitatation in asthma. Ped Allergy Immunol 1990; 1:79-86.

38. Wahn U, Lau S, Bergmann R, Kulig M, Forster J, Bergmann K, et al. Indoor allergens exposure is a risk factor for sensitization during first three years of life. J. Allergy Clin Immunol 1997; 99:763-9.

39. Saarinen UM, Kajosaari M. Breastfeeding as prophylaxis against atopic disease : prospective follow-up study until 17 years old. Lancet 1995; 346:1065-69.

40. Poysa I, Korppi M, Remes K, Juntunen-Backman K. Atopy in childhood and diet in infancy. A nine-year follow-up study. Allergy Proc 1991; 12(2)107-11.

41. Falth-Magnusson $\mathrm{K}$, Kjellman NI. Allergy prevention by maternal diet during late pregnancy: a 5-year follow-up study. J Allergy Clin Immunol 1992; 89:709-13.

42. Herrmann ME, Dannemann A, Grüters A, Radisch B, Dudenhausen JW, Bergmann R, Coumbos A, et al. Prospective study on the atopy preventive effect of maternal avoidance of milk and eggs during pregnancy and lactation. Eur J Pediatr 1996; 155:770-74.

43. Zeiger RS, Heller $\mathrm{S}$. The development and prediction of atopy in high-risk children: follow-up seven years in a prospective randomized study of combined maternal an infant food allergen. $J$ Allergy Clin Immunol 1995; 95:1179-90.

44. Chandra RK, Puri S, Suraya C, Cheema PS. Influence of maternal food antigen avoidance during pregnancy and lactation on incidence of atopic eczema in infants. Clin Allergy 1986;16:563-9.

45. Halken S, HØst A, Hansen LG, Østerballe O. Effect of an allergy prevention programme on incidence of atopic symptoms in infancy. A prospective study of 159 'high risk' infants. Allergy 1992:47; 545-53.

46. Halken S, Jacobson HP, Host A, Holmenlund D. The effect of hypoallergenic formulas in infants of risk of allergic disease. Eur J Clin Nutr 1995; 49:1:S77-83.

47. Bruno G, Milita O, Ferrara M, Nisin R, Cantani A, Businco L. Prevention of atopic diseases in high risk babies (long term follow-up) Allergy Proc 1993; 14:181-6.

48. Kramer MS, Moroz B. Do breastfeeding and delayed introduction of solid foods protect against subsequent atopic eczema? J Pediatr 1981; 98:546-550. 
49. Kajoosari M, Saarinen U. Prophylaxis of atopic disease by six month' total solid food elimination. Acta Paediatr Scand 1993; 72:441-4.

50. Fergusson DM, Horwood LJ. Early solid food diet and eczema in childhood: a 10-year longitudinal study. Pediatr Allergy Immunol 1994; 5:44-7.

51. Hide DW, Matthews S, Tariq S, Arshad SH. Allergen avoidance in infancy and allergy at 4 years at age. Allergy 1996;51:89-93.

52. Hattevig G, Kjellman B, Sigurs N, Björksten B, Kjellman NIM. Effect of maternal avoidance of eggs, cow's milk and fish during lactation upon allergic manifestation in infants. Clin Exp Allergy 1989; 19:27-32.

53. Bardare M, Vaccari A, Allievi E, Brunelli L, Coco F, de Gaspari GC, Fauto U. Influence of dietary manipulation on incidence of atopic disease in infants at risk. Ann Allergy 1993; 71:366-71.

54. Sigurs N, Hattevig G, Kjellman B. Maternal avoidance of eggs, cow's milk, and fish during lactation: effect on allergic manifestations, skinprick tests, and specific IgE antibodies in children at age 4 years. Pediatrics 1992; 89:735-9.

55. Fergusson DM, Horwood LJ, Shannon FT, Taylor B. Parental smoking and lower respiratory illness in the first three years of life. J Epid Comm Health 1981; 35:180-84.

56. Stoddard JJ, Miller T. Impact of parental smoking on the prevalence of wheezing respiratory illness in children. Am J Epidemiol 1995; 141 96-101.

57. Stick SM, Burton PR, Gurrin L, Sly PD, LeSouëf PN. Effects of maternal smoking during pregnancy and a family history of asthma on respiratory function in newborn infants. Lancet 1996; 348:1060-4.

58. Wilson JHG, Jungner G. Principles and practice of screening for disease. Geneve WHO, 1968.

59. Sibbald B, Horn M, Gregg I. A family study of the genetic basis of asthma and wheezy bronchitis. Arch of Dis Childh 1980; 55:354-7.

60. Dold S, Wijst M, von Mutius E, Reitmer P, Stiepel E. Genetic risk for asthma, allergic rhinitis, and atopic dermatitis. Arch of Dis Childh 1992; 67:1018-22.

61. Kuster W, Petersen M, Christophers E, Goos M, Sterry W. A family study of atopic dermatitis. Arch Derm Res 1990; 282: 98-102

62. Schönberger HJAM, van Schayck CPM, van Beerendonk J, Metsemakers J,Knottnerus J. The identification of children with a high risk of developing asthma in primary care. In: The challenge of asthma. Proceedings Lancet 1997 abstract 102.

63. Ehnert B, Lau-Schadendorf S, Weber A, Buettner P, Scou C, Wahn U. Reducing domestic exposure to dust mite allergen reduces bronchial hyperreactivity in sensitive children with asthma J Allergy Clin Immunol 1992; 90:135-8.

64. Wickman M, Nordvall SL, Pershagen G, Korsgaard J, Johansen N, Sundell J. Mite allergens during 18 months of intervention. Allergy 1994; 114:114-9.

65. Collof MJ, Ayres J, Carswell F, Howarth PH, Merret TG, Mitchell EB, Walshaw MJ, et al. The control of allergens of dust mites and domestic pets: a position paper. Clin Exp Allergy 1992; 22(suppl.2):1-28.

66. Carswell F, Birmingham $\mathrm{K}$, Oliver J, Crewes A, Weeks J. The respiratory effects of reduction of mite allergen in the bedrooms of asthmatic children: a double blind controlled trial. Clin Exp Allergy 1996; 26:368-96.

67. Weeks J, Oliver J, Birminham K, Crewes A, Carswell F. A combined approach to reduce mite allergens in the bedroom. Clin Exp Allergy 1995; 25:1179-83.

68. Frederick JM, Warner JO, Jessop WJ, Enander I, Warner JA. Effect of a bed covering system in children with asthma and house dust mite hypersensitivity. Eur Respir J 1997; 10:361-6.

69. Harvin H, Hansen LG, Korsgaard J, Nielsen PA, Olsen OF, Romer J, Svendsen UG, Osterballe $\mathrm{O}$. House dust mite allergy and anti-mite measures in the indoor environment. Allergy 1991; 46,suppl 11:33-8.

70. Harvin H, Korsgaard J, Dahl R 1994. Clinical efficacy of reduction in housedust mite exposure in specially designed, mechanically ventilated, healthy homes. Allergy 1994; 49:866-70.

71. Custovic A, Simpson A, Chapman MD, Woodcock A. Allergen avoidance in the treatment of asthma and atopic disorders. Thorax 1998; 53:63-72. 
72. Custovic A, Simpson A, Pahdi H, Green R, Chapman M, Woodcock A. Distribution, aerodynamic characteristics, and removal of the major cat allergen Fel d 1 in British homes. Thorax 1998; 53:33-38.

73. Avner DB, Perzanowski MS, Platts-Mills TAE, Woodfolk JA. Evaluation of different techniques for washing cats: quantititation of allergen removed from the cat and the effect on airborne Fel d 1. J Allergy Clin Immunol 1997; 100:307-12.

74. Perzanowski MS, Wheatley LM, Avner DB, Woodfolk JA, Platts-Mills TAE. The effectiveness of Allerpet/c in reducing the cat allergen Fel d 1. J Allergy Clin Immunol 1997; 100:428-30.

75. Ahlsten $\mathrm{G}$, Cnattisgius S, Lindmark $\mathrm{G}$. Cessation of smoking during pregnancy improves fetal growth and reduces infant morbidity in the neonatal period. Acta Paediatr Scand 1993; 82:177-81.

76. Hovell MF, Meltzer B, Zakarian JM, Walgren DR, Emerson JA, Hofstetter CR, Leaderer BP et al. Reduction of environment tobacco smoke exposure among asthmatic children. A controlled trial. Chest $1994 ; 106: 440-7$.

77. Van den Bogaard C, van den Hoogen HJ, Huygen FJ, van Weel C. Is the breast best for children with a family history of atopy. The relation between way of feeding and early childhood morbidity. Fam Med 1993; 25 (7):471-5.

78. Wilson A, Forsyth JS, Greene SA, Irvine L, Hau C, Howie PW. Relation of infant diet to childhood health: seven year follow up cohort of children in Dundee infant feeding study. BMJ 1998:21-5.

79. Joyce DP, Chapman KR, Balter M, Kesten S. Asthma and allergy avoidance knowledge and behavior in post partum women. Ann Allergy Asthma Immunol 1997; 79:35-42.

80. Meyer GG, Postma DS, van der Heide S, de Reus DL, Roorda RJ, Koëter GH, van Aalderen WMC. Exogenous stimuli and circadian peak expiratory flow variations in allergic asthmatic children. Am J Crit Care Med 1996; 153:237-42.

81. McBride CM, Pirie PL. Post partum smoking relapse. Addictive Behaviors 1990; 15: 165-8.

82. Prochaska LO, DiClemente CC. Stages and processes of self-change of smoking: Toward an integrative model of change. J Cons Clin Psychol 1993; 51:390-5.

83. de Vries $\mathrm{H}, \mathrm{Backbier}$ E. Self-efficacy as an important determinant of quitting among smoking pregnant women. Preventive Medicine 1994;23:167-74.

84. Mudde AN, De Vries H, Willemsen MC, van Assemam P. Development and utilization of a self-help manual for community smoking interventions. In : Richmond R (Edt.) Interventions for smokers: An international perspective. Williams and Wilkens, ISBN 0-683-072 72-2, Baltimore USA.

85. Knottnerus JA, Dinant GJ. Medicine based evidence, a prerequisite for evidence based medicine. Br Med J 1997; 315:1109-10.

86. Zelen M. Randomized consent design for clinical trials: an update. Statistics in Medicine 1990; 9:645-6. 


\section{Chapter 3}

\section{The room for improvement in asthmatic families in reducing exposure}

\section{Published as:}

Environmental exposure reduction in high-risk newborns: where do we start?

Ann Allergy Asthma Immunology 2003: $91161: 531-8$

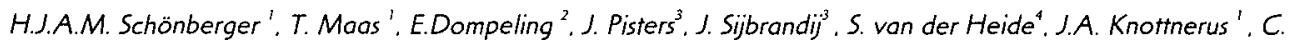

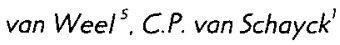

1.Department of General Practice. Research Institute CAPHRI. University of Maastricht. The Netherlands.

2. Department of Pediatrics Pulmonology, University Hospital Maastricht. Maastricht. The Netherlands:

3. Centre for Data and Information Management. University of Maastricht. The Netherlands

4. Department of Allergology. University Hospital, Groningen. The Netherlands.

5. Department of General Practice. University Medical Centre, Radboud University Nijmegen. The Netherlands. 


\section{Abstract}

\section{Background}

When analyzing the effect of environmental exposure reduction measures on asthma in high-risk children, one must know in how far asthmatic families already have applied such measures, because this would affect the effectiveness and efficiency of interventions aimed at reducing environmental exposure.

\section{Objective}

To describe the room for improvement by asthmatic families in mite, pet and food allergens reducing measures and in parental passive smoking, and to determine the resulting levels of mite and pet allergens by the applied sanitation measures.

\section{Method}

Descriptive follow-up study in primary care of 211 asthmatic families, expecting an infant.

\section{Results}

Frequencies of applied measures were: having a smooth floor covering in $36 \%$. daily house cleaning in $27 \%$, use of parental and infant's anti-mite encasings in $13 \%$ and $9 \%$. respectively: keeping no pets in 66\%; no cow's milk based regular formula in $13 \%$ and no solid foods in the first 6 months of life in 28\%; abstinence of smoking by the mother. prenatally in $89 \%$, and postnatally in $85 \%$, and by her partner in $76 \%$. Measures were not applied as a consequence of specific professional advice, but most probably on one's own initiative. Having a smooth floor covering and daily cleaning. but not use of anti-mite encasings resulted in significantly lower mite and pet allergen levels.

\section{Conclusion}

In asthmatic families, there is (still) enough room for improvement to reduce of exposure to inhalant and food allergens, especially by application of encasings, for giving exclusive breast-feeding and/or hypoallergenic formula feeding, and for postponing the first solids. 


\section{Introduction}

Asthma is the most common chronic disease in childhood. Prevalence of asthma is still increasing.' and the disease forms an important burden for children and their parents. ${ }^{2}$ Therefore, interest in the primary prevention of asthma by influencing relevant environmental factors is growing. The best-known environmental exposures in Western Europe are allergens of the house dust mite (mite) and pets, food allergens and passive smoking. These exposures can be effectively reduced. ${ }^{3.4}$ although the relevance of a reduction of some environmental factors is under debate nowadays. ${ }^{5}$ The effectiveness of such preventive measures in high-risk families has still to be proved in daily care. ${ }^{6}$ To study the effect of environmental exposure-reducing measures to prevent asthma, insight into the room for improvement (RFI) of these preventive measures is necessary. In this article, we examine (1) the application of environmental exposure-reducing measures in asthmaaffected families expecting a child and the existing RFI in measures to reduce mite, pet, and food allergens and prenatal and postnatal smoking; (2) the influence of different types of preventive measures on the levels of mite and pet allergens in homes; and (3) the determinants of preventive behavior of asthmatic families.

\section{Material and Methods}

\section{Study subjects}

The data were collected in a birth cohort study (PREVASC) which explores risk factors for asthma in children from the southeastern part of The Netherlands. High-risk infants (i.e. mother, father, or both and/or sibling(s) have physician-diagnosed asthmal were recruited by primary caregivers (general practitioners and midwives) when the mother visited their practices in early pregnancy. The mothers were asked to participate in a study to elucidate the role of environmental exposure on the development of asthma. To avoid changes in preventive behavior, induced by information about the study, no information was given about the specific prenatal and postnatal environmental exposures and their hypothesized positive association with the development of asthma. Exposure was determined as (1) the measures applied to reduce exposure to mite, pet and food allergens and passive smoking and (2) prenatal and postnatal levels of exposure to mite and pet allergens in samples of 
settled house dust from the living room and on the parental and crib mattresses. The study was approved by the Ethical Committee of the University Maostricht, Maastricht. The Netherlands.

\section{Preventive measures studied}

Reduction or avoidance of the following were studied: (1) mite and pet allergens by sanitation measures such as the use of anti-mite bed covers, duvets and pillows thereafter referred to as encasingl, a frequent cleaning of the newborn's living-environment, having a smooth floor-covering in the living room and the bedroom, and removing pets from the home by disposing of them or keeping them outside: (2) food allergens by feeding the infant breast milk and/or hydrolyzed cow milk instead of cow-milk based humanized cow milk and postponing the first weaning solids such as juice, fruits or vegetables until 6 months of age: 13) prenatal smoking by the mother and postnatal smoking by the mother, her partner, and others in the house.

\section{Data sampling and measuring}

Data were sampled by abservation (housing characteristics), weekly diary entries (kind of feeding) and by questionnaire when the infant was six months old (the first solids) and one year old (sanitation measures, smoking). Special attention was paid to the timing of the parental questionnaires, because parents might change their existing preventive lifestyle just by asking questions about the applied measures (Hawthorn effect). Questions were included whether reported measures were applied or induced by information or advice given by the general practitioner, midwife, specialist, or specialized nurse. To trace changes in exposure to inhalant allergens, concentration of the allergens was assessed prenatally and postnatally lat baseline and, to avoid seasonal influences, 1 year laterl. Sociodemographic characteristics lage and education level of the mother, number of siblings. family history of asthma, duration of pregnancy, birth weight of infant. place of birth and mode of delivery) were recorded.

To know whether the study population was representative, we compared the eligible families who had been recruited by the general practitioner but had refused to participate (hereafter 
referred to as non-participants), with the participants. For this purpose, the non-participants were asked to answer a few additional questions on relevant characteristics including age and education of the mother, family history of asthma, their smoking behavior, presence of pets, and the furnishing of the house.

\section{Collection and measurement of inhalant allergens}

Dust samples were collected by vacuuming 11.300-W-vacuum; Bosch. Hoofddorp. The Netherlands) the floor of the living room ( 2 areas of $1 \mathrm{~m}^{2}$ for 2 minutes each) and the parental and infant mattresses $17 \mathrm{~m}^{2}$ for 2 minutes) with covers but without sheets. Parents were asked not to vacuum the bedroom and living room floor before the dust collection.

The preparation of dust samples for measurement and the measurement of mite allergen (Der $\mathrm{p} 1$ ), cat allergen (Fel d 1), and dog allergen (Can $f 1$ ) is described elsewhere. The detection limit was $2 \mathrm{ng} / \mathrm{g}$ for Der $\mathrm{p} 1$ and $1 \mathrm{ng} / \mathrm{g}$ of dust for Fel $d 1$ and Can $\mathrm{f}\}$.

\section{Data analysis}

Differences between participants and non-participants were analyzed using $X^{2}$ test and ttest when appropriate. Frequencies of measures already applied were computed. Differences between prenatal and postnatal levels of the inhalant allergens were tested with the Wilcoxon signed rank test. For each case, exposure to Der $p$ I. Can $f 1$ and Fel $d I$ was calculated as the mean of the prenatal and postnatal allergen content in dust samples of the infant and the parental mattress and as the mean of prenatal and postnatal allergen content in dust samples of the of the living room. To receive one expression for the overall exposure (prenatal and postnatal), the mean of allergen content in the mattresses and living room floor was calculated. The RFI was expressed as the number of households that had not applied the prevailing preventive measures for each exposure.

Several multiple logistic regression analyses were applied with the preventive measures as the dependent variables: the use of mattress encasing. having a smooth floor covering. having pets, exclusive breast feeding and/or hypo-allergenic formula during the infants' first 6 months, and passive smoking. Family characteristics served as independent variables (Table 1). SPSS statistical software version 10 (SPSS Inc. Chicago,III) was used for all analyses. For all analyses $\mathrm{P}<0.05$ was considered statistically significant. 
Table 1. Comparison of some family characteristics and environmental exposure in participating $(\mathrm{n}=211)$ and non-participating subjects $(\mathrm{n}=84)$. Statistic differences in bold.

\begin{tabular}{|c|c|c|}
\hline & participants & non-participants \\
\hline Age mother in years, mean (SD) & $31.0(3.65)$ & $33.2(4.0)^{*}$ \\
\hline \multicolumn{3}{|l|}{ Education level mother $\uparrow$} \\
\hline low & $18(8.5)$ & $17(19.1)$ * \\
\hline middle & $103(48.8)$ & $44(49.4)$ \\
\hline high & $90(42.7)$ & $28(31.5)$ \\
\hline \multicolumn{3}{|l|}{ Family history of asthma } \\
\hline mother & $62(29.4)$ & $20(25.6)$ \\
\hline father & $41(19.4)$ & $16(20.5)$ \\
\hline both parents & $15(7.1)$ & $4(5.1)$ \\
\hline siblings & $41(19.4)$ & $15(19.2)$ \\
\hline mother and sibling & $28(13.3)$ & $10(12.8)$ \\
\hline father and sibling & $19(9.0)$ & $11(14.1)$ \\
\hline both parents and sibling & $5(2.4)$ & $2(2.6)$ \\
\hline \multicolumn{3}{|l|}{ Birth order } \\
\hline first-born & $79(37.4)$ & $29(32.6)$ \\
\hline second-born & $84(39.8)$ & $32(36.0)$ \\
\hline third or later born & $60(27.9)$ & $28(31.4)$ \\
\hline \multicolumn{3}{|l|}{ Pets } \\
\hline no & $122(57.8)$ & $52(60.5)$ \\
\hline only a cat & $26(12.3)$ & $8(9.3)$ \\
\hline only a dog & $41(19.4)$ & $22(25.6)$ \\
\hline both & $5(2.4)$ & $4(4.6)$ \\
\hline Anti-house dust mite covers parents & $27(12.8)$ & $11(12.4)$ \\
\hline Smoking mother & $22(11.1)$ & $24(27.0)$ * \\
\hline Smooth floor-covering in the house & $110(53.1)$ & $48(53.9)$ \\
\hline
\end{tabular}

${ }^{*} \mathrm{p}<0.05$; $\uparrow$ low: primary school, middle: secondary school, high: university. 


\section{Results}

Of the 311 families who were asked to participate, 227 gave their informed consent. There were 16 dropouts: 5 were lost during follow-up and 11 were excluded (stillbirth and abortion 7: long-lasting hospitalization 1: moved abroad 31. The data of 211 patients were available for analysis. Table 1 shows the baseline characteristics of the participants and the comparison with non-participants. Participating mothers had a higher education and were more often non-smoker compared with non-participating mothers.

Table 2 reports data on already applied measures and behavior to reduce the exposure to mite, pet and food allergens and passive smoking. It also shows whether the reported measures and behavior were applied at the advice of professionals. Only half of the used encasings had proven anti-mite efficacy (data not shown).

\section{Exposure to allergens of house dust mite and pets}

There was no difference between the prenatal and postnatal concentrations of allergens in the house during the study period. Mite and pet allergens were found in nearly all the houses (Figure 1).

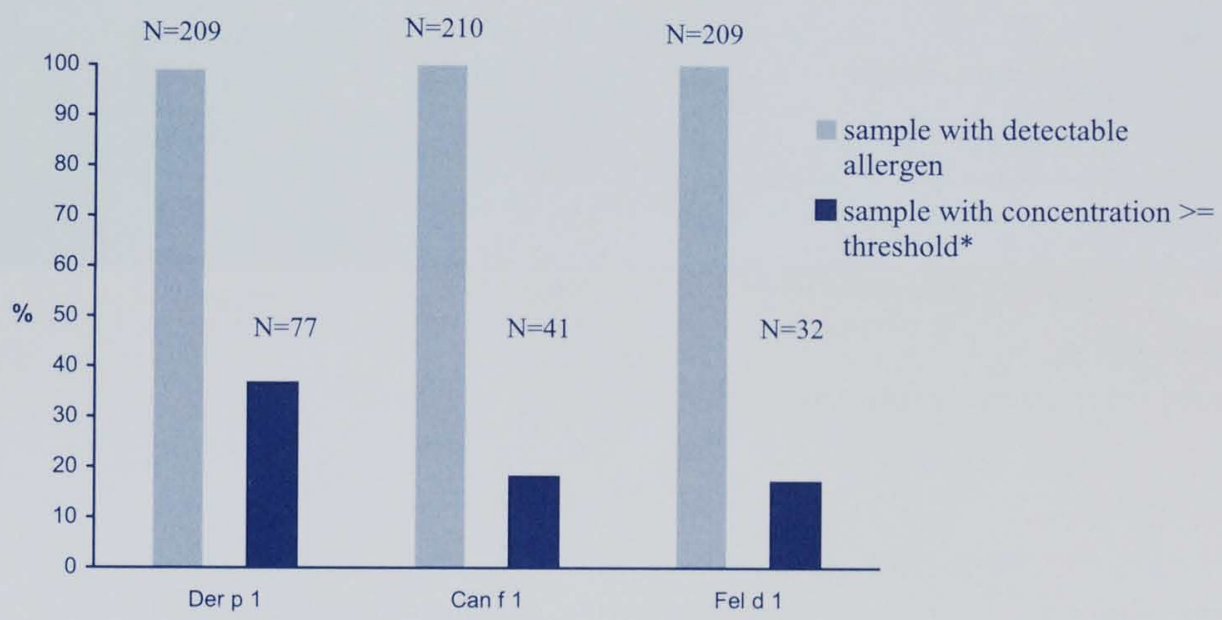

Figure 1. Percentage and numbers of cases with detectable levels of Der p 1, Can f 1 and Fel $\mathrm{d} 1$ and with levels $\geq$ threshold value* for sensitization in either living room or mattress of parents or mattress of the infant (during pregnancy and their first year of life).

* for Der p1: $2000 \mathrm{ng} / \mathrm{g}$ dust; ${ }^{9}$ for Can f 1: $10.000 \mathrm{ng} / \mathrm{g}$ dust; for Fel d 1: $8.000 \mathrm{ng} / \mathrm{g}$ dust. ${ }^{23.24}$ 
Table 2. Presence of reported exposure to allergens and passive smoking in asthmatic families, expecting a child and the influence of the advice of professionals* on measures to reduce exposure. Birth cohort $\mathrm{n}=211$. Figures are numbers (percentages).

\section{Exposures}

\section{House dust mite}

smooth floor-covering $\dagger$

$76(36.0)$ 17

floor cleaning daily $\dagger \dagger$

$19(9.0)$

$27(12.8)$

$83(39.3)$

$31(14.7)$

presence of cats

of which disposed of

of which keeping outside

presence of dogs

of which disposed of

of which keeping outside

Food

exclusive breast-feeding during the first 6

months of life

intake of solid foods $\geq 6$ months of life

Passive smoking

prenatal and/or postnatal smoking by

mother

smoking partner

smoking by others in the house
$46(21.8)$

$6(13.0)$

$6(13.0)$
11

7

12

3
$62(29.4) \quad 10$

$66(27.5) \quad \S$

$32(16.3) \quad \S$

$45(24.1) \quad \S$

$91(43.1) \quad \S$
Numbers influenced

by professional advice

* professionals: general practitioner, midwife, specialist, specialized nurse, healthy child clinic; $\uparrow$ smooth floor-covering: polished wood, vinyl or tiled floor covering; $\uparrow \uparrow$ : daily cleaning of floors by vacuum-cleaner or damp mop. $\S$ : not asked in the study.

The exposure to allergen levels of mite, cat and dog was above the sensitization threshold in $37 \%, 17 \%$ and $18 \%$ of the cases, respectively (Figure 3). The levels of mite and pet allergens in relation to sanitation measures are shown in Table 3 and Table 4 . On daily 
cleaned living room floors as well as floors with a smooth cover, lower mite and pet allergens levels were found compared with living room floors that were not daily cleaned as well as with textile-covered floors (Table 3).

Table 3. Relationship between applied sanitation measures to reduce exposure to allergens in the living room of high risk families and the resulting levels of Der $\mathrm{p} 1$, Fel $\mathrm{d} 1$ and Can $\mathrm{f} 1^{*}$, expressed in medians $\mathrm{ng} / \mathrm{g}$ dust with interquartile range between parentheses (IQR).

level of allergens in the living room

\begin{tabular}{|c|c|c|c|c|c|c|}
\hline \multirow{2}{*}{ Applied measure } & \multicolumn{2}{|c|}{ Derpl } & \multicolumn{2}{|c|}{ Feld I } & \multicolumn{2}{|c|}{$\operatorname{Can} f 1$} \\
\hline & $\begin{array}{c}\text { Median (IQR) } \\
n g / g \text { dust }\end{array}$ & $\begin{array}{c}P \\
\text { value } \S\end{array}$ & $\begin{array}{c}\text { Median (IQR) } \\
n g / g \text { dust }\end{array}$ & $\begin{array}{c}P \\
\text { value } \$\end{array}$ & $\begin{array}{c}\text { Median (IQR) } \\
n g / g \text { dust }\end{array}$ & $\begin{array}{c}P \\
\text { value } \$\end{array}$ \\
\hline \multicolumn{7}{|l|}{$\begin{array}{l}\text { Smooth floor } \\
\text { covering } \dagger\end{array}$} \\
\hline $\begin{array}{l}\text { Yes } n=79 \\
\text { No } n=131\end{array}$ & $\begin{array}{c}56(154) \\
427(106831)\end{array}$ & 0.001 & $\begin{array}{l}448(1125) \\
556(1166)\end{array}$ & 0.03 & $\begin{array}{l}199(1005) \\
310(1790)\end{array}$ & 0.009 \\
\hline \multicolumn{7}{|l|}{ Daily cleaning $\ddagger$} \\
\hline $\begin{array}{ll}\text { Yes } & n=56 \\
\text { No } & n=129\end{array}$ & $\begin{array}{l}44(230) \\
100(519)\end{array}$ & 0.001 & $\begin{array}{c}259(702) \\
565(1299)\end{array}$ & 0.002 & $\begin{array}{c}358(11252) \\
243(996)\end{array}$ & 0.07 \\
\hline
\end{tabular}

* levels of Der p I, Fel d l and Can f l are measured as the mean of pre- and postnatal levels in settled dust of living room; †Smooth floor covering: polished wood, vinyl or tiled floor-covering; $\ddagger$ daily cleaning (every day cleaning by vacuuming or damp mop; §: Mann-Whitney U test. 
In the bedrooms, neither a smooth floor covering nor daily floor cleaning reduced the allergen levels in dust samples of the mattresses (Table 4). Levels of mite and pet allergens on parental and infant mattress encasings differed, but not significantly, from the levels on nonencased mattresses (Table 4).

Table 4. Relationship between applied sanitation measures to reduce exposure in bedrooms of high-risk families to allergens of the house dust mite, cat and dog and the resulting levels of Der $\mathrm{p} 1$, Fel $\mathrm{d} 1$ and Can $\mathrm{f} 1^{*}$, (expressed in medians $\mathrm{ng} / \mathrm{g}$ dust with interquartile range between parentheses (IQR)).

level of allergens on mattresses of baby and parents

\begin{tabular}{|c|c|c|c|c|c|c|}
\hline & \multicolumn{2}{|c|}{ Der pl } & \multicolumn{2}{|c|}{ Feld 1} & \multicolumn{2}{|c|}{ Can fl } \\
\hline pplied measure & $\begin{array}{c}\text { Median (IQR) } \\
n g / g d u s t\end{array}$ & $\begin{array}{c}P \\
\text { value } \S\end{array}$ & $\begin{array}{c}\text { Median (IQR) } \\
n g / g d u s t\end{array}$ & $\begin{array}{c}P \\
\text { value } \$\end{array}$ & $\begin{array}{c}\text { Median }(Q R) \\
n g / g d u s t\end{array}$ & $\begin{array}{c}P \\
\text { value } \S\end{array}$ \\
\hline
\end{tabular}

\section{Smooth}

Floor covering ${ }^{\dagger}$

Yes $\mathrm{n}=110$

$511(1874)$

No $\mathrm{n}=97$

$941(3132)$

0.3

506 (1893)

503 (1573)

0.9

255 (938)

213 (1312)

Daily cleaning $f$

Yes $\mathrm{n}=56$

487 (2450)

600 (2884)

$308(831)$
$0.5 \quad 496(1710)$

0.03

$183(720)$

423 (5770)

0.002

Anti-mite

encasings

parental and

crib mattress

Yes $\mathrm{n}=42$

412 (1891)

0.4

594 (3725)

648 (2786)

458 (1003)

0.5

164 (312)

265 (1456)

0.1

* levels of Der p I, Fel $d I$ and Can fl are measured as the mean of prenatal and postnatal levels in settled dust of mattresses of the baby and parents; $\uparrow$ Smooth floor covering: polished wood, vinyl or tiled floor covering; $\ddagger$ every day cleaning by vacuuming or damp mop; $\S$ : statistic test: Mann-Whitney $U$ test.

Table 5 shows higher levels of the pet-specific allergen in dust samples of the living room as well as in those of mattresses in the houses of pet owning families, compared with non-petowning families. 
Table 5. Relationship between presence of pets in asthmatic families and the resulting levels* of Fel $\mathrm{d} 1$ and $\operatorname{Can} \mathrm{f}$ (expressed in medians ng/g dust with interquartile range between parentheses (IQR)).

Dust living room (IQR)

Pets $\ddagger$

None $\mathrm{n}=122$

$\operatorname{Dog} \mathrm{n}=41$

$451(623) \dagger$

$183(382)$

Cat $n=26$

63180 (145698)

Both $\mathrm{n}=5$
Canf 1

$308(280) \dagger$

$51103(87020)$

$108(145)$

6593 (98728)
Dust mattresses baby and parents

Fel d 1

Can $f 1$

$345(851) \dagger$

$148(279) \dagger$

342 (435)

7191 (17937)

$133(250)$

74125 (173246)

$12965(52311)$

* levels of Fel d 1 and Can $\mathrm{f} 1$ are measured as the mean of prenatal and postnatal levels in settled dust of living room and of parental and baby mattress, respectively; $\uparrow: \mathrm{P}=<0.0001$ (Statistic test of levels in the four categories: Kruskal Wallis test). $\ddagger$ : mutually exclusive categories

The additional RFI in preventive measures is shown in Figure 2. Theoretically, plenty of RFI was present regarding the advice to use parental and infant mattress encasings, exclusive breast-feeding, hypoallergenic formula feeding and postponing the first solids until 6 months after birth. Less RFI existed for reduction of passive smoking.

A

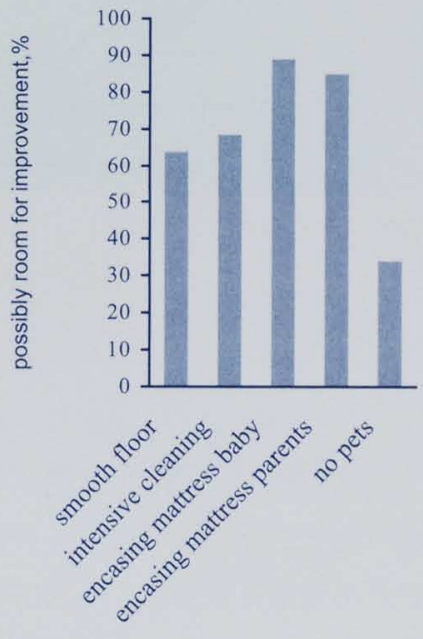

$\mathrm{B}$
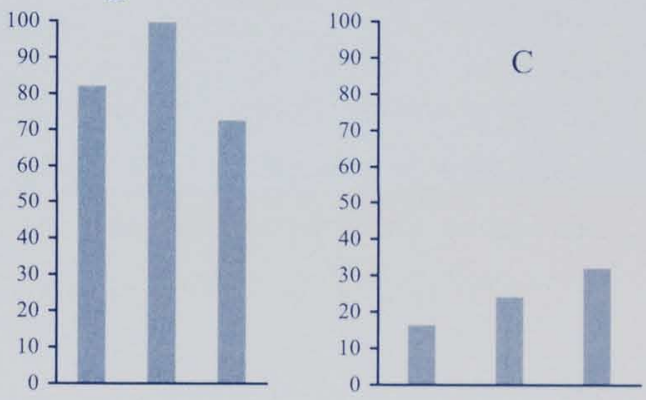

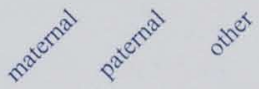

Figure 2. The room for improvement in asthmatic families for preventive measures to reduce exposure to house dust mite and pets (A), food allergens (B) and passive smoking (C). Bars represent the percentage of possible improvement 
Determinants of preventive behavior.

Multiple logistic regression analyses showed that the type of floor covering in the house and use of encasings was not influenced by the kind of family history, education of the mother or family size. Older (>31 years) mothers less frequently had smooth floors in their houses compared with younger mothers (OR, 0.40;95\% Cl. 0.19-0.83: $P=0.02$ ). In those houses where encasings were used, textile floor coverings $1 O R, 2.4: 95 \% \mathrm{Cl}, 1.01-5.7: \mathrm{P}=0.04$ ) and pets (OR.3.4: 95\% Cl. 1.3-8.5; $P=0.009$ ) were also present less frequently. With regard to pets, analysis revealed that older mothers had pets less frequently compared with younger mothers IOR 2.2.95\% Cl, 1.7-4.7; $\mathrm{P}=0.03$ ).

Breast-feeding was not influenced by family history, the age of the mother, birthplace, mode of delivery and birth weight, but was negatively associated with the education of the mother and being born before 36 weeks of gestation ltesting the likelihood ratio, $P=0.003$ and $P=0.04$ respectively). (Odds ratios could not be calculated because numbers were too small).

Postponement of the first weaning solids was independently positively associated with exclusive breast-feeding (OR, 5.1:95\% Cl, 2.3-1 1.9; $\mathrm{P}=0.001)$ and being born second or later (OR, 3.0; 95\% Cl. 1.2-7.1: $\mathrm{P}=0.014$ )

Prenatal maternal smoking and postnatal maternal smoking was not influenced by family history, age or education of the mother or presence of other children, but they were significantly associated with a smoking partner: $O R, 4.5 ; 95 \% \mathrm{Cl}, 1.8-11.5 ; P=0.001$ ), (OR, 7.7: $95 \% \mathrm{Cl} 2.5-23.0 ; P=0.04$ ) respectively.

\section{Discussion}

In this study of asthmatic families expecting a child we analyzed the RFI in preventive measures that aimed to reduce exposure to mite, pet and food allergens and passive smoking. Because we planned to investigate the (combined) effect of preventive measures on the development of asthma, we sought insight into what extent these preventive measures are already applied, since this would affect the RFI in the preventive measures.

We established that a number of asthmatic families had applied preventive measures already. We also showed that most measures were not applied as a consequence of specific 
professional advice, but most probably on the family's own initiative. Some (mite-reducing) measures such as having a smooth (tiled) floor, may not have been planned but already existed in the houses before the family moved in.

We were able to ascertain to what extent applied sanitation measures were effective in reducing allergen levels. Allergens in the floor dust were reduced -in two third of the caseswhen there was a smooth floor covering in the living room, as others have reported. ${ }^{8.9}$ We found no reduction of allergens in the mattress dust in bedrooms with a smooth floor, which disagrees with other studies. ${ }^{10}$ In addition, a daily cleaning of the house floors resulted in low levels of mite and cat allergens in living room floor dust samples, in conformity with others reports. ${ }^{10.11}$ If floors were cleaned daily, we found a lower level of cat allergens, but not lower levels of mite allergens in mattress dust samples. Surprisingly, we found higher levels of dog allergens in dust samples of both the living room and the mattresses when the house floors were cleaned daily compared with when they were not. We do not have an explanation for this.

When mattresses were encased, however, we did not find significantly lower allergen levels compared with mattresses that were not encased. One explanation for this might be that half of the used encasings did not have approved anti-mite protection and therefore were not approved by the Dutch Asthma Foundation.

As others found, ${ }^{12.13}$ houses with pets contain much higher pet-specific allergens in floor and mattress dust than houses without pets.

Allergens of the mite were detectable in nearly all houses, and allergens of both cat and dog were detectable in all the houses. Exposure above the supposed threshold of sensitization for mite allergens ${ }^{14}$ occurred in one third of the cases. For cat and dog allergens, this was the case in approximately 1 in 5 cases.

The RFI in measures to reduce exposure to mite and pet allergens

We found a considerable RFI in sanitation measures, which were applied independently of family history, family size or education. However, we expect the largest reducing effect to be 
caused by the advice to use encasings, especially, because mite levels were much higher on mattresses than on living room floors and encasings are efficacious in reducing these levels. ${ }^{15}$ The RFI in encasing the crib mattresses was substantial. However, we should realize, that the RFI may differ from country to country. In the United States, for instance. virtually all new crib mattresses are manufactured with plastic encasings. The RFI is also very large when it comes to encasing the parental mattress. The advice to use encasings seems far more feasible to execute than to provide a smooth floor or the advice of cleaning daily. Therefore, the use of encasings seems the most efficient measure to reduce overall exposure to mite allergens.

With regard to the RFI for disposing of pets, it seems unlikely that families will get rid of their pet(s). The feasibility and effectiveness of alternatives, such as keeping pets outside and/or washing them has yet to be established. We found that families using mattress encasing had significantly fewer pets and more often a smooth floor. This suggests that some asthmatic families are inclined to a more comprehensive preventive approach as they take sanitation measures to reduce exposure to both mite and pet allergens.

Because the general public may have been aware of the ongoing discussion about the suggested protective effect of owning pets on asthma. ${ }^{1617}$ some asthmatic families may have bought a pet in stead of disposed of their pet. Only recently, however, reports have shown that allergic families do not have more pets than non-allergic families. ${ }^{13.18}$ Furthermore, the Dutch Guidelines for Asthma ${ }^{18}$ advise pet-keeping allergic asthma patients to dispose of their pets.

\section{The $R F I$ in reduction of food allergens}

As reported by others, ${ }^{19}$ a high proportion of children in this study were exposed to cow's milk and solid foods before the age of 6 months. Women who formula feed their infants are also more likely to introduce solid foods early, ${ }^{20}$ and this relation is an additional argument to stimulate breast-feeding. We demonstrated that there was much RFI in avoiding food allergens: by promoting exclusively breast-feeding and/or hypoallergenic formula feeding and by postponing the introduction of the first weaning solids until after 6 months of life. We expect, however, that parents will comply with the latter 2 measures because these measures 
seem more feasible compared with the advice to breast-feed exclusively during the first 6 months of life. Special attention has to be paid to mothers with lower education, because we found that they breast-fed their infants less often than mothers with higher education.

Despite the lack of evidence regarding a beneficial effect of hypoallergenic formula on asthma, ${ }^{5}$ we studied the RFI for the preventive advice to give hypoallergenic milk instead of regular formula in case breast-feeding is stopped or supplementary milk feeding is needed. However, since asthma is an multifactorial disease and is related to exposure to food, mite and pet allergens and passive smoking, avoidance of only a single exposure might be marginally or not effective when other exposures still exist. ${ }^{21-23}$ On the contrary, a simultaneous avoidance of the relevant environmental exposures in high-risk cases, might be effective indeed. The combined effect of these 4 environmental reduction measures will be investigated in another part of the PREVASC study.

\section{The RFI in reduction of passive smoking}

As others reported, we found that approximately 1 in 4 infants was prenatally and postnatally exposed to smoke from maternal and/or paternal smoking. ${ }^{24}$ Smoking mothers more offen had smoking partners. No relation was found between a low education and smoking behavior. Other researchers, however, did find such a relation. ${ }^{25}$ Whether relatively successful smoking cessations programs also are successful in reducing passive smoking in asthmatic families, expecting a child, has still to be proved. A considerable proportion of the infants $(30 \%)$ was regularly exposed to smoke from people other than the parents, which also should be a subject for improvement.

In our cohort smoking mothers were underrepresented and therefore the (theoretically) RFI concerning smoking might be larger than reported here. The participating families all had a higher education. As a result, this may lead to an underestimation of the real RFI in breastfeeding in the population at risk whereas we found that mothers with a higher education breast-fed their infants more frequently then mothers with a lower education.

Ideally, estimation of the size of exposure has to be objectified by measuring the level or of the irritant of interest. We were able to do that for exposure to mite and pet allergens. For food allergens and smoking, we used "proxy" measures, with the possible disadvantage of 
inaccuracy. For food allergens, we used self-report of the kind of feeding given to the infant because objective measures are lacking. For smoking. cotinine, a metabolite product of nicotine in the urine or blood would be more suitable for measuring the actual exposure to smoke. However, parent-reported smoking correlates well with cotinine values in the infant and is a reliable method of measuring the burden of passive smoking. ${ }^{26}$

Recall bias must be considered because some data on applied measures were sampled by questionnaires when the baby was 1 year old. However, this seems unlikely for obvious issues such as presence of pets, daily cleaning, use of mattress encasings, and passive smoking. Reporting bias is also possible because parents, asked for their actual behavior of exposure reduction, might give socially desirable answers. This holds true especially for smoking and it may lead to an underestimation of the exposure by passive smoking in the population at risk.

For the sake of clearness, our figures on RFI only concern the theoretical potential for preventive advice on reducing environmental exposures. Whether the preventive advice will be adhered by asthmatic families, will be effective in reducing exposures, and will prevent asthma, is yet to be established in long-term follow-up intervention studies.

In summary, there appears to be much RFI in the avoidance behavior of asthmatic families. Most RFI exists in the reduction of inhalant allergens by use of anti---house dust mite encasings for parents (and infants). in the reduction of exposure to food allergens by stimulating breast-feeding during the first 6 months of the infant's life and/or hypoallergenic formula feeding and by postponing the first solids until 6 months after birth. A modest RFI exists in the reduction of exposure to pet allergens by disposing of pets or keeping them outside the house as well as in the reduction of non-parental passive smoking. Less RFI is available for reduction of passive smoking by parents. The data presented herein should aid physicians in determining the effectiveness and efficiency of primary prevention programs for asthma that focus reducing environmental exposures. 
Supported by: The Dutch Asthma Foundation, Praevention Fund and the Dutch Royal Academy of Science (KNAW)

\section{Acknowledgement}

The PREVASC study is a joint project of the Departments of General Practice of the University Maastricht and the University Nijmegen. We thank the general practitioners allied to these departments and the participating midwives for recruiting the eligible families. We are grateful to all the families that were willing to participate and their devotion to the study. We would also like to thank the research-assistants: Ilse van Beerendonck and Karin Manders; the data managers: Jacqueline Pisters and Kitty Coolen and the PREVASC secretary Annemarie Spaninks.

We thank Ton Tillemans for correcting English in the paper. 


\section{References}

1. Burney PG, Chinn S, Rona RJ. Has the prevalence of asthma increased in children? Evidence from the national study of health and growth 1973-86. BMJ 1990;300(6735):1306-10.

2. Gustafsson PA. Family dysfunction in asthma: results from a prospective study of the development of childhood atopic illness. Pediatr Pulmonol Suppl 1997;16:262-4.

3. Peat J, Bjorksten B. Primary and secondary prevention of allergic asthma. Eur Respir J Suppl 1998;27:28s-34s.

4. Oddy WH. Breastfeeding and asthma in children: findings from a West Australian study. Breastfeed Rev 2000;8(1):5-11.

5. Wright AL, Holberg CJ, Taussig LM, Martinez FD. Factors influencing the relation of infant feeding to asthma and recurrent wheeze in childhood. Thorax 2001;56(3):192-197.

6. Schonberger HJ, Van Schayck CP. Prevention of asthma in genetically predisposed children in primary care--from clinical efficacy to a feasible intervention programme. Clin Exp Allergy 1998;28(11):1325-31.

7. van der Heide S, van Aalderen WM, Kauffman HF, Dubois AE, de Monchy JG. Clinical effects of air cleaners in homes of asthmatic children sensitized to pet allergens. $J$ Allergy Clin Immunol 1999;104(2 Pt 1):447-51.

8. Verhoeff AP, Van Strien RT, Van Wijnen JH, Brunekreef B. House dust mite allergen (Der p I) and respiratory symptoms in children: a case-control study. Clin Exp Allergy 1994;24(11):1061-9.

9. Arlian LG, Neal JS, Morgan MS, Rapp CM, Clobes AL. Distribution and removal of cat, dog and mite allergens on smooth surfaces in homes with and without pets. Ann Allergy Asthma Immunol 2001;87(4):296-302.

10. van Strien RT, Verhoeff AP, van Wijnen JH, Doekes G, de Meer GE, Brunekreef B. Der p I concentrations in mattress surface and floor dust collected from infants' bedrooms. Clin Exp Allergy 1995;25(12):1184-9.

11. Vojta PJ, Randels SP, Stout J, et al. Effects of physical interventions on house dust mite allergen levels in carpet, bed, and upholstery dust in low-income, urban homes. Environ Health Perspect 2001;109(8):815-9.

12. Chan-Yeung M, Ferguson A, Dimich-Ward H, Watson W, Manfreda J, Becker A. Effectiveness of and compliance to intervention measures in reducing house dust and cat allergens levelstie. Annals of Allergy, Asthma \&Immunology 2002;88:52-58.

13. Wijga A, Smit HA, Brunekreef B, et al. Are children at high familial risk of developing allergy born into a low risk environment? The PIAMA Birth Cohort Study. Prevention and Incidence of Asthma and Mite Allergy. Clin Exp Allergy 2001;31(4):576-81.

14. Platts-Mills TA, Vervloet D, Thomas WR, Aalberse RC, Chapman MD. Indoor allergens and asthma: report of the Third International Workshop. J Allergy Clin Immunol 1997;100(6 Pt 1):S224.

15. Custovic A, Simpson BM, Simpson A, et al. Manchester Asthma and Allergy Study: low-allergen environment can be achieved and maintained during pregnancy and in early life. $J$ Allergy Clin Immunol 2000;105(2 Pt 1):252-8.

16. Hesselmar B, Aberg N, Aberg B, Eriksson B, Bjorksten B. Does early exposure to cat or dog protect against later allergy development? Clin Exp Allergy 1999;29(5):611-7.

17. Nafstad P, Magnus P, Gaarder PI, Jaakkola JJ. Exposure to pets and atopy-related diseases in the first 4 years of life. Allergy 2001;56(4):307-12.

18. Dirksen WJ, Geijer RMM, De Haan M, De koning G, Flikweert S, Kolnaar BGM. NHGStandaard Astma bij Kinderen (eerste herziening). Huisarts Wet 1998(41(3)):130-43.

19. van den Bogaard C, van den Hoogen HJ, Huygen FJ, van Weel C. Is the breast best for children with a family history of atopy? The relation between way of feeding and early childhood morbidity. Fam Med 1993;25(7):471-5.

20. Kwavnick BS, Reid DJ, Joffres MR, Guernsey JR. Infant feeding practices in Ottawa-Carleton: the introduction of solid foods. Can J Public Health 1999;90(6):403-7. 
21. Koopman LP, van Strien RT, Kerkhof M, et al. Placebo-controlled trial of house dust miteimpermeable mattress covers: effect on symptoms in early childhood. Am J Respir Crit Care Med 2002;166(3):307-13.

22. ExI BM, Deland U, Secretin MC, Preysch U, Wall M, Shmerling DH. Improved general health status in an unselected infant population following an allergen reduced dietary intervention programme. The ZUFF-study-programme. Part I: Study design and 6-month nutritional behaviour. Eur J Nutr 2000;39(3):89-102.

23. Custovic A, Simpson BM, Simpson A, Kissen P, Woodcock A. Effect of environmental manipulation in pregnancy and early life on respiratory symptoms and atopy during first year of life: a randomised trial. Lancet 2001;358(9277):188-93.

24. Joyce DP, Chapman KR, Balter M, Kesten S. Asthma and allergy avoidance knowledge and behavior in postpartum women. Ann Allergy Asthma Immunol 1997;79(1):35-42.

25. Jaakkola $N$, Ruotsalainen $R$, Jaakkola JJ. What are the determinants of children's exposure to environmental tobacco smoke at home? Scand J Soc Med 1994;22(2):107-12.

26. Emerson JA, Hovell MF, Meltzer SB, et al. The accuracy of environmental tobacco smoke exposure measures among asthmatic children. J Clin Epidemiol 1995;48(10):1251-9. 


\section{Chapter 4}

The compliance with and the effectiveness in exposure reducing measures recommended in the PREVASC program.

Compliance of asthmatic families with a primary prevention program of asthmo and effectiveness of measures to reduce inhalant allergens - a randomised trial.

H.J.A.M. Schönberger', T. Maas '. E. Dompeling '. J.A. Knottnerus' . C. van Weel ${ }^{3}$. C.P. van Schayck'

1. Department of General Practice, Research Institute CAPHRI. University Maastricht, Maastricht. The Netherlands.

2. Department of Pediatrics Pulmonology. University Hospital Maastricht. Maastricht. The Netherlonds:

3. Department of General Practice. University Medical Centre, Radboud University Nijmegen. Nijmegen. The Netherlands. 


\section{ABSTRACT}

\section{Background}

Compliance with and the effect of prenatal and postnatal exposure reduction measures to prevent asthma in high-risk children from asthmatic families were studied.

\section{Method}

Families were randomised to a special care group $(n=222)$ and a control group $(n=221)$. Educational advice on measures to reduce their newborn's exposure to allergens and smoke was provided to the special care group during 3 visits $(2$ prenatal and 1 postnatal). The control group received usual care.

\section{Result}

After the intervention the special care group differed significantly $(p<0.01)$ from the usual care group in: use of anti-mite encasings (parental: $88 \%$ versus $14 \%$; infant: $98 \%$ versus 10\%): keeping pets outside $(51 \%$ versus 19\%): combined breast-feeding and hypoallergenic formula feeding (55\% versus $22 \%$ ), first solids postponement until after the sixth month (71\% versus $28 \%$ ): maternal postnatal smoking (52\% versus $28 \%$ ). Little or no compliance was found with other sanitary measures (cleaning habits, smooth floor covering. ventilation/airing, pet removall; exclusive breast-feeding; prenatal smoking and partner smoking. In spite of pre-existent low allergen levels in both groups, there was a significant reduction of mite, cat, and dog allergens on the mattresses, and mite and cat allergens in the living room in the special care group.

\section{Conclusion}

High compliance was found with the use of anti-mite encasings; substantial compliance with using hypoallergenic formula, solid food postponement, keeping pets outside and reported postnatal maternal smoking. There was no compliance with sanitary measures and the reduction of maternal prenatal passive smoking. Mite and pet allergens on mattresses were strongly reduced by anti-mite encasings. 


\section{Introduction}

There is growing interest in the primary prevention of asthma, because of its ever increasing prevalence, ${ }^{1.2 .3}$ and the resulting burden of illness for patients and the community. ${ }^{4.5}$ It is generally agreed that asthma is a multifactorial disease which can develop when genetically predisposed children are exposed to certain environmental stimuli in early life or even in utero. ${ }^{6.7}$ The best-known modifiable environmental exposures are inhalant allergens of the house dust mite (hereafter referred to as mitel, pet and food allergens, and passive smoking. The importance of reducing some exposures are currently under debate, ${ }^{8}$ and even contradict each other. ${ }^{9.10}$ It is not clear whether the reduction of some of these stimuli prevents or possibly enhances the development of asthma.

Several cohort studies aiming to reduce one or more of the above-mentioned exposures have been started, and report promising results. ${ }^{11-14}$ The PREVASC study (Prevention of ASthma in Children) to which this report refers, investigates whether a multi-faceted approach of a simultaneous reduction of important exposures before and after birth might prevent allergy and asthma and also the effectiveness of such an approach. Study of the effectiveness of a specific intervention is important in that it takes into account the real life circumstances at hand. In contrast. efficacy pertains to the effect of a therapy under optimally controlled circumstances. Efficacy studies are an important first step but often the positive results from efficacy studies might be less or even absent when repeated under daily life circumstances. Thus, effectiveness must also be studied, before a (prevention) therapy can be implemented. The effectiveness of preventive recommendations is mainly determined by the compliance of the subjects to whom the advice is offered. ${ }^{15}$ Therefore, insight into (non)-compliance is an important matter. This paper reports the results of a randomised intervention trial with newborns with at high risk of developing asthma, and investigated: (1) the compliance of the parents receiving advice to reduce exposure to mite, cat, dog and food allergens, and to avoid passive smoking and (2) the effectiveness of mite cat and dog allergen reduction measures on the levels of mite, cat and dog allergens. 


\section{Methods}

\section{Study subjects}

The PREVASC study is a randomised intervention study on the effectiveness of a primary prevention program of asthma directed towards high-risk families expecting a child. ${ }^{15}$ The study started in 1997 in the southeast of the Netherlands. Families were eligible when (1) at least one first-degree relative (mother, father, or sibling) had doctor-diagnosed asthma and (2) the mothers were pregnant. Families were recruited during routine consultation by general practitioners (CPs) and midwives before their sixth month of pregnancy. From 1997 until the end of 1999, 476 families were enrolled in the study. The trial profile is shown in Figure 1. As the intervention could not be executed blindly, allocation to either the intervention group (special care group) or the control group (usual care group) was done by pre-randomisation in which the control group was not informed about the intervention trialarm (randomised consent). ${ }^{16}$ In order to prevent contamination between the intervention and the control group, clusters were formed on the basis of sub-regional ZIP-codes, taking into account the domicile of the family and the location of the general practice they attend.

\section{The prevention program}

The intervention consisted of a primary prevention program that focussed on the reduction of four main environmental exposures of newborns: mites, pets and food allergens and passive smoking. The recommended measures and their timing are shown in the Box.

The families in the special care group were informed about the relation between environmental exposures and the development of allergy and asthma, and were taught methods to reduce allergen and smoke exposure. Trained nurses performed this during three home visits: at 3-5 month, at month 7-8 and $1-3$ weeks after birth.

The education consisted of material from the Dutch Asthma Foundation on allergen avoidance measures for mites, pets and food. For reduction of passive smoking the protocol and brochures of the Minimal Intervention Strategy (MIS), also provided by the Dutch Asthma Foundation, were used. ${ }^{17}$ 


\section{Box. Prevention program of asthma in high-risk children in the PREVASC study}

Recommended measures to reduce exposure to

1. mite and pet allergens from birth of the child through at least the first two years of life:

allergens of mite, starting 1 month before birth.

- providing a smooth floor covering in living, bedroom and nursery

- thorough cleaning by vacuuming/damp mop

- washing bed-clothes at 60 degrees Celsius

- providing anti house dust mite covers for parental and crib mattresses, pillows and duvets (provided free of charge at 8 months of pregnancy)

allergens of pets, starting at least 3 month before birth.

- not keeping pets

- in case of pet-owning: re-housing pets and when objected to, regularly washing and keeping them outside the house

2. food allergens during at least the first six months of life:

- no regular formula but breast feeding and/or use of hypo-allergenic formula (subsidized)

- no intake of weaning solid foods

3. passive smoking:

- no maternal prenatal and postnatal smoking and

- no paternal postnatal smoking during at least the first year of life

- no smoking by others inside the house during at least the first year of life

During the second visit, special care patients were educated on the use of anti-mite covers for parental and crib mattresses, pillows, duvets, anti-mite sleeping bags for the infant (hereafter referred to as anti-mite encasings). These were furnished, without charge 
(Mitecare . Sanalife B.V., Lelystad, the Netherlands) I month before birth with the advice applying them before the birth of the child.

When no breast milk was given or additional milk feeding was needed in the first 6 months after birth, extensive hydrolysed formulae were supplied on demand at the price of normal humanized formulae (Nutrilon Pepti. Numico, Zoetermeer. The Netherlands).

Asthmatic families in the control group received usual care according to the guidelines of the Dutch College of Ceneral Practitioners $(\mathrm{NHC)})^{18}$ According to these guidelines. reduction of exposure to passive smoking and to mite and pet allergens (by furnishing the home, reducing air humidity, use of anti-mite encasings, no pets) are only recommended for allergic asthmatic patients. No advice is given to prevent the development of asthma in newborns of high-risk families. Breast feeding is recommended for all infants. Pregnant women are recommended not to smoke and, after birth, smoking in the presence of the infant is recommended against.

\section{Data sampling}

\section{Compliance}

Compliance was determined by the assessment of the factually performed measures of the prevention program. Data on feeding, breast-feeding and/or kind of bottle-feeding during the first six months of life were derived from weekly kept diaries, and data on solid food introduction were obtained from questionnaires when the child was six months old. Data on the adherence to advice given to reduce mite and pet allergens and to smoking were sampled by parental questionnaires when the child was one year.

\section{Allergen measurement}

Allergen levels of mite (Der p 1), cat (Fel d 1) and dog (Can f 1) were assessed for all participating families in three separate settled dust reservoirs: the living room floor, the parental and the crib mattresses. This was done apart from the educational visits, when the family entered the study (at 3-6 months before birth) and exactly one year later, in order to avoid seasonal influences on allergens levels. Dust was collected in a standardized way by vacuuming (1300-W-vacuum, Bosch". The Netherlands). Dust samples were obtained from the living-room floor by vacuuming 2 areas of $1 \mathrm{~m}^{2}, 2$ minutes each. Dust samples from 
parental mattress were obtained by vacuuming the mattress for 2 minutes $1 \mathrm{~m}^{2}$ with encasing but without bedclothes. Parents were asked not to vacuum the bedroom and living room floor prior to dust collection.

The preparation of dust samples for measurement and the measurement of Der $p 1$. Fel $d 1$. and Can $f \mathrm{l}$ is described elsewhere. ${ }^{19}$ One IU Can $\mathrm{f}$ corresponds to $I \mathrm{ng}$ Can $\mathrm{f} l$, whereas $1 \mathrm{mU}$ Fel $\mathrm{d} l$ corresponds to $4 \mathrm{ng}$ Fel $\mathrm{d} 1$. The detection limit was $2 \mathrm{ng} / \mathrm{g}$ for Der $\mathrm{p} 1$ and 1 $\mathrm{ng} / \mathrm{g}$ of dust for Fel $d \mathrm{l}$ and Can $\mathrm{f}$ 1. Allergen concentrations were calculated as $\mathrm{ng} / \mathrm{m}^{2}$ vacuumed surface.

\section{Data analysis}

Loss to follow-up during the study period and the reasons for the loss were determined. Differences in baseline characteristics and adoption of preventive measures between the special care and usual care group were analysed by $\chi^{2}$ analysis for categorical and by t-tests for normally distributed continuous data.

Der $p$ 1, Fel $d 1$ and Can $f 1$ levels were not normally distributed leven after logarithmic transformation). Median levels, expressed in $\mathrm{ng} / \mathrm{m}^{2}$ vacuumed surface, with interquartile range (IQR) were therefore used for further analyses. For each dust reservoir, within-group differences between the allergen levels at baseline and after 1 year were analysed with the Wilcoxon signed rank test. Between-group differences were tested by the Mann Whitney $U$ test. The Statistical Package for the Social Sciences (SPSS version 10) was used for analysis. The study was approved by the Ethical Committee, University Maastricht, Maastricht. The Netherlands.

\section{Results}

After 1 year 443 of the 476 families were still participating in the study, 222 in the special care and 221 in the usual care group. Figure 1 shows the number of families lost to followup as well as the reasons for the loss. Table 1 presents socio-demographic factors and birth characteristics in the special and usual care group. revealing that there were no statistical differences between the two groups. 
Compliance to sanitation measures on mite and pet allergens

Frequencies of sanitary measures, applied by the special care group after intervention and by the usual care group are shown in Table 2 . With respect to the compliance with reducing exposure to mite allergens, only new crib mattresses and crib and parental anti-mite encasings were significantly more frequently applied in the special care group compared with the usual care group. All other recommended anti-mite measures did not differ significantly between the groups.

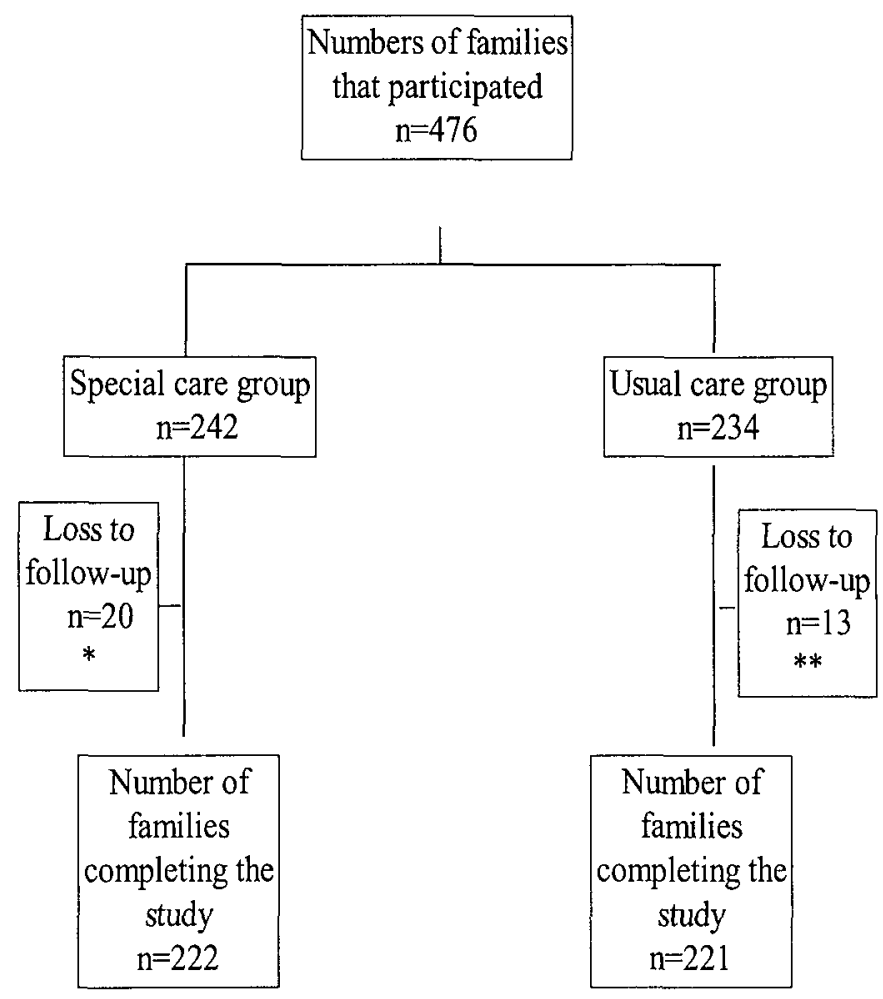

Figure 1. Trial profile of the PREVASC study. Numbers of lost to follow-up.

*: abortion 11; death 2; moved 4; withdrawal 3. **: abortion 6; long lasting hospitalization

2; death 1 ; moved 3 ; withdrawal 1 . 
Table 1. Characteristics of the special care and usual care group. Figures are numbers with percentages between parentheses, unless otherwise listed. No statistical difference between the groups.

Characteristic

\section{Special care group} $n=222$

Male

Mean age mother at birth in years (SD*)

Education mother

low

middle

high

Family member with asthma

father
mother
both
siblings
parent and sibling

Place of birth

$$
\begin{aligned}
& \text { at home } \\
& \text { out-patient clinic } \\
& \text { in-patient clinic }
\end{aligned}
$$

Mode of delivery

$$
\begin{aligned}
& \text { normal } \\
& \text { caesarian section } \\
& \text { vacuum extraction } \\
& \text { forceps }
\end{aligned}
$$

Age house in years

$$
\leq 20
$$

$101(47.4)$

$173(77.8)$

$22(10.0)$

$19(10.0)$

$8(3.6)$

\section{Usual care group} $n=221$

$118(53.2)$

$30.9(3.8)$

$111(50.0)$

$31.0(3.6)$

32 (14.5)

20(9.0)

98 (44.3)

107 (48.6)

$94(42.3)$

49 (22.0)

41 (18.6)

$62(28.1)$

$15(6.7)$

42 (19.1)

$61(27.5)$

$71(32.0)$

81 (36.7)

56 (25.3)

$84(38.0)$

$100(45.0)$

$168(76.0)$

33 (14.9)

$14(6.3)$

$6(2.7)$

$120(54.8)$

Sibship-size

$$
\begin{aligned}
& 0 \\
& 1 \\
& \geq 2
\end{aligned}
$$

Birth season in spring/summer

Birth weight, mean (SD) in grams

Pregnancy duration, mean (SD) in weeks

$\begin{array}{ll}87(39.2) & 85(38.3) \\ 93(41.9) & 85(38.3) \\ 42(18.9) & 50(23.4) \\ 108(49.5) & 112(50.5) \\ 3387(528) & 3475(583) \\ 39.7(1.7) & 39.7(1.6)\end{array}$$$
112(50.5)
$$$$
3475 \text { (583) }
$$

* $\mathrm{SD}=$ standard deviation 
Table 2. Frequencies of applied measures to reduce allergens of the house dust mite and pets in asthmatic families. Comparison between special care group and usual care group (Chi-square test). Absolute numbers are given. Percentages between parentheses. Significant differences in bold.

\begin{tabular}{|c|c|c|}
\hline & $\begin{array}{c}\text { Special care } \\
\text { group } \\
n=222\end{array}$ & $\begin{array}{c}\text { Usual care } \\
\text { group } \\
n=221\end{array}$ \\
\hline \multicolumn{3}{|l|}{ Applied measures } \\
\hline $\begin{array}{l}\text { Smooth floor covering living-room, parental bedroom and } \\
\text { nursery }\end{array}$ & $103(51.5)$ & $116(57.1)$ \\
\hline Every day floor cleaning & $65(53.3)$ & $57(46.7)$ \\
\hline Crib mattress new & $108(54.0)^{*}$ & $88(43.6)$ \\
\hline Anti-mite encasing crib mattress & $197(98.0) \dagger$ & $20(9.9)$ \\
\hline Anti-mite encasing parent mattress & $193(87.6) \dagger$ & $29(14.4)$ \\
\hline Ventilating & $121(61.1)$ & $112(56.0)$ \\
\hline Airing & $176(88.0)$ & $171(84.2)$ \\
\hline Dog present & $45(22.7)$ & $46(22.7)$ \\
\hline of which disposed of & $9(20.0)$ & $6(13.0)$ \\
\hline of which keeping outside & $22(51.2) \dagger$ & $8(18.6)$ \\
\hline Cat present & $25(12.6)$ & $31(15.3)$ \\
\hline of which disposed of & $3(12.0)$ & $1(3.2)$ \\
\hline of which keeping outside & $14(58.3) \dagger$ & $3(9.7)$ \\
\hline
\end{tabular}

* $\mathrm{P}<0.01 ; \uparrow: \mathrm{P}<0.0001$.

Table 2 shows also that pets were owned in equal proportion by the special and usual care group. Significantly more pet-owning families in the special care than in the usual care group reported keeping their pet outside.

\section{Resulting mite and pet levels}

Mite, cat and dog allergen levels in living rooms and on parental and crib mattresses are shown in Table 3. In the special care group. mite and cat allergen levels decreased significantly in all three locations. Dog allergens were only reduced in dust samples from the 
mattresses, but not from the living room. In the usual care group, cat allergen levels from living room dust samples decreased also significantly.

Pet-owning families, keeping their dog or cat outside, had lower levels of animal specific allergen in dust reservoirs, than families keeping the animal inside the house. This difference was only significant for dog allergens in the dust samples from the living room (46 $v 1881$ $\left.\mathrm{ng} / \mathrm{m}^{2}, \mathrm{P}=0.005\right)$, but not for those from mattresses $\left(67 \vee 486 \mathrm{ng} / \mathrm{m}^{2}, P=0.06\right)$.

Compliance with the advice to reduce food allergens and passive smoking Feeding regimens during the first 6 months of life are shown in Table 4 . The same number of infants was breast-fed exclusively in the special care group as in the usual care group (Table 4). However, significantly more infants in the special care group received hypo-allergenic formula, exclusively or in combination with breast-feeding. Special care infants also received their first weaning solids significantly later than usual care infants. Special care mothers did not breast-feed their newborns any more than usual care mothers: $75 \%(n=166)$ and $72 \%$ $(n=160)$, respectively. The proportion children still breast-fed after 6 months from birth was $21 \%$ in both groups.

Table 4 also shows that significantly more mothers in the special care group reported to have quit smoking postnatally. No significant differences were observed for the other smoking parameters. 
Table 3. Allergen levels of house dust mite (Der p 1), cat (Fel d l) and $\operatorname{dog}(\mathrm{Can} f 1)$ in the special care group before and after intervention ( $n=222)$, compared* to the usual care group $(n=221)$. Allergen levels are expressed in $\mathrm{ng} / \mathrm{m}^{2}$ with interquartile range (IQR) between parentheses.

Dust

Special care

Usual care

samples

$\begin{array}{ccccccc}\text { Living- } & \text { Baseline } & P & \text { Measurement } & \text { Baseline } & P & \text { Measurement } \\ \text { room } & \text { measurement } & \text { value } & \text { after one year measurement } & \text { value } & \text { after one year }\end{array}$

$\begin{array}{ccccccc}\text { Der p 1 } & 5.5(43.8) & <0.03 & 0.6(40.0) & 2.1(17.1) & \text { n.s. } \dagger & 2.2(21.4) \\ \text { Fel d 1 } & 27.8(105.6) & <0.001 & 14.2(50.0) & 21.3(117.8) & \text { n.s. } \dagger & 17.2(85.3) \\ \text { Can f 1 } & 10.0(103.0) & \text { n.s. } \dagger & 8.1(79.6) & 10.5(107.9) & \text { n.s. } \dagger & 9.8(89.4)\end{array}$

\section{Parental}

mattress

$\begin{array}{ccccccc}\text { Der p 1 } & 279.4(2150.0) & <0.001 & 15.3(78.9) & 117.6(692.4) & \text { n.s. } \dagger & 113.4(764.3) \\ \text { Fel d 1 } & 128.8(434.6) & <0.001 & 27.6(88.0) & 104.7(366.6) & <0.001 & 83.8(210.4) \\ \text { Can f 1 } & 49.3(487.7) & <0.001 & 9.6(80.8) & 54.1(373.8) & \text { n.s. } \dagger & 42.4(219.6)\end{array}$

Crib

mattress

\begin{tabular}{lllllll} 
Der p 1 & $74.5(927.6)$ & $<0.001$ & $4.6(39.2)$ & $15.8(118.6)$ & n.s. $\dagger$ & $22.3(152.8)$ \\
Fel d 1 & $48.9(188.1)$ & $<0.001$ & $14.9(46.7)$ & $38.3(215.4)$ & n.s. $\dagger$ & $33.3(186.7)$ \\
Can f 1 & $33.8(131.7)$ & $<0.001$ & $4.5(35.4)$ & $18.8(123.2)$ & n.s. $\dagger$ & $26.3(130.7)$ \\
\hline
\end{tabular}

*: Statistic testing by Mann-Whitney U test. $\dagger$ n.s.: not significant. $\ddagger: 50$ and 54 of the crib mattresses of the special and usual care group, respectively were not present at the time of the baseline measurement. Therefore a change could not be determined. 
Table 4. Frequencies of applied measures to reduce exposure to food allergens and exposure to passive smoking in the special care group. Comparison with the usual care group (Chi-square test). Absolute numbers are given. Percentages between parentheses.

\begin{tabular}{lccc}
\hline & special care & P value & usual care \\
Applied measures & $n=222$ & & $n=221$
\end{tabular}

Feeding regimen in the first 6 months after birth*

$\begin{array}{lccc}\text { exclusive breast-feeding } & 21(9.6) & \text { n.s. } \ddagger & 26(11.8) \\ \text { breast-feeding and hypoallergenic formula } & 115(55.3) & <0.001 & 49(22.3) \\ \text { exclusive normal formula } & 3(1.4) & <0.001 & 36(16.4) \\ \text { ever normal formula } & 102(49.5) & <0.001 & 162(77.9)\end{array}$

Introduction of weaning solids foods $\dagger$

$\begin{array}{lccc}<4 \text { month } & 1(0.5) & <0.001 & 13(6.3) \\ 4-6 \text { month } & 58(28.9) & <0.001 & 137(65.9) \\ >6 \text { month } & 142(70.6) & <0.001 & 58(27.9)\end{array}$

Maternal smokings"

during pregnancy

of whom quit smoking

23 (11.6)

n.s. $\ddagger$

$22(11.1)$

$15(65.2)$

n.s. $\ddagger$

$12(54.4)$

during 1st year

27 (13.5)

n.s. $\ddagger$

$30(14.7)$

of whom quit smoking

14 (51.9)

$<0.04$

8 (27.6)

44 (23.3)

$45(24.1)$

Partner smoking!"

of whom quit smoking

$14(31.1)$

n.s. $\ddagger$

n.s. $\ddagger$

$9(19.6)$

Smoking by others

$93(46.5)$

n.s. $\ddagger$

$101(49.8)$

* missing: special care group $n=16$, usual care group $n=14 ;+$ missing: special care group $n=21$, usual care group $n=13 ; \ddagger n . s .:$ not significant. $\S$ : missing special care group 22 , usual care group $17 ; \|$ : missing: special care group 22, usual care group 18 . 


\section{Discussion}

In this study we analysed the compliance of asthmatic families with the advice on environmental exposures reducing measures, and the resulting effectiveness on the levels of mite and pet allergens. Parents complied quite well with the advice to use anti-mite parental and crib encasings. A substantial compliance was noted with the advice to use new crib mattresses, to give extensive hydrolysed formula, to postpone the intake of the first weaning solids and with keeping pets outside. Compliance was low with disposing of pets and with avoidance of smoking. As a result of the intervention mite cat and dog allergen levels were reduced on dust samples of crib and parental mattresses and in the living room.

In both groups relatively low baseline levels of mite in the dust samples were found, especially in the living room. This might be due to anti-mite measures that had already been taken in asthmatic families on the advice of professionals or on people's own initiative, as has been reported by others. ${ }^{20}$ Consequently, this may have affected the potential room for improvement in some of our sanitary recommendations. It might be the reason why the advice to apply a smooth floor covering was not complied with, a finding which has also been reported by others. ${ }^{21}$ The same holds for non-compliance with daily floor cleaning and ventilating and airing rooms. Notwithstanding the fact that we found no difference in the frequencies of these sanitary measures between the special care and the usual care group: we observed a significant decrease in living-room mite levels in the special care group. This suggests that some elements of the education on mite reducing measures were still effective.

The compliance with the advice on applying anti-mite encasings was very good. We were able to confirm reports that encasings are very effective in reducing mite allergens. ${ }^{21-23}$ We did not advise applying acaricides to reduce mite allergens, as this measure is probably not efficacious $^{22}$ and adherence to this measure diminishes considerably over time. ${ }^{21}$

One in five pet-owning special care families were willing to get rid of their pet, but not more often than the usual care group. A low compliance for this measure has also been reported by others. ${ }^{24}$ Compliance might appear to be low as most asthmatic families no longer procure pets to begin with. ${ }^{25}$ The advice for pet-owning families "to keep pets outside" appeared to be more feasible to adhere to. Moreover, it resulted in a decrease of dog 
allergens. The same could not be demonstrated for cat allergens probably because the number of families involved was too small lonly in three families of the special care group were the cats kept outside).

Anti-mite encasings also appeared to be effective in decreasing the amount of pet allergens on parental and crib mattresses. which supports findings of others. ${ }^{21.26}$

Many mothers did not comply with the advice to breast-feed their children exclusively during the first 6 months of life. This is remarkable in view of the considerable room for improvement existing in exclusive breast-feeding as is indicated by the observed frequency of $12 \%$ of exclusive breast-feeding in the usual care group. The special care group did comply however with the advice to use hypo-allergenic instead of cow-milk based formula feeding when supplementary feeding was needed or as replacement when breast-feeding was stopped. In this way a moderate reduction of exposure to cow milk was achieved. However. in the special care group $50 \%$ of the infants were still fed normal formula at least once over the first 6 months of life.

The introduction of the first weaning solids in the special care group was postponed until after the child was 6 months old in $70 \%$ of the cases.

We observed that about one in eight mothers smoked pre- and/or postnatally which is similar to figures given by others. ${ }^{25.27}$ The advice to avoid passive smoking, neither altered prenatal maternal smoking nor smoking by the partner or others in the house, although significantly more mothers in the special care group reported to have quit smoking after childbirth than mothers in the usual care group.

There are only a few studies that have investigated compliance and effectiveness of combined measures to reduce environmental exposure. Bruno et al. reported compliance to advice on avoidance of mite, pet and food allergens and passive smoking but did not have a control group. ${ }^{28}$ Others reported only compliance for the nutritional recommendations. ${ }^{29.32}$ The intervention measures in the study of Chan-Yeung et al. were directed towards reduction of mite and cat allergens, but data on "spontaneous" compliance in the control 
group were not given. ${ }^{21}$ Comparison with earlier studies is also hampered by the varying methods used to determine compliance, and by the different definitions of being high-risk.

A matter that should be tackled in studies like the present one is contamination in the usual care group. Contamination is not imaginary when pregnant mothers in the special and usual care group live in the same neighbourhood, visit the same midwife, hospital. 'pregnancy' courses, and schools, and so on. Exchange of information might lead to the spontaneous application of measures of interest by the usual care group. We have tried to prevent this by means of a randomisation by ZIP-code and by not informing the usual care group about the existence of an intervention group (randomised consent design). Moreover, the timing of the questionnaires about smoking and feeding regimes was chosen in such a way that a "Hawthorne effect" (drawing unintended aftention in the usual care group just by questioning about the presence of preventive measures) could be avoided. There seemed to be no indication of compliance in the usual care group as a result of contamination. except for the reduction of cat allergen levels, which appeared to be decreased after one year.

Ideally, not only the compliance to measures reducing exposures must be determined but also the effect of compliant behaviour on resulting levels of exposures must be assessed. We were able to do this only for mite and pet allergens. Exposure to food allergens and smoke was assessed through parental reporting, with the danger of recall- or reporting bias. For cigarette smoke exposure, infants' serum or urinary cotinine may be used, but this is not feasible for prenatal smoking. Questionnaire based data are likely to be reasonably valid for nicotine exposure. ${ }^{29}$ For exposure to food allergens, a valid biomarker is not available. By using weekly diaries, recall bias was minimised.

Since anti-mite beddings were supplied free of charge and hypoallergenic bottle-feeding was subsidized, this might have affected compliance positively. However our reasoning for providing these materials was that in case of proved (cost) effectiveness of the primary prevention, health insurance companies will be probably reimburse the costs for these preventive measures as they do now for cow milk allergy and mite allergic asthma patients. 
In summary, the compliance among families expecting an infant at high risk for asthma in a multi-faceted primary prevention program of asthma is excellent with the use of anti-mite encasings, hypoallergenic formula feeding, postponing first solids and with keeping pets outside. In spite of pre-existing low allergen levels, the anti-mite measures recommended here led to a strong reduction of exposure to mite, cat and dog allergens on the crib and parental mattresses and for mite and dog allergen in the living room. Whether the compliance with the program will lead to clinically assessable effectiveness, still needs to be established.

\section{Conflict of interest: none}

Funded by: The Dutch Asthma Foundation, Prevention Fund and the Dutch Royal Academy of Science (KNAW)

\section{Acknowledgement}

The PREVASC study is a joint project of the Departments of General Practice of the University Maastricht and the University Nijmegen. We thank the general practitioners allied to these departments and the participating midwives for recruiting the eligible families. We are grateful to all the families that were willing to participate and their devotion to the study. We would also like to thank the research-assistants: Ilse van Beerendonck and Karin Manders; the data managers: Jacqueline Pisters and Kitty Coolen; the statistical adviser, Jildou Sijbrandij, and the nurses, who visited and educated the participating families: Cindy Brink, Kitty van der Meer, Marjorie Rovers, Twanny Rouwhorst, Inke Schaap, Marjan Terhaar and Elly de Vree and the PREVASC secretary Annemarie Spaninks.

We thank Numico NV (Zoetermeer, the Netherlands) for the supply of Nutrilon pepti ${ }^{\circledR}$ and Artu Biological (Lelystad, the Netherlands) for the supply of the house dust mite impermeable covers $\left(\right.$ Mitecare ${ }^{\mathbb{Q}}$ ) and bedding.

We would like to thank Nico van der Maas of Skiltec B.V., Beek, the Netherlands, for his linguistic comments and suggestions. 
References:

1. Burney PG, Chinn S, Rona RJ. Has the prevalence of asthma increased in children? Evidence from the national study of health and growth 1973-86. BMJ 1990;300(6735):1306-10.

2. Downs SH, Marks GB, Sporik R, Belosouva EG, Car NG, Peat JK. Continued increase in the prevalence of asthma and atopy. Arch Dis Child 2001;84 (1):20-23.

3. Upton MN, McConnachie A, McSharry C, et al. Intergenerational 20 year trends in the prevalence of asthma and hay fever in adults: the Midspan family study surveys of parents and offspring. BMJ 2000;321(7253):88-92.

4. Lenney W. The burden of pediatric asthma. Pediatr Pulmonol Suppl 1997;15:13-6.

5. Wever-Hess J, Wever AM, Yntema JL. Mortality and morbidity from respiratory diseases in childhood in The Netherlands, 1980-1987. Eur Respir J 1991;4(4):429-33.

6. Warner JA, Jones AC, Miles EA, Colwell BM, Warner JO. Prenatal origins of asthma and allergy. Ciba Found Symp 1997;206:220-8; discussion 228-32.

7. Holloway JA, Warner JO, Vance GH, Diaper ND, Warner JA, Jones CA. Detection of housedust-mite allergen in amniotic fluid and umbilical-cord blood. Lancet 2000;356(9245):1900-2.

8. Von Ehrenstein OS, Von Mutius E, Illi S, Baumann L, Bohm O, von Kries R. Reduced risk of hay fever and asthma among children of farmers. Clin Exp Allergy 2000;30(2):187-93.

9. Sears MR, Greene JM, Willan AR, et al. Long-term relation between breastfeeding and development of atopy and asthma in children and young adults: a longitudinal study. Lancet 2002;360(9337):901-7.

10. Oddy WH. Breastfeeding and asthma in children: findings from a West Australian study. Breastfeed Rev 2000;8(1):5-11.

11. Zeiger RS, Heller S, Mellon MH, et al. Effect of combined maternal and infant food-allergen avoidance on development of atopy in early infancy: a randomized study [published erratum appears in J Allergy Clin Immunol 1989 Nov;84(5 Pt 1):677]. J Allergy Clin Immunol 1989;84(1):72-89.

12. Hide DW, Matthews S, Tariq S, Arshad SH. Allergen avoidance in infancy and allergy at 4 years of age [see comments]. Allergy 1996;51(2):89-93.

13. Chan-Yeung M, Manfreda J, Dimich-Ward H, Ferguson A, Watson W, Becker A. A randomized controlled study on the effectiveness of a multifaceted intervention program in the primary prevention of asthma in high-risk infants. Arch Pediatr Adolesc Med 2000;154(7):65763.

14. Custovic A, Simpson BM, Simpson A, Kissen P, Woodcock A. Effect of environmental manipulation in pregnancy and early life on respiratory symptoms and atopy during first year of life: a randomised trial. Lancet 2001;358(9277):188-93.

15. Schonberger HJ, Van Schayck CP. Prevention of asthma in genetically predisposed children in primary care--from clinical efficacy to a feasible intervention programme. Clin Exp Allergy 1998;28(11):1325-31.

16. Zelen M. A new design for randomized clinical trials. N Engl $J$ Med 1979;300(22):1242-5.

17. Pieterse ME, Seydel ER, DeVries H, Mudde AN, Kok GJ. Effectiveness of a minimal contact smoking cessation program for Dutch general practitioners: a randomized controlled trial. Prev Med 2001;32(2):182-90.

18. Dirksen WJ, Geijer RMM, de Haan M, de Koning G, Flikweert S, Kolnaar BGM. NHGStandaard Astma bij Kinderen (eerste herziening). Huisarts Wet 1998(41(3)):130-43.

19. van der Heide S, van Aalderen WM, Kauffman HF, Dubois AE, de Monchy JG. Clinical effects of air cleaners in homes of asthmatic children sensitized to pet allergens. $J$ Allergy Clin Immunol 1999;104(2 Pt 1):447-51.

20. van Strien RT, Verhoeff AP, van Wijnen JH, Doekes G, de Meer GE, Brunekreef B. Der p I concentrations in mattress surface and floor dust collected from infants' bedrooms. Clin Exp Allergy 1995;25(12):1184-9.

21. Moira CY, Ferguson A, Dimich-Ward H, Watson W, Manfreda J, Becker A. Effectiveness of and compliance to intervention measures in reducing house dust and cat allergen levels. Ann Allergy Asthma Immunol 2002;88(1):52-8. 
22. Custovic A, Simpson BM, Simpson A, et al. Manchester Asthma and Allergy Study: lowallergen environment can be achieved and maintained during pregnancy and in early life. $J$ Allergy Clin Immunol 2000; 105(2 Pt 1):252-8.

23. Koopman LP, van Strien RT, Kerkhof M, et al. Placebo-controlled trial of house dust miteimpermeable mattress covers: effect on symptoms in early childhood. Am J Respir Crit Care Med 2002;166(3):307-13.

24. Chan-Yeung M, Ferguson A, Dimich-Ward H, Watson W, Manfreda J, Becker A. Effectiveness of and compliance to intervention measures in reducing house dust and cat allergens levelstie. Annals of Allergy, Asthma \&lmmunology 2002;88:52-58.

25. Wijga A, Smit HA, Brunekreef B, et al. Are children at high familial risk of developing allergy born into a low risk environment? The PIAMA Birth Cohort Study. Prevention and Incidence of Asthma and Mite Allergy. Clin Exp Allergy 2001;31(4):576-81.

26. Colloff MJ, Ayres J, Carswell F, et al. The control of allergens of dust mites and domestic pets: a position paper. Clin Exp Allergy 1992;22 Suppl 2:1-28.

27. Bruno G, Cantani A, Ragno V, Milita O, Ziruolo G, Businco L. Natural history of IgE antibodies in children at risk for atopy. Ann Allergy Asthma Immunol 1995;74(5):431-6.

28. Bruno G, Milita O, Ferrara M, Nisini R, Cantani A, Businco L. Prevention of atopic diseases in high risk babies (long-term follow-up). Allergy Proc 1993;14(3):181-6.

29. Brunekreef B, Leaderer BP, van Strien $R$, et al. Using nicotine measurements and parental reports to assess indoor air: the PIAMA birth cohort study. Prevention and Incidence of Asthma and Mite Allergy. Epidemiology 2000;1 1(3):350-2. 


\section{Chapter 5}

\section{The clinical effectiveness of the PREVASC intervention}

Hubert J.A.M. Schönberger. M.D. '. Edward Dompeling. M.D., Ph.D. ', André J. Knottnerus, M.D., Ph.D. ', Tanja Maos. M.Sc., 'Jean W.M. Muris, M.D., Ph.D. ', Chris van Weel M.D.. Ph.D. . Onno.P. van Schayck. Ph.D.' The clinical effectiveness of a multi-facet randomised intervention to prevent childhood asthma during the first two years of life.

1. Department of Ceneral Practice, Research Institute CAPHRI. University Maastricht, Maastricht. The Netherlands.

2. Department of Pediatric Pulmonology. Research Institute CAPHRI. University Hospital Moastricht. Maastricht. The Netherlands.

3. Department of Ceneral Practice, University Medical Centre. Rodboud University Nijmegen. Nijmegen. The Netherlonds.

In submission 


\section{Abstract}

\section{Background}

As asthma is the most common chronic disease in childhood, with huge socio-economic consequences, much attention is directed towards the possibilities for primary prevention of this disease. We studied the clinical effectiveness of the combined reduction of allergic and non-allergic irritants in the first two years of life in a primary care setting.

\section{Method}

Expectant families with asthma in at least the mother, father, and/or children were recruited by general practitioners and midwives: 242 were randomly allocated to the intervention group (IC) and 234 to control group (CC). Families received instruction to apply preventive measures to achieve a low mite, pet and food allergen level from birth and to avoid prenatal and postnatal smoking. The $C G$ received usual care. Main outcome measures were parental reported and CP observed asthma-like and atopic symptoms in the first two years of life and at age two.

\section{Findings}

222 infants in the $I C$ and 221 in the CC could be followed-up. The incidence of wheezing symptoms in the first two years of life was similar in both groups. However, at age two children in the $\mathrm{IC}$ were less likely to have wheezing lodds ratio 0.73 [95\% Cl 0.56-0.96]), shortness of breath $10.76(0.61-0.96)$ and night-time cough (0.72 (0.55-0.95) than those in the CC. No significant differences in total and specific lgE were found between the groups. In subanalysis, symptoms in the first two years of life as well as at age two were significantly reduced in the female IG, but not the male IC.

\section{Interpretation}

A multi-facet anti-asthma intervention was on average not effective in reducing asthma-like symptoms in high-risk children in the first two years of life and modestly effective at age two. Follow-up is necessary to confirm that the intervention can actually prevent the development of asthma. 


\section{Introduction}

Asthma is the most common chronic disease in childhood, and is responsible for a large burden of disease, with huge socio-economic consequences. ${ }^{1-4}$ As the prevalence of asthma is still increasing. ${ }^{5-9}$ much attention is directed towards the possibilities for primary prevention of this disease.

It is generally agreed that asthma is a multi-factorial disease which develops in very early life or even intrauterine. ${ }^{10.13}$ Environmental exposure to allergens and tobacco smoke during pregnancy or in very early life may enhance sensitisation and allergic morbidity, especially in children with a genetic predisposition. ${ }^{14.15}$ Several primary prevention trials are currently in progress or will be finished soon and have recently been reviewed. ${ }^{16}$ Some trials study the preventive effect of a reduction of a single exposure, such as food allergens ${ }^{17}$ or mite and pet allergens, ${ }^{18.19}$ or a dual approach of avoidance of food allergens and mite allergens, ${ }^{20}$ combined with reduction of passive smoking. ${ }^{21}$ The study reported here - the Prevention of ASthma in Children (PREVASC) study- differs from the above-cited trials in recruiting eligible cases from a primary care population in a routine primary care setting. The study evaluates the effects of a multi-faceted approach by combining reduction of prenatal and postnatal exposure to mite, pet and food allergens and prenatal and postnatal passive tobacco smoke exposure on the development of asthma in children at high risk from at least one first-degree relative with asthma. Through this approach the PREVASC study acknowledges the multi-factorial nature of asthma. It brings together the factors that can be addressed in daily primary care; in addition, the comprehensive preventive effect rather than the effect of a reduction of a single exposure is being assessed. Since airway morbidity is influenced by gender, ${ }^{22}$ and gender-specific effects of environmental exposure on asthma have been reported recently. ${ }^{23}$ we also analyzed the clinical effectiveness of the intervention program in boys and girls separately.

\section{Methods}

\section{Study population}

The PREVASC study is a randomised intervention study in Dutch primary care on the effectiveness of a primary prevention program of asthma directed towards high-risk families 
expecting a child. The rationale and design of the PREVASC study have been described previously. ${ }^{15}$

In summary, pregnant mothers were recruited by general practitioners (CPs) and midwives during the first two trimesters of their pregnancy when they visit their GP or midwife. In the Dutch health care system all patients are registered with a CP over a longer period of time. consulting 'their' $\mathrm{CP}$ for all health care needed, including pregnancy. ${ }^{24}$ Mothers were asked for written informed consent when the $C P$ had established that their unborns were at high risk from familial occurrence of asthma (asthma in at least the mother, father or sibling(s)). This allowed antenatal identification of those who would subsequently be at increased risk of developing asthma

\section{Intervention}

The intervention group received a standardized instruction from (specially trained) nurses in three home visits: at the start at 4-6 months of pregnancy, at 8 months of pregnancy and 13 weeks after birth. The instruction consisted of recommendations to reduce four main environmental exposures. (1) Mite allergens by sanitation measures, including daily cleaning of the house floors, washing bed-clothes on a hot cycle (at least 60 degrees Celsius). removing textile floor covering, reducing air humidity by ventilating/airing and heating. application of mite impermeable bedding (mattresses, quilt and pillow, sleeping bag) of parent and infant (Mitecare', Sanalife B.V., Lelystad. The Netherlands). These measures have been shown to be effective in reducing mite allergen levels. ${ }^{15}$ Parents were informed on these anti-mite measures in the second visit and recommended to apply them before the infant was born and during the first two years of life. Anti-mite encasings were provided one month before birth. (2) Pet allergens by disposing of pets or keeping them outside the house and washing them at least once a month. Instruction on these measures was given in the first visit and repeated in the second and third visit. Parents were asked to start with applying the measure at least 3 months before birth and to continue this during the first two years of life. The prenatal timing of the instruction to apply the anti-mite and pet allergen measures was chosen in such a way that a low level of these allergens could be achieved at the time the child was born. (3) Food allergens by breast-feeding the infant during at least the first 6 months of life. When breast-feeding was stopped before the children were 6 month old or supplementation was necessary, an extensive hydrolyzed formula milk (Nutrilon Pepti. 
Numico, Zoetermeer. The Netherlands) was prescribed. In addition, introduction of the first solid food intake was recommended to postpone until after six months of age. Instruction on these measures was given in the second visit, and repeated in third visit. (4) Passive smoking during pregnancy by maternal abstention from smoking and postnatally by parental abstention from smoking in the first two years of life. Instruction on these measures was given in the first visit and repeated in the second and third visit.

The control group received the usual care of the GP. In the guidelines of the Dutch College of General Practitioners on asthma in children, ${ }^{25}$ preventive measures are recommended only when children are already asthmatic (secondary prevention). Measures to prevent asthma in high-risk infants are currently not part of the guidelines.

\section{Outcome variables}

As asthma in the first two years of life cannot be reliably determined, we used asthma-like symptoms that might point at the possible development of asthma as primary clinical outcome. We sampled data on asthma-like symptoms during the first two years of life and at the end of the second year of life, hereafter referred to as current symptoms.

For measuring asthma-like symptoms during the first two years of life we used parental reported as well as doctor recorded symptoms. Parental reports were derived from questionnaires (the International Study of Asthma and Allergies in Childhood questionnaires. $|S A A C|^{26}$, administered at age six months, at age one and two years. In order to enable comparison of the results. ISAAC outcomes were brought into line with those used in other primary prevention studies. ${ }^{19}$ The items were. "night-time cough without cold". "wheezing at least once", "wheezing with awakening", and "recurrent wheezing" ( $\geq 4$ times) at any time in the first two years of life. CPs reports consisted of prospectively recorded asthma-like symptoms ("wheezing without fever", "shortness of breath" and "coughing") observed when the parents consulted the GP in case their child was ill during the first two years of life. Also standardized diagnoses (atopic dermatitis, bronchiloli)tis, pneumonial were recorded based on definitions of the International Classification of Health Problems in Primary Care (ICHPPC). ${ }^{27}$ As a gold standard for asthma at the age 0-4 is lacking, asthma diagnosis was based on the Dutch Guideline "Asthma in Children" (further referred to as CP based diagnosis asthmal. ${ }^{25}$ 
Current asthma-like symptoms were defined as parental reported "wheeze". "shortness of breath" and "night-time coughing"). occurring in the 4 weeks prior to the second birthday, This period was chosen in an attempt to avoid sampling wheezing symptoms caused by bronchiolitis, as this disease occurs mainly before that period.

\section{Measurement of $\lg E$}

Atopic status was determined at age two years by measuring total and specific gE against mite (Der p 1), cat (Fel d 1) and dog (Can f 1 ) allergens. Total and specific IgE were determined in heel prick blood sampled on filter paper at age two. Absorbed material was eluted by incubation with PBS-T (PBS/Tween-20 $10.1 \% \mathrm{v} / \mathrm{v}]$ ) for 16 hours under constant rotation. Eluates were separated from filter paper by centrifugation. Determination of total $\mathrm{lgE}$ in eluted blood spots was performed as previously described ${ }^{28}$ using Sepharoseimmobilized reagents and ${ }^{125}$-labeled anti-lgE raised in sheep. Test results were expressed in $\mathrm{IU} / \mathrm{ml}$ ( $1 \mathrm{IU}$ representing approximately $2.4 \mathrm{ng}$ of $\mathrm{gE}$ ).

Specific lgE against mite, cat and dog were assessed with a radioallergosorbent fluorescent immunoassay (RAST)

Measurement of environmental exposures to mite, pet and food allergens, and passive smoking

We measured the effect of the intervention on mite and pet allergen levels by comparing the allergens levels in three settled dust reservoirs (the living room floor, parental and baby mattress) at baseline, directly after enrolment (3-5 month before birth and exactly 1 year later (7-9 month after birth) in order to avoid seasonal influences in allergen levels. ${ }^{29}$ At the same moments, dust samples were taken in the control group. Dust collecting was performed by research-assistants in a standardized way by vacuuming $11300-\mathrm{W}$-vacuum. Bosch. The Netherlands) the living room floor ( 2 areas of $1 \mathrm{~m}^{2}$, during 2 minutes) and the parental and crib mattress (1 $\mathrm{m}^{2}$ during 2 minutes) with covers but without sheets. The preparation of dust samples for measurement and the measurement of Der $p l$, Fel $d l$ and $\operatorname{Can} f 1$ is described elsewhere. ${ }^{30}$ One IU Can $f 1$ corresponds to $1 \mathrm{ng}$ Can $f 1$, whereas $1 \mathrm{mU}$ Fel d 1 corresponds to $4 \mathrm{ng}$ Fel d 1 . The detection limit was $2 \mathrm{ng} / \mathrm{g}$ of dust for Der $\mathrm{p} 1$ and $1 \mathrm{ng} / \mathrm{g}$ of 
dust for Fel $d 1$ and Can $f 1$. Allergen concentrations were calculated as $\mathrm{ng} / \mathrm{m}^{2}$ vacuumed surface.

Data on exposure to food allergens (breast feeding and/or type of formula feeding) were derived from weekly diary recording and regarding the introduction of the first solid foods from a questionnaire when the children were six months old.

Prenatal and postnatal passive smoking was assessed on the basis of a parentally recorded questionnaire when the children were one year old.

\section{Randomisation}

As blinding for the intervention measures was not possible, families were allocated to the intervention and control group by pre-randomisation (randomised consent design in which. both groups are informed about their own trial arm but not on the other. ${ }^{32}$ To prevent contamination between the intervention group and the control group, the pre-randomisation was performed in clusters, taking into account the Zip code of the domicile of the recruited family in combination with the location of the general practice the family attended. Once a general practice was allocated, every family recruited afterwards in that practice was allocated automatically to the same group as the practice was allocated to. Our aim was to recruit a similar number of patients in each group. Because it is a common experience that co-operating GPs, allocated to the intervention group will recruit more cases than GPs allocated to the control group. the study protocol prescribed in that case to change the unweighted randomisation in a weighted randomisation when necessary. Indeed, half way the study, it appeared that twice as many families in the intervention group as in the control group had been recruited. Therefore, we applied a weighted randomisation in the second half of the study during which new practices had a chance of $2: 1$ to be allocated to the control grouping instead of the intervention group. In this way 242 families, recruited in 106 general practices with a mean 2.4 patients in each practice (SD 3.4 ) were allocated to the intervention group and 234 families recruited by 146 general practices with a mean of 1.6 patients (SD 1.8) were allocated to the control group.

\section{Analysis}

Differences between intervention group and control group in baseline characteristics and in exposures were tested by $\chi^{2}$ tests for proportions and by t-tests for normally distributed 
continuous variables. The dependent variables were reported and observed asthma-like morbidity, atopic dermatitis and total $\lg E$ and specific lgE at age two years. Some data on frequencies of smoking (in the intervention and control group. $23(10 \%)$ and $17(8 \%)$. respectively), and of breast-feeding (in the intervention and control group, $14(6.3 \%)$ and 2 (1\%), respectively) were missing. Therefore, analyses were performed both ways: considering missing data as such (adherers-only analysis) and considering cases with incomplete smoking data as to passive smokers and without breast feeding data as not being breast-fed. Differences between the groups on morbidity outcome were expressed in odds ratio (OR) with $95 \%$ confidence interval $(95 \% \mathrm{Cl})$.

Total IgE data were normally distributed after logarithmic transformation.

In a post hoc analysis, the comparisons between intervention and control group were repeated for males and females, separately.

Because bed-sharing of infants and parents is very common ${ }^{33}$ and the child is also exposed to allergens in the living room, the mean of the specific allergen concentrations measured in the parental and crib mattress dust and in the living room dust was calculated for each case, to obtain an overall measure of the infants' allergen exposure.

As the concentration of mite, cat and dog allergens in samples of house dust and mattresses were not normally distributed even after logarithmic transformation, their median levels were used for the estimation of the effect of allergen reducing measures. To assess in addition the independent effects of the exposure to mite, pets and food allergens and of passive smoking on the outcome measures, multiple logistic regression analysis was performed. Differences between the groups were tested by the Mann-Whitney U-test and within the groups by Wilcoxon signed rank test. A two-sided $P$-value of less than 0.05 was considered to be significant.

The Ethical Committee of the University of Maastricht. Maastricht, the Netherlands approved the study.

\section{Results}

Study population

From 1997-2000, 476 families were recruited of whom $93 \%(n=443)$ completed the twoyear study period. Figure 1 shows the trial profile. After two years follow-up, $9 \%(n=20)$ in the intervention group and $6 \%(n=13)$ in the control group dropped out, resulting in the 
participation of 222 families in the intervention group and 221 in the control group. No differences in baseline socio-demographic characteristics were found between the intervention and control group neither as a whole nor within the subgroups of boys and girls. with the exception of lower mite allergen levels in the control group (Table 1). Significant more intervention families enrolled in the autumn/winter than control families: $182(82 \%)$ versus $152(69 \%), P=0.001$. Baseline mite allergen levels were found to be lower in the control group than in the intervention group (Table 1). This was also the case when analysed within the male and female group (Table 1 ).

After two years follow-up some data on applied intervention measures were missing. However, they were equally divided over the intervention and control group. There were no indications for a selective item non-response (data not shown).

Pregnant women who met inclusion criteria and gave informed consent $\mathrm{n}=476$

cluster- randomization on ZIP code and family practice

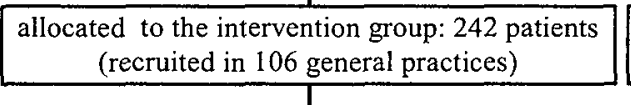

20 families dropped out (abortion 11 ; still birth 2; moved 4; withdrawal 3)

222 children completed the study allocated to the control group: 234 patients (recruited in 140 general practices)

13 families dropped out

(abortion 6; long lasting hospitalization 2; still birth 1; moved 3; withdrawal 1)

221 children completed the study

Figure 1. Trial profile of the PREVASC study after recruitment 
Table 1. Demographic and other baseline characteristics of the control and intervention group, and separately for males and females. Figures are numbers with percentages between parentheses, unless otherwise listed. Significant differences in bold.

\begin{tabular}{|c|c|c|c|c|c|}
\hline \multicolumn{2}{|c|}{ Total group } & \multicolumn{2}{|c|}{ Boys } & \multicolumn{2}{|c|}{ Girls } \\
\hline Intervention & Control & Intervention & Control & Intervention & Control \\
\hline$n=222$ & $n=221$ & $n=118$ & $n=111$ & $n=104$ & $n=110$ \\
\hline
\end{tabular}

Mean age mother

$\left(S D^{*}\right)$

Educationt mother

low

Family history of

asthma

\begin{tabular}{lcccccc}
\multicolumn{1}{l}{ Father } & $84(38.0)$ & $80(36.5)$ & $48(41.0)$ & $36(32.7)$ & $36(34.6)$ & $44(40.4)$ \\
\multicolumn{1}{c}{ Mother } & $118(53.4)$ & $111(50.7)$ & $60(51.3)$ & $59(53.6)$ & $58(55.8)$ & $52(47.7)$ \\
\multicolumn{1}{c}{ Siblings } & $83(60.1)$ & $95(68.3)$ & $43(59.7)$ & $46(65.7)$ & $40(60.6)$ & $49(71.0)$ \\
Mean birth weight & $3387(528)$ & $3475(583)$ & $3438(569)$ & $3492(624)$ & $3329(474)$ & $3465(538)$ \\
gram, (SD*) & & & & & \\
Mean pregnancy & $39.7(1.7)$ & $39.7(1.6)$ & $39.6(1.8)$ & $39.7(1.8)$ & $39.7(1.4)$ & $39.7(1.6)$ \\
duration (SD*), wks & & & & & \\
Delivery at home & $71(32.0)$ & $81(36.7)$ & $34(28.8)$ & $46(41.8)$ & $37(35.6)$ & $35(31.8)$ \\
Uncomplicated & $172(77.8)$ & $168(76.0)$ & $85(72.6)$ & $81(73.6)$ & $87(83.7)$ & $86(78.2)$ \\
delivery & & & & & \\
Age house $\leq 20$ years & $101(47.4)$ & $120(54.8)$ & $52(45.6)$ & $59(53.6)$ & $49(49.5)$ & $61(56.0)$ \\
Firstborn & $87(39.2)$ & $85(38.3)$ & $46(39.0)$ & $43(38.7)$ & $41(39.4)$ & $41(37.3)$ \\
Day-care attendance & $78(38.2)$ & $70(36.6)$ & $41(36.9)$ & $34(36.2)$ & $37(39.8)$ & $36(37.1)$ \\
Born in & $108(49.5)$ & $112(50.5)$ & $54(45.8)$ & $55(49.5)$ & $53(51.0)$ & $59(53.6)$
\end{tabular}

spring/summer

Exposure at baseline:

Der p $1 \mathrm{ng} / \mathrm{m} 2(\mathrm{IQR})^{\#}$

Fel d $1 \mathrm{ng} / \mathrm{m} 2(\mathrm{IQR})^{\#}$

Can f $1 \mathrm{ng} / \mathrm{m} 2(\mathrm{IQR})^{\#}$

Smoking mother

Smoking father

Presence of cat or dog

$2(14.5) \quad 20(9.0) \quad 17(14.4) \quad 12(10.8) \quad 15(14.6) \quad 8(7.3)$

$30.9(3.8)$

$31.0(3.6)$

$31.1(4.1)$

$30.7(3.7)$

$30.7(3.5)$

$31.3(3.4)$

$$
2(14.5) \quad 20(9.0)
$$

$17(14.4)$

$12(10.8)$

$15(14.6)$ 
The effect of the intervention program on exposure.

The effect of the intervention program on the exposure to food allergens and passive smoking is shown in Figure 2, and to mite and pet allergens in Figure 3.

Infants in the intervention group, compared to the control group were considerably more exclusively breast-fed and/or received more hypoallergenic bottle-feeding. The intervention group received their first solid food less frequently before they were six months old than the control group. Prenatal and postnatal exposure to smoking was equal for the intervention and the control group.

exposure to food allergens

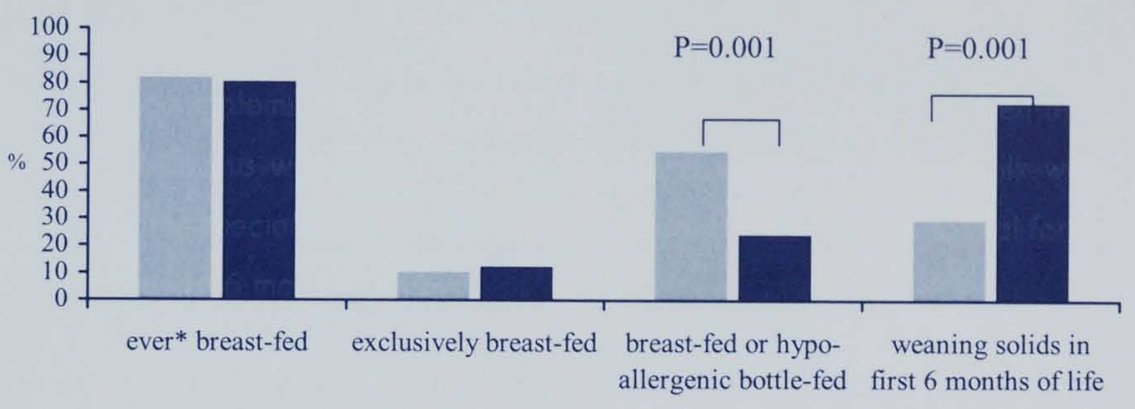

exposure to tobacco smoke

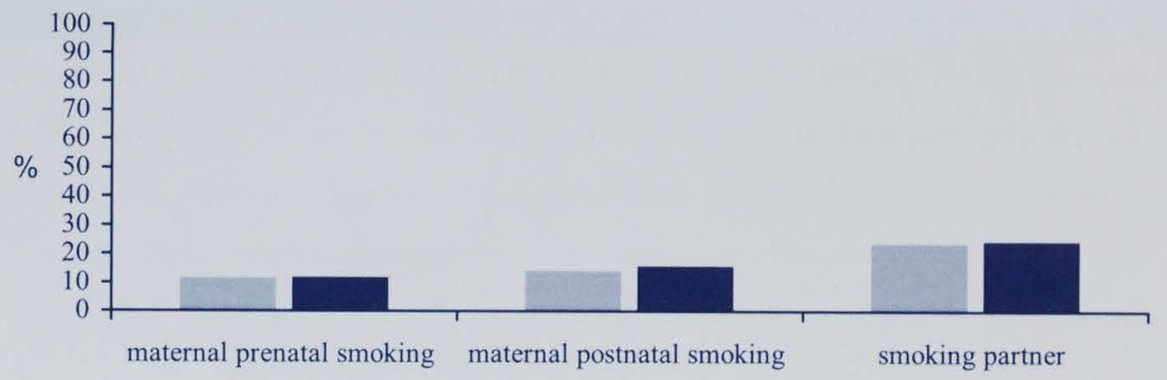

Figure 2.Effectiveness of the PREVASC intervention program on exposure to food allergens (graph above ) and tobacco smoking (graph below). Bars indicate \% of exposure. Intervention group ( $\mathrm{n}=222$ ) indicated by bars and control group $(\mathrm{n}=221)$ by $\square$ bars. Statistic testing by Pearsons Chi-square test.* ever: ever breast-fed from birth until 6 months of life 
One year after baseline measurements, mite, cat and dog allergen concentrations were significantly lower in the intervention group than in the control group (Figure 3). The same results were found within the boys and girls group (data not shown).

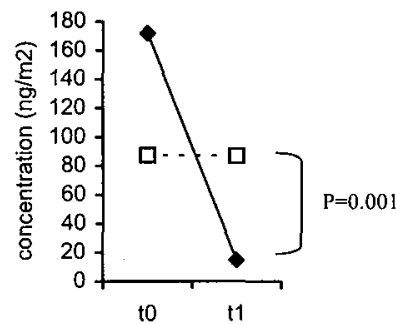

mite allergen

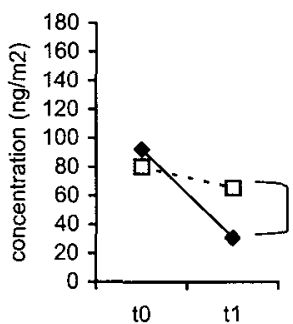

cat allergen

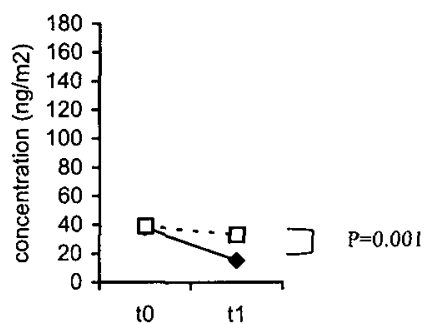

dog allergen

Figure 3. Effectiveness of the PREVASC program on exposure to mite and pet allergens. Median overall concentrations ( $\mathrm{ng} / \mathrm{m}^{2}$ ) of mite, cat and dog allergens in dust samples of living room, parental and baby mattress at baseline $(\mathrm{t} 0)$ and one year later $(\mathrm{t} 1)$ for the intervention group (line) and the control group (dashed line). The asterices * indicate a significant difference $(P=0.001)$ between intervention and control group after the intervention (t1) tested by Mann Whitney U test.

\section{Clinical effectiveness}

Table 2 shows the frequencies of the asthma-like symptoms in the intervention and control group and their risk estimates, with $95 \% \mathrm{Cl}$. No differences were found between the groups for parental reported and CP observed asthma-like symptoms during the first two years. The same held for the CP-based diagnosis asthma. Parental reported current asthmalike symptoms occurred significantly less in the intervention group compared with the control group (Table 2). 
Table 2. Occurrence of asthma-like symptoms and allergic morbidity from age $0-2$, and at age 2 in the intervention and control group. Associations in odds ratio (OR) and $95 \%$ confidence interval between parentheses $(95 \% \mathrm{CI})$. Reference group is the control group. Significant effects in bold.

$\begin{array}{lcc}\text { Intervention } & \text { Control } & \text { OR }(95 \% C I) \\ \%(n / n \text { total }) & \%(n / n \text { total })\end{array} \quad$

Parental reported symptoms in the first

2 years of life

Runny nose without cold at

least once

Wheezing at least once

Wheezing with awakening

at least once

Recurrent wheezing $(\geq 4 \mathrm{x}$ )

Night-time cough without a

cold at least once

Parentally reported current " symptoms

at age 2

Wheezing

Shortness of breath

Night-time cough

$G P^{\dagger}$ recorded morbidity in the first 2

years of life

Wheezing without fever at

least once

Shortness of breath at least

once

Coughing at least once

Diagnosis asthma

Diagnosis atopic eczema

$$
64 \%(128 / 200) \quad 71 \%(139 / 200) \quad 0.89(0.51-1.5)
$$

$64 \%(127 / 200) \quad 57 \%(113 / 200) \quad 1.4(0.83-2.4)$

$14 \%(26 / 188) \quad 17 \%(30 / 182) \quad 0.88(0.45-1.7)$

$26 \%(49 / 189) \quad 26 \%(47 / 184) \quad 1.1(0.61-2.0)$

$48 \%(95 / 197) \quad 53 \%(101 / 190) \quad 0.78(0.46-1.3)$ $\begin{array}{lll}8 \%(15 / 187) & 15 \%(25 / 171) & \mathbf{0 . 7 3}(\mathbf{0 . 5 6 - 0 . 9 6}) \\ 16 \%(30 / 187) & 25 \%(43 / 171) & \mathbf{0 . 7 6 ( 0 . 6 1 - 0 . 9 6 )} \\ 44 \%(57 / 184) & 56 \%(72 / 168) & \mathbf{0 . 7 2}(\mathbf{0 . 5 5}-\mathbf{0 . 9 5})\end{array}$

$34 \%(72 / 212) \quad 40 \%(80 / 200) \quad 0.87(0.72-1.1)$

$27 \%(57 / 212) \quad 31 \%(62 / 200) \quad 0.90(0.73-1.1)$

$68 \%(144 / 212) \quad 70 \%(139 / 200) \quad 0.96(0.77-1.2)$

$26 \%(54 / 212) \quad 31 \%(61 / 200) \quad 0.88(0.72-1.1)$

$27 \%(58 / 212) \quad 23 \%(46 / 200) \quad 1.1(0.88-1.4)$

*at least one reported episode in the last 4 weeks before the second birthday; $\uparrow:$ GP: General practitioner 
When analysed for females and males separately, both asthma-like symptoms in the first two years of life as well as current symptoms occurred significantly less among females in the intervention group than in the female control group whereas among males there was no difference. This held for all outcome: for parental reported symptoms during the first two year of life, the current symptoms (Figure 4) as well as for CP observed symptoms and CPs diagnoses (Figure 5). In the female intervention group CP's diagnosis of asthma tended to be less frequently present $(P=0.08)$ compared with the female control group, whereas among males this was not the case.

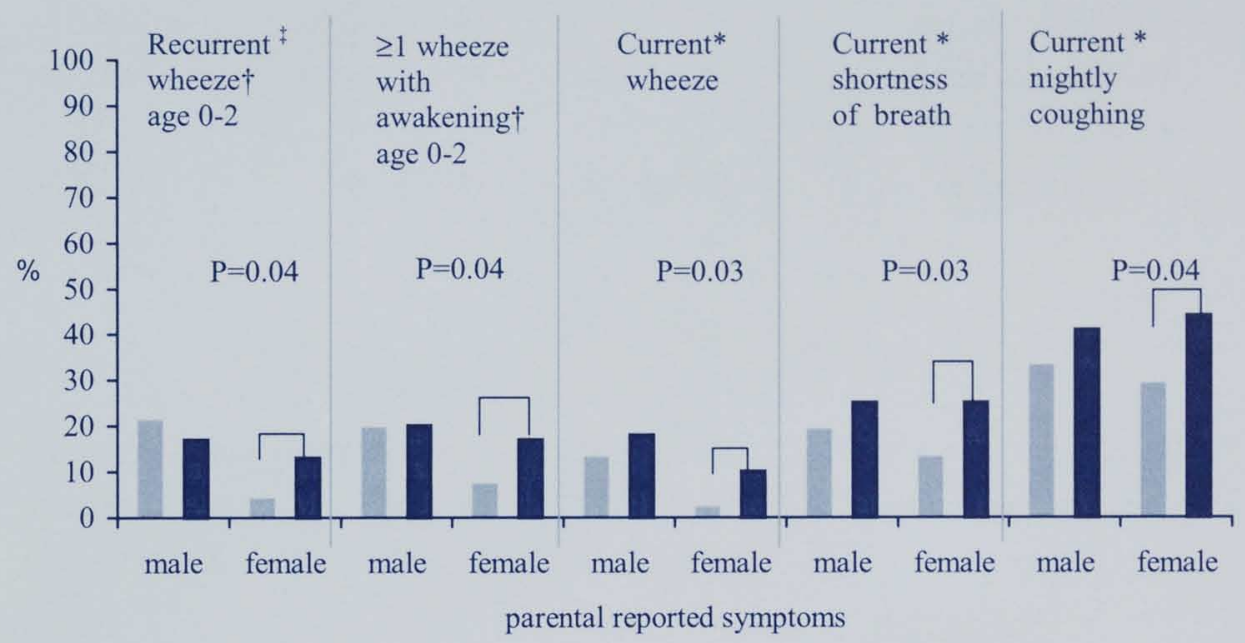

Figure 4. Occurrence of parentally reported asthma-like symptoms (current* and in the first two years of life), for male and female children in the intervention ( $\square$ bars) and control group ( bars); ${ }^{*}$ current: at least 1 episode within 4 weeks prior to the $2^{\text {nd }}$ birthday. $\ddagger$ recurrent: at least 4 or more episodes of wheezing during the first two years of life

\section{Observed symptoms and diagnoses of the general practitioner}

No statistically significant differences in the occurrence of symptoms and diagnosis of asthma and atopic dermatitis were reported by the CP between the unstratified control group and the intervention group (Table 2). In the stratified analysis, however, again an influence of gender was apparent (Figure 5). Wheezing without fever, shortness of breath, but not coughing occurred less frequently among females compared with males. In addition. CP's 
diagnosis of asthma tended to be present also less frequently $(P=0.08)$ in the female intervention group than in the female control group, whereas among males this was not the case.

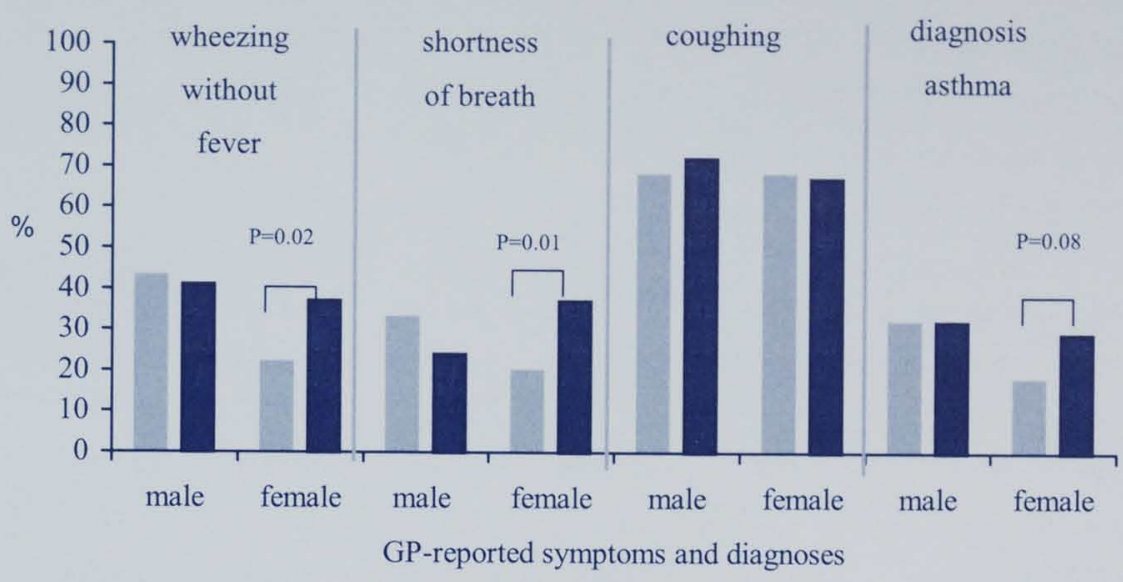

Figure 5. Occurrence of asthma-like symptoms in the first 2 years of life as diagnosed by the general practitioners (GP) for male and female children in the intervention group ( bars) and control group ( $\square$ bars).

\section{Serum lgE levels}

The mean serum concentration of total IgE was similar for the intervention and control group (Table 3). Also mite, cat and dog specific lgE was equal between the groups. Subanalysis of the outcomes for males and females separately revealed that females in the intervention group tended to be less sensitised against mite, although the differences did not reach statistical significance ( $P=0.09$ ) (Table 3)

When the analyses on the association between asthma-like and atopic morbidity were repeated, assuming that the children with missing data on smoking and breastfeeding behaviour were exposed to passive smoke and were not breast-fed, respectively, the results did not change essentially (data not shown). 
Table 3. Serum total and specific IgE for mite, cat, dog at age two years in the intervention and control group, stratified for gender. Figures are percentages with number/total between parentheses, unless otherwise listed.

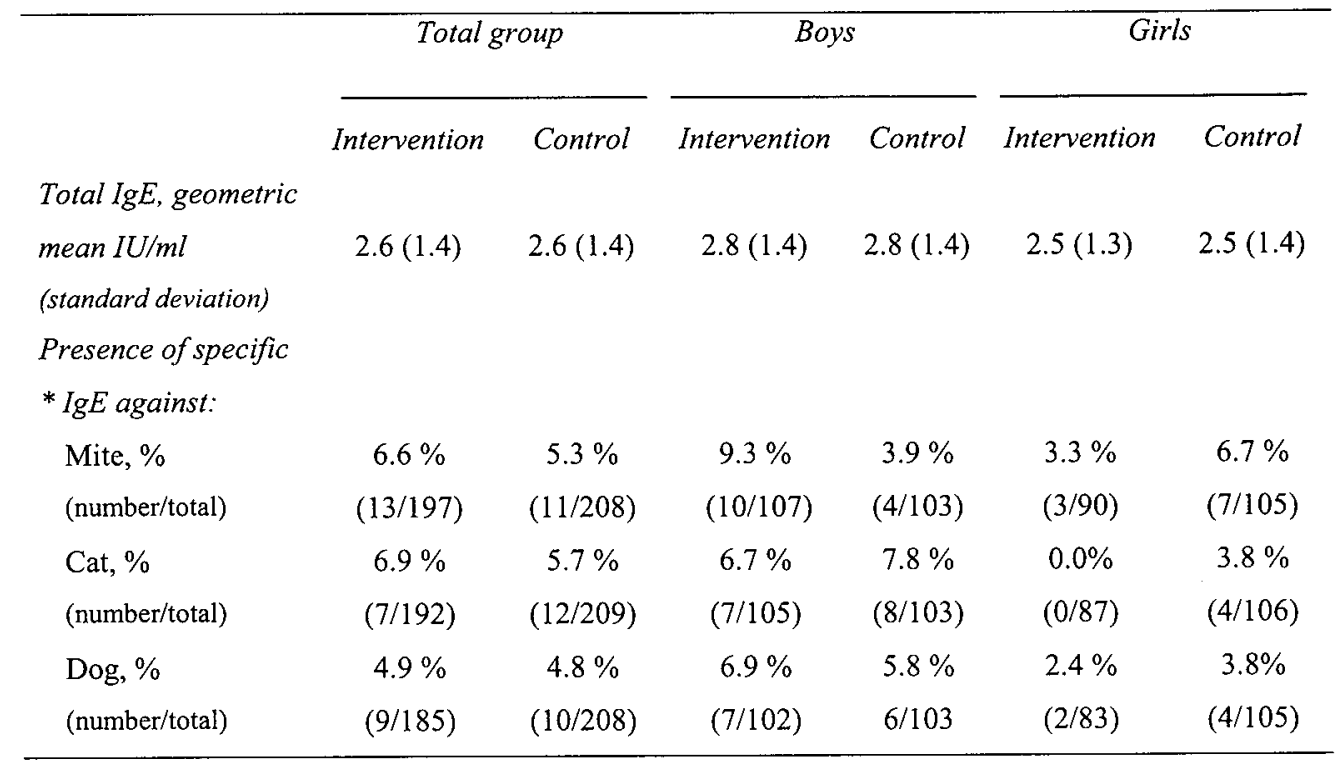

*: positive RAST $\geq 0.35 \mathrm{IU} / \mathrm{ml}$. Statistical testing between groups: no significant differences between the intervention en control groups for Total $\operatorname{IgE}(\mathrm{t}$-test) and for specific $\operatorname{IgE}$ (Chi-square test).

\section{Relation exposure and asthma-like and atopic morbidity}

Table 4 shows the odds ratios of asthma-like and atopic morbidity for the group as a whole (the intervention and control group together) in relation to exposure to mite, cat, dog and food allergens and passive smoking, adjusted for each other in multiple logistic regression analysis. Being breast-fed (for at least one week) from birth decreased the risk of recurrent wheeze, wheeze with awakening and current wheeze at age 2. Abstinence from maternal smoking - also independently - reduced the risk of recurrent wheeze, and of current wheeze at the end of year 2. Low mite levels significantly decreased the risk on current wheezing and on shortness of breath. 
Table 4. Associations of exposure to mite, cat and dog and food allergens and passive smoking, with parental reported symptoms, without group allocation. Results of the multiple logistic regression analysis. Odds ratio* with $95 \%$ confidence interval between parentheses. Significant effect in bold.

\begin{tabular}{|c|c|c|c|c|}
\hline & $\begin{array}{c}\text { Recurrent } \\
\text { wheezing } 0-2 \\
\text { years of age }\end{array}$ & $\begin{array}{l}\text { Ever wheezing } \\
\text { with awakening } \\
\text { 0-2 years of age }\end{array}$ & $\begin{array}{l}\text { Current } \dagger \\
\text { wheezing }\end{array}$ & $\begin{array}{c}\text { Current } \dagger \\
\text { shortness of } \\
\text { breath }\end{array}$ \\
\hline Breastfeeding $\ddagger$ & $0.32(0.19-0.56)$ & $0.35(0.19-0.66)$ & $0.42(0.18-0.97)$ & $0.61(0.34-1.1)$ \\
\hline Hypoallergenic formulc & & & & \\
\hline feeding $t$ & $1.3(0.72-2.3)$ & $0.72(0.38-1.4)$ & $0.66(0.27-1.6)$ & $0.95(0.53-1.7)$ \\
\hline Introduction of first & & & & \\
\hline solid foods $<6$ month & $1.1(0.59-2.0)$ & $1.3(0.63-2.7)$ & $1.4(0.61-3.2)$ & $0.77(0.41-1.46)$ \\
\hline No maternal smoking & $0.49(0.25-1.0)$ & $0.68(0.29-1.6)$ & $0.38(0.14-1.0)$ & $1.1(0.52-2.5)$ \\
\hline $\begin{array}{l}\text { No paternal/partner } \\
\text { smoking }\end{array}$ & $0.91(0.46-1.8)$ & $0.65(0.30-1.4)$ & $0.67(0.28-1.6)$ & $0.65(0.32-1.3)$ \\
\hline $\begin{array}{l}\text { Mite allergens below } \\
\text { median }\end{array}$ & $0.78(0.44-1.4)$ & $0.63(0.32-1.2)$ & $0.30(0.12-0.71)$ & $0.54(0.29-1.0)$ \\
\hline $\begin{array}{l}\text { Cat allergen below } \\
\text { median }\end{array}$ & $0.87(0.48-1.6)$ & $0.66(0.33-1.3)$ & $1.2(0.54-2.6)$ & $0.75(0.40-1.4)$ \\
\hline $\begin{array}{l}\text { Dog allergen below } \\
\text { median }\end{array}$ & $1.4(0.79-2.4)$ & $1.6(0.81-3.0)$ & $1.2(0.54-2.7)$ & $0.78(0.42-1.4)$ \\
\hline
\end{tabular}

*: Odss ratios are adjusted for the other listed exposures. $\uparrow:$ current: at least one episode in the 4 weeks before the second birthday. $\ddagger$ : ever breast-fed or ever hypoallergenic bottle-fed.

\section{Discussion}

The PREVASC study is the first study in a primary care environment to investigate the clinical effectiveness of a multi-faceted approach to prevent the development of asthma in high-risk children. The results of this study indicate that the intervention was able to reduce exposure to mite, pet and food allergens, but not of passive smoking. Despite this reduction there was neither an effect on parental reported and CP observed symptoms occurring during the first two years of life, nor on total and specific lgE at age two years. However. asthma-like symptoms at the end of the second year were less frequently reported in the 
intervention group. Moreover, the decrease appeared to be more pronounced in and mainly confined to the female part of the intervention group.

The intervention might have caused the differences in symptoms at the end of the second year but other explanations for the reported decrease in current asthmatic symptoms have to be considered as well. A major limitation is the fact that most of the measures focusing on environmental exposure reducing such as breast-feeding, weaning practices, procuring pets and smoking cannot be executed blinded. All birth cohort interventions studies have this problem. ${ }^{18.21}$ Therefore we can not exclude reporting bias as explanation for the decrease in asthma-like symptoms in the intervention group at age two years. Parents in the intervention group are aware of the applied intervention and might expect their children to have a reduced asthma-like morbidity, whereas in the control group no such "placebo" effect is to be expected. CPs in the intervention group were also not blinded for the intervention and this could have influenced their interpretation of the observed symptoms and their diagnostic labeling. However, we found that both the parents and GPs allocated to the intervention group reported and classified asthma-like symptoms less frequently in the female children than in the male children and it is unlikely that a reporting bias is influenced by gender.

Several randomised intervention studies have reported results on various clinical symptoms at age one, ${ }^{18.21 .39 .40}$ two. $^{19}$ four. ${ }^{40}$ and eight years. ${ }^{20}$ When the results of intervention studies are compared, we have to keep in mind that comparison is hampered as the studies differ in defining high-risk cases, the applied intervention(s) and definition of outcomes. In the Manchester Allergy and Asthma Study ( ${ }^{\text {noc }} \mathrm{MAAS}$ ) study. ${ }^{18}$ stringent anti-mite measures were provided in the homes of expecting atopic parents with mothers, who had to be at least sensitised for mite, cat or dog allergens as shown by skin testing but who had no cats or dogs. They found a significant reduction of (reported) severe wheeze with breathlessness and with exertion at age 1. The Prevention and Incidence of Asthma and Mite Allergy (PIAMA) ${ }^{19}$ study recruited pregnant women at high risk on the basis of a reported personal history of asthma. hay fever or reported allergy for house dust, mite or pet allergens. Anti-mite covers for crib and parental mattresses and pillows were provided. At two years of age, only a small but significant reduction in reported night-time cough without a cold was reported, whereas the other (ISAAC) outcomes were not significantly different. The small improvement in the 
PIAMA study was attributed by the authors to pre-existent low mite levels. However, in the PREVASC study low mite levels at baseline were also found, but in contrast to the PIAMA study, we did find a more pronounced effect of the intervention at age two, not only on night-time cough but also on other asthma-like symptoms, which might be explained by the multi-facet approach used in the PREVASC study. The Isle of Wight study ${ }^{20}$ defined high-risk cases when allergy in at least two first-degree relatives or in one first-degree relative with an elevated cord blood $\mathrm{g} E$ was present. $A$ dual preventive approach was used, i.e. encasement of the crib mattress (not the parental mattress) and maternal avoidance of food allergens during lactation. At age 8 , the intervention group was found to be at a significantly reduced risk for wheeze in the past year, nocturnal cough and mite sensitisation, however the numbers were small because of the relatively high drop-out rate. ${ }^{20} \mathrm{~A}$ Canadian intervention study ${ }^{21}$ had a university hospital based setting. used comparable inclusion criteria and also carried out a multi-facet approach like the PREVASC study. In their study, the clinical outcome (probable or possible asthma diagnosed by paediatric allergists) at age 1 was significantly (significance one-sided tested) less present in the intervention group (15\%) than in the control group (20\%), which is comparable to the $5 \%$ difference in CP diagnosed asthma in the PREVASC study, although this difference, tested two-sided, did not reach statistical significance.

We found no significant effect of the intervention on the incidence of specific lgE against mite, cat a dog allergen at age two. The Canadian study ${ }^{21}$, the PIAMA ${ }^{19}$ and the ${ }^{\text {noc MAAS }}$ study ${ }^{18}$ found also no effect of the intervention on mite sensitisation at age one. $A$ hypothetical reason for the absence of an effect on sensitisation might be that the intervention was started to late, as sensitisation might already occur in utero. ${ }^{36.37}$ Another explanation might be that total and specific $\operatorname{gE}$ is only predictive for the presence of atopy but not for asthma.

We showed that it was possible to reduce exposure to mite. pet and food allergens but not to passive smoking. The main reduction in mite levels was attained in mattress dust by the use of anti-mite encasings. In general, we found low pre-intervention levels of mite and pet allergens at baseline, probably as a result of (already) successful efforts of asthmatic families to achieve a low allergen environment, as reported elsewhere. ${ }^{38}$ In spite of the pre-existent 
low mite level, infants with mite allergens levels below the median had a reduced risk on current asthma-like symptoms when compared to infants exposed to levels above the median.

Multiple logistic regression analyses of the relation between exposure and asthma-like (wheezing) symptoms revealed that exposure to mite and food allergens and passive smoking contributed independently of each other to asthma-like symptoms The finding may also explain why avoidance of a single exposure has only marginal or no effects, when other exposures are still existing, as might be the case in other prevention studies. ${ }^{19}$ it supports the multi-factorial origin of asthma, and is a plea in favor of pursuing a multi-faceted approach with respect to the prevention of asthma.

In contrast to most other intervention studies, the PREVASC study was designed to fit in primary care by approximating regular primary care circumstances as good as possible. This is important when the intervention, once proven to be effective to prevent asthma, would become part of regular primary care. As has been shown in the PREVASC study, GPs and midwives were able to identify high-risk cases during routine consultation in early pregnancy. The intervention can be initiated in primary care as was done in the research setting and executed with the help of practice nurses and/or well-baby clinics.

In a post hoc analysis, we did the interesting observation that the clinical effect of the intervention was mainly confined to the female part of the intervention group. To our knowledge, this is the first intervention study reporting that gender might modify the effect of reduction of environmental exposure on symptoms. The difference between the male and female group was striking and very consistent for almost all outcomes, which makes chance as an explanation less likely. For the presence of specific lgE a non-significant trend for a gender-specific intervention effect was observed. However, as these were post hoc analyses indeed we cannot draw conclusions but only present the possibility of the modification by gender as a suggestive hypothesis. So far, the results permit a speculative explanation of possible effect modification by gender, although there is support in the literature for this interesting observation. Airway physiology and pathology during the whole life span, starting in the intrauterine period is subjected to the influence of gender and might be under 
hormonal control. ${ }^{22.42-45}$ The production of $\lg \mathrm{E}$ is also influenced by gender, as the concentration of total serum was higher in boys than girls. Furthermore, the effect of environmental exposure on symptoms is reported to be influenced by gender. ${ }^{23.46}$ From the above, one might hypothesize that given the different reactions of the male and female immune systems and/or airways to environmental exposure. males and females might react also differently on reduction of the exposures. This should be evaluated in further (biomedical) research.

In conclusion, we found no effect of a multi-facet intervention program on asthma-like symptoms in high-risk children during their first two years of life and atopic sensitisation at age two, but a small effect on the symptoms at the end of their second year of life. Further follow-up is necessary to determine whether the intervention measures can actually prevent the development of asthma.

\section{Conflict of interest: none}

Supported by: The Dutch Asthma Foundation, Prevention Fund and the Dutch Royal Academy of Science (KNAW)

\section{Acknowledgement}

The PREVASC study is a joint project of the Departments of General Practice of the University Maastricht and the Radboud University Nijmegen. We would like to thank the general practitioners allied to these departments and the participating midwives for recruiting eligible families. We are grateful to all families who readily participated in the project. We also like to thank the researchassistants: Ilse van Beerendonck and Karin Manders; the data managers: Jacqueline Pisters and Kitty Coolen; the statistical adviser, Jildou Sijbrandij, and the nurses, who visited and instructed the participating families: Cindy Brink, Kitty van der Meer, Marjorie Rovers, Twanny Jeijsman, Inke Schaap, Marjan Terhaar and Elly de Vree and the PREVASC secretary Annemarie Spaninks.

We thank Numico NV (Zoetermeer, the Netherlands) for the supply of Nutrilon pepti ${ }^{(B)}$ and Sanalife (Lelystad, the Netherlands) for the supply of the house dust mite impermeable covers (Mitecare ${ }^{(2)}$ ) and bedding.

We would like to thank Nico van der Maas of Skiltec B.V., Beek, the Netherlands, for his linguistic comments and suggestions. 


\section{References:}

1. Holgate ST. The Rising Trends in Asthma. Ciba Foundation Bullitin Nat Genet 1997;no. 206.

2. Lenney W. The burden of pediatric asthma. Pediatr Pulmonol Suppl 1997;15:13-6.

3. Wever-Hess J, Wever AM, Yntema JL. Mortality and morbidity from respiratory diseases in childhood in The Netherlands, 1980-1987. Eur Respir J 1991;4(4):429-33.

4. Gustafsson PA. Family dysfunction in asthma: results from a prospective study of the development of childhood atopic illness. Pediatr Pulmonol Suppl 1997;16:262-4.

5. Burney PG, Chinn S, Rona RJ. Has the prevalence of asthma increased in children? Evidence from the national study of health and growth 1973-86. BMJ 1990;300(6735):1306-10.

6. Lewis S, Butland B, Strachan D, et al. Study of the aetiology of wheezing illness at age 16 in two national British birth cohorts. Thorax 1996;51(7):670-6.

7. Downs SH, Marks GB, Sporik R, Belosouva EG, Car NG, Peat JK. Continued increase in the prevalence of asthma and atopy. Arch Dis Child 2001;84(1):20-23.

8. Upton MN, McConnachie A, McSharry C, et al. Intergenerational 20 year trends in the prevalence of asthma and hay fever in adults: the Midspan family study surveys of parents and offspring. $B M J 2000 ; 321(7253): 88-92$.

9. Tirimanna PR, van Schayck CP, den Otter JJ, et al. Prevalence of asthma and COPD in general practice in 1992: has it changed since 1977? BrJ Gen Pract 1996;46(406):277-81.

10.Warner JA, Jones AC, Miles EA, Colwell BM, Warner JO. Prenatal origins of asthma and allergy. Ciba Found Symp 1997;206:220-8; discussion 228-32.

11. Holloway JA, Warner JO, Vance GH, Diaper ND, Warner JA, Jones CA. Detection of housedust-mite allergen in amniotic fluid and umbilical- cord blood. Lancet 2000;356(9245):19002.

12.Holt PG, Macaubas C, Sly PD. Strategic targets for primary prevention of allergic disease in childhood. Allergy 1998;53(45):72-6.

13.Tariq SM. Allergen avoidance in the primary prevention of atopy. Br J Clin Pract 1996;50(2):99-102.

14.Dold S, Wjst M, von Mutius E, Reitmeir P, Stiepel E. Genetic risk for asthma, allergic rhinitis, and atopic dermatitis. Arch Dis Child 1992;67(8):1018-22.

15.Schonberger HJ, Van Schayck CP. Prevention of asthma in genetically predisposed children in primary care--from clinical efficacy to a feasible intervention programme. Clin Exp Allergy 1998;28(11):1325-31.

16.Gore C, Custovic A. Preventive measures and their effects. Results from cohort studies. Paediatr Respir Rev 2002;3(3):205-18.

17.Exl BM, Deland U, Secretin MC, Preysch U, Wall M, Shmerling DH. Improved general health status in an unselected infant population following an allergen reduced dietary intervention programme. The ZUFF-study-programme. Part I: Study design and 6-month nutritional behaviour. Eur J Nutr 2000;39(3):89-102.

18.Custovic A, Simpson BM, Simpson A, Kissen P, Woodcock A. Effect of environmental manipulation in pregnancy and early life on respiratory symptoms and atopy during first year of life: a randomised trial. Lancet 2001;358(9277):188-93.

19.Koopman LP, van Strien RT, Kerkhof M, et al. Placebo-controlled trial of house dust miteimpermeable mattress covers: effect on symptoms in early childhood. Am J Respir Crit Care Med 2002;166(3):307-13.

20.Arshad SH, Bateman B, Matthews SM. Primary prevention of asthma and atopy during childhood by allergen avoidance in infancy: a randomised controlled study. Thorax 2003;58(6):489-93.

21.Chan-Yeung M, Manfreda J, Dimich-Ward H, Ferguson A, Watson W, Becker A. A randomized controlled study on the effectiveness of a multifaceted intervention program in the primary prevention of asthma in high-risk infants. Arch Pediatr Adolesc Med 2000;154(7):657-63.

22.Becklake MR, Kauffmann F. Gender differences in airway behaviour over the human life span [see comments]. Thorax 1999;54(12):1119-38. 
23.Chen $Y$, Dales R, Tang M, Krewski D. Sex-related interactive effect of smoking and household pets on asthma incidence. Eur Respir J 2002;20(5):1162-6.

24.van Weel C. International research and the discipline of family medicine. Eur J General Practice 1999;5:110-114.

25.Dirksen WJ, Geijer RMM, de Haan M, de Koning G, Flikweert S, Kolnaar BGM. NHGStandaard Astma bij Kinderen (eerste herziening). Huisarts Wet 1998(41(3)):130-43.

26.Asher MI, Keil U, Anderson HR, et al. International Study of Asthma and Allergies in Childhood (ISAAC): rationale and methods. Eur Respir J 1995;8(3):483-91.

27.WONCA CCo. An international glossary for primary care. In: Classification Committee of WONCA in collaboration with the WHO. ICHPCC-2-defined (3rd edition). London: Oxford University Press, 19831983.

28. Aalberse RC, Koshte V, Clemens JG. Immunoglobulin E antibodies that crossreact with vegetable foods, pollen, and Hymenoptera venom. J Allergy Clin Immunol 1981;68(5):35664.

29.Meijer GG, Postma DS, van der Heide S, et al. Seasonal variations in house dust mite influence the circadian peak expiratory flow amplitude. Am J Respir Crit Care Med 1996;154(4 Pt 1):881-4.

30.van der Heide S, van Aalderen WM, Kauffman HF, Dubois AE, de Monchy JG. Clinical effects of air cleaners in homes of asthmatic children sensitized to pet allergens. $J$ Allergy Clin Immunol 1999;104(2 Pt 1):447-51.

31.Luczynska CM. Identification and quantification of mite allergens. Allergy 1998;53(48 Suppl):54-7.

32.Zelen M. A new design for randomized clinical trials. N Engl J Med 1979;300(22):1242-5.

33.Nelson EA, Taylor BJ, Jenik A, et al. International Child Care Practices Study: infant sleeping environment. Early Hum Dev 2001;62(1):43-55.

34.Koopman LP, Brunekreef B, de Jongste JC, Neijens HJ. Definition of respiratory symptoms and disease in early childhood in large prospective birth cohort studies that predict the development of asthma. Pediatr Allergy Immunol 2001;12(3):118-24.

35.Castro-Rodriguez JA, Holberg CJ, Wright AL, Martinez FD. A clinical index to define risk of asthma in young children with recurrent wheezing. Am J Respir Crit Care Med 2000;162(4 Pt 1):1403-6.

36.Miller RL, Chew GL, Bell CA, et al. Prenatal exposure, maternal sensitization, and sensitization in utero to indoor allergens in an inner-city cohort. Am J Respir Crit Care Med 2001;164(6):995-1001.

37. Warner JA, Jones CA, Jones AC, Miles EA, Francis T, Warner JO. Immune responses during pregnancy and the development of allergic disease. Pediatric Allergy and Immunology 1997;8 Suppl. 10:5-10.

38. Wijga A, Smit HA, Brunekreef B, et al. Are children at high familial risk of developing allergy born into a low risk environment? The PIAMA Birth Cohort Study. Prevention and Incidence of Asthma and Mite Allergy. Clin Exp Allergy 2001;31(4):576-81.

39.Tsitoura S, Nestoridou K, Botis P, et al. Randomized trial to prevent sensitization to mite allergens in toddlers and preschoolers by allergen reduction and education: one-year results. Arch Pediatr Adolesc Med 2002;156(10):1021-7.

40. Hide DW, Matthews S, Tariq S, Arshad SH. Allergen avoidance in infancy and allergy at 4 years of age [see comments]. Allergy 1996;51(2):89-93.

41.Schönberger HJAM, Maas T, Dompeling E, et al. Envrionmental exposure reduction in highrisk newborns: where do we start? Ann Allergy Asthma Immunology 2003;91:531-538.

42.Davis JB, Bulpitt CJ. Atopy and wheeze in children according to parental atopy and family size. Thorax 1981;36(3):185-9.

43.Arshad SH, Stevens M, Hide DW. The effect of genetic and environmental factors on the prevalence of allergic disorders at the age of two years. Clin Exp Allergy 1993;23(6):504-11.

44.Sears MR, Holdaway MD, Flannery EM, Herbison GP, Silva PA. Parental and neonatal risk factors for atopy, airway hyper-responsiveness, and asthma. Arch Dis Child 1996;75(5):3928. 
45.Young S, Arnott J, O'Keeffe PT, Le Souef PN, Landau LI. The association between early life lung function and wheezing during the first 2 yrs of life. Eur Respir $J 2000 ; 15(1): 151-7$. 46.Sunyer J, Soriano J, Anto JM, et al. Sensitization to individual allergens as risk factors for lower FEVI in young adults. European Community Respiratory Health Survey. Int $J$ Epidemiol 2000;29(1):125-30. 


\section{Chapter 6}

\section{The timing of the intervention}

Prenatal exposition to mite and pet allergens and total serum lgE at birth

H.J.A.M. Schönberger, M.D.', E. Dompeling. M.D., Ph.D.', J.A..Knottnerus. M.D., Ph.D. ', S.Kuiper. M.Sc.' C. van Weel. M.D. Ph.D. ${ }^{3}$, and C.P. van Schayck, Ph.D.

Prenotal exposition to mite and pet allergens is related to total serum lgE at birth in high-risk children

1. Department of General Practice. University Maastricht, Maastricht, Research Institute CAPHRI. The Netherlands:

2. Department of Pediatric Pulmonology, University Hospital Moastricht. Research Institute CAPHRI. The Netherlands:

3. Department of General Practice, University Medical Centre, Radboud University Nijmegen. Nijmegen. The Netherlonds.

In submission 


\section{Abstract}

\section{Objective}

To examine the relationship between prenatal exposure to mite, cat and dog allergens and total serum lgE at birth in newborns at high risk of asthma.

\section{Design}

In the homes of 221 newborns with at least one first-degree relative with asthma. concentrations (ng/g dust) of allergens of house dust mite (mite), cat and dog were measured at the $4^{\text {th }}-6^{\text {th }}$ month of pregnancy in dust samples from the maternal mattress and living room. At day 3-5 after birth. newborns total lgE was measured in capillary heel blood. Prenatal passive smoking, maternal and paternal mite allergy, socio-demographic factors and birth characteristics and (breast) feeding practice in the first week of life were taken into account.

\section{Result}

A total number of 174 blood samples was available 111 mothers refused newborns blood sampling, and in 36 cases the blood sample was too small for analysis). In $24 \%$ of the newborns, total lgE was elevated (cut-off value $0.5 \mathrm{IU} / \mathrm{ml}$ ). A significant dose response relationship was found between increasing mite allergen levels (divided in quartiles $\mathrm{ng} / \mathrm{g}$ dust [qrt]) and the presence of elevated lgE: $1^{\text {st }} q^{\text {tl }}(0-85 \mathrm{ng} / \mathrm{g}) 13 \%: 2^{\text {nd }}(86-381) 19 \%: 3^{\text {rd }} \mathrm{q}^{\text {tl }}$ $(382-2371) 26 \%: 4^{\text {th }} q+1(\geq 2372) 42 \%$, respectively, $P=0.01$. This relationship remained significant after adjusting for possibly confounding factors.

\section{Conclusion}

In high-risk newborns, prenatal exposure to mite allergens, but not to cat and dog allergens from dust of the living room and of the maternal mattress was associated with total serum IgE at birth. 


\section{Introduction}

It is supposed that the development of atopy in children is dependent on a complex interaction between genetic and environmental factors. The hallmark of atopy is sensitisation.' Sensitisation may develop very early in life and may even commence in utero. ${ }^{2-6}$ Immune responses at birth implicate intrauterine exposure to allergens from the maternal environment.' A high cord blood lgE was identified as a risk factor for sensitisation and allergic disease $e^{8.12}$ The suggested relation between prenatal exposure and immune response has been supported by reports on the presence of cat and house dust mite (hereafter referred to as mite) allergens in the foetal circulation, as well as in the amnion fluid. ${ }^{13}$ Hence, one might suggest that prevention of sensitisation by environmental manipulation of allergens has to start before birth. The concept of sensitisation to inhalant allergens in utero is however not unanimously accepted. ${ }^{14}$ The aim of this study was to analyse whether prenatal exposure to mite, cat and dog allergens is related to total lgE at birth within a cohort of high-risk newborns.

\section{Material \& Methods}

\section{Subjects and design}

The study was a cohort analysis, relating mite and pet allergens exposure of the mother during the prenatal period to newborn's IgE status 3-5 days after birth. The study was part of the PREVASC (Prevention of Asthma in Children) birth cohort study. The PREVASC study is a randomised intervention study of the effects of early life environmental exposure reduction on the prevention of asthma. ${ }^{15}$ The PREVASC intervention focuses on achieving a low mite and pet allergen level at the time the child has been born by instructing expectant families on prevailing mite and pet allergen reducing measures. For that purpose, the families were asked to apply the measures including sanitation measures, use of anti-mite encasings and pet removal, before birth already. Only the participants allocated to the control group were included in the study presented here. The reason for this was that prenatal application of the measures, advised to the intervention group could interfere between the relationship allergen exposure in early pregnancy and postnatal lgE levels. Therefore, the intervention 
group was not included in the analysis. The control group was unaware of the existence of the intervention group and received no preventive instructions.

The eligible subjects were unborn infants at high risk of developing asthma due to asthmo in their mother, father or sibling(s). Their mothers were recruited by general practitioners (CPs) and midwives during the first 2 trimesters of their mothers' pregnancy when they visited their GP or midwife and were asked for written informed consent.

The dependent variable was total serum $\lg E$ at birth. Total $\mathrm{g} E$ was related to mite, cat and dog allergen levels from dust samples of the maternal mattress and the living room. Allergen levels were collected within 4 weeks after the families entered the study (mean point of time of collection was week 16.6 of pregnancy (standard deviation 7.2. normally distributed). Variables, listed in Table 1 that might influence this relationship were taken into account. The study was approved by the Ethical Committee of the University of Maastricht. Maastricht, the Netherlands.

\section{Data sampling and measurement}

Data on prenatal exposure to mite, cat and dog allergens

Dust samples for the allergen measurement were collected by vacuuming $11.300-\mathrm{W}$ vacuum; Bosch. Hoofddorp. The Netherlands) the floor of the living room (2 areas of $1 \mathrm{~m}^{2}$ for 2 minutes each) and the parental and infant mattresses ( $1 \mathrm{~m}^{2}$ for 2 minutes) with covers but without sheets. Parents were asked not to vacuum the bedroom and living room floor before the dust collection. The dust was catched in a collection device of (ALK. Hørsholm. Denmark), weighed and stored at $4^{\circ} \mathrm{C}$ until extraction. A $10 \%(w / v)$ extract was prepared in borate-buffered saline with $0.1 \%$ Tween-20 by overhead rotation for $2 \mathrm{hr}$ at room temperature. After centrifugation, the supernatants were stored at $-20^{\circ} \mathrm{C}$ until measurement of the allergens.

HDM allergen Der $p 1$, cat allergen Fel $d 1$, and dog allergen Can $f 1$ were measured in the extracts with two-site monoclonal antibody enzyme-linked immunosorbent assay's (ELISA) according to the instructions of the manufacturer (Indoor Biotechnologies Inc. Charlottesville, VA, USA). The HDM allergen standard 93/03 (containing $2500 \mathrm{ng} / \mathrm{ml}$ Der p 1), the cat allergen standard $94 / 01$ (containing $1.6 \mathrm{JU} / \mathrm{ml} \mathrm{Fel} \mathrm{d} 1$ ) and the dog allergen standard $99 / 01$ (containing $5000 \mathrm{IU} / \mathrm{ml}$ Can $\mathrm{f} 1$ ) were used for calculation of the results. 
Allergen concentrations were expressed in $n g / g$ dust, assuming that 1 IU Can $f 1$ corresponds to $1 \mathrm{ng}$ Can $\mathrm{f} \mathrm{l}$, whereas $1 \mathrm{mU}$ Fel d $\mathrm{l}$ corresponds to $4 \mathrm{ng}$ Fel $\mathrm{d} \mathrm{I}^{16}$

\section{Data on Total lgE}

At day 3-5 after birth, heel prick blood was sampled on filter paper. IgE was measured using the method of Aalberse et al. ${ }^{17}$ Absorbed material was cut out and eluted by incubation with PBS-T (PBS/Tween-20 $(0.1 \% \mathrm{v} / \mathrm{v})$ ) for 16 hours under constant rotation. Eluates were separated from filter paper by centrifugation. Determination of total $\mathrm{lg} E$ in eluted blood spots was performed as previously described using Sepharose-immobilized reagents and ${ }^{125} \%$ labeled anti-lgE, raised in sheep. Test results were expressed in $\mathrm{U} / \mathrm{ml}$ ( I IU representing approximately $2.4 \mathrm{ng}$ of $\mathrm{g} \mathrm{g}$ ).

Data on variables possibly influencing IgE

Data on possibly $\mathrm{g} E$ influencing factors were recorded, comprising self-reported doctordiagnosed paternal or maternal allergy for mite allergens, gender, birth weight, birth order. birth season, duration of pregnancy, age of the mother and self-reported maternal smoking prenatally. The kind of the feeding of the infant in de first days of life, before the blood sample was taken, was also recorded.

\section{Data analysis}

Differences between frequencies were tested, for proportions with the $\chi^{2}$ test, and for continuous variables with the t-test. As the $\mathrm{g}$ E levels were not $(\log )$ normally distributed, cases were dichotomised according to their lgE value at or above $0.5 \mathrm{IU} / \mathrm{ml}$ thereafter referred to as elevated $\mathrm{lgE}$ ) or below $0.5 \mathrm{IU} / \mathrm{ml}$ (hereafter referred to as non-elevated $\mathrm{gE}$ ). Allergen levels were not (log) normally distributed even after logarithmic transformation. We used the overall exposure in the house to estimate maternal exposure to allergens. Overall exposure was calculated, for each case, as the mean of the allergen levels from dust samples of the maternal mattress and of the living room. The calculations were performed for mite, cat and dog allergens separately. To investigate whether there was a dose response relation between allergen exposure and having elevated IgE we categorized allergen levels in quartiles. The independence of the relation of elevated IgE (dependent variable) with allergen exposure variables was explored by multiple logistic regression analyses. Dummy variables for the quartiles of the exposure variables were used, introducing potential confounding and co-variables. These included paternal or maternal mite allergy, gender. 
maternal smoking, birth season and kind of feeding before blood sampling lexclusively breast-fed or not). The Statistic Package for the Social Sciences (SPSS version 10) was used for all analyses. A two-sided $P$-value of less than 0.05 was considered to be significant.

\section{Results}

\section{Study population}

A total of 221 newborns were eligible for this study. Blood samples of 210 newborns were taken. 11 parents refused blood sampling of their infant. In 36 somples the amount of blood was too small for analysis. Table 1 compared relevant clinical characteristics in newborns with and without lgE data.

Table 1. Frequencies of birth and family characteristics in children with and without serum total IgE data in capillary heel blood 3-5 days after birth. No statistical differences were found between the groups.

\section{$\operatorname{Ig} E$ data}

$$
\text { Yes, } n=174 \quad \text { No, } n=47
$$

Males

$87(50 \%)$

$24(51 \%)$

Firstborn

$67(39 \%)$

$16(34 \%)$

Born in spring/summer

$83(48 \%)$

$18(39 \%)$

Mother allergic to house dust mite

$62(36 \%)$

$18(39 \%)$

Father allergic to house dust mite

$46(27 \%)$

$11(23 \%)$

Exclusively breast-fed in first week of life

$71(41 \%)$

$20(44 \%)$

Maternal smoking

$19(11 \%)$

$3(7 \%)$

Age mother in years ( $\left.S D^{*}\right)$

$30.9(3.4)$

$31.2(4.2)$

Birth weight in grams ( $S D^{*}$ )

$3486(486)$

$3465(851)$

Duration of pregnancy in weeks (SD*)

$39.8(1.5)$

477 (2885)

438 (2128)

74 (258)

59 (504)

$420(804)$

$390(696)$ 
There were no significant differences in frequencies of basic characteristics and median exposure levels to mite and pet allergens between newborns with and without IgE data.

Of the available 174 cases, 41 (24\%) of the newborns had elevated $\lg E$. IgE levels at birth were not influenced by gender, birth order, birth season, a paternal or maternal allergy for house dust mite or pets, being breast-fed in the first week of life and exposure to maternal smoking during pregnancy (Table 2). Neither was IgE influenced by birth weight (mean weight 3410 gram standard deviation (SD) 450 versus 3520 gram (SD 543). duration of pregnancy (39.7 weeks (SD 1.2) versus 39.8 weeks (SD 1.6)) and the age of their mothers $(31.6$ years (SD 4.5$)$ versus 30.8 years (SD 3.7 ).

Table 2. The relation between birth and family characteristics and elevated total $\operatorname{IgE}(\geq 0.5 \mathrm{IU} / \mathrm{ml})$ in capillary heel blood 3-5 days after birth. No significant differences were found.

$\%$ with total $\operatorname{IgE} \geq 0.5 \mathrm{IU} / \mathrm{ml}$

$\operatorname{Sex}$

Boys $\quad n=87 \quad 24$

Girls $\quad \mathrm{n}=87 \quad 23$

Birth-order

First $\quad \mathrm{n}=68 \quad 28$

Second or later $\quad \mathbf{n}=106 \quad 21$

Birth season

Spring/summer $\quad \mathrm{n}=80 \quad 20$

Autumn/winter $\quad \mathrm{n}=94 \quad 27$

Mother allergic to house dust mite

Yes $\quad \mathrm{n}=61 \quad 26$

No $\quad \mathrm{n}=107 \quad 22$

Father allergic to house dust mite

Yes $n=46 \quad 20$

No $\quad n=122 \quad 25$

Exclusively breast-fed in first week of life

Yes $\mathrm{n}=102 \quad 25$

No $\quad \mathrm{n}=72 \quad 22$

Maternal smoking

Yes $n=19 \quad 26$

No $\quad n=144 \quad 24$ 


\section{Environmental exposure and total serum lgE at birth}

The median levels of allergens (interquartile range between parentheses) of mite, cat and dog were low: in living room dust: 70 (271), 484 (1548), 270 (1627) ng/g dust. respectively, and in mattress dust, 474 (6410), 434 (927) and 130 (1088) ng/g dust. respectively. Mite, cat and dog allergen levels in mattress dust samples were clearly correlated with the same allergens in living room dust samples (Spearman's correlation coefficient $0.553,0.683,0.700$, respectively, for all correlations $P<0.0001$ ). Therefore, overall exposure was used for further analyses.

In the Figure, the frequencies of newborns with elevated $\mathrm{g} E$ are shown when exposed to increasing quantities of mite, cat and dog allergens divided in quartiles. The proportion newborns with elevated $\mathrm{g} E$ increased significantly with increasing quantities of mite allergens, but not of cat or dog allergens. Multiple logistic regression analyses with adjustment for gender, birth season, prenatally smoking mother, receiving breast-feeding before blood sampling, maternal and paternal mite allergy, did not change the results. Likewise did not introducing the interaction term breast-feeding $x$ maternal mite allergy.

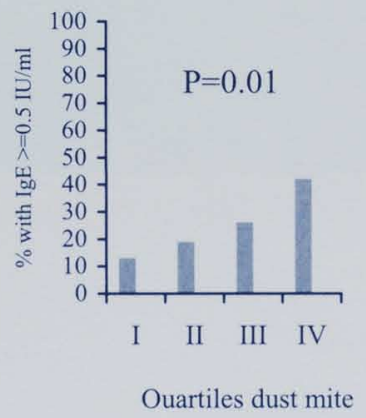

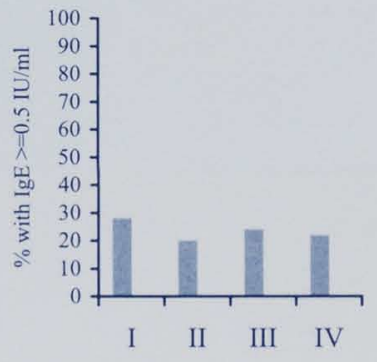

Ouartiles cat allergens

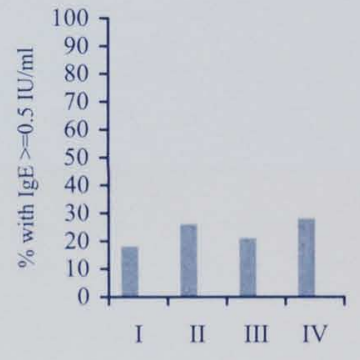

Ouartiles dog allergens

Figure. Percentage of children with a total $\mathrm{IgE} \geq 0.5 \mathrm{IU} / \mathrm{ml}$ by levels of allergens of house dust mite and pets in percentiles (quartiles), I: $<25^{\text {the }}$ perc; II $: 25-50^{\text {the }}$ perc; III: $50-75^{\text {the }}$ perc; IV: $\geq 75^{\text {th }}$ perc. Between parenthesis: number of cases with $\geq 0.5 \mathrm{IU} / \mathrm{ml} \mathrm{ml}$ by total numbers, present in listed quartile.

Quartiles Der p 1: I: 0-85 (6/46); II: 86-381 (10/53); III: 382-2371 (10/39); IV: $\geq 2372$ (14/33) ng/g dust. Quartiles Fel d 1: I: 0-200 (13/47); II 200-489.9 (9/46); III: 490-1590 (9/37); IV: $\geq 1590$ (9/41) ng/g dust. Quartiles Can f 1: I: 0-101 (7/390), II 102-249 (10/38); III: 250-1255 (11/52); IV $\geq 1256$ (12/42) ng/g dust. 


\section{Discussion}

In this study we found a dose response relationship between increasing prenatal exposure to mite allergens and the presence of elevated total serum $\mathrm{lgE}$ of high-risk infants 3 days after birth. The relation was not found for cat and dog allergens.

We used a more or less arbitrarily a cut-off level for $\mathrm{g} E$ of $0.5 \mathrm{IU} / \mathrm{ml}$, $^{18.19}$ but our findings did not change essentially when we used higher cut-off values $(0.7$ or $0.9 \mathrm{lU} / \mathrm{ml})$ or lower values (lgE $0.2 \mathrm{lU} / \mathrm{ml}$ ). (data not shown). In our study, $24 \%$ of the children had a $\lg E \geq 0.5 \mathrm{lU} / \mathrm{ml}$. which is more or less the same as has recently been reported, using a cut-off level of cord blood lgE of $0.45 \mathrm{IU} / \mathrm{ml} .^{20}$

Total IgE was measured at day 3-5 after birth in capillary heel blood. It is known that the concordance between cord blood lgE and lgE at day 3-5 after birth is good. ${ }^{21.22}$ The advantage of our sampling method, compared to cord-blood measurement is the avoidance of contamination with maternal blood.

How we have to interpret the results? It is well known that the foetal immune system is capable to produce lgE in utero from $11-20$ weeks of gestation. ${ }^{23}{ }^{24}$ Since $\lg E$ is unlikely to pass the placenta. ${ }^{25}$ the presence of elevated lgE in cord blood must be the result of foetal immune response.

The immune response is thought to be (partly) under genetic control, ${ }^{26.27 .14}$ because it differs between subjects with and without an atopic predisposition. ${ }^{510.14 .28}$ As the infants in our study were all predisposed, the here found dose-response relationship confirms that besides genetically influences, environmental exposure plays also a role in determining intrauterine immune responses.'

Elevated lgE at birth may be a sign of a normal "educational" reaction of the developing immune system on the prevailing extra-uterine environment. ${ }^{29.30}$ However, it may also indicate immune deviation and sensitisation, as high cord-blood lgE levels are predictive for sensitisation later in life,,$^{10.31 .19}$ and for atopic syndromes, including asthma at an older age. ${ }^{18.32}$ This holds especially for high-risk children. ${ }^{5}$ Because we were not able to determine specific lgE against mite, cat and dog allergens, we connot furnish proof whether sensitisation was actually present at birth. It is to expect however that presence of specific lgE against 
inhalant indoor allergens would be very low as other studies found no measurable specific lgE against dust mite and cat in cord blood. ${ }^{33}$

In multiple regression analysis the relationship between prenatal mite exposure and infants' total serum IgE at birth was not modified by the presence or absence of mite allergy in either the father or the mother. This is in agreement with other studies, ${ }^{3.20}$ but in contrast with reports that infants with asthmatic mothers do have higher cord-blood IgE than newborns with atopic fathers. ${ }^{21.34 .35}$ We used, however, parentally reported data on sensitisation for mite, cat and dog allergens and, accordingly, reporting bias cannot be excluded.

Maternal total serum lgE has been found to be correlated with cord blood total serum ICE as well as with amnion fluid $\mathrm{g} g \mathrm{E}^{29}$ As mother and foetus share the same environment, stimuli from the maternal environment, reaching the foetus by transamniotic and transplacental passage might determine foetal immune response. ${ }^{5.29 .36}$ Our findings support that vision. It has been hypothesized that (allergic) mothers may react on environmental exposure by allergens, also during pregnancy, with an increase of $T_{2}$-like cytokines, which could cross the placenta and evoke foetal immune response. ${ }^{37}$

We found a prenatal exposure to mite allergens, but not to cat and dog allergens to be related with elevated $\mathrm{g} E$ at birth, which might be (partly) explained by privileged diaplacental passage of particular allergens. ${ }^{3.38}$ It means that varying CBMC responses have been found for different allergens, like was reported for cow's milk, house dust mite and seasonal allergens. ${ }^{39}$ This could also be the case for the here reported difference in foetal lgE response on mite and pet allergen exposure. Although, a linear association between prenatal cat allergen exposure and cord-blood IgE was reported recently. ${ }^{20}$

In conclusion, we found that prenatal exposure to house dust mite allergens, but not to cat and dog allergens were significantly related to serum total lgE at birth in infants at high risk of asthma.

The findings support the hypothesis that diminishing allergen exposure prenatally might also decrease foetal allergic sensitisation by changing maternal-foetal interactions. ${ }^{34.35} \mathrm{On}$ cannot exclude that the small effects on sensitisation that intervention studies have shown so far. ${ }^{40.41}$ had been caused by starting the environmental manipulation to late. To elucidate the issue of the importance of the precise timing of the intervention, it is important to 
compare the effect of environmental allergen manipulation in early pregnancy with the effect of starting manipulation from birth.

Conflict of interest: None

Funding: The PREVASC study was supported by The Dutch Asthma Foundation, Prevention Fund and Royal Academy of Science (KNAW).

\section{Acknowledgement}

The study was a joint project of the Departments of General Practice of the University Maastricht and the Radboud University Nijmegen. We would like to thank the general practitioners allied to these departments and the participating midwives for recruiting eligible families. We are grateful to all families for their participation in and devotion to the study. We also like to express our thanks to the research-assistants: Tanja Maas, Ilse van Beerendonck and Karin Manders; the data managers: Jacqueline Pisters and Kitty Coolen; the nurses, who visited the participating families and sampled data: Cindy Brink, Kitty van der Meer, Marjorie Rovers, Twanny Jeijsman, Inke Schaap, Marjan Terhaar and Elly de Vree, the PREVASC secretary Annemarie Spaninks and the secretary of Care and Public Health Research Institute (Caphri) Annemarie Korsten.

We would like to thank Nico van der Maas of Skiltec B.V., Beek, the Netherlands, for his linguistic comments and suggestions. 
References:

1. Platts-Mills TA, Rakes G, Heymann PW. The relevance of allergen exposure to the development of asthma in childhood. $J$ Allergy Clin Immunol 2000;105(2 Pt 2):S503-8.

2. Miller RL, Chew GL, Bell CA, et al. Prenatal exposure, maternal sensitization, and sensitization in utero to indoor allergens in an inner-city cohort. Am J Respir Crit Care Med 2001;164(6):9951001 .

3. Van Duren Schmidt K, Pichler J, Ebner C, et al. Prenatal contact with inhalant allergens. Pediatr Res 1997;41(1):128-31.

4. Prescott SL, Holt PG, Jenmalm M, Bjorksten B. Effects of maternal allergen-specific IgG in cord blood on early postnatal development of allergen-specific T-cell immunity. Allergy 2000;55(5):470-5.

5. Warner JA, Jones CA, Jones AC, Miles EA, Francis T, Warner JO. Immune responses during pregnancy and the development of allergic disease. Pediatric Allergy and Immunology 1997;8 Suppl. 10:5-10.

6. Szepfalusi Z, Todoran L, Elsasser S, Jagdt B, Wank H, Urbanek R. Cord blood leucocytes/basophils produce and release sulfidoleucotrienes in response to allergen stimulation. Clin Exp Allergy 1999;29(3):382-7.

7. Warner JA, Miles EA, Jones AC, Quint DJ, Colwell BM, Warner JO. Is deficiency of interferon gamma production by allergen triggered cord blood cells a predictor of atopic eczema? Clin Exp Allergy 1994;24(5):423-30.

8. Kjellman NI, Croner S. Cord blood IgE determination for allergy prediction--a follow-up to seven years of age in 1,651 children. Ann Allergy 1984;53(2):167-71.

9. Halonen M, Stern D, Taussig LM, Wright A, Ray CG, Martinez FD. The predictive relationship between serum IgE levels at birth and subsequent incidences of lower respiratory illnesses and eczema in infants. Am Rev Respir Dis 1992;146(4):866-70.

10. Bergmann RL, Edenharter G, Bergmann KE, et al. Predictability of early atopy by cord blood-IgE and parental history. Clin Exp Allergy 1997;27(7):752-60.

11. Hansen LG, Halken S, Host A, Moller K, Osterballe O. Prediction of allergy from family history and cord blood IgE levels. A follow-up at the age of 5 years. Cord blood IgE. IV. Pediatr Allergy Immunol 1993;4(1):34-40.

12. Nambu M, Shintaku N, Ohta S. Relationship between cord blood level of IgE specific for Dermatophagoides pteronyssinus and allergic manifestations in infancy. Biol Neonate 2003;83(2):102-6.

13. Holloway JA, Warner JO, Vance GH, Diaper ND, Warner JA, Jones CA. Detection of housedust-mite allergen in amniotic fluid and umbilical- cord blood. Lancet 2000;356(9245):1900-2.

14. Smillie FI, Elderfield AJ, Patel F, et al. Lymphoproliferative responses in cord blood and at one year: no evidence for the effect of in utero exposure to dust mite allergens. Clin Exp Allergy 2001;31(8):1194-204.

15. Schonberger HJ, Van Schayck CP. Prevention of asthma in genetically predisposed children in primary care--from clinical efficacy to a feasible intervention programme. Clin Exp Allergy 1998;28(11):1325-31.

16. van der Heide S, van Aalderen WM, Kauffman HF, Dubois AE, de Monchy JG. Clinical effects of air cleaners in homes of asthmatic children sensitized to pet allergens. $J$ Allergy Clin Immunol 1999; 104(2 Pt 1):447-51.

17. Aalberse RC, Koshte V, Clemens JG. Immunoglobulin $E$ antibodies that crossreact with vegetable foods, pollen, and Hymenoptera venom. J Allergy Clin Immunol 1981;68(5):356-64.

18. Hansen LG, Host A, Halken S, et al. Cord blood IgE. II. Prediction of atopic disease. A follow-up at the age of 18 months. Allergy 1992;47(4 Pt 2):397-403.

19. Kaan A, Dimich-Ward H, Manfreda J, et al. Cord blood IgE: its determinants and prediction of development of asthma and other allergic disorders at 12 months. Ann Allergy Asthma Immunol 2000;84(1):37-42.

20. Heinrich J, Bolte G, Holscher B, et al. Allergens and endotoxin on mothers' mattresses and total immunoglobulin E in cord blood of neonates. Eur Respir $J$ 2002;20(3):617-23. 
21. Lilja G, Magnusson CG, Kusoffsky E, Johansson SG, Oman H. Neonatal IgA and IgE levels among infants with paternal heredity for atopic disease. Allergy 1995;50(9):723-8.

22. Hansen D, Hornnes P, Poulsen LK. IgE levels in cord and capillary blood at 5 days of age. Pediatr Allergy Immunol 1993;4(1):30-3.

23. Miller DL, Hiravonen T, Gitlin D. Synthesis of IgE by the human conceptus. J Allergy Clin Immunol 1973;52(3):182-8.

24. Lima JO, Zhang L, Atkinson TP, Philips J, Dasanayake AP, Schroeder HW, Jr. Early expression of iepsilon, CD23 (FcepsilonRII), IL-4Ralpha, and IgE in the human fetus. J Allergy Clin Immunol 2000;106(5):911-7.

25. Avrech OM, Samra Z, Lazarovich Z, Caspi E, Jacobovich A, Sompolinsky D. Efficacy of the placental barrier for immunoglobulins: correlations between maternal, paternal and fetal immunoglobulin levels. Int Arch Allergy Immunol 1994;103(2): 160-5.

26. Cookson WO, Hopkin JM. Dominant inheritance of atopic immunoglobulin-E responsiveness. Lancet 1988;1(8577):86-8.

27. Marsh DG, Neely JD, Breazeale DR, et al. Linkage analysis of IL4 and other chromosome $5 q 31.1$ markers and total serum immunoglobulin E concentrations. Science 1994;264(5162):1152-6.

28. Dizier MH, Hill M, James A, et al. Detection of a recessive major gene for high IgE levels acting independently of specific response to allergens. Genet Epidemiol 1995;12(1):93-105.

29. Thornton CA, Holloway JA, Popplewell EJ, Shute JK, Boughton J, Warner JO. Fetal exposure to intact immunoglobulin E occurs via the gastrointestinal tract. Clin Exp Allergy 2003;33(3):30611.

30. King CL, Malhotra I, Mungai $P$, et al. B cell sensitization to helminthic infection develops in utero in humans. $J$ Immunol 1998; 160(7):3578-84

31. Tariq SM, Arshad SH, Matthews SM, Hakim EA. Elevated cord serum IgE increases the risk of aeroallergen sensitization without increasing respiratory allergic symptoms in early childhood. Clin Exp Allergy 1999;29(8):1042-8.

32. Illi $\mathrm{S}$, von Mutius $\mathrm{E}, \mathrm{Lau} \mathrm{S}$, et al. The pattern of atopic sensitization is associated with the development of asthma in childhood. J Allergy Clin Immunol 2001;108(5):709-14.

33. Platts-Mills TA, Erwin EA, Allison AB, et al. The relevance of maternal immune responses to inhalant allergens to maternal symptoms, passive transfer to the infant, and development of antibodies in the first 2 years of life. J Allergy Clin Immunol 2003;111(1):123-30.

34. Shirakawa T, Morimoto K, Sasaki S, et al. Effect of maternal lifestyle on cord blood IgE factor. Eur J Epidemiol 1997;13(4):395-402.

35. Liu CA, Wang CL, Chuang H, Ou CY, Hsu TY, Yang KD. Prenatal prediction of infant atopy by maternal but not paternal total IgE levels. J Allergy Clin Immunol 2003;112(5):899-904.

36. Jones CA, Kilburn SA, Warner JA, Warner JO. Intrauterine environment and fetal allergic sensitization. Clinical and Experimental Allergy 1998;28(6):655-659.

37. Jones CA, Holloway JA, Warner JO. Fetal immune responsiveness and routes of allergic sensitization. Pediatr Allergy Immunol 2002;13 Suppl 15:19-22.

38. Szepfalusi Z, Pichler J, Elsasser S, et al. Transplacental priming of the human immune system with environmental allergens can occur early in gestation. $J$ Allergy Clin Immunol 2000;106(3):530-6.

39. Kopp MV, Pichler J, Halmerbauer G, et al. Culture conditions for the detection of allergenspecific T-cell reactivity in cord blood: influence of cell number. Pediatr Allergy Immunol 2000;11(1):4-11.

40. Custovic A, Simpson BM, Simpson A, Kissen P, Woodcock A. Effect of environmental manipulation in pregnancy and early life on respiratory symptoms and atopy during first year of life: a randomised trial. Lancet 2001;358(9277):188-93.

41. Koopman LP, van Strien RT, Kerkhof M, et al. Placebo-controlled trial of house dust miteimpermeable mattress covers: effect on symptoms in early childhood. Am J Respir Crit Care Med 2002;166(3):307-13. 


\section{Chapter 7}

\section{The early diagnosis of childhood asthma in general practice.}

H.J.A.M.Schönberger' M.D., C.P. van Schayck' Ph.D., J. Muris' M.D., Ph.D.

H. Bor'. H. van den Hoogen', J.A. Knotnerus' M.D., Ph.D. C. von Weel M.D. Ph.D. Towards improving the occuracy of the early diagnosis of asthma in wheezing children

1. Department of General Practice, Research Institute CAPHRi. University Moastricht. Maastricht. The Netherlands

2. Department of Ceneral Practice, University Medical Centre. Radboud University Nijmegen. Nijmegen, The Netherlands

In submission 


\begin{abstract}
Background

Early and correctly diagnosing asthma in wheezing children is essential for early treatment and prevention of under- or over treatment.
\end{abstract}

\title{
Objective
}

To study whether combining frequency and age of onset of wheezing illness with respiratory and atopic morbidity at age 0-6 and socio-demographic parameters for asthma might be helpful for the general practitioner to diagnose asthma early and accurate.

\section{Method}

In a birth cohort, mean follow-up 20 years (SD 4.8), the outcome, adolescent asthma, was analysed in relation to wheezing and non-wheezing respiratory, and personal and familial atopic morbidity in a primary care population. All diagnoses were from the Continuous Morbidity Registration of the Department of Ceneral Practice of the Radboud University Nijmegen. The Netherlands.

\section{Result}

$1586(64 \%)$ of the children could be followed. Adolescent asthma occurred in $6.4 \%$. There were indications for under- and over diagnosis of asthma at age 0-6 years. Non-recurrent (only one episode), and recurrent wheezing ( $\geq 2$ episodes) in the first three years of life. and recurrent wheezing at age 4-6 increased the risk with odds ratios (95\% confidence interval) of $3.3(1.9-5.6), 4.7(2.8-8.2)$ and 15.4 (7.1-33.7), respectively. The risk additionally increased independently by a family history for asthma. (2.0 (1.1-3.6)), by atopic dermatitis $(1.7(1.1-2.7))$ and sinusitis $(2.9(1.3-6.4))$ and decreased by being $\geq 2$ nd born 10.38 (0.19-0.74)) and low social-economic status 10.61 (0.39-0.94)). Examples of probability of asthma by combining clinical signs, personal and familial atopic symptoms are given. In children with recurrent wheezing in their first three years of life, a probability of adolescent asthma could be attained of nearly $50 \%$.

\section{Conclusion}

Easily available history and clinical data can facilitate the early diagnosis of asthma in children with wheezing illness. 


\section{Introduction}

The cumulative prevalence of wheezing in childhood is high.' In nearly $50 \%$ of children at least one episode of wheezing are reported, before their 6th year of age, ${ }^{2}$ and most episodes will be presented to the general practitioner (CP). Wheezing is a sensitive symptom of asthma, as most older children and adults with asthma have reported wheezing in their early childhood. Unfortunately the opposite is not true: children with a history of wheezing do not necessarily develop asthma, and wheeze is not a specific symptom: childhood wheezing illness is a heterogeneous syndrome, ${ }^{3}$ most often caused by a viral infection or pre-existent small airways. ${ }^{4}$ As only in a minority of the (wheeze) cases it is caused by early asthma, a correct identification of the asthmatics among those with childhood wheezing illness is essential to prevent under treatment or over treatment and to start as early as possible early therapy of asthma. Particularly early anti-inflammatory treatment with inhaled corticosteroids might prevent remodeling of the lung. ${ }^{5.6 .7}$ although hard evidence for that is still wanted. However, given the relatively low predictive value of wheeze and other symptoms for asthma, the correct identification of the asthmatic children among those with wheezing illness is a problem for CPs, pediatricians and child-pulmonologists with underdiagnosis and misclassification as a result. ${ }^{8.9 .1}$ Before 6 years of age asthma cannot be diagnosed on the basis of objective assessment of aifflow obstruction, so practitioners have to rely on other indicators, which are predictive for the development of asthma. These include: age of onset and/or the frequency of the wheezing. ${ }^{2}$ recurrent (upper and lower) non-wheezing respiratory tract infections, ${ }^{10}$ the presence of a positive family history ${ }^{11.12}$ and concomitant allergic diseases. ${ }^{13}$ In addition socio-demographic data such as gender. prematurity or dysmaturity. ${ }^{14}$ birth order. ${ }^{14}$ birth month, family size. ${ }^{15}$ age of the mother and socio-economic level ${ }^{14}$ have been reported as risk factors as well. As usually the diagnosis of asthma is made in general practice, better insight is necessary in the predictive value of wheezing patterns and other mentioned clinical indicators, based on patients representing a primary care population. However, studies that are available ${ }^{16.17}$ are not based on data presented to the CP and this hampers their applicability in general practice. ${ }^{18}$ Longitudinal analysis of outcome of wheeze in a birth cohort of children from general practice would be the best way to present evidence for primary care decision-making and this was the basis of this study. We performed a prospective birth cohort study of the risk for asthma in 
adolescence, of early childhood wheeze in relation to other clinical and social characteristics. The primary question was which wheezing patterns and other relevant clinical and socio-demographic parameters can best predict adolescent asthma

\section{Material and Methods}

Study subjects and data sampling

A birth cohort of 1586 children was recruited from the practice population ( $n=12.000$ ) of the Continuous Morbidity Registration (CMR) of the Department of Ceneral Practice of the University Medical Centre Nijmegen. The Netherlands. ${ }^{19}$ The CMR recording is grounded in the Dutch health care system, where all patients are registered with a CP and all access to care must come through this physician. Nearly everyone is insured by a single payer source and the population is relatively stable. As a consequence, the CPs records contain the full details of patient care, irrespective of where patients have been treated. These factors allow excellent patient tracking and outstanding opportunities for studying diseases longitudinally. ${ }^{20}$

All children had been born alive between 1967 (start of the CMR recording) and 1989. which allowed for a follow-up for at least 12 years. In the database, all morbidity presented in general practice and hospital care has been prospectively recorded in a standardized way. with definitions according to the International Classification of Health Problems in Primary Care (ICHPPC) (see Box). ${ }^{21}$ Analysis in this paper is based throughout on ICPC-defined cases.

Definitions of the outcome and independent variables.

The study outcome was the diagnosis of asthma in children of at least 12 years of age (hereafter referred to as adolescents), registered by the CP or specialist. The predictor variable "wheezing" at age 0-6 years was defined as an episode of respiratory symptoms with bronchial obstruction (wheeze), cough with scattered or generalized abnormal chest signs." Wheezing episodes were categorized as non-recurrent if only one episode of wheezing was registered and recurrent in case two or more episodes were recorded. According to the ICHPPC-criteria, CPs may wheezing episodes code as acute bronchitis/bronchiolitis or as (an exacerbation of asthma when specific criteria are fulfilled (see Box). 


\begin{tabular}{|c|c|c|}
\hline Disease (Code) & Diagnostic criteria & $\begin{array}{l}\text { Prevalence } \\
\text { in study } \\
\text { group } \\
(n=1586)\end{array}$ \\
\hline $\begin{array}{l}\text { Asthma } \\
(086)\end{array}$ & $\begin{array}{l}\text { Recurrent episodes of acute bronchial obstruction with one of the following: } \\
\text { (a) Pulmonary function tests showing variable obstruction, relieved by } \\
\text { bronchodilatators, } \\
\text { (b) Two of the three following: (i) wheeze, (ii) dry cough, (iii) prolonged } \\
\text { expiratory phase of respiratory cycle }\end{array}$ & $6 \%$ \\
\hline $\begin{array}{l}\text { Acute bronchitis } \\
(247)\end{array}$ & $\begin{array}{l}\text { Both of the following: } \\
\text { (a) Cough } \\
\text { (b) Scattered or generalized abnormal chest signs -wheeze, coarse or moist } \\
\text { sounds. } \\
\text { Incl. bronchiolitis; tracheobronchitis }\end{array}$ & $34 \%$ \\
\hline \begin{tabular}{|l|} 
Pneumonia \\
$(246)$
\end{tabular} & $\begin{array}{l}\text { Evidence of pulmonary consolidation shown by one of the following: } \\
\text { (a) Typical X-ray appearance } \\
\text { (b) Clinical signs of three of the following: (i) diminished air entry (ii) dullness to } \\
\text { percussion (iii) bronchial breath sounds (iv) fine crepitations (v) increased vocal } \\
\text { fremitus and resonance } \\
\text { Incl, bacterial and viral pneumonia; influenzal pneumonia. Excl. Aspiration } \\
\text { pneumonia. }\end{array}$ & $10 \%$ \\
\hline $\begin{array}{l}\text { Allergic rhinitis } \\
(085)\end{array}$ & $\begin{array}{l}\text { Three of the following criteria on a chronic or seasonal basis: (a) sneezing, (b) } \\
\text { nasal obstruction, (c) clear nasal discharge, (d) watering eyes, (e) edema of the } \\
\text { nasal mucosa }\end{array}$ & $2 \%$ \\
\hline $\begin{array}{l}\text { Laryngitis and } \\
\text { tracheitis } \\
(244)\end{array}$ & $\begin{array}{l}\text { A. For laryngitis, acute, croup and epiglottitis- one of the following: } \\
\text { (a) Hoarseness } \\
\text { (b) Stridor } \\
\text { (c) Visibly red epiglottis } \\
\text { B. For tracheitis, acute - both of the following } \\
\text { (a) Persistent deep dry painful cough (barking in children) } \\
\text { (b) Absence of abnormal chest signs }\end{array}$ & $9 \%$ \\
\hline $\begin{array}{l}\text { Tonsillitis } \\
(242)\end{array}$ & $\begin{array}{l}\text { Four of the following: } \\
\text { (a) Sore throat } \\
\text { (b) Reddening of the tonsil(s) more than posterior pharyngial wall } \\
\text { (c) Pus on tonsil(s) } \\
\text { (d) Swelling of the tonsil(s) } \\
\text { (e) Enlarged tender regional lymph nodes } \\
\text { (f) Fever } \\
\text { inclusive proven streptococcal infections }\end{array}$ & $46 \%$ \\
\hline
\end{tabular}


Box continued:

\begin{tabular}{|c|c|c|}
\hline $\begin{array}{l}\text { Hypertrophy and } \\
\text { chronic } \\
\text { infections of } \\
\text { tonsils and } \\
\text { adenoids } \\
\text { (249) }\end{array}$ & $\begin{array}{l}\text { A. For hypertrophy of tonsils: } \\
\text { (a) Eniargement of the tonsils sufficient to cause one of the following:(i) tonsils } \\
\text { touch in midline (ii) respiratory difficulty (iii) difficulty in swallowing } \\
\text { (b) No acute respiratory infections within the previous } 4 \text { weeks } \\
\text { B. For chronic infection of the tonsils } \\
\text { More than } 4 \text { medically diagnosed episodes of acute tonsillitis in } 2 \text { years (or } 3 \text { in } 1 \\
\text { year) } \\
\text { C. For hypertrophy of adenoids-two of the following: } \\
\text { (a) Mouth breathing } \\
\text { (b) Demonstration of enlarged adenoids } \\
\text { (c) At least } 4 \text { episodes of medically diagnosed otitis media in } 2 \text { years (or } 3 \text { in } 1 \\
\text { year) }\end{array}$ & $19 \%$ \\
\hline $\begin{array}{l}\text { Sinusitis, acute } \\
\text { and chronic } \\
\text { (250) }\end{array}$ & $\begin{array}{l}\text { (a) Pus obtained directly from sinus } \\
\text { (b) Two of the following:(i) purulent nasal or postnasal discharge, or previous } \\
\text { medically treated episodes of sinusitis (ii) tenderness over one or more sinuses, or } \\
\text { deep-seated aching facial pain aggravated by dependency of head (iii) radioligical } \\
\text { evidence of sinusitis or opacity on transillumination }\end{array}$ & $3 \%$ \\
\hline $\begin{array}{l}\text { Otitis media } \\
(183)\end{array}$ & $\begin{array}{l}\text { One of the following: } \\
\text { (a) Recent perforation of the tympanic membrane discharging pus } \\
\text { b) Inflamed and bulging tympanic membrane } \\
\text { c) One eardrum is more red than the other } \\
\text { d) Red tympanic membrane, with ear pain } \\
\text { e) Bulla on the tympanic membrane }\end{array}$ & $20 \%$ \\
\hline $\begin{array}{l}\text { Common cold } \\
\text { Without fever } \\
(240) \\
\text { With fever } \\
(241)\end{array}$ & $\begin{array}{l}\text { Both of the following: } \\
\text { a) Evidence of acute inflammation of nasal or pharyngeal mucosa } \\
\text { b) Absence of criteria for more specifically defined acute respiratory infection } \\
\text { Incl. cold, nasopharyngitis, pharyngitis, rhinitis }\end{array}$ & $\begin{array}{l}44 \% * \\
24 \% *\end{array}$ \\
\hline $\begin{array}{l}\text { Atopic } \\
\text { dermatitis or } \\
\text { eczema } \\
(379)\end{array}$ & $\begin{array}{l}\text { Incl. infantile eczema and flexural dermatitis } \\
\text { Excl: diaper rash, seborrhoic dermatitis } \\
\text { A pruritic skin lesion with erythema, vesiculation, weeping, crusting, peeling, or } \\
\text { lichenification and three of the following: } \\
\text { (a) Predilection for flexural areas (under the age of } 2 \text { predilection for face, scalp, } \\
\text { extensor aspects of the limbs, trunk, diaper area) } \\
\text { (b) Onset in infancy } \\
\text { (c) Chronic relapsing course } \\
\text { (d) Association with asthma, allergic rhinitis, or allergic conjunctivitis } \\
\text { (e) Personal or family history of atopy }\end{array}$ & $20 \%$ \\
\hline
\end{tabular}

$* \geq$ three or more episodes

However, diagnosing asthma in early childhood is difficult, as it cannot be objectified reliably at that age. Therefore, we analysed the diagnosis asthma at age 0-6 both ways: (1) supposing the children with the diagnosis asthma to have "recurrent wheezing", as the ICPC diagnosis asthma requires obligatory recurrent episodes of acute bronchial obstruction (see Box) and (2) accepting the CP-diagnosis asthma. So, the recurrent wheezing group consisted of children who had two or more times a registered diagnosis of acute bronchitis/bronchiolitis and of children with the diagnosis asthma. Further, to explore the importance of age of the onset of wheezing for adolescent asthma, non-recurrent wheezing and recurrent wheezing 
were grouped in "early" onset wheezing (before age 3 years). versus "late" onset wheezing (at age 4-6 years). This resulted in four (mutually exclusive) wheezing patterns: early and late non-recurrent, and early and late recurrent.

Atopic dermatitis and allergic rhinitis, lower respiratory tract morbidity, including pneumonia and laryngitis, and upper respiratory tract morbidity, including tonsillitis, adenoiditis, influenza, sinusitis, common cold with and without fever and otitis media, were all defined according to the ICHPPC-2 criteria (see Box).

The socio-demographic variables listed and categorized as in Table 2 were included in the analyses. Cenetic predisposition for asthma was defined as presence of a mother, father or sibling(s) with registered asthma, allergic rhinitis, or atopic dermatitis.

\section{Data analysis}

To assess the representativeness of the study group, the participants were compared with the subjects who had left the practice or had died before their twelfth year on the prevalence of atopic diseases in the first 6 years of life (for so far available) and on socio-economic status. When the child had died before their $12^{\text {th }}$, the cause of death was analyzed. Univariate associations between wheezing illness patterns and adolescent asthma were expressed in relative risk (RR) with 95\% confidence intervals $(95 \% \mathrm{Cl})$.

Likewise this was done for the relationship of asthma with (1) a family history of AS. AR and $A D$ and patients' birth, and socio-demographic characteristics, (2) a medical history of other atopic illiness. (3) the frequency of other URM and LRM episodes at age 0-6 years. Next, all significant correlations $(P<0.05)$ with asthma were added in three successive steps of a stepwise logistic regression analysis. The Statistical Package SPSS for Windows, version 10.1. Chicago. USA was used.

\section{Results}

We could follow $1586(64 \%)$ of the 2475 children in the database for at least 12 years from birth: the study cohort. Their mean age at the end of the study was 19.7 years (standard deviation 4.8) with a range from 12-32 years. Twenty-six children had died before the age of twelve years (none of them because of asthma or other respiratory causes) and 863 children had left the practice region and therefore the practices, before that age. 
Significantly more participants had a lower socio-economic status than the children who had left $138.1 \% \vee 31.4 \%, p=0.00011)$. There were no differences in the prevalence of asthma and other allergic morbidity of the study cohort and those who left the practices after their second (data available for 170 subjects) and after their sixth birthday (data available for 556 subjects).

The total number of children with asthma at 12 years of age or later was 102 (6.4\%), 52 boys and 50 girls.

\section{Univariate association of wheezing morbidity and asthma in adolescence}

In the first six years of life. $543(34 \%)$ children had non-recurrent wheezing: $437(28 \%)$ in the first three years of life and $106(7 \%)$ at age 4-6. Non-recurrent wheeze was registered in $321(19 \%)$ subjects, while $222(14 \%)$ children had recurrent wheeze.

Of those with adolescent asthma. 51 (50\%) had non-recurrent wheezing in their first 3 years of life and $68(66.8 \%)$ in their first 6 years of life.

Table 1 summarizes the correlation between the four wheezing patterns and asthma in adolescence. Those with non-recurrent as well as those with recurrent wheezing in the first three years of life were at increased risk of having adolescent asthma. Of those who had wheezing at age 4-6. only children with recurrent wheeze had an increased risk of adolescent asthma, whereas those with non-recurrent wheeze had not. 
Table 1. The risk of asthma in adolescence by early (age 0-3) and late occurrence (age 4-6) of nonrecurrent and of recurrent wheezing illness, diagnosed as asthma or not during the first six years of life. Non-adjusted relative risk (RR) with $95 \%$ confidence intervals $(95 \% \mathrm{CI})$ Cohort $n=1586$.

Wheezing morbidity

No wheezing illness

Early wheezing illness

non-recurrent
recurrent
of which not diagnosed as asthma
of which diagnosed as asthma

Late wheezing illness

non-recurrent
recurrent
of which not diagnosed as asthma
of which diagnosed as asthma

Number (\%) with

$R R(95 \% C I)$

adolescent asthma

$$
\mathrm{n}=1043
$$

$34(3 \%)$

1.0

$\begin{array}{ll}\mathrm{n}=250 & 25(10 \%) \\ \mathrm{n}=187 & 26(14 \%) \\ \mathrm{n}=140 & 17(12 \%) \\ \mathrm{n}=47 & 9(19 \%)\end{array}$

$\mathrm{n}=71$

$5(7 \%)$

$\mathrm{n}=35$

$12(34 \%)$

$\mathrm{n}=24$

$3(13 \%)$

$n=11$

$9(82 \%)$

Univariate association of a familial history. socio-demographic and birth variables with asthma in adolescence

Table 2 shows that asthma or allergic rhinitis either in one or both parents and/or siblings were significantly related to adolescent asthma. Of the socio-demographic and birth variables only birth order was, negatively, associated with adolescent asthma (Table 2 ). 
Table 2. Associations of patients' birth, and family characteristics with asthma in adolescence.

Unadjusted relative risks (RR) with $95 \%$ confidence interval (CI); study group $n=1586$. Significant associations in bold

number $\quad$ \% asthma $\quad R R(95 \%$ CI $)$

variable

male sex

820

$6 \%$

$0.97(0.66-1.4)$

birth weight $<2800$ (SD)

85

$7 \%$

$1.1(0.49-2.4)$

birth order

first or second born

1235

$7 \%$

1.0

$\geq$ third born

344

$3 \%$

$0.44(0.24-0.82)$

birth period

spring/summer

804

$7 \%$

1.0

autumn/winter

782

$7 \%$

$1.1(0.75-1.6)$

age of the mother ${ }^{*}$

$$
<25
$$

361

$8 \%$

$\geq 25$

1216

$7 \%$

$1.4(0.91-2.1)$

socio economic status $\dagger$

low

755

$6 \%$

1.0

middle

692

$8 \%$

$0.70(0.47-1.0)$

high

$4 \%$

$1.5(0.61-3.8)$

family history ${ }^{s}$

asthma

$11 \%$

$2.2(1.0-4.6)$

allergic rhinitis

96

$9 \%$

$1.9(1.0-3.7)$

atopic dermatitis

357

$6 \%$

$1.2(0.73-2.1)$

*: missing 9 ; $\uparrow$ :missing 2 , classification according to the occupation of the head of the family; $\S$ :

missing 22; presence of listed atopic disease in either or both paternal, maternal or siblings asthma

Univariate association of atopic morbidity and non-wheezing upper and lower respiratory tract infections with asthma in adolescence.

Table 3 shows the positive relationship of atopic dermatitis, but not allergic rhinitis at age 0 6 years and asthma in adolescence. Also in Table 3 the upper and lower tract morbidity at age 0-6 years, significantly positive related to asthma in adolescence, has been shown. Tonsillitis, adenoiditis and common cold(s) with fever were not associated with asthma later in life (data not shown). Further analyses were done after stratification for early lage 0-3) 
and late lage 4-6) occurrence of the upper and lower tract morbidity. Only for otitis media present in the first 3 years of life the risk was increased, but not anymore at age 4-6 (data not shown).

\section{Multiple logistic regression analysis}

The result of the multiple logistic regression analysis is presented in Table 4 and shows the influence on the relation wheezing morbidity and asthma of successively the family history (model 1), non wheezing respiratory morbidity (model 2) and other atopic morbidity (model 3). Also in Table 4, the model with the best percentage explained variance $\left(R^{2}=0.062\right)$ is presented (model 4). The risk of asthma in wheezing children was, independently, and significantly increased by a family history of asthma, atopic dermatitis and sinusitis.

Birth order of 2 or higher, and low socio-economic status were inversely related to asthma in adolescence. Table 5 lists some examples of probability estimates of adolescent asthma, for the different early childhood recurrent wheezing patterns in case of the co-existence of other risk factors.

\section{Discussion}

In this long term follow-up study we estimated the risk of adolescent asthma by early childhood wheezing presented to the GP and the contribution to that risk when other relevant clinical factors were present, including a history of non-wheezing respiratory and allergic morbidity, a positive family history of asthma and socio-demographic factors.

This is particularly relevant for general practice, where usually wheezing is presented first and the GP has to interpret the clinical significance of the wheezing episode, deciding which therapy might be appropriate.

The prognosis of wheezing in the first three year of life was relatively good. This counts for non-recurrent wheezing with a predictive value for asthma of only $8 \%$, comparable with observations of others, ${ }^{22}$ but also for recurrent wheezing that increased the predictive value for asthma to $14 \%$. When recurrent wheezing in the first three years of life had been diagnosed as asthma, still only $19 \%$ of these children actually had asthma in adolescence. This indicates that GPs diagnosis of asthma at age $0-3$ is not accurate. Recurrent wheezing at age 4-6 years showed a stronger relation to adolescent asthma, but it had still a relatively good prognosis: only one in three had adolescent asthma. At this age, correctly diagnosing 
asthma appeared to be less problematic for the CP as still $80 \%$ of the children with asthma at the age 4-6 had asthma in adolescence.

Table 3. The association of atopic diseases, and non-wheezing upper (URM) and lower respiratory morbidity (LRM) in the first six years of life with asthma in adolescence. Unadjusted relative risks (RR) with $95 \%$ confidence intervals $(95 \% \mathrm{CI}) . n=1586$.

atopic diseases

atopic dermatitis

$\begin{array}{llcc}\text { no } & \mathrm{n}=1265 & 5 \% & 1.0 \\ \text { yes } & \mathrm{n}=321 & 10 \% & 1.9(1.3-2.8) \\ \text { gic rhinitis } & & & \\ \text { no } & \mathrm{n}=1556 & 6 \% & 1.0 \\ \text { yes } & \mathrm{n}=30 & 13 \% & 2.2(0.85-5.5)\end{array}$

episodes of non-wheezing upper respiratory

morbidity

$\geq 3$ common colds without fever

$\begin{array}{lll}\text { no } & \mathrm{n}=883 & 5 \% \\ \text { yes } & \mathrm{n}=703 & 8 \%\end{array}$

1.0

$\geq 1 \mathrm{x}$ sinusitis

no $n=1538 \quad 6 \%$

yes $n=48 \quad 21 \%$

$5 \%$

$1.5(1.0-2.1)$

$\geq 3 \mathrm{x}$ otitis media

$\begin{array}{ll}\text { no } & \mathrm{n}=1265 \\ \text { yes } & \mathrm{n}=321\end{array}$

$6 \%$

$9 \%$

episodes of non-wheezing lower respiratory

morbidity

$\geq 1 \mathrm{x}$ laryngitis/tracheitis

$\begin{array}{llcc}\text { no } & \mathrm{n}=1444 & 6 \% & 1.0 \\ \text { yes } & \mathrm{n}=142 & 12 \% & 2.0(1.2-3.2) \\ \text { pneumonia } & & & \\ \text { no } & \mathrm{n}=1428 & 6 \% & 1.0 \\ \text { yes } & \mathrm{n}=158 & 11 \% & 1.8(1.1-2.9)\end{array}$


Table 4. Adjusted* odds ratios (OR) with $95 \%$ confidence interval $(95 \% \mathrm{CI})$ of different wheezing patterns for adolescent asthma by a family history (model 1), non wheezing respiratory morbidity (model 2 ), allergic morbidity (model 3 ), all factors combined with socio-demographic variables $\dagger$ (model 4)

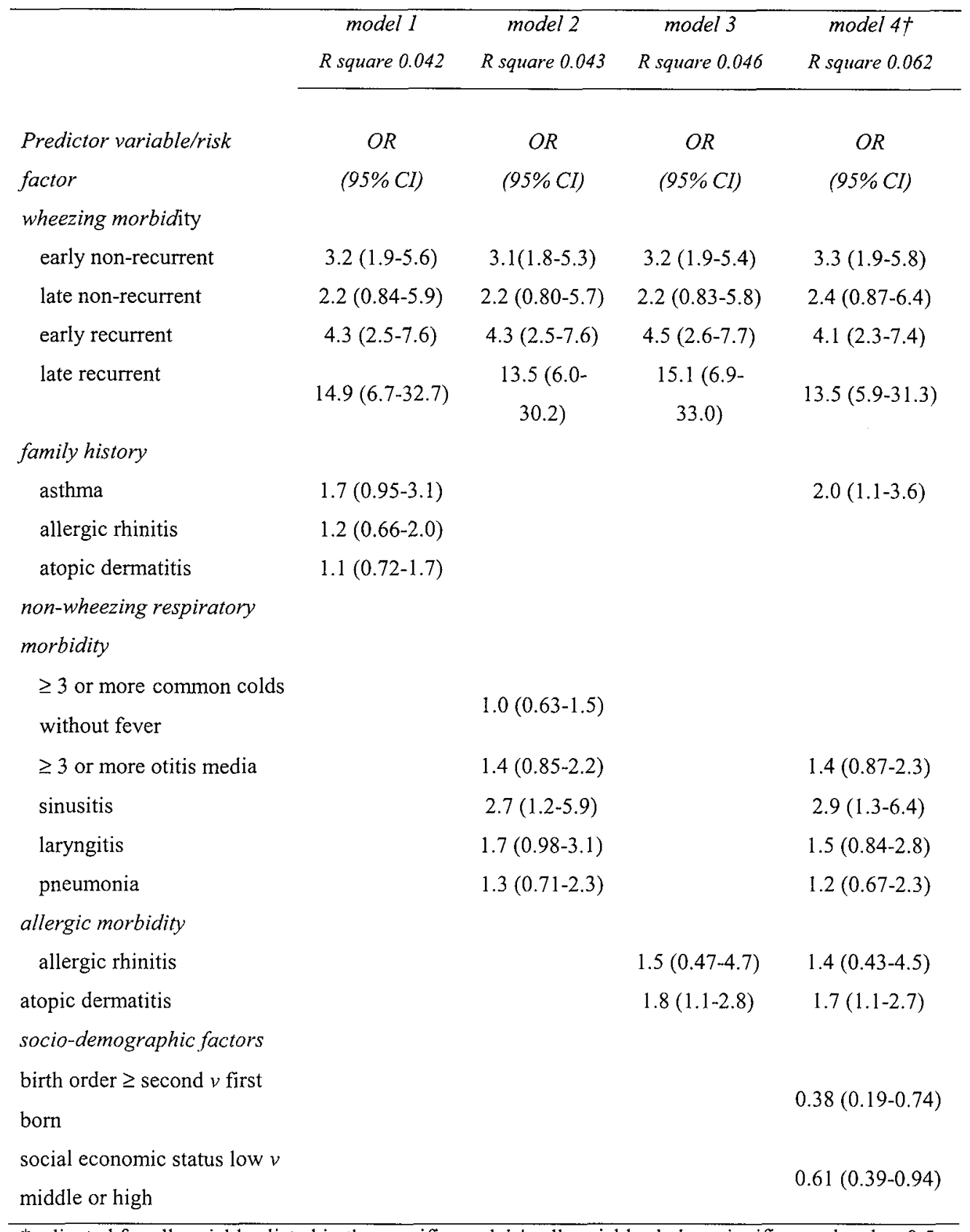

* adjusted for all variables listed in the specific model + : all variables below significance level $p=0.5$ 
Table 5. Examples of probability of adolescent asthma by non-recurrent $(1 \mathrm{x})$ and recurrent $(\geq 2 \mathrm{x})$ wheezing, age $0-3$ years in presence of some other risk indicators. $95 \%$ confidence limits between parentheses.

\begin{tabular}{|c|c|c|}
\hline & \multicolumn{2}{|c|}{ Probability of having asthma in adolescence } \\
\hline & $\begin{array}{c}\text { Non-recurrent early } \\
\text { wheezing }\end{array}$ & $\begin{array}{l}\text { Recurrent early } \\
\text { wheezing }\end{array}$ \\
\hline a priori risk for asthma & $0.10(0.05-0.15)$ & $0.12(0.07-0.19)$ \\
\hline \multicolumn{3}{|l|}{ with additionally risk indicator: } \\
\hline atopic dermatitis & $0.15(0.09-0.25)$ & $0.18(0.11-0.30)$ \\
\hline atopic dermatitis + laryngitis & $0.22(0.11-0.38)$ & $0.25(0.13-0.43)$ \\
\hline atopic dermatitis + otitis media* & $0.24(0.12-0.43)$ & $\dagger$ \\
\hline atopic dermatitis + sinusitis & $\dagger$ & $0.39(0.19-0.64)$ \\
\hline atopic dermatitis + otitis media* + familial asthma & $\dagger$ & $0.47(0.20-0.78)$ \\
\hline familial asthma & $0.17(0.09-0.30)$ & $0.20(0.11-0.35)$ \\
\hline familial asthma + atopic dermatitis & $0.26(0.14-0.44)$ & $0.31(0.17-0.48)$ \\
\hline familial asthma + laryngitis & $0.24(0.12-0.44)$ & $0.28(0.14-0.49)$ \\
\hline familial asthma + sinusitis & $0.37(0.17-0.63)$ & $\dagger$ \\
\hline familial asthma + pneumonia & $0.24(0.11-0.44)$ & $0.28(0.14-0.49)$ \\
\hline sinusitis & $0.23(0.10-0.44)$ & $\dagger$ \\
\hline laryngitis + otitis media & $0.19(0.10-0.34)$ & $0.22(0.11-0.40)$ \\
\hline otitis media* + sinusitis + pneumonia & $\dagger$ & $0.40(0.19-0.65)$ \\
\hline
\end{tabular}

$* \geq 3 \mathrm{x}$ otitis media; $\uparrow$ combinations not present in or cells too small to calculate probability

The importance of this study is that the CPs prediction of asthma might be enhanced in children who present recurrent episodes of wheezing. especially in the first three years of life by using other easy available clinical information, including personal history of atopic dermatitis, otitis media, sinusitis, laryngitis, pneumonia, and a family history for asthma. A quantification of the added probability of asthma might add considerably to the diagnostic process in primary care, as have been explored in table 5.

Ideally, medical decision-making should be based on predictive values and risk estimations of symptoms and signs for diseases. Predictive values and risk calculations are dependent of the prevalence of the symptoms and the diseases. As the prevalence of wheezing and asthma 
differ between the general population and the GP population, we can only estimate the risk of infant wheezing for adolescent asthma in the GP population if we use data on the prevalence of wheezing and asthma derived from the same population. Therefore, we have to use data on symptoms and signs presented to the CP.

We found that atopic dermatitis but not allergic rhinitis occurring in the first six years of life was significantly positively associated with adolescent asthma. Although, the occurrence of adolescent asthma in the children with allergic rhinitis was of the same magnitude compared to children with atopic dermatitis. Therefore, the lack of significance of the relation allergic rhinitis with asthma might be due to the relative infrequency of the diagnosis allergic rhinitis in the first 6 years of life.

Otitis media, sinusitis, laryngitis and pneumonia were positively associated with adolescent asthma. The relationship of otitis, sinusitis and pneumonia with asthma is also reported by others. ${ }^{24.25 .26}$ This counts also for recurrent laryngitis, especially in children with a family history of asthma. ${ }^{23}$ It might be that (viral) upper and lower respiratory tract infections further asthma, but the other way around is also possible: children with (undiagnosed) asthma might have more respiratory infections. Upper respiratory tract infections (together or when analysed according to separate diagnostic rubrics) in the first three years of life were not protective for adolescent asthma, in contradistinction with other studies ${ }^{27}$

We choose to analyse the GP diagnosis "asthma" in the first six years of life also as recurrent wheezing illness. The reason for that was that recurrent wheezing at that age is a very sensitive symptom of "asthma", but might also point to many other non-asthmatic wheezing phenotypes. $^{28}$ The lack of specificity of wheezing for asthma, especially in the first three years of life, is confirmed in this study. Unfortunately, the diagnosis asthma cannot be made more reliably at this age because the hallmark of asthma, the presence of reversible and/or variable bronchus obstruction is not to determine feasibly.

We confirmed that the incidence of wheezing illness in the first six years of life was high $(34 \%)^{2}$. The prevalence of asthma in adolescence was $6 \%$, in the same order as reported in other general practice populations. ${ }^{29,30,31}$ 
Although the prognosis of childhood wheezing and/or asthma has been studied and reviewed extensively, ${ }^{32}$ this is to our knowledge the first prospective study with a very long follow-up from birth to adolescence in an unselected primary care population. A number of studies used only high-risk populations ${ }^{33.34}$ or followed only children with wheeze. ${ }^{35}$ or sampled data retrospectively in early childhood. ${ }^{36 .} 37$ Our study confirms their findings of childhood asthma persisting into later life ${ }^{37}$ but reports lower rates of asthma, ${ }^{2 .} 22.38$ thus demonstrating the difference in prevalence based on data from a primary care population compared to the prevalence based on data from the general population.

The consistency and reliability of diagnoses is a major worry for the CMR database. ${ }^{39}$ In general, recorded diagnoses in the database appear to have a strong agreement to international diagnostic criteria. ${ }^{19.40}$ In case of asthma, a study by Kolnaar et al. ${ }^{8}$ found a good concordance between CPs diagnosis of asthma in adolescence and asthma objectified by spirometry and questionnaires. For that reason we accepted doctor-diagnosed asthma in this adolescent population as the endpoint of this study. This outcome seems to be firm. Firstly, the diagnosis adolescent asthma was standardized made according to the ICPHHC-2 defined criteria. The diagnosis asthma was only (yearly re) coded when the asthma was clinically important in terms of the need for medication, being under specialist-treatment or in case of presentation of asthmatic symptoms in the past year. Thirdly, the diagnosis asthma was (still) present at the age of average 20 years. However, we have to be aware that a diagnosis of asthma in early infancy is not completely independent of the diagnosis of asthma in adolescence. Asthmatic symptoms presented in adolescence may be more likely interpreted as asthma when a (temporarily) diagnosis of asthma was made in childhood. However this is the clinical reality we have to deal with in primary care. It includes that prevalence and incidence are made by views and perceptions of the CPs and their patients. Therefore, the data presented here cannot be used to determine the real incidences of asthma or to study the etiology of asthma. The strength and novelty of this study is that it reflects the real attitude of parents, presenting symptoms and of doctors, interpreting asthmatic symptoms, thus representing exactly real daily primary care.

An inherent problem of cohort studies is that diagnostic criteria change over time. ${ }^{19}$ This may have influenced our study as well. However, no differences in children from different 
birth years were found and for that reason we conclude that temporal effects were in this case limited.

The subjects had to be listed to general practices for at least eleven years. Consequently, a considerable number of subjects left the practice before the age of twelve years and were lost for follow-up in this study. There were, however, no indications of selection bias. Compared to the participants, those who were lost to follow-up differed only in social class. indicating higher social mobility of higher social class families, but the higher mobility of these families could not be ascribed to asthma in their children.

We showed that wheezing symptoms in children are often misinterpreted, especially in the first 3 years of life. This led to over-diagnosis of asthma: only one in five children with the diagnosis asthma at age 0-3 years had still the diagnosis asthma in adolescence. However, disappearance of asthmatic symptoms might also reflect the natural history of asthma with resolution of airway abnormality. At the same time, we found indications for under-diagnosis of asthma. Of the children with adolescent asthma, $50 \%$ had a diagnosis of at least one wheezing episodes at age 0-3, but in only the minority asthma was diagnosed. Over- and under-diagnosis of asthma may be diminished by using other relevant clinical information and a family history of asthma. For example: our findings indicate that risk on adolescent asthma in early recurrent wheezing children was about $12 \%(7-19)$ and increased to $47 \%$ (20-78) when a family history of asthma, a history of recurrent otitis media and atopic dermatitis was present. However, the calculations presented here must be interpreted with caution, as the confidence intervals for these probability results were wide and have to be confirmed first independently, in other, sufficiently large primary care populations.

Recently, Castro Rodriguez et al. presented a comparable estimation of predicting adolescent asthma. ${ }^{16}$ An important difference with our study was that their data were based on a population survey and this implies a large-scale population screening. Our predictions are based on data collected in and easily available through regular primary care for children. This substantially enhances its application in routine patient care.

In conclusion, recurrent wheezing in the first six years of life was related to asthma later in life. But in itself, the predictive value was low, which causes problems for clinical practice and will lead to under and over-diagnosis of asthma, especially in the first three years of life. 
Doctors can increase their prognostic acuity for asthma in recurrently wheezing young children -even in the absence of pulmonary function measurement- when they take into account and combine clinical information of the personal history of atopy, recurrent otitis media and sinusitis, pneumonia and laryngitis and a family history of asthma.

The data here presented could form the basis for the development of a quantified decision procedure for early childhood asthma in primary care.

Conflict of interest: None 


\section{References}

1. Kaur B, Anderson HR, Austin J, et al. Prevalence of asthma symptoms, diagnosis, and treatment in 12-14 year old children across Great Britain (international study of asthma and allergies in childhood, ISAAC UK). Bmj 1998;316(7125):118-24.

2. Martinez FD, Wright AL, Taussig LM, Holberg CJ, Halonen M, Morgan WJ. Asthma and wheezing in the first six years of life. The Group Health Medical Associates [see comments]. $N$ Engl J Med 1995;332(3):133-8.

3. Martinez FD, Helms PJ. Types of asthma and wheezing. Eur Respir J Suppl 1998;27:3s-8s.

4. Martinez FD, Morgan WJ, Wright AL, Holberg C, Taussig LM. Initial airway function is a risk factor for recurrent wheezing respiratory illnesses during the first three years of life. Group Health Medical Associates. Am Rev Respir Dis 1991;143(2):312-6.

5. Agertoft L, S P. Effects of long term treatment with an inhaled corticosteroid on growth and pulmonary fubction in asthmatic children. Respir Med 1994;88:373-81.

6. van Essen-Zandvliet EE, Hughes MD, Waalkens HJ, Duiverman EJ, Pocock SJ, Kerrebijn KF. Effects of 22 month of treatment with inhaled corticosteroids and/or beta-2-agonists on lung function, airway responsiveness, and symptoms in children with asthma. The Dutch Chronic Non-specific Lung Disease Study Group. Am Rev Respir Dis 1992;146(3):547-54.

7. Pedersen S, Hansen OR. Budenoside treatment of moderate and severe asthma in children: a dose -response study. J Allergy Clin Immunol 1995;95:29-33.

8. Kolnaar BG, van Lier A, van den Bosch WJ, et al. Asthma in adolescents and young adults: relationship with early childhood respiratory morbidity. Br J Gen Pract 1994;44(379):73-8.

9. Siersted HC, Boldsen J, Hansen HS, Mostgaard G, Hyldebrandt N. Population based study of risk factors for underdiagnosis of asthma in adolescence: Odense schoolchild study. $B M J$ 1998;316(7132):651-5.

10. Ponsonby AL, Couper D, Dwyer T, Carmichael A. Cross sectional study of the relation between sibling number and asthma, hay fever, and eczema. Arch Dis Child 1998;79(4):328-33.

11. Dold S, Wjst M, von Mutius E, Reitmeir P, Stiepel E. Genetic risk for asthma, allergic rhinitis, and atopic dermatitis. Arch Dis Child 1992;67(8):1018-22.

12. Horwood LJ, Fergusson DM, Shannon FT. Social and familial factors in the development of early childhood asthma. Pediatrics 1985;75(5):859-68.

13. Bergmann RL, Edenharter G, Bergmann $\mathrm{KE}$, et al. Atopic dermatitis in early infancy predicts allergic airway disease at 5 years. Clin Exp Allergy 1998;28(8)):965-970.

14. Lewis SA, Britton JR. Consistent effects of high socioeconomic status and low birth order, and the modifying effect of maternal smoking on the risk of allergic disease during childhood.

Respir med 1998;92(10)):1237-1244.

15. Ball TM, Castro-Rodriguez JA, Griffith KA, Holberg CJ, Martinez FD, Wright AL. Siblings, day-care attendance, and the risk of asthma and wheezing during childhood. $N$ Engl $J \mathrm{Med}$ 2000;343(8):538-43.

16. Castro-Rodriguez JA, Holberg CJ, Wright AL, Martinez FD. A clinical index to define risk of asthma in young children with recurrent wheezing. Am J Respir Crit Care Med 2000;162(4 Pt 1):1403-6.

17. Clough JB, Keeping KA, Edwards LC, Freeman WM, Warner JA, Warner JO. Can we predict which wheezy infants will continue to wheeze? Am J Respir Crit Care Med 1999;160(5 Pt 1):1473-80.

18. Knottnerus JA. Medical decision making by general practitioners and specialists. Fam Pract 1991;8(4):305-7.

19. Weel van C. Validating long-term morbidity recording. J Epidemiol Comm Health 1995;49 (suppl):29-32.

20. van Weel C, van den Bosch WJ, van den Hoogen HJ, Smits AJ. Development of respiratory illness in childhood--a longitudinal study in general practice. $J R$ Coll Gen Pract 1987;37(302):404-8.

21. WONCA CCo. An international glossary for primary care. In: Classification Committee of WONCA in collaboration with the WHO. ICHPCC-2-defined (3rd edition). London: Oxford University Press, 19831983. 
22. Park ES, Golding J, Carswell F, Stewart-Brown S. Preschool wheezing and prognosis at 10. Arch Dis Child 1986;61(7):642-6.

23. Nicolai T, Mutius EV. Risk of asthma in children with a history of croup. Acta Paediatr 1996;85(11):1295-9.

24. Clark CE, Coote JM, Silver DA, Halpin DM. Asthma after childhood pneumonia: six year follow up study. Bmj 2000;320(7248):1514-6.

25. Jones A. Asymptomatic bronchial hyperreactivity and the development of asthma and other respiratory tract illnesses in children. Thorax 1994;49(8):757-61.

26. Sherman CB, Tosteson TD, Tager IB, Speizer FE, Weiss ST. Early childhood predictors of asthma. Am J Epidemiol 1990;132(1):83-95.

27. Illi S, von Mutius E, Lau S, et al. Early childhood infectious diseases and the development of asthma up to school age: a birth cohort study. BMJ 2001;322(7283):390-395.

28. Wright AL, Taussig LM. Lessons from long-term cohort studies. Childhood asthma. Eur Respir J Suppl 1998;27:17s-22s.

29. Gellert AR, Gellert SL, Iliffe SR. Prevalence and management of asthma in a London inner city general practice. Br J Gen Pract 1990;40(334):197-201.

30. Jones A, Sykes A. The effect of symptom presentation on delay in asthma diagnosis in children in a general practice. Respir Med 1990;84(2):139-42.

31. Tse M, Cooper C, Bridges Webb C, Bauman A. Asthma in general practice. Opportunities for recognition and management. Aust Fam Physician 1993;22(5):736-41.

32. Sears MR. Evolution of asthma through childhood. Clin Exp Allergy 1998;28(Suppl 5):82-9; discussion 90-1.

33. Sporik R, Holgate ST, Cogswell JJ. Natural history of asthma in childhood--a birth cohort study. Arch Dis Child 1991;66(9):1050-3.

34. Klinnert MD, Nelson HS, Price MR, Adinoff AD, Leung DY, Mrazek DA. Onset and persistence of childhood asthma: predictors from infancy. Pediatrics 2001;108(4):E69.

35. Foucard T, Sjoberg O. A prospective 12-year follow-up study of children with wheezy bronchitis. Acta Paediatr Scand 1984;73(5):577-83.

36. Strachan DP, Butland BK, Anderson HR. Incidence and prognosis of asthma and wheezing illness from early childhood to age 33 in a national British cohort. Bmj 1996;312(7040):1195-9.

37. Jenkins MA, Hopper JL, Bowes G, Carlin JB, Flander LB, Giles GG. Factors in childhood as predictors of asthma in adult life [see comments]. BMJ 1994;309(6947):90-3.

38. Lewis S, Richards D, Bynner J, Butler N, Britton J. Prospective study of risk factors for early and persistent wheezing in childhood. Eur Respir $J$ 1995;8(3):349-56.

39. van Weel C, Smith H, Beasley JW. Family practice research networks. Experiences from 3 countries. J Fam Pract 2000;49(10):938-43.

40. de Grauw WJ, van de Lisdonk EH, van den Hoogen HJ, van Weel C. Cardiovascular morbidity and mortality in type 2 diabetic patients: a 22-year historical cohort study in Dutch general practice. Diabet Med 1995;12(2):117-22. 
Chapter 8

General discussion 
In this chapter we present an integrated view on the studies on primary prevention of asthma in this thesis:

- The answers to the research questions and the main results, presented in the Chapters 2 to 6 , are discussed and interpreted.

- Recommendations for further research on primary and secondary prevention of asthma are given.

\section{Aim and main findings}

In this thesis we reported on the effectiveness of a prenatally started health educational prevention program to reduce asthmatic morbidity in high-risk infants. The aim of the prevention program was to reduce simultaneously four main sources of indoor environmental exposures facing the newborn; allergens of house dust mite, allergens of pets (cat and dog). food allergens and prenatal and postnatal passive tobacco smoking. Measures to reduce these exposures were included in a health educational intervention program thereafter referred to as the PREVASC program) in which parents were given instructions about the prevailing way to reduce the four exposures. Trained nurses provided advice during three home visits before birth (two) and directly after birth (one). The PREVASC program is summarized in appendix 1 and an excerpt of the educational protocol in appendix 2 . The answers to the research questions mentioned in the introduction and the main findings are summarized below.

Research question 1.

Which of the preventive measures recommended in the PREVASC program have asthmatic families already taken? (Chapter 3)

Findings:

- In asthmatic families considerable room for improvement exists in the prevailing preventive measures i.e. applying anti house dust mite covers for mattresses, pillows and duvets, in applying new crib mattresses, in providing a smooth floor covering, in avoidance of cow's milk by stimulating exclusive breast-feeding, in postponing the 
first solids until after the first 6 months of life and in disposing of pets or in keeping them outside:

- In asthmatic families less room for improvements exists in the preventive measures to abstain from prenatal and postnatal smoking.

Research question 2.

What is the parental compliance with the PREVASC program? (Chapter 4)

Findings:

Asthmatic families did comply with the advice on:

- using anti-mite covers for the parental and crib mattresses, pillows and duvets;

- providing a new crib mattress:

- keeping pets outside:

- diminishing cow's milk exposure by avoiding regular formula feeding and feeding the newborn with breast milk or hypo-allergenic formula;

- postponing the first solids until after the first 6 months of life.

Asthmatic families did not comply with the advice on:

- exclusive breast-feeding their infants during the first 6 months of life;

- abstaining from maternal and partner smoking and smoking by others:

- disposing of pets;

- replacing textile-covered floors with a smooth floor covering:

- ventilating the rooms continuously and airing them daily for one hour;

- daily cleaning the floors.

Research question 3.

Are the recommended preventive measures effective in reducing house dust mite and pet allergen exposure? (Chapter 4)

Findings:

- anti-mite and parental crib mattress covers decreased house dust mite allergen and pet allergen levels in parental and crib mattress dust:

- sanitation measures in the living room decreased house dust mite allergen and cat but not dog allergen exposure in the living room. 
Research question 4.

Is the PREVASC program effective in the prevention of asthmo morbidity and atopy? (Chapter 5)

Findings:

- in the intervention group current asthma symptoms, including wheezing, shortness of breath and night-time cough at age 2 were reduced:

- the reduction in clinical symptoms was mainly confined to and more pronounced in females:

- the risk of asthmatic symptoms was independently reduced by receiving breast-feeding. low exposure to allergens of house dust mite, and increased by exposure to maternal smoking.

Research question 5.

What is the relationship between the prenatal environmental exposure and lgE at birth? (Chapter 7)

Findings:

- Increasing prenatal exposure to house dust mite allergens from living room dust and from maternal mattress was related to elevated total serum $\lg E$ at birth.

\section{The choice for a multi-facet approach}

As asthma is a multi-causal disease, in which, besides a genetic predisposition, several environmental triggers play a role, the prevention of asthma deserves also a multi-causal approach. The PREVASC intervention acknowledged this multi-causality in focussing on a simultaneously and combined reduction of four main environmental exposures (exposure to house dust mite allergens, to pet allergens, to food allergens and, to passive tobacco smoking), which are each, independently, related to asthma. Moreover, the exposures to manipulate were chosen because an efficacious reduction of the exposures appeared to be possible (Chapter 2) and, additonally, because the measures had been shown promising clinical efficacy in reducing asthmatic morbidity in those who have asthma (Chapter 2 ). Concerning environmental tobacco smoking, for ethical reasons, no trials were available that explored the clinical efficacy of avoidance of prenatal and postnatal passive smoking on asthma. Yet we included avoidance of passive smoking in the PREVASC program as its' 
negative effect on respiratory morbidity is evident. Indeed. proof of such an effect was confirmed in our study by the evidence that prenatal and postnatal maternal tobacco smoking increased the risk of asthmatic symptoms independently of the other exposures (Chapter 5). The PREVASC program aimed at reducing simultaneously the four environmental exposures, rather than to manipulate only one exposure. This was based on the assumption that influencing only one exposure may have no or little effect because other exposures could have caused symptoms to develop. In the clinical effectiveness study (Chapter 5) we found evidence that pleads in favour of the combined multi-facet approach. as the risk of asthmatic symptoms at age 2 increased by receiving no breast-feeding, high exposure to allergens of house dust mite, and exposure to maternal smoking independently of each other (Chapter 5). In addition. when exposures are simultaneously present they may interact with each other and exert a synergistic effect on the development of asthma. as have been reported. ${ }^{1-3}$ We found arguments for that as in the intervention infants exposed to dust mite levels above the median $(n=73)$ had more frequently serum specific lgE against mite at age two than infants exposed to dust mite levels below the median $(n=120)$ : $9(12.3 \%)$ and $4(3.3 \%)$ respectively, $P=0.03$. This effect was not seen in the control group. The different reaction on low mite exposure between intervention and control group suggests that being exposed to a low mite allergen level alone is not enough to prevent mite sensitization. Obviously, a simultaneous reduction of other environmental exposures together with reduction of mite levels is necessary. This also substantiates the multi-faceted approach in preventing mite sensitization.

In whole cohort analyses, exposure to pet allergens did not appear to increase the risk (Chapter 5) of asthma-like symptoms. However, in additional analysis we found indications of a synergistic effect between pet allergen exposure and other exposures on symptoms, as was reported likewise in the literature. ${ }^{1.2 .4}$ In the intervention group as well as in the control group cat allergens levels were significantly reduced, in the first group (partly or completely) as a result of the PREVASC intervention and in the latter on families' own initiative (Chapter 4 and 51. However, in the intervention group, infants with cat allergen levels below the median had less current asthmatic symptoms than those with levels above the median $113 \%$ versus $5 \%$, respectively, $P=0.05)$, whereas this was not the case in the control group (1 $3 \%$ versus $17 \%$, respectively, $P=0.41$. The fact that in the intervention group, but not in the control group. besides cat allergen exposure also other exposures were reduced significantly, 
but only in the intervention group symptoms were reduced, may indicate that simultaneous exposure reduction has a synergistic effect. From the above we suggest that a multi-facet approach is likely to have the best effect in reducing asthma-like symptoms in high-risk children. In Figure 1 the (hypothetical) additional synergistic effect on the risk of asthma when all the four exposures are present is shown.



Figure 1. The hypothetical risk of asthma in percentages in high-risk children when exposed to only one exposure (the four left bars). The right bar shows the risk of asthma when exposed to all exposures simultaneously. One might expect the risk of asthma when exposed to all the four exposures to be the sum of the individual risks: $15+10+20+15=60 \%$, but by synergistic effects the risk increased with $30 \%$ to $90 \%$ additionally.

\section{The strength of the PREVASC study}

Besides focussing on the comprehensive effect of reducing environmental exposure on asthma development, the PREVASC study had the additional advantage of being designed to fit in an implementable primary care setting, approximating daily circumstances as good as possible. In this aspect, the PREVASC study differed from all other birth cohorts. ${ }^{5-10}$ Design characteristics of the PREVASC study were: (1) the recruitment of eligible infants was performed by general practitioners and midwives during routine practice in early pregnancy. As practically all pregnant women in the Netherlands visit their general practitioner or 
midwife in early pregnancy for routine consultation, the prevention program was on offer to all families fulfilling the selection criteria. The advantage of this way of recruitment wos avoiding as much a possible selection bias; (2) the high risk. i.e. the occurrence of asthma in father, mother or siblings(s) was determined by the general practitioner. This in contrast to other intervention studies that recruited high-risk infants on the basis of self reported asthma/allergy in first-degree relatives, ${ }^{4-10}$ with the risk of classification bias or recall bias. Another advantage of the selection of high-risk unborn by the general practitioner is that it is relatively easy and cheap to perform, as general practitioners know the families in which asthma occurs; (3) the PREVASC multi-facet intervention was based on health educational approach in which specialised nurses taught parents the best way to reduce their newborns' environmental indoor exposures. For this purpose, the preventive advice was composed of measures that were easy to apply, easy to maintain and cheap, thus encouraging compliance of the parents to execute the preventive measures: (4) the intervention used in most other studies was less focussed on implementation in daily life both in recruitment and design. ${ }^{4.5}$ and in focussing on an intervention not easily applicable in daily life (for example, replacing carpets free of charge with total vinyl floor covering ${ }^{4}$ ).

Compliance with house dust mite allergen reducing measures and their effectiveness on allergen levels

We introduced the notion of "net compliance gain" defined as the net effect of the PREVASC health education program on applying the preventive measures, i.e. the percentage of intervention families that had applied the measures minus the percentage of control families that spontaneously had provided the measures already (Table). We found that in the control group parental anti-mite encasings were used in $14 \%$. This is surprisingly low when one realizes that anti-mite encasing have been advised for allergic asthma as secondary prevention in the Dutch asthma guidelines. In our cohort, in $78 \%$ of the cases at least one parent had asthma of whom more than $51 \%$ reported house dust mite allergy. which makes them candidate for the use of anti-mite encasings. This signifies a considerable under-treatment of house dust mite allergic asthma. The net compliance with the advice to use anti-mite encasings was excellent (Table). 
Table. The percentage of already present or applied preventive measures as advised in the PREVASC intervention program in the control group and the intervention group and the percentage of families in the intervention group that complied with the advised preventive measures due to the educational intervention of the PREVASC program. Significant changes in bold.

\begin{tabular}{|c|c|c|c|}
\hline$:$ & \begin{tabular}{l}
\multicolumn{1}{c}{$\%$} \\
of families in the \\
control group \\
that applied \\
listed measures
\end{tabular} & \begin{tabular}{l}
\multicolumn{1}{c}{$\%$} \\
of families in \\
intervention \\
group that \\
applied listed \\
measure
\end{tabular} & $\begin{array}{l}\quad \% \\
\text { net compliance } \\
\text { gain" by the } \\
P R E V A S C \\
\text { program }\end{array}$ \\
\hline \multicolumn{4}{|l|}{$\begin{array}{l}\text { Advised preventive measures in the } \\
P R E V A S C \text { program, concerning } \\
\text { reduction of: }\end{array}$} \\
\hline \multicolumn{4}{|l|}{ house dust mite allergens } \\
\hline providing a smooth floor-covering $\dagger$ & 57 & 52 & -5 \\
\hline daily cleaning of floor $\uparrow \dagger$ & 44 & 54 & 10 \\
\hline $\begin{array}{l}\text { using anti-mite encasing of the crib } \\
\text { mattress }\end{array}$ & 10 & 98 & 88* $^{*}$ \\
\hline $\begin{array}{l}\text { using anti- mite encasings of the } \\
\text { parental mattress }\end{array}$ & 14 & 88 & $74^{*}$ \\
\hline providing a new crib mattress & 44 & 54 & $10^{*}$ \\
\hline ventilating continuously & 56 & 61 & 5 \\
\hline airing one hour a day & 84 & 88 & 4 \\
\hline \multicolumn{4}{|l|}{ pet allergens } \\
\hline presence of cats & 15 & 13 & -2 \\
\hline disposing of them & 3 & 12 & 9 \\
\hline keeping them outside & 10 & 58 & $48^{*}$ \\
\hline presence of dogs & 23 & 23 & - \\
\hline disposing of them & 13 & 20 & 7 \\
\hline keeping them outside & 19 & 51 & $32 *$ \\
\hline \multicolumn{4}{|l|}{ food allergens } \\
\hline $\begin{array}{l}\text { feeding exclusively with breast-milk } \\
\text { during the first } 6 \text { months of life }\end{array}$ & 12 & 10 & -2 \\
\hline $\begin{array}{l}\text { breast-feeding and/or hypo-allergenic } \\
\text { formula }\end{array}$ & 22 & 55 & $3^{*}$ \\
\hline no normal formula feeding & 22 & 50 & $28^{*}$ \\
\hline $\begin{array}{l}\text { postponing solid foods until after } 6 \\
\text { months of life }\end{array}$ & 28 & 71 & $43^{*}$ \\
\hline \multicolumn{4}{|l|}{ passive smoking } \\
\hline $\begin{array}{l}\text { no prenatal and/or postnatal } \\
\text { smoking by mother }\end{array}$ & 84 & 86 & 2 \\
\hline no smoking by the partner & 86 & 87 & 1 \\
\hline no smoking by others in the house & 54 & 58 & 4 \\
\hline
\end{tabular}

$*: p<0.05$; $\dagger$ smooth floor-covering: polished wood, vinyl or tiled floor covering; $\dagger \dagger$ : daily cleaning of floors by vacuum-cleaner or damp mop. $\uparrow:$ the difference between the percentage of families in the intervention group that applied the measures minus the percentage of families in the control group that also provided the measures, reveals the percentage families that complied with the listed measure as a result of the PREVASC health education program, i.e. the net compliance gain. 
For the other sanitation measures, aiming at reduction of exposure to house dust mite allergens, including providing a smooth floor-covering. daily cleaning of floor, and ventilating continuously) there was also considerable room for improvement. The net compliance was, however, minimal or absent. Only new crib mattresses were significantly more applied in the intervention group than in the control group. Provision of a new crib mattress seems less relevant for the reduction of house dust mite exposure when at the same time anti-mite encasings are used, as the latter measure is very effective in reducing mite levels. House dust mite levels in old mattresses that were encased differed not from levels in dust from encased new mattresses (data not shown). Moreover, it is expected that the house dust mite infestation in new crib mattresses will increase with time if anti-mite encasings are not used." Accordingly, providing a new crib mattress is not necessary in our view if the existing mattress is encased with anti-mite covers.

Use of anti-mite encasings appeared to be very effective in reducing house dust mite allergens exposure as compared with the effect that sanitation measures had on the house dust mite reservoir in the living room (Chapter 4 ). We were unable to unravel which of the two sources of mite allergens exposure was the most important, as they were correlated with each other. As we reported in Chapter 6. we found arguments for starting to combat mite infestation in mattress dust. The median amount of house dust mite allergens was seven-fold higher in mattress dust than in living room dust. Apart from this, infants spend most of the time in bed in their first year of life. ${ }^{12}$ Obviously, the risk of inhaling house dust mite allergens in any dosage is higher when staying in bed than in the living room.

Despite the non-compliance with the sanitation measures for the living room, yet lower house dust mite allergens levels were found in living room dust of the intervention group compared with the control group (Chapter 4). It demonstrates that there has to be some intervention effect, possibly because it was the quality of the way sanitation measures were applied (e.g. the quality of cleaning) rather than the reported frequency of applying these measures that reduced allergens levels. Our data did not permit to elaborate this supposition. Non-compliance with "daily cleaning" and "applying a smooth floor-covering" advice. despite considerable room for improvement here (Chapter 4). was disappointing as we showed that these measures were capable of diminishing the amount of house dust mite and 
pet allergens in the living room dust (Chapter 3). We can only speculate about the reasons for the non-compliance with sanitation measures. Non-compliance with the advice to replace a textile floor covering with a smooth floor is probably due to financial reasons. However, this did not apply for measures such as cleaning, ventilating and airing. Noncompliance with the latter must be based on other obstacles, than financial.

Compliance with cat and dog allergen reducing measures and their effectiveness on allergen levels

There was less room for improvement in reduction of allergens by getting rid of pets. Two thirds of the families did not own pets (Chapter 4). Like others, ${ }^{13.14}$ we found that cat or dog owning families had much higher levels of the pet-specific allergens than those without pets (Chapter 3 and Chapter 4). Therefore, the advice to reduce exposure by removal of pets appeared to be a logical step in reducing exposure to pet allergens. ${ }^{15}$ However, only one in five pet-owning families was willing to get rid of their pet, as has also been reported by others (Chapter 4). ${ }^{15}$ This points to possibly emotional barriers. The alternative, keeping pets outside was less objected to and was also effective (Chapter 4). Additional analysis revealed that, compared to those who kept their pets inside, the level of pet specific allergen was significantly lower in living room dust as well as in parental and crib mattress dust of those who kept their pets outside (for both analyses, $P<0.001$ ), proving the efficacy of this measure. Anti-mite encasings also reduced cat and dog allergen in mattress dust, as we found a five-fold reduction of the cat and dog allergen on mattresses with anti-mite encasings, probably by the physical properties (e.g. smoothness of the surface) of such encasings (Chapter 4). ${ }^{1617}$ This stresses again the importance of using anti-mite encasings.

From the above, we may conclude that in asthma primary prevention programs the exposure to mite and pet allergens may effectively avoided by the use of encasings and also, for pet allergens by keeping pets outside. Despite a considerable room for improvement in sanitation measures (providing a smooth floor, daily cleaning of the floors, ventilation and airing) families did not comply with these measures. The sanitation measures as a whole led to lower house dust mite and pet allergen levels in the living room. 


\section{Compliance with food allergens reducing measures}

To reduce exposure to cow's milk, we advised to give exclusively breast milk during the first 6 months of life. When breast-feeding was insufficient, or substitution was wanted, the advice was to replace breast milk by hypo-allergenic bottle feeding instead of regular formula bottle-feeding. As only about one in ten mothers in asthmatic families exclusively breast-fed their infants during 6 months from birth, a considerable room for improvement (theorefically at least) in this measure seems to be present. However, the percentage of mothers that breast-fed their infant, for a longer or shorter period, exclusively or not, was the same in the intervention and control group (Table). This indicates that breast-feeding attitudes may be difficult to change. As $88 \%$ of the high-risk children received regular bottle-feeding in the first 6 months of life, a considerable room for improvement existed here (Chapter 3 ). Nevertheless, in the intervention group $50 \%$ of the infants received cow milk based regular formula for shorter or longer periods (Chapter 4). Despite the provision of subsidized hypoallergenic milk, the resulting net compliance with this advice was $28 \%$ (Table) which in our opinion is a disappointing result.

The room for improvement in postponing the first weaning solids was also considerable as only about $28 \%$ of the high-risk infants received the first solids after their sixth month of age (Chapter 3). Adherence to the advice given here was good as $71 \%$ in the special care group received the first solids not before the $6^{\text {th }}$ months of life (Chapter 4). So, the net gain of the intervention advice was $43 \%$ (Table).

\section{Compliance with tobacco smoke reducing measures}

In asthmatic families, $20 \%$ of the infants were exposed to maternal passive smoking pre- and postnatally and in $25 \%$ of the cases to passive smoke from the partner. One of three children was regularly exposed to passive tobacco smoke from other persons than their parents, which is similar to figures given by others. ${ }^{18.19}$ For reduction of passive smoking the protocol and brochures of the Minimal Intervention Strategy (MIS). provided by the Dutch Asthma Foundation, were used (Chapter 4$).{ }^{20}$ We found, however, no compliance with quitting prenatal and postnatal smoking. Although significantly more mothers in the intervention group reported abstaining from smoking after childbirth than mothers in the control group (Chapter 4), we suppose that smoking mothers in the intervention group gave 
socially desirable answers to questions addressing this issue. It is clear that those parents who continued smoking while expecting or having a baby belong to the hard-core smokers, who ore not inclined to quit smoking. It underlines the addictive nature of tobacco smoking. which may only be influenced by tailor-made interventions.

It is important to trace existing obstacles to the above discussed non-compliance in the intervention group and to remove them whenever possible. Full compliance is likely to be attained when preventive measures are embedded in a tailor-made personal intervention strategy. This may improve the clinical effectiveness of the prevention and deserves further study.

\section{The effect of the PREVASC prevention program on asthmatic and atopic morbidity}

Despite the moderate compliance with some preventive measures, the multi-faceted intervention of the PREVASC study was able to decrease to some extent the risk of asthmalike symptoms (wheezing, shortness of breath and night-time cough) at the end of the second year of life (Chapter 5). The decrease was more pronounced in female than male children. We did not find an effect on total and specific lgE, against house dust mite, cat and dog allergens at age 2 .

One of the issues that have to be addressed is how much reduction in mite and pet allergens is needed to prevent asthma. In general, in our population of asthmatic families, we found low pre-intervention levels of mite and pet allergens at baseline, probably as a result of (already) successful efforts by the families to achieve a low allergen environment, as also reported elsewhere. ${ }^{18}$ In spite of these pre-existent low mite levels, infants with mite allergens levels below the median had nevertheless a reduced risk of respiratory symptoms at age 2 when compared to infants exposed to levels above the median (Chapter 5). This indicates that in prevention of asthmatic morbidity, further reduction of already low house dust mite allergen levels in asthmatic families is still important. For pet allergens, we cannot conclude this on basis of our data.

In Chapter 6, we found that even in a prenatal environment with relatively low house dust mite levels the risk of an elevated total serum gE clearly increased (dose-response curve) with rising house dust mite allergen levels. The finding confirms results of studies establishing 
the capability of the foetal immune system to respond in utero, probably before week 20 of pregnancy. ${ }^{21}$ If elevated total serum lgE at birth appears to be a risk factor for asthma in later life, as is reported in studies. ${ }^{22.23}$ avoidance of allergen exposure starting in early pregnancy may result in a better clinical effect than starting from birth as was aimed at in the PREVASC program. This should be subject of future research.

An intriguing finding of the PREVASC study was what we found regarding the effect of the intervention in males and females. For most outcomes, the effect of the intervention was mainly restricted to female infants (Chapter 5). How can we explain the gender-specific effects of the intervention program? In general, gender differences in airway physiology and pathology, starting in the intrauterine period are well known and might be under hormonal control. ${ }^{24.28}$ In addition, the impact of environmental exposure to symptoms has been reported to differ between the sexes. ${ }^{1.2}$ For example, when exposed to passive tobacco smoking in utero, the lung function of boys with asthma is lower than of girls with asthma, ${ }^{29}$ and pet-owning females were found to be more susceptible than men for asthma when they also smoke. ${ }^{2}$ Others reported that the lung function in females sensitized by cat and pollen allergens was more affected than in males.' From these reports one might speculate that the gender-specific effects of the intervention we found, had been caused by a gender-specific reaction on reduction to the exposures. If our finding is right, the ultimate consequence could be that preventive measures in early life are only efficacious in girls and not in boys. However, it is far too early to draw such a conclusion on the basis of our data and further study is required. It would be of interest if all ongoing cohort studies included information specifying a gender whenever it occurs.

The finding of the positive effects of the PREVASC prevention program on asthmatic symptoms and its gender-specific effects cannot be used in daily practice at this moment. It is important to follow the cohort further and investigate the effect of the intervention on asthmatic morbidity at age 6 , when the presence of asthma can be objectified.

\section{Methodological considerations of the PREVASC study}

Some methodological issues and possible limitations of the PREVASC study should be considered including the randomisation procedure, the prevention of contamination, the 
occurrence of bias, the external validity, the high-risk identification and the measurement of the exposures. These issues are discussed below, successively.

\section{Randomisation}

For the compliance study (chapter 4) and the effectiveness study (chapter 5) families were allocated to the intervention and control group by means of pre-randomisation in clusters. The clusters were based on the ZIP-code of domicile of the participating families in combination with the location of the general practice attended. The pre-randomisation in clusters was done for three reasons. First, as some parts of the PREVASC intervention, e.g. promoting breast-feeding, re-housing pets or abstinence from tobacco smoking could not be executed in a (double) blinded fashion. In this case. pre-randomisation. ${ }^{30}$ in which the control group is not informed about the intervention care in the intervention arm of the study (when asked for informed consentl, is the only reliable way to avoid contamination of the intervention and of the control group. Further, pre-randomisation in clusters was done to prevent spontaneously compliant behaviour in the control group by unwanted exchange of information on the preventive measures between the groups. This might have happened if (pregnant) mothers in the control group had met mothers in the intervention group, for example when visiting the same general practice or midwife. Lastly, by cluster randomisation we prevented possible confounding and treatment errors by participating general practitioners treating patients from both groups.

\section{Avoiding spontaneous preventive behaviour in the control group}

Besides avoiding spontaneous preventive behaviour in the control group by means of cluster-randomisation. spontaneous changes in preventive behaviour could be induced by questionnaires (Hawthorne effect ${ }^{31}$ ). For example, questionnaires administered to patients in the control group containing questions on already applied house dust mite avoidance measures could have led to unwanted changes in avoidance behaviour. Therefore special attention was paid to the timing of administering the questionnaires. Questionnaires on preand postnatal smoking and on self-applied allergens reducing measures in the control group were administered at age 1 of the infant. Questions on feeding patterns in the first 6 months of life were administered after the $6^{\text {th }}$ month of life. In addition, care was taken not to publish the contents of the intervention program in the media during the PREVASC project. We 
found no indications for changing behaviour in the control group due to contamination. although cat allergens were lower after one year. We do not have an explanation for that, other than that the advice on pet allergen exposure is a common feature in health educational instructions to young mothers and patients with asthma (Chapter 4).

\section{Reporting bias}

As a consequence of the allocation to the intervention group or control group by prerandomisation, bias might have occurred, as parents and general practitioners were not blinded for the intervention. This could have influenced their symptom reporting or practitioners' diagnostic labeling. However, an effect on morbidity in the intervention group seems unlikely, as we cannot explain why parents and doctors randomized to the intervention group reported less morbidity in female than in male children (chapter 5 ).

\section{External validity}

In chapter 3, we reported that smoking mothers and low educated mothers were underrepresented in the study. The under-representation of smoking mothers is in our opinion inevitably in intervention studies that focus on reduction of passive smoking. It is plausible that some women, who continue to smoke when pregnant, belong to the hard core of the smokers, are unable to quit smoking and for that reason refuse to participate in the study. However, the fact that smoking and lower educated mothers were under-represented in the PREVASC study has, in our opinion, no consequences for the efficiency of the intervention, once the intervention is implemented in primary care. It is the reality of everyday practice that not all patients will be compliant with the therapies proposed by their physician. It is logical to suppose that this also hold for the preventive PREVASC therapy after implementation in primary care. The therapy would be offered then to the same population and proposed by the same general practitioner as was done in the research setting of the PREVASC study.

Apart from the fact that there will always be patients who refuse to follow a therapeutic proposal, we believe that patients are more willing to cooperate when they are informed by their general practitioner of the underlying reasons and the effectiveness of the intervention, than when invited and informed by research units or public health services as is suggested by some reports. ${ }^{32.33}$ 
A further point that must be discussed is that children in the control group seemed to be exposed to lower baseline mite level than those in the intervention group. The most probable explanation is that the higher baseline mite levels in the intervention group reflects the seasonal influence on mite infestation, as more intervention families than control families enrolled in the autumn and winter, $182(82 \%)$ versus $152(69 \%) . P=0.001$. An alternative explanation might be that the difference was caused by a more stringent allergen reducing life style of the control group. However, this would diminish the baseline contrast between the intervention and control group regarding mite allergen exposure and would lead to underestimation of the clinical effect of the anti-mite measures.

The identification of the high-risk infants

In the PREVASC study, we selected the high-risk infants prenatally. The identification of the high-risk cases in the PREVASC study was performed by the general practitioner on the basis of his/her knowledge about the presence of asthmo in the father, the mother or the sibling(s). We assumed on the basis of a pilot study in three practices that most pregnant women (80$90 \%$ ) consulted their general practitioner during pregnancy (data not shown), thereby offering the opportunity to identify most high-risk infants during pregnancy. In the PREVASC study we did not aim at gaining insight into the total number of pregnant women whose unborn were at high risk for asthma in the participating general practices. Accordingly, we did not know the proportion of high-risk unborns, not identified by their general practitioner. These data are necessary to judge the cost-effectiveness of the selection instrument and studies have been designed to obtain these data.

We choose to study the effect of the intervention in high-risk infants, as asthma is much more prevalent and often more serious in high-risk children than in children not at high risk. ${ }^{34,35}$ However ideally, the choice between a high-risk and a whole population approach has to be made by comparing the effectiveness and health economic effects of the intervention in these populations. Such comparisons are not available to date.

We used the presence of a positive family history of asthma to establish the high risk. A positive family history is at the moment the best proxy measure to determine the genetic predisposition of asthma prenatally. However, it cannot be ruled out that some high-risk infants have not been identified. This might be the case when a first-degree relative has an asthmatic phenotype that has not (yet) manifested itself in clinical symptoms, for example. 
when their immune mechanism is not exposed to environmental triggers or has developed tolerance. However, this could only be tackled by genetic screening of the first-degree relative. It is currently not possible to identify high-risk cases on the basis of genetic features.

\section{Measurement of exposures}

Before the clinical effect of environmental manipulation can be judged, one hast to know whether the preventive measures to reduce indoor environmental exposure did what they were supposed to do, namely reducing exposure. Ideally, the change in exposure has to be assessed using valid biomarkers of the specific exposure. We measured the effect of the sanitation advice to reduce mite, cat and dog allergens by measuring Der $p$ 1. Fel $d 1$ and Can $f 1$, respectively, in settled dust samples of mattresses and living room dust (chapter 4 . chapter 5). One could argue that this method does not necessarily reflect the amount of allergens, really inhaled by the mother (chapter 4, chapter 5) or unborn (chapter 6). However, mite and dog allergen levels in settled dust correlate well with airborne mite and dog allergen levels, respectively. ${ }^{36}$ This holds also for the cat allergen in houses without a cat. However, in houses with cats, measurement of cat allergens should be preferably done in the airborne reservoir. ${ }^{36}$

Exposure to food allergens and smoke was assessed through parental reporting (chapter 4 , chapter 5), with recall bias or reporting bias as a possible result. The alternative for measuring tobacco smoke exposure, infants' serum or urinary cotinine may be used. However, this is not feasible for measuring the reduction in prenatal passive smoking. Moreover, questionnaire based data are likely to be reasonably valid for nicotine exposure. ${ }^{37}$ For exposure to food allergens, a valid biomarker is not available. By using weekly diaries, recall bias was minimised.

\section{Recommendations and further research}

The PREVASC study raises new research questions. Future research is recommended on the following topics:

1. The effect of the PREVASC prevention program on asthma and atopic morbidity at age 6.

2. The reasons, obstacles and determinants for non-compliance with some measures of the PREVASC program. 
3. The additional value of an improved tailor made prevention program and will such a program turn out to be clinically more effective than the original PREVASC program.

4. The sensitivity and specificity of the identification of the high-risk unborn in general practice.

5. The health economic evaluation of the PREVASC prevention program.

6. The additional value of an intervention to avoid mite and pet allergen exposure in early pregnancy (started before the $20^{\text {th }}$ week) versus started at birth.

7. The most important source of house dust mite allergen infestation in the house to combat: on the living room floor or on the mattress.

8. (Relanalyses of data of published intervention studies stratified for gender.

With regard to secondary prevention further research should directed towards:

1. The development of a quantified decision procedure for the diagnosis of asthma in (recurrent) wheezing infants in general practice combining frequencies and age of onset of the wheezing illness with registered upper and lower respiratory, and/or atopic morbidity, with familial atopic symptoms, and with socio-demographic characteristics.

2. The additional contribution to the risk of asthma in (recurrent) wheezing infants of elevated levels of total and specific lgE for food allergens and allergens of house dust mite and pets and of eosinophilic cationic protein in serum or urine (ECP and EPX respectively).

3. The additional contribution to the risk on asthma in (recurrent) wheezing children of a positive response to a trial with a beta-agonist. 
1. Sunyer J, Soriano J, Anto JM, et al. Sensitization to individual allergens as risk factors for lower FEV1 in young adults. European Community Respiratory Health Survey. Int J Epidemiol 2000; 29:125-30.

2. Chen $Y$, Dales R, Tang M, Krewski D. Sex-related interactive effect of smoking and household pets on asthma incidence. Eur Respir J 2002; 20:1162-6.

3. Kulig M, Luck W, Lau S, et al. Effect of pre- and postnatal tobacco smoke exposure on specific sensitization to food and inhalant allergens during the first 3 years of life. Allergy 1999; 54:220-228.

4. Custovic A, Simpson BM, Simpson A, Kissen P, Woodcock A. Effect of environmental manipulation in pregnancy and early life on respiratory symptoms and atopy during first year of life: a randomised trial. Lancet 2001; 358:188-93.

5. Koopman LP, van Strien RT, Kerkhof M, et al. Placebo-controlled trial of house dust miteimpermeable mattress covers: effect on symptoms in early childhood. Am J Respir Crit Care Med 2002; 166:307-13.

6. Simpson BM, Custovic A, Simpson A, et al. NAC Manchester Asthma and Allergy Study (NACMAAS): risk factors for asthma and allergic disorders in adults. Clin Exp Allergy 2001; 31:391-9.

7. Chan-Yeung M, Manfreda J, Dimich-Ward H, Ferguson A, Watson W, Becker A. A randomized controlled study on the effectiveness of a multifaceted intervention program in the primary prevention of asthma in high-risk infants. Arch Pediatr Adolesc Med 2000; 154:65763.

8. Tsitoura S, Nestoridou K, Botis P, et al. Randomized trial to prevent sensitization to mite allergens in toddlers and preschoolers by allergen reduction and education: one-year results. Arch Pediatr Adolesc Med 2002; 156:1021-7.

9. Mihrshahi S, Peat JK, Webb K, et al. The childhood asthma prevention study (CAPS): design and research protocol of a randomized trial for the primary prevention of asthma. Control Clin Trials $2001 ; 22: 333-54$.

10. Hide DW, Matthews S, Tariq S, Arshad SH. Allergen avoidance in infancy and allergy at 4 years of age [see comments]. Allergy 1996; 51:89-93.

11. Custovic A, Simpson BM, Simpson A, et al. Manchester Asthma and Allergy Study: lowallergen environment can be achieved and maintained during pregnancy and in early life. $J$ Allergy Clin Immunol 2000; 105:252-8.

12. Mahmic A, Tovey ER, Molloy CA, Young L. House dust mite allergen exposure in infancy. Clin Exp Allergy 1998; 28:1487-92.

13. Woodcock A, Addo-Yobo EO, Taggart SC, Craven M, Custovic A. Pet allergen levels in homes in Ghana and the United Kingdom. J Allergy Clin Immunol 2001; 108:463-5.

14. Parvaneh S, Kronqvist M, Johansson E, van Hage Hamsten M. Exposure to an abundance of cat (Fel d 1) and dog (Can f 1) allergens in Swedish farming households. Allergy 1999; 54:229-234.

15. Moira CY, Ferguson A, Dimich-Ward H, Watson W, Manfreda J, Becker A. Effectiveness of and compliance to intervention measures in reducing house dust and cat allergen levels. Ann Allergy Asthma Immunol 2002; 88:52-8.

16. Colloff MJ, Ayres $\mathbf{J}$, Carswell F, et al. The control of allergens of dust mites and domestic pets: a position paper. Clin Exp Allergy 1992; 22 Suppl 2:1-28.

17. Carswell F, Oliver J, Weeks J. Do mite avoidance measures affect mite and cat airborne allergens? Clin Exp Allergy 1999; 29:193-200.

18. Wijga A, Smit HA, Brunekreef B, et al. Are children at high familial risk of developing allergy born into a low risk environment? The PIAMA Birth Cohort Study. Prevention and Incidence of Asthma and Mite Allergy. Clin Exp Allergy 2001; 31:576-81.

19. Ownby DR, Johnson CC, Peterson EL. Passive cigarette smoke exposure of infants: importance of nonparental sources. Arch Pediatr Adolesc Med 2000; 154:1237-41. 
20. Pieterse ME, Seydel ER, DeVries H, Mudde AN, Kok GJ. Effectiveness of a minimal contact smoking cessation program for Dutch general practitioners: a randomized controlled trial. Prev Med 2001; 32:182-90.

21. Szepfalusi Z, Pichler J, Elsasser S, et al. Transplacental priming of the human immune system with environmental allergens can occur early in gestation. J Allergy Clin Immunol 2000; 106:530-6.

22. Sears MR, Burrows B, Flannery EM, Herbison GP, Holdaway MD. Atopy in childhood. I. Gender and allergen related risks for development of hay fever and asthma. Clin Exp Allergy 1993; 23:941-8.

23. Sporik R, Holgate ST, Platts Mills TA, Cogswell JJ. Exposure to house-dust mite allergen (Der $\mathrm{p} \mathrm{I}$ ) and the development of asthma in childhood. A prospective study [see comments]. $\mathrm{N}$ Engl J Med 1990; 323:502-7.

24. Becklake MR, Kauffmann F. Gender differences in airway behaviour over the human life span [see comments]. Thorax 1999; 54:1119-38.

25. Davis JB, Bulpitt CJ. Atopy and wheeze in children according to parental atopy and family size. Thorax 1981; 36:185-9.

26. Arshad SH, Stevens M, Hide DW. The effect of genetic and environmental factors on the prevalence of allergic disorders at the age of two years. Clin Exp Allergy 1993; 23:504-11.

27. Sears MR, Holdaway MD, Flannery EM, Herbison GP, Silva PA. Parental and neonatal risk factors for atopy, airway hyper-responsiveness, and asthma. Arch Dis Child 1996; 75:392-8.

28. Young S, Amott J, O'Keeffe PT, Le Souef PN, Landau LI. The association between early life lung function and wheezing during the first 2 yrs of life. Eur Respir J 2000; 15:151-7.

29. Li YF, Gilliland FD, Berhane K, et al. Effects of in utero and environmental tobacco smoke exposure on lung function in boys and girls with and without asthma. Am J Respir Crit Care Med 2000; 162:2097-104.

30. Zelen M. A new design for randomized clinical trials. N Engl J Med 1979; 300:1242-5.

31. Lied TR, Kazandjian VA. A Hawthorne strategy: implications for performance measurement and improvement. Clin Perform Qual Health Care 1998; 6:201-4.

32. Smith WC, Crombie IK, Campion PD, Knox JD. Comparison of response rates to a postal questionnaire from a general practice and a research unit. Br Med J (Clin Res Ed) 1985; 291:1483-5.

33. Jacoby A. Possible factors affecting response to postal questionnaires: findings from a study of general practitioner services. J Public Health Med 1990; 12:131-5.

34. Sarafino EP, Goldfedder J. Genetic factors in the presence, severity, and triggers of asthma. Arch Dis Child 1995; 73:112-6.

35. Gaspar AP, Morais-Almeida MA, Pires GC, et al. Risk factors for asthma admissions in children. Allergy Asthma Proc 2002; 23:295-301.

36. Custovic A, Simpson B, Simpson A, Hallam C, Craven M, Woodcock A. Relationship between mite, cat, and dog allergens in reservoir dust and ambient air. Allergy 1999; 54:6126.

37. Brunekreef B, Leaderer BP, van Strien R, et al. Using nicotine measurements and parental reports to assess indoor air: the PIAMA birth cohort study. Prevention and Incidence of Asthma and Mite Allergy. Epidemiology 2000; 11:350-2. 


\section{Chapter 9}

\section{Summary}

"I didn't know that. Can you provide me with the evidence for what you just said?"

From: Evidence based medicine in de praktijk (Practicing evidence based medicine), Press: Boom Amsterdam, 2001, page 16, quotation David Sacket) 
This thesis is a study of primary and secondary prevention of asthma in children.

To investigate primary prevention, we designed the PREVASC (Prevention of Asthma in Children) study, a randomised intervention study of a birth cohort of 476 infants at high-risk of asthma, recruited from 1997 through 2000 and followed during 2 years.

The study on secondary prevention states the results of a historical birth cohort study of 1586 children, followed for at least 12 years. For this study, we used data of the Continuous Morbidity Registration (CMR) of the Department of General Practice of the University of Nijmegen.

Chapter 1 describes the background of this thesis. The definitions of primary and secondary prevention are discussed and in addition the importance of primary and secondary prevention of asthma in childhood.

We described three possible underlying mechanisms, which may explain the increasing prevalence of asthma and allergy: the hygiene, the diefary, and the "increased exposure" hypothesis. The intervention of the PREVASC study is based on the last hypothesis and aims at preventing asthma by advising measures on a (combined) reduction of the exposure of the baby to four environmental exposures: house dust mite allergens, cat and dog allergens, food allergens and, parental prenatal and postnatal smoking. The measures have been advised by especially trained nurses during three home visits. The intervention is hereafter referred to as the PREVASC program.

In this chapter, the research questions on primary and secondary prevention studied in the thesis were formulated and an outline of the studies to answer these questions were given.

The research questions on primary prevention of asthma addressed the room for improvement in and the compliance with the measures advised, the effectiveness in reducing exposure, the clinical effectiveness of the PREVASC program and the timing of the prevention:

- Which measures in the PREVASC program have asthmatic families already taken? (Chapter 3)

- What is the parental compliance with the PREVASC program? (Chapter 4) 
- Are the recommended preventive measures regarding house dust mite and pet allergens effective in reducing environmental exposure to these allergens? (Chapter 4)

- Is the PREVASC program effective in prevention of asthma in primary care? (Chapter 5)

- What is the relationship between the prenatal environmental exposure and $\lg E$ at birth? (Chapter 6)

The research questions on secondary prevention of asthma were

- What in early wheezing children is the risk of asthma? (Chapter 7)

- What in early wheezing children is the additional diagnostic value of familial occurrence of atopic diseases for asthma? (Chapter 7)

- What in early wheezing children is the additional diagnostic value of nonwheezing respiratory and atopic morbidity for asthma? (Chapter 7)

Chapter 2 can be considered as the basic study on whose data the PREVASC study was designed and the prevention program was composed. The conditions on which a feasible primary prevention of asthma by means of reduction of environmental exposures are discussed. The following measures were included:

1. Reduction of mite allergens from birth through at least the first two years of life by having a smooth floor covering in living room, bedroom and nursery; thorough cleaning floors: washing bed-clothes at 60 degrees Celsius; use of house dust mite impermeable covers for the parental and crib mattresses, quilts, pillows and infants' sleeping bags: provision of new crib mattresses; and, ventilating continuously and daily airing for one hour.

2. Reduction of allergens of pets from birth through at least the first two years of life by not keeping pets and, in case of pet owning by re-housing them and when this was objected to by regular washing them and keeping them outside the house from at least 3 months before infant's birth.

3. Reduction of food allergens for at least the first six months of life by exclusive breastfeeding of the infant and, when not possible or when breast-feeding was insufficiently by using hypoallergenic formula instead of regular formula. and by postponing the intake of the first solid food until the child is six months old. 
4. The avoidance of prenatal and postnatal passive smoking.

The design of PREVASC was outlined and the methodological characteristics were described. These were:

recruitment of pregnant mothers was done by the general practitioner or midwife:

- unborns were eligible when they hod at least a mother or father or sibling with asthma (high risk was determined by the general practitioner):

- participating unborns were allocated to the intervention and control group by pre-randomisation in sub-regional clusters:

porents in the intervention group were instructed during three home visits on measures included in the PREVASC intervention program by specially trained nurses:

- $\quad$ the control group received the usual care and remained unaware of the infervention:

- clinical outcomes were asthma-like symptoms. recorded by the general practitioner and parents and, total and specific $\lg E$ at age two:

- the degree of compliance with the various measures applied by the parents, was established by questionnaires:

- for anti house dust mite and pet allergen measures. the compliance in the intervention group and the spontaneous compliance in the control group was checked by repeated measurements of these allergen levels in dust samples of the living room and mattress.

Chapter 3 deals with the research question as to what extent measures in the PREVASC program had already been taken by asthmatic families.

The research carried out enabled us to gain insight into the existing room for improvement in the advised preventive PREVASC measures. This was important to assess the effectiveness and efficiency of the PREVASC program.

In a descriptive follow-up study of 211 asthmatic expectant families, recruited in primory care, the frequencies of applied preventive measures were analysed. Determinants of 
preventive behaviour were equally analysed. $36 \%$ of the families had smooth floor covering and $27 \%$ cleaned the house daily. Parental and infants' anti house dust mite encasings were used in only $13 \%$ and $9 \%$, respectively. $66 \%$ had no no pets. High-risk infants were not exclusively breast-fed during the first 6 months of life in $88 \%$ and in $87 \%$ they received cow's milk based regular formula. In only $28 \%$ the intake of first solid foods was postponed. Mothers did not smoke prenatally in $89 \%$, and postnatally in $85 \%$, and the partner did not in $76 \%$. Cenerally, measures were not applied as a result of specific professional advice, but probably on parents' own initiative.

The conclusion was that there was much room for improvement in allergen avoidance behaviour of asthmatic families. Most room for improvement existed in reduction of house dust mite allergens by use of anti house dust mite encasings (for parents and infants), daily cleaning and by providing a smooth floor covering, and in the reduction of exposure to food allergens by breast-feeding for 6 months and/or feeding the infant with hypoallergenic formula and by postponing the intake of the first solids until the sixth month after birth.

A modest room for improvement existed in the reduction of exposure to pet allergens by getting rid of pets or keeping them outside the house as well as in the reduction of nonparental passive smoking.

The least room for improvement was present in reduction of passive smoking by parents.

Chapter 4 answers the research question on parental compliance with the PREVASC intervention program. In addition, the effectiveness of the recommended preventive measures in reducing environmental exposure was assessed. Insight into these issues are important as a low compliance with the advised preventive measures and/or a low effectiveness in reducing exposure by the preventive measures will also diminish the (supposed) effect of the preventive measures on clinical symptoms. We assessed compliance with and effectiveness (in reducing exposures) of the PREVASC program in a birth cohort study in which 222 asthmatic families were prenatally randomised to an intervention group and 221 asthmatic families to a control group. Families in the intervention group were instructed on the measures in the PREVASC program during three home visits by specialised nurses. The control group received the usual care. 
The instruction was successful as the intervention group differed significantly $(P<0.01)$ from the control group in: use of anti-mite encasings (parental: $88 \%$ versus 14\%: baby: $98 \%$ versus 10\%): keeping pets outside (51\% versus 19\%): combined breast-feeding and hypoallergenic formula feeding $(55 \%$ versus $22 \%$ ). postponement of the first solids intake until the infants were six month old $171 \%$ versus $28 \%$ ); maternal postnatal smoking $152 \%$ versus $28 \%$ ).

Little or no compliance was found with other sanitary measures (cleaning habits, applying smooth floor covering, ventilation/airing), with pet removal, with exclusive breast-feeding and, with abstaining from prenatal smoking and partner smoking.

In spite of the already pre-existing low allergen levels, in crib and parental mattress dust the anti-mite measures led to a strong reduction of exposure to mite, cat and dog allergens and in living room dust to mite and dog allergens, but not to cat allergens.

Chapter 5 forms the main study of this thesis and reported the results of the PREVASC randomized intervention trial on clinical symptoms. Data on asthma-like symptoms and atopic morbidity were compared between the intervention group (222 infants) and the control 1221 infants). In a subanalysis, all comparisons between the intervention group and the control group were analysed, separately, for boys and girls.

Current asthma-like symptoms, at the end of second year of life occurred less frequently in children in the intervention group than in the control group: wheezing (odds ratio (OR) 0.73 ; $95 \% \mathrm{Cl}, 0.56-0.96)$. shortness of breath (OR 0.76: $95 \% \mathrm{Cl}, 0.61-0.96)$ and night-time cough (OR 0.72: $95 \% \mathrm{Cl}, 0.55-0.95)$. However, in subanalyses only the females showed significantly fewer symptoms, suggesting that the effect of the intervention was modified by gender.

Looking at the whole period of the first two years of life, we found asthma-like symptoms to be equally distributed between the intervention group and control group. However, we found again that among females asthma-like symptoms occurred significantly less in the intervention group. whereas this was not the case within the male group. 
Asthma (diagnosed by the general practitioner) was diminished, but not significantly, in the intervention group. We found here also indications for gender influences as the decrease became significant in the female intervention group but not in the male intervention group. No significant differences in total and specific lgE were found between the groups.

In whole group analysis (so, the intervention and the control group together) the risk of asthmatic symptoms by exposure to mite, cat and dog. and food allergens and passive smoking was determined. It revealed that being (partially) breast-fed, not being exposed to maternal smoking and not being exposed to high mite levels, significantly decreased the risk of asthmatic symptoms independently of each other. The odds ratios $195 \%$ confidence interval) were $0.42(0.18-0.97), 0.38(0.14-1.0), 0.30(0.12-0.71)$, respectively.

We concluded that the PREVASC program, aiming at reduction of mite, pet and food allergens and passive smoking successfully, diminished asthma-like symptoms in high-risk children at age two. We found indications that the effect of the intervention was modified by gender, as the intervention effects were mainly confined to and more pronounced in female infants.

The moderate positive effects we found cannot be used in clinical practice at this moment. Whether the intervention is indeed successful in preventing asthma and what may be the significance of the gender-specific effects can only be established when the children are six years of age, i.e. the age at which the presence or absence of asthma can be objectified.

The study presented in chapter 6 provides a contribution to the ongoing discussion on the most optimal timing of the intervention. Should a low environmental allergen exposure already be pursuit during pregnancy. when the immune system is capable of reacting on antigens reaching the foetal environment, or start immediately after birth?

A study was designed and set up to examine the relationship between prenatal exposure to mite, cat and dog allergens and total lgE at birth in newborns at high risk of asthma. In the homes of 221 newborns with at least one first-degree relative with asthma, concentrations (ng/g dust) of allergens of house dust mite, cat and dog were measured at the $4^{\text {th }}-6^{\text {th }}$ month of pregnancy in dust samples from the maternal mattresses and the living rooms. 
At day 3-5 after birth, total IgE was measured in capillary heel blood. Prenatal passive smoking, maternal and paternal mite allergy, gender, age of the mother, duration of pregnancy, and (breast-) feeding practice in the first week of life were taken into account.

It was reported that $24 \%$ of the high-risk newborns had an elevated total serum lgE, using a cut-off value of $0.5 \mathrm{IU} / \mathrm{ml}$. The amount of house dust mite allergens, but not of cat or dog allergens from living room dust and from maternal mattress dust was significantly higher in newborns with elevated $\mathrm{gE}$ compared with newborns with non-elevated lgE. The relation between the risk of elevated $\mathrm{g} E$ and increasing house dust mite exposure revealed a clear dose-response curve.

We concluded that in high-risk newborns, prenatal exposure to house dust mite allergens. but not to cat and dog allergens in dust of the living room and of the maternal mattress was related to total serum $\mathrm{g} E$ at birth. Studies should be setup comparing the clinical effect of house dust mite reducing measures started in early pregnancy with the clinical effect of these measures started from birth.

In chapter 7. we presented the studies on secondary prevention. Early and correctly diagnosing asthma in wheezing children is essential for early treatment and prevention of under- or over-treatment. It was studied whether combining frequency and age of onset of wheezing illness with respiratory and atopic morbidity at age 0-6 and socio-demographic parameters might be helpful for the general practitioner to correctly diagnose asthma as early as possible.

We performed a birth cohort study, using data from the Continuous Morbidity Registration (CMR) of the Department of Ceneral Practice of the Radboud University Nijmegen. Of the 2475 children, 1586 (64\%) children could be followed at least 12 years from birth with a mean follow-up of 20 years (SD 4.8). The outcome was adolescent asthma.

Adolescent asthma occurred in 6.4\%. In the first three years of life non-recurrent wheezing occurred in $16 \%$ and recurrent wheezing in $12 \%$. From age four to six years non-recurrent occurred in $5 \%$ and recurrent in $2 \%$. Non-recurrent and recurrent wheezing in the first three years of life and recurrent wheezing at age 4-6 increased the risk with odds ratios $195 \%$ confidence interval) of 3.3 (1.9-5.6), $4.7(2.8-8.2)$ and 15.4 (7.1-33.7), respectively. The risk additionally increased by a family history for asthma, 2.0 (1.1-3.6), by atopic dermatitis 
1.7 (1.1-2.7) and sinusitis 2.9 (1.3-6.4), independently of each other. Those who were second or later born and those who were born in families with low social-economic status had less risk on adolescent asthma: $0.38(0.19-0.74)$ and $(0.61(0.39-0.94)$, respectively. There were indications for under- and over-diagnosis of asthma at age 0-6 years.

In children with recurrent wheezing in the first three years of life a probability of adolescent asthma of nearly $50 \%$ (20-78) could be achieved when in that period atopic dermatitis and sinusitis was diagnosed and also a positive family history was present.

We concluded that easily available data on family history and personal atopic and respiratory morbidity could facilitate the early diagnosis of asthma in children with wheezing illness. A quantified decision procedure could be developed if the data presented here are confirmed, independently, in other sufficiently large primary care populations.

Chapter 8 constitutes the general discussion. It summarizes and integrates the main findings of the 4 PREVASC studies presented in the chapters 3-6 and gives recommendations for further research on primary and secondary prevention.

We found support that favours the combined intervention strategy as carried out in the PREVASC study. Receiving no breast milk, high exposure to allergens of house dust mite, and exposure to maternal smoking increased the risk on asthma, independently of each other. For exposure to pet allergens, the relation was less clear. However, our study demonstrated synergistic effects of pet allergens and other exposures on respiratory symptoms.

In this chapter, we discussed also some methodological issues of the PREVASC study concerning the choice for the multi-facet approach, the randomisation procedure, the prevention of contamination, the occurrence of bias, the external validity, the high-risk identification and the measurement of the exposures.

As the PREVASC program could not be executed blindly, we used a clustered randomised consent design. The advantage of the design is that the control group is not informed about the preventive measures recommended to the intervention group. This prevents unwanted spontaneous changes in preventive life style in the control group. In general, we found in the 
control group no indication that contamination had occurred, although the amount of cat allergens was also diminished in this group.

The importance of the PREVASC program is that it is the first study that reports on the effects of a multi-facet primary prevention program in a setting that approximates real life circumstances The advantage is that any future implementation of the PREVASC intervention in primary care can be directed towards the same primary care population and that the recruitment and the identification of the high-risk unborn can be carried out relatively easy and economically by the general practitioner as in the PREVASC study. 
Samenvatting (voor de geïnteresseerde leek)

"I didn't know that. Can you provide me with the evidence for what you just said?"

Uit: Evidence based medicine in de praktijk, uitg. Boom Amsterdam, blz 16. citaat David Sacket 
Dit proefschrift beschrijft de resultaten van onderzoek op het gebied van primaire en secundaire preventie van astma bij kinderen.

Voor de studies op het gebied van primaire preventie werd de PREVASKstudie (Preventie van Astma in Kinderen) opgezet. De PREVASKstudie is een gerandomiseerde interventiestudie waarbij 476, voor astma familiair belaste kinderen zijn gevolgd vanaf de geboorte. In de studie wordt nagegaan of het geven van preventieve adviezen de ontwikkeling van astma kunnen voorkömen. De kinderen werden gerecruteerd van 1997 tot 2000 in de provincies Limburg. Celderland en Noord-Brabant. In het proefschrift zijn de effecten ervan in de eerste 2 levensjaren gerapporteerd.

De studies op het gebied van secundaire preventie maakten gebruik van huisartsgegevens van 1586 kinderen die vanaf hun geboorte minimaal 12 jaor zijn gevolgd (historisch cohort). De gegevens zijn opgeslagen door de Continue Morbiditeits Registratie (CMR) van de vakgroep huisartsgeneeskunde van de Radboud Universiteit Nijmegen.

In Hoofdstuk 1 is de aanleiding voor het onderzoek beschreven. De begrippen primaire en secundaire preventie worden toegelicht. Primaire preventie betekent het voorkōmen van nieuwe ziektegevallen door de oorzaak van de ziekte weg te nemen. Bij secundaire preventie gaat het om het zo vroeg mogelijk opsporen en behandelen van de eerste verschijnselen van de ziekte. Het belang van deze twee soorten van preventie voor astma bij kinderen wordt besproken.

Astma en allergie komen in de de westerse wereld steeds vaker voor. Drie mechanismen zijn beschreven, die daarvoor een mogelijke verklaring vormen. Dat zijn de hygiëne hypothese. de diëet hypothese en de hypothese die uitgaat van "toegenomen blootstelling aan allergische en niet allergische prikkels". De PREVASK studie is gebaseerd op de laatste hypothese. Zij onderzoekt of de ontwikkeling van astma kan worden voorkōmen indien we de blootstelling aan allergische en niet allergische prikkels verminderen. Het gaat dan om het verminderen van prikkels waarvan is bewezen dat ze samenhangen met astma. Dat zijn allergische prikkels door blootstelling aan huisstofmijt-, huisdier- en voedselallergenen en. niet allergische prikkels door blootstelling aan tabaksrook voóór en na de geboorte (passief roken van de baby). In de PREVASK studie worden de ouders voorgelicht op welke wijze ze het beste deze 4 prikkels kunnen verminderen. De voorlichting is gegeven door 
gespecialiseerde verpleegkundigen en wordt in het hiernavolgende aangeduid als "PREVASK programma".

In het hoofdstuk zijn vervolgens de onderzoeksvraagstellingen m.b.t. primaire en secundaire preventie besproken. Met betrekking tot primaire preventie van astma bestuderen we vijf aspecten van de preventie: (1) de aanwezige ruimte voor verbetering voor de preventieve adviezen van het PREVASK programma (welke PREVASK maatregelen hebben ouders, met zelf astma of met een kind met astma, al genomen?): (2) de compliantie met de gegeven instructies (zullen ouders doen wat we ze vragen te doen?): (3) de effectiviteit van de maatregelen om de blootstelling aan allergenen te verminderen (wordt de blootstelling inderdaad verminderd?); (4) het effect van het PREVASK programma op de astmatische symptomen en allergie (hebben de kinderen waarbij de maatregelen zijn toegepast minder klachten van astma en allergie dan kinderen in de controlegroep?): en (5) de timing van de preventie (wat is het beste moment om preventie te starten: vōōr of na de geboorte?)

De onderzoeksvragen luidden alsvolgt:

- Welke maatregelen, geadviseerd in het PREVASK programma hebben gezinnen waarin astma vōoorkomt al genomen (Hoofdstuk 3)?

- Wat is de compliantie van ouders met het PREVASK programma KHoofdstuk $41 ?$

- Zijn de aanbevolen preventieve maatregelen tegen de expositie aan allergenen van de huisstofmijt en huisdieren effectief in het terugdringen van deze exposities (Hoofdstuk 4)?

- Is het PREVASK programma effectief in het voorkómen van astma, astmatische klachten en allergie (Hoofdstuk 5)?

- Wordt het serum totaal gE bij de geboorte beinvloed door blootstelling aan huisstofmijt- en huisdierallergenen vōór de geboorte (Hoofdstuk 6)?

De onderzoeksvragen ten aanzien van secundaire preventie van astma zijn:

- Wat is bij kinderen met symptomen van piepen, zagen en volzitten in de eerste zes levensjaren (verder te noemen "wheezen") het risico op astma na het $12^{\mathrm{e}}$ joar (hoofdstuk 7 )? 
- Wat is bij wheezende kinderen de aanvullende diagnostische waarde van het familiaire vōoorkomen van allergische ziekten voor het aanwezig zijn van astma na het $12^{\mathrm{e}}$ jaar (hoofdstuk 7)?

- Wat is bij wheezende kinderen de aanvullende diagnostische waarde van vōórkomende luchtwegaandoeningen zonder wheezen en bijkomende allergische aandoeningen voor het aanwezig zijn van astma na het $12^{\mathrm{e}}$ jaar (hoofdstuk 7)?

In hoofdstuk 2 zijn de literatuurgegevens gepresenteerd, op basis waarvan het PREVASK programma is samengesteld en de sfudie opzet is gebaseerd. Voordat besloten kan worden primaire preventie van een ziekte algemeen toe te passen, moeten we nagaan in hoeverre de preventie aktiviteiten voldoen aan een aantal voorwaarden. De belangrijkste is de voorwaarde dat de te nemen preventieve maatregelen effectief en doelmatig moeten zijn. Dat wil zeggen dat de preventie niet alleen werkzaam moet zijn in een onderzoeksetting waarbij de meest optimale omstandigheden zijn gecreëerd (=efficacy), maar ook werkzaam is wanneer de preventie uitgevoerd wordt in alledaagse omstandigheden (=effectiviteit). Daarbij is van belang dat de preventie uitvoerbaar én acceptabel is voor ouders, kinderen en hulpverleners en. of de baten van de preventie opwegen tegen de kosten. Het gaat. kortom, om de vraag of de uit te voeren primaire preventie kosteneffectief is. Met betrekking tot primaire preventie van astma zijn tot nu toe alleen enkele efficacy studies gedaan, die een wisselend resultaat lieten zien. De PREVASK studie en haar vervolgstudies willen inzicht geven in de kosteneffectiviteit van primaire preventie van astma.

Op grond van de literatuur is allereerst nagegaan welke maatregelen voldoende efficacy hebben om te worden opgenomen in het PREVASK programma. Dat zijn de volgende:

1. Het vermijden van blootstelling aan huisstofmijtallergenen vanaf het moment dat de baby is geboren door zorg dragen voor: een gladde vloerbedekking in woonkamer en slaapkamer van ouder en kind; het grondig schoonmaken van de vloeren; het wassen van het beddegoed op 60 graden Celsius; het gebruik van huisstofmijtondoorlaatbare hoezen voor de ouder- en babymatras, en voor het dekbed, kussen en babyslaapzak; de aanschaf en het gebruik van een nieuw 
babymatras; woon- en slaapkamers continue te ventileren en dagelijks te luchten gedurende minimaal éēn uur bij een juiste kamertemperatuur.

2. Het vermijden van blootstelling aan allergenen van kat en hond vanaf het moment dat de baby is geboren door het niet aanschaffen van de huisdieren of. als deze aanwezig zijn, ze weg te doen. Indien dit nief haolboar is, de huisdieren regelmatig te wassen en hen buitenshuis te houden.

3. Het vermijden van blootstelling aan voedselallergenen gedurende de eerste 6 maanden van het leven door uitsluitend borstvoeding te geven. Wanneer dat niet mogelijk is of wanneer de borstvoeding te kort schiet, een hypoallergene flesvoeding te geven in plaats van de normale flesvoeding. Daarbij wordt geadviseerd het eerste hapje uit te stellen tot de baby 6 maanden oud is.

4. Het vermijden van blootstelling van de baby aan tabaksrook (=passief roken) voór en na de geboorte. De efficacy van het vermijden van passief roken is weliswaar niet bewezen, maar de maatregel is opgenomen vanwege het wël bewezen nadelig effect op de longfunctie van het kind.

Zie ook appendix 1 voor aanvullende informatie.

Vervolgens is de opzet van de uit te voeren PREVASK studie geschetst en zijn de methodologische karakteristieken beschreven. Deze zijn de volgende:

- Zwangere moeders werden geinformeerd over het onderzoek en gerecruteerd door de huisarts of vroedvrouw vōór de $7^{\mathrm{e}}$ maand van de zwangerschap.

- Alleen ongeborenen met een hoog risico op astma werden geincludeerd:

- Van hoog risico op astma was sprake indien de huisarts vaststelde dat moeder, vader of broertje of zusje van de ongeborene astma had.

- Om een effect te kunnen aantonen waren op zijn minst 400 baby's nodig. waarvan de helft de PREVASK adviezen krijgt en de andere helft de normale, bestaande zorg krijgt.

- Een probleem bij de opzet van de PREVASK studie is dat sommige van de preventieve maatregelen niet "blind" kunnen worden voorgeschreven (b.v wel of geen borstvoeding geven, wel of niet roken en wel of niet houden van huisdieren). Los daarvan is het om ethische redenen niet toegestaan een deel van de ouders te vragen af te zien von gezondheidsbevorderend gedrag zoals het geven van 
borstvoeding of hen te vragen te gaan roken. Om dit probleem te ondervangen werd het recruteringsgebied opgedeeld in ca. 246 subregio's (clusters). Zij werden vervolgens, door het lot bepaald, verdeeld in interventie- en controleclusters (cluster pre-randomisatiel. De patienten, gerecruteerd binnen ēēn cluster, kregen dus dezelfde behandeling. Bij pre-randomisatie ontvangen de patiënten in de controleclusters geen informatie over het bestaan van interventieclusters Izie appendix $4 a$ en 4b). Door cluster-randomisatie wordt de kans dat deelnemers van de interventiegroep en de controlegoep elkaar ontmoeten klein. Dit zou immers kunnen leiden tot uitwisseling van informatie en ongewenste spontane verandering van preventief gedrag bij gezinnen in de controlegroep (spontane compliantie) in de hand werken.

- Ouders in de interventiegroep werden op een gestandaardiseerde wijze geinstrueerd over de te nemen maatregelen van het PREVASK programma door speciaal daarvoor opgeleide verpleegkundige gedurende drie huisbezoeken Izie voor gedetailleerde informatie appendix 2)

- De controlegroep ontving de zorg van de huisarts en verloskundige, zoals te doen gebruikelijk.

- De kinderen werden 2 jaar gevolgd. Het effect van het PREVASK programma werd gemeten door de frequentie van opgetreden "astmatische" symptomen die op tweejarige leeftijd kunnen wijzen op astma in de controle- en interventiegroep te vergelijken. Het optreden van de "astmatische" klachten werd bijgehouden door door ouders in dagboekjes en vragenlijsten en door de huisarts, wanneer deze het kind zag als het ziek was. Daarnaast maten we de hoeveelheid antistoffen tegen de allergenen van de huisstofmijt, kat en hond in het bloed (het totaal en specifiek serum lgE) bij de geboorte, en na 1 en 2 jaar.

- De mate van compliantie van de ouders in de interventiegroep met de gegeven instructies en ook eventueel opgetreden veranderingen in preventief gedrag. spontaan of door contaminatie, van de controlegroep werden gemeten aan de hand van vragenlijsten;

- De compliantie met de adviezen ten aanzien van het vermijden van huisstofmijt- en huisdierallergenen in de interventiegroep en spontane compliantie in de controlegroep werden tevens vastgesteld door herhaald meten van de hoeveelheid 
van deze allergenen in het stof van de woonkamer en op het matras van ouder en kind.

Hoofdstuk 3 bespreekt de onderzoeksvraag in hoeverre maatregelen geadviseerd in het PREVASK programma al waren toegepast in gezinnen met astma. In een beschrijvende follow-up studie van 211 astmatische gezinnen, die een baby verwachtten, is nagegaan hoe vaak zij al de gewenste PREVASK maatregelen hadden toegepast. We analyseerden tevens factoren die het preventief gedrag positief of negatief beinvloedden. Het bleek dat $36 \%$ van de gezinnen al een gladde vloerbedekking had en $27 \%$ maakte de vloeren dagelijks schoon. Anti-mijt matrashoezen voor het ouderlijk matras werden gebruikt in 13\%, voor de matras van de baby in $9 \%$. Huisdieren waren afwezig in $66 \%$. In de eerste 6 maanden na de geboorte kreeg slechts $12 \%$ uitsluitend moedermelk en ontving $87 \%$ van de babies flesvoeding op basis van koemelk. Het eerste hapje werd slechts in $28 \%$ van de gevallen uitgesteld tot na de zesde maand. $89 \%$ van de moeders rookte niet prenataal en $85 \%$ niet postnataal. Hun partner rookte niet in $76 \%$. De meeste maatregelen bleken niet te zijn genomen op grond van professioneel advies, maar op initiatief van de ouders zelf. De conclusie was dat er nog voldoende ruimte voor verbetering is voor het verminderen van allergische prikkels in astmatische families. De meeste ruimte voor verbetering is anwezig voor het terugdringen van blootstelling aan mijtallergenen door het gebruik van anti-mijt hoezen, voor het dagelijks schoonmaken van de vloeren, voor het zorg dragen voor een gladde vloerbedekking, en voor het terugdringen van blootstelling aan voedselallergenen door het uitsluitend geven van moedermelk en/of het geven van hypoallergene flesvoeding alsmede door het uitstellen van het eerste hapje tot na de zesde maand.

Een matige ruimte voor verbetering is aanwezig voor het terugdringen van blootstelling aan huisdierallergenen door het niet houden van huisdieren. Dat geldt eveneens voor blootstelling aan tabaksrook door anderen dan de ouders.

De minste ruimte voor verbetering was aanwezig voor het terugdringen van het prenataal en postnataal passief meeroken van de baby veroorzaakt door de ouders.

Hoofdstuk 4 beschrijft in hoeverre ouders compliant waren met de gegeven PREVASK adviezen. Tevens werd nagegaan in hoeverre de aanbevolen maatregelen effectief waren in het verminderen van de blootstelling aan allergenen. Deze gegevens zijn van belang omdat 
beiden mede het effect van de gegeven adviezen bepalen. Wij analyseerden de compliantie met en het effect op de blootstelling van het PREVASK programma in een geboortecohortstudie bij 443 gezinnen, die een baby verwachtten. De baby's waren familiair belast voor astma door het vóörkomen van astma in het gezin. 222 gezinnen werden geplaatst in de interventiegroep en 221 in een controlegroep volgens het principe van pre-randomisatie.

Gezinnen in de interventiegroep werden door gespecialiseerde verpleegkundigen gedurende drie huisbezoeken (twee prenataal en ëén direct na de geboorte) geadviseerd over het PREVASK programma De controlegroep werd niet geinstrueerd en ontving de gebruikelijke eerstelijnszorg.

Het PREVASK programma was gedeeltelijk succesvol in de vermindering van de exposities. De interventiegroep verschilde significant $(P<0.01)$ van de controlegroep in: het gebruik van anti-mijt matrashoezen voor het ouderlijk bed ( $88 \%$ versus $14 \%$ ) en voor het bed van de baby (98\% versus 10\%): het houden van huisdieren buitenshuis (51\% versus 19\%); het geven van borstvoeding al of niet gecombineerd met hypoallergene flesvoeding $155 \%$ versus $22 \%$ ), uitstel van het eerste hapje tot na de $6^{\mathrm{e}}$ maand $(71 \%$ versus $28 \%$ ) postnaal roken door de moeder $(52 \%$ versus $28 \%)$. Een geringe tot afwezige compliantie werd gevonden voor de geadviseerde saneringsmaatregelen (wijze van schoonmaken huis. zorg dragen voor gladde vloeren, ventilatie/luchten, de aanschaf van een nieuwe baby matras en het wegdoen van de kat of de hond), voor het geven van uitsluitend borstvoeding gedurende de eerste 6 maanden en, voor het afzien van prenataal roken door de moeder en van roken door de partner.

De gemiddelde hoeveelheid huisstofmijtallergeen, aangetroffen bij de basismeting. op de matrassen en in de woonkamer was relatief gering. Desondanks leidde het gebruik van antimijthoezen voor het matras van de ouders en de baby in de interventie groep niet alleen tof een sterke afname van huisstofmijtallergenen maar ook van de allergenen van kat en hond. In de controlegroep werden geen significante veranderingen gevonden.

Ondanks het feit dat de interventiegroep niet vaker de geinstrueerde saneringsodviezen voor de woonkamer uitvoerde dan de confrolegroep, nam toch de hoeveelheid huisstofmijtallergeen in de woonkamers van de interventiegroep significant af. Een verklaring 
kan zijn dat de interventiegroep weliswaar niet haar saneringsgedrag heeft veranderd in kwantitatieve zin maar wel in kwalitatieve zin, m.a.w. niet vaker maar wel beter poetsten.

In hoofdstuk 5 wordt de hoofdstudie van het proefschrift beschreven en worden de klinische effecten van de PREVASK interventie gerapporteerd. Frequenties van astmatische en atopische morbiditeit in de de interventiegroep (222 kinderen) en de controle groep (22) kinderen) werden vergeleken. Aanvullend werden dezelfde analyses gedaan maar nu apart voor jongens en meisjes. Telden we het vōorkomen van astmatische symptomen over de gehele eerste twee levensjaren dan vonden we geen verschillen tussen de interventie- en controlegroep. Aan het einde van het tweede levensjaar kwamen astmatische symptomen echter significant minder frequent voor bij kinderen in de interventiegroep dan in de controlegroep. Voor wheezen was de odds ratio (met tussen aanhalingstekens het $95 \%$ betrouwbaarheidsinterval) 0.73 (0.56-0.95), voor kortademigheid $0.76(0.61-0.96)$ en voor nachtelijk hoesten $0.72(0.55-0.95)$. Herhaalden we deze analyse voor jongens en meisjes apart, dan bleek dat de meisjes in de interventiegroep wél significant minder vaak deze astmatische symptomen hadden maar de jongens niet. Ook bij de analyse van astmatisch klachten aan het einde van het tweede jaar stelden we vast dat alleen de meisjes. niet de jongens. minder klachten hadden (15-20\%).

Voor de diagnose astma, in de eerste 2 levensjaren gesteld door de huisarts, vonden we geen verschil tussen de interventie- en controlegroep. Maar ook hier waren het alleen de meisjes in de interventiegroep die significant minder vaak astma hadden dan meisjes in de controlegroep, terwijl er bij de jongens geen significant verschil was tussen de groepen.

Het totaal IgE gehalte en het percentage kinderen met specifiek IgE verschilde niet tussen de groepen. Hier was eveneens een (weliswaar niet significante) trend zichtbaar waarbij bij meisjes wel een positief effect was waar te nemen maar bij jongens niet. De groepen waren echter te klein om hieruit harde conclusies te mogen trekken. Desalniettemin lijkt er gezien de consistentie van de gevonden man-vrouw verschillen sprake te zijn van een seksespecifiek effect van de interventie op astmatisch klachten. Onze hypothese is dat het vrouwlijk immuunapparaat kennelijk anders reageert op het verminderen van allergische en niet allergische prikkels dan het manlijk immuunapparaat, een hypothese die nader onderzoek verdient. 
We analyseerden aanvullend in de totale groep (dus in de inferventie- en controlegroep samen) het risico op astmatische symptomen door blootstelling aan allergenen van de huisstofmijt. van kat en hond, aan voedselallergenen of aan tabaksrook. Daaruit bleek dat het geven van borstvoeding. het niet roken door de moeder en het blootgesteld zijn aan een relatief lage hoeveelheid (onder de mediaan) huisstofmijtallergeen elk significant, en onafhankelijk van elkaar, het risico op astmatische symptomen verminderden: de respectievelijke odds ratio's waren $0.42(0.18-0.97)$. $0.38(0.14-1.0)$ en 0.3010 .12 0.711. Dit ondersteunt de gedachte dat het ontstaan van astma door meerdere omgevingsfactoren tegelijk wordt bepaald en is een pleidooi voor de gecombineerde aanpak van deze factoren, zoals gedaan in het PREVASK onderzoek.

We concludeerden dat het PREVASK programma, dat met redelijk succes de blootstelling aan huisstofmijt, kat, hond en voedselallergenen verminderde, leidde tot minder astmatische symptomen aan het einde van het tweede levensjaar. We vonden tevens aanwijzingen voor een sekse-specifieke effect van de interventie. In de eerste 2 levensjaren en aan het einde van het tweede jaar waren het hoofdzakelijk de meisjes die minder klachten hadden. Deze bevindingen zijn nog nief bruikbaar in de dagelijkse praktijk. In hoeverre het PREVASK programma werkelijk astma kan voorkómen en wat de betekenis is van het hier gevonden gevonden sekse-specifiek interventie-effect, kan immers pas definitief worden vastgesteld als de kinderen zes jaar zijn. Dan kan de aanwezigheid van astma betrouwbaar en objectief worden gemeten.

De studie in hoofdstuk 6 is een bijdrage in de lopende discussie over de timing van de interventie. Het is bekend dat het imuunapparaat van de foetus is in staat te reageren op allergene stoffen die hem/haar bereiken via de moeder. Een verhoogde hoeveelheid antistoffen (totaal $\mathrm{g} E$ ) in het bloed bij de geboorte zou een eerste teken kunnen zijn van een allergische ontwikkeling, hetgeen op zijn beurt weer zou kunnen leiden tot ontwikkeling van astma. We stelden ons daarom de vraag in hoeverre het van belang is de blootstelling van de moeder aan allergenen van de huisstofmijt, kat en hond te verminderen vroeg in de zwangerschap of dat volstaan kan worden met vermindering van de blootstelling vanaf de geboorte. Indirect zouden we daarvoor aanwijzigingen kunnen vinden indien het totaal serum lgE bij de geboorte, afhankelijk zou blijken te zijn van de mate van expositie aan 
allergenen van de mijt, kat en hond in de zwangerschap. Dit onderzochten we bij 221 pasgeborenen met een vader, moeder of broertje of zusje met astma. In de huizen van deze families werden de concentraties (ng/g dust) van allergenen van de huisstofmijt, kat en hond gemeten in de 4-6 maand van de zwangerschap in stofmonsters afkomstig van de matras van de moeder en van de woonkamer. Op dag 3-5 na de geboorte maten we het totaal lgE gemeten in bloed verkregen via de hielprik. Bij de analyse werd rekening gehouden met factoren die eveneens het totaal lgE zouden kunnen beinvloeden, zoals de aard van de genetische predispositie (het vōorkomen van huisstofmijtallergie bij vader of moeder). de aanwezigheid van andere exposities zoals prenataal passief roken, de wijze van voeding (borst, fles) in de dagen voordat het bloed werd afgenomen, en andere kenmerken zoals het geslacht van de baby, de leeftijd van de moeder en de duur van de zwangerschap.

Bij $24 \%$ van de baby's werd een verhoogd totaal lgE aangefroffen lgebruikt afkappunt voor verhoogd versus normaal $\mathrm{lgE}$ was $0.5 \mathrm{IU} / \mathrm{ml}$ ). Bij kinderen met een verhoogd lgE werd significant vaker een grotere hoeveelheid huisstofmijtallergeen aangetroffen dan bij kinderen met een niet verhoogd $\lg E$. De hoeveelheid allergenen van de kat en de hond verschilde echter niet tussen beide groepen. De kans op verhoogd totaal lgE nam evenredig toe bij een toename van huisstofmijtallergeenconcentraties. De relatie was onafhankelijk van de andere (bovengenoemde) lgE beïnvloedende factoren.

De conclusie was dat het totaol serum lgE van baby's met een hoog risico op astma wordt beinvloed door de mate van prenatale blootstelling aan allergenen van de huisstofmijt maar niet van de kat en hond. Dit zou erop kunnen wijzen dat het immuunsysteem van het familiair belaste, ongeboren kind abnormaal reageert op allergische prikkels. Wij pleiten er dan ook voor studies op te zetten die het klinisch effect van huisstofmijtreducerende maatregelen, gestart in de vroege zwangerschap (voór de $20^{\mathrm{e}}$ week) vergelijken met het klinisch effect van dezelfde maatregelen, gestart vanaf de geboorte.

De studies m.b.t secundaire preventie worden besproken in hoofdstuk 7. Het vroegtijdig en correct diagnosticeren van astma bij kinderen die wheezen (piepen, zagen, volzitten) is essentieel voor een vroege behandeling. Bovendien wordt daarmee voorkómen dat astma wordt over- en onderbehandeld. Onderzocht werd in hoeverre het combineren van de klinische gegevens die de huisarts al tot zijn beschikking heeft kan helpen bij het correct en 
vroeg diagnosticeren van astma. Voor dat doel werd een geboortecohortstudie uitgevoerd, waarbij we de prospectief geregistreerde huisartsgegevens van de Continue Morbiditeits Registratie (CMR) van de vakgroep huisartsgeneeskunde van de Radboud Universiteit Nijmegen gebruikten. We gingen na wat het risico op astma na het $12^{\mathrm{e}}$ levensjaar was bij kinderen die nooit. een keer of twee of meer keer hadden gewheezd in de eerst zes levensjaren. We maakten daarbij onderscheid tussen kinderen die dat "vroeg" (van 0-3 jaar). en "laat" deden (4-6 jaar), We onderzochten tevens in hoeverre dit risico veranderde als de kinderen in de eerste levensjaren al dan niet eczeem of hooikoorts hadden, en/of al dan niet andere aondoeningen van de bovenste en onderste luchtwegen en/of al dan niet familiair belast waren. Van de 2475 kinderen hebben we 1586 (64\%) vanaf de geboorte minimaal 12 jaar gevolgd. De gemiddelde follow-up tijd was 20 jaar (SD 4.8).

$\mathrm{Na}$ het $12^{\mathrm{e}}$ jaar hadden $6.4 \%$ van de kinderen astma. In de eerste zes levensjaren maakte $16 \%$ van alle kinderen 1 episode en $12 \%$ minsten 2 episodes van 0-3 jaar. Van 4-6 jaar had $5 \%$ éen episode van wheezen en $2 \%$ twee of meer.

Bij éen episode van wheezen 0-3 jaar was het risico op astma na het $12^{e}$ jaar 3.3

(1.9-5.6) Igetallen zijn odds ratio's met 95\% betrouwbaarheidsinterval tussen aanhalingstekens), Bij twee of meer episodes van 0-3 jaar 4.7 (2.8-8.2). Bij twee of meer episodes van wheezen van 4-6 jaar nam het het risico op astma na het $12^{\mathrm{e}}$ jaar sterk toe: 15.4 (7.1-33.7). Het familiair voorkomen van astma was een onafhankelijke risicofactor: 2.0 (1.1-3.6). Dat gold ook voor atopische dermatitis, 1.7 (1.1-2.7) en voor sinusitis, 2.9 (1.3-6.4). Kinderen, met één of meer broertjes of zusjes en kinderen uit een gezin met een lage sociale status hadden daarentegen een verminderd risico op astma, respectievelijk 0.38 (0.19-0.74) en 0.61 (0.39-0.94). Bij kinderen met 2 of meer episodes van vroeg wheezen had $12 \%(7-19)$ asthma na hun $12^{2}$. Hadden ze tevens atopische dermatitis en sinusitis in de eerste drie levensjaren alsmede een familiaire belasting, dan was astma na het $12^{\mathrm{e}}$ jaar aanwezig in bijna 50\% (20-78). Er waren aanwijzingen voor onder- en overdiagnose van astma in de eerste 6 levensjaren. We concludeerden dat de diagnose astma bij kinderen die (vroeg) wheezen eerder en accurater gesteld zou kunnen worden indien de huisarts de frequentie en de leeftijd van het optreden van het wheezen laat meewegen en combineert met het aanwezig zijn van een familiaire belasting en/of van atopische en andere opgetreden aandoeningen van de luchtwegen. 
Op basis van deze gegevens zou in de toekomst een beslissingsprocedure ontwikkeld kunnen worden als de hier gepresenteerde gegevens bevestigd worden door studies in andere. voldoend grote populaties in de eerste lijn.

Hoofdstuk 8 bevat de algemene discussie. Daarin werden de belangrijkste bevindingen van de 4 PREVASK studies, gepresenteerd in de hoofdstukken 3-6 integraal becommentariëerd. Tevens deden we aanbevelingen voor verder onderzoek met betrekking tot primaire en secundaire preventie.

Wij vonden steun voor het uitvoeren van een gecombineerde interventiestrategie zoals uitgevoerd in de PREVASK studie. Het niet krijgen van moedermelk, het blootgesteld zijn aan (relatief) hoge concentraties van huisstofmijtallergenen en aan tabaksrook door de moeder, blijken onfhankelijk van elkaar een risico te zijn voor het krijgen van astmatische klachten. Blootstelling aan allergenen van de kat en hond deed het risico niet toenemen. Wij vonden echter wel dat blootstelling aan een hogere dosis allergenen van huisdieren het negatieve effect dat andere exposities hebben op astmatische symptomen versterken.

In deze algemene discussie bespraken ook enkele methodologische karakteristieken van de PREVASK studie. Aangezien het PREVASK programma niet geblindeerd kon worden uitgevoerd, gebruikten we een geclusterde randomised informed consent procedure. Het voordeel van het randomised consent design is dat de controlegroep niet geinformeerd werd over de preventieve maatregelen geadviseerd aan de interventiegroep. Daardoor konden ongewenste en spontane veranderingen in preventieve leefstijl voorkomen worden. Wij vonden geen aanwijzingen voor contaminatie, zij het dat wij in de controlegroep wel een significante afname vonden van de hoeveelheid allergeen afkomstig van de kat.

We bediscussiëerden het belang van de PREVASK studie. Het is de eerste studie die de effecten van een gecombineerd primair preventieprogramma rapporteert in een setting die de alledaagse werkelijkheid in de eerste lijn nabootst. Het voordeel van de wijze waarop de PREVASK studie is opgezet is dat bij toekomstige implementatie het PREVASK programma in de eerste lijn aangeboden zal worden aan dezelfde populatie en dat het selecteren van 
ongeborene met een hoog risico op dezelfde gemakkelijke en economische wijze uitgevoerd kan worden door de huisarts als is gedaan in de PREVASK studie.

Enkele belangrijke bevindingen van de PREVASK studie staan hieronder samengevat.

- De adviezen van het PREVASK programma verminderen de expositie aan de allergenen van de huisstofmijt, kat, en hond. De meeste reductie wordt bereikt door het gebruiken van huisstofmijtwerende matrashoezen:

- De expositie aan koemelk allergenen kan verminderd worden door als bijvoeding of vervanging voor borstvoeding een hypoallergene voeding aan te bevelen. Ouders zijn echter niet compliant met het advies alleen maar borstvoeding te geven gedurende de eerste zes maanden na de geboorte.

- Ondanks de gegevens voedings adviezen krijgt toch nog $50 \%$ van de kinderen gedurende een korte of lange periode een (gehumaniseerde) koemelkvoeding.

- Het risico op astmatische klachten wordt vergroot door de expositie aan huisstofmijt. aan voedingsallergenen en aan tabaksrook.

- Blootstelling aan het katteallergeen versterkt het effect dat de bovengenoemde prikkels hebben op astmatische klachten. Dit pleit voor de gecombineerde aanpak van de exposities zoals gedaan in de PREVASK studie.

- Het PREVASK programma resulteert aan het einde van het tweede jaar in een bescheiden (circa 8-10\%) maar significante vermindering van astmatische klachten (piepen, kortademigheid en nachtelijk hoesten).

- Er lijkt een sekse-specifiek effect van de interventie te zijn aangezien meisjes minder astmatische klachten hebben (15-20\%), maar jongens niet.

- Baby's die vōór de geboorte zijn blootgesteld (via de moeder) aon grotere hoeveelheden dosis huisstofmijtallergenen vormden meer afweerstoffen dan baby's met een lagere blootstelling. Dif zou kunnen betekenen dat voor het voorkömen van atopie een anti-mijt interventie nodig is die vroeg in de zwangerschap start in plaats van vanaf de geboorte. zoals is gedaan bij de PREVASK interventie. 


\section{Na-en dankwoord}

Als je de dankwoorden leest van promovendi die mij zijn voorgegaan dan valt op dat vele van hen wat somber getinte metaforen gebruiken om de periode waarin hun zeergeleerdheid gevormd werd te karakteriseren. Het promoveren blijkt dan "een avontuur" (eenzaamheid, gevaar alom, toch goede afloop) of "een wedstrijd" (willen opgeven, niet gedaan, uiteindelijk toch gewonnen), "een agrarische groeiproces" (zaad goed, maar oogst onzeker). "een spannende pelgrimage" (pad vol obstakels, doel goed) "een zeiltocht" (mooi schip. veel storm, toch veilige haven dankzij goede loodsen)" etcetera. Uit de dankbetuigingen klinkt vaak geleden kommer en kwel: dank aan de lieve partner. voor het begrip. voor het klaar staan, voor het er altijd zijn, ondanks de jammerlijke maar noodzakelijke verwaarlozing door de zeergeleerde. Lieve kinderen worden beloofd dat papa's/mama's, nu het boek echt klaar is, eindelijk weer tijd voor hen zullen hebben. Verwaarloosde vrienden zullen weer kunnen rekenen op hun maatje, dat ze zo node gemist hebben.

"Je begrijpt niet dat er nog iemand gaat promoveren als je al die ellende tussen de regels door leest. Dankwoorden moeten in een opgewekte stijl geschreven te worden zodat de lezer bij wijze van spreken er zelf zin in krijgt te promoveren!". Woorden van dergelijke strekking sprak André Knottnerus, één van mijn promotores. Hij sloot daarmee voor mij, zijn volgzame leerling. bij voorbaat de deur om mijn eigen nawoord te larderen met een treurigmakende metafoor of larmoyante dankbetuiging. Ik was dat overigens ook niet van plan. Huisartsen klagen niet, doen gewoon hun werk en áls ze al lijden, dan doen ze dat in stilte.

Nee, bij mij geen kommer en kwel. In tegendeel, met genoegen kijk ik terug op de afgelopen jaren. Daarbij dringt zich bij mij een vergelijking op tussen het consult bij de huisarts en het doen van wetenschappelijk onderzoek. In het consult beantwoordt de huisarts de vraag van de patiënt op een gerichte en systematische wijze. Wat is exact de hulpvraag? Welke gegevens heb ik nodig om deze te beantwoorden? Wat kan ik zelf en wat moet een ander voor mij uitzoeken? Wat is de conclusie en hoe breng ik deze zo goed mogelijk over? Het is dezelfde systematische aanpak die vereist is bij het doen van wetenschappelijk onderzoek. Het verschil zit hem erin dat de huisarts voor het beantwoorden van de 20-30 hulpvragen per dag gemiddeld 10 minuten per vraag nodig heeft terwijl voor het beantwoorden van éên wetenschappelijke onderzoeksvraag minimaal 4 jaar uitgetrokken mag worden. $U$ zult mijn feestelijk en weldadig gevoel kunnen begrijpen -de hectische gehaastheid van de huisartspraktijk van alledag. na 25 jaor te mogen afwisselen met het op rustige en gedegen wijze uitbenen van éen wetenschappelijke vraagstelling!

Met het schrijven van dit proefschrift heb ik zo heet het in officiële termen "een proeve van bekwaamheid tot het zelfstandig verrichten van onderzoek in de medische wetenschappen" afgelegd. Alhoewel in de zinsnede het woordje "zelfstandig" staat zult u begrijpen dat het onderzoek van een dergelijke omvang alleen mogelijk was doordat velen daaraan hebben meegewerkt. Die wil ik nu bedanken. Daarbij zal ik namen gaan noemen. Dat is een precaire zaak, want je kunt ervan op aan dat juist degene die dank verdienen, dankwoorden lezen en je slaat zo maar iemand over. Mist u uw naam, denk dan niet dat uw inbreng niet is gewaardeerd, maar wijt dat dan aan mijn ouder wordende hersenen. 
Voor het bewaken van de kwaliteit van mijn "proeve van bekwaamheid" zijn de promotores de eindverantwoordelijken.

Ik ben de hoogleraren Onno van Schayck. André Knottnerus en Chris van Weel zeer dankbaar voor de zorgvuldige, intensieve. kritische en amicale wijze waarop ze dat hebben gedaan. Wat een kennis ligt in die hoofden opgeslagen!

Onno, onder jouw enthousiasmerende en deskundige leiding heb ik mijn oorspronkelijke idee dat veel te breed was, kunnen uitwerken tot een werkbaar onderzoeksvoorstel en is de PREVASK studie uitgebreid tot een onderzoeksproject, waaraan inmiddels 5 promovendi werken.

André. je subtiele kritiek was altijd zorgvuldig en altijd bruikboar, je spitse humor is weldadig. je eruditie fenomenaal.

Chris, de snelle en nauwgezette wijze waarop je telkens reageerde op mijn concepten is zeer prettig. Ik heb veel geleerd van je nuchtere aanwijzingen, van je prachtige engelse zinnen. van je kennis van het huisartsgeneeskundig onderzoek door huisartsen en van het belang ervan voor de huisartsgeneeskunde.

Dr. Edward Dompeling, kinderpulmonoloog, heeft mij zeer geholpen bij het interpreteren van de data. Ik had hem graag hier als mijn co-promotor willen bedanken. Helaas stelde het promotiereglement dat er naast 3 promotores geen plaats meer is voor een co-promotor. Edward, zeer bedankt voor je deskundige hulp!

De PREVASK begeleidingscommissie bestond, naast de promotores, uit personen met een specifieke deskundigheid op het gebied van het astma- en allergieonderzoek in Nederland. Ik dank Prof. Dr. R. Aalberse (VU. Amsterdam). Dr. S. Stapel (VU. Amsterdam). Dr. J.Cerritse, (AZC/RUC. Groningen), Drs. J.Yntema (Radboud/KUN, Nijmegen). Dr. S. van der Heide (AZC/RUC. Groningen). Dr. C. Thijs,(UM/CW. Maastricht). Mevr. Dr. Ilse Mesters (UM/CW. Maastricht) en Mevr. Drs. A. Bögels, (Astmafonds, Leusden), ieder voor hun inbreng.

De PREVASK Projectgroep was van groot belang als, maandelijks samenkomende. denktank en was zeer noodzakelijk als coördinatieplatform voor een complex onderzoek als de PREVASK studie. Zij bestond (in mijn tijd) uit Onno van Schayck. André Knottnerus, Edward Dompeling, Jean Muris, Ilse Mesters, Guido van den Boom. Tanja Maas. Sandra Kuiper. Annemiek Nijholt, Lisette van den Bemt. Marjolein de Vries, Barbara Gijsbers, Kittie Coolen, Kitty van der Meer, Kirsten Ritter, Foekje Stelma. Allen bedankt en succes met jullie eigen projecten!

De secretaresses die werkten voor het PREVASK onderzoek dank ik voor hun werkzaamheden. Achtereenvolgens waren dat respectievelijk Annemarie Korsten. Angelique Lefebure, en Annemarie Spaninks.

In het eerste jaar hebben llse van Beerendonck en later Karin Manders en Tanja Maas geweldig veel werk verzet als onderzoek-assistent, waarvoor mijn grote dank. Tanja heeft zich, ook na haar aanstelling als onderzoeker op het vervolgonderzoek van PREVASK, met grote inzet bezig gehouden met de instructie en begeleiding van de PREVASK verpleegkundigen. Daarnaast was ze onmisbaar als coördinator van de dataverzameling. Tanja, zeer bedankt voor je fijne steun en veel succes met je eigen project! 
Kitty Coolen. Annemarie Spaninks en Jacqueline Pisters hebben de data verzameld. gecontroleerd en gecorrigeerd. Jacqueline heeft onvermoeibaar grote aantallen variabelen aangemaakt, waarmee ik dan weer verder kon.

De PREVASK verpleegkundigen deden circa 2500 huisbezoeken. Zij voerden de interventie uit en verzamelden de gegevens met groot enthousiasme. In de begin periode werd dat gedaan door Tanja Maas en Karin Manders later opgevolgd door Cindy Brink. Gertie van Driel. Twanny Jeijsman-Rouwhorst. Kitty van der Meer, Marjorie Rovers, Inke Schaap, Marian Terhaar, Elly de Vree en Monique Welbers.

De PREVASK studie is een samenwerkingproject van de vakgroepen huisartsgeneeskunde van de Universiteit Maastricht en de Radboud Universiteit Nijmegen. Ik wil dan ook de personen van de vakgroep huisartsgeneeskunde Nijmegen bedanken voor hun aandeel in het welslagen van de PREVASK studie. Willem van Gerwen die de data van de NMP huisartsen verzamelde en aanleverde. Hans Bor voor het statistisch bewerken van de data van het CMR cohort. Henk van de Hoogen voor zijn nuchtere en leerzame interpretaties van de statistische gegevens. Twannie Jeijsman-Rouhorst en Caroline Roos voor de secretariële ondersteuning.

De 476 gezinnen die bereid waren mee te werken aan dit onderzoek ben ik veel dank verschuldigd voor hun onbaatzuchtige inzet en hun bereidheid gedurende een aantal jaren de vele gegevens te (laten) verzamelen.

Aan het PREVASK onderzoek werkten 272 huisarts(groeps) praktijken met in totaal circa 700 huisartsen (voor de namen zie blz 189-190). Zij includeerden de gezinnen en registreerden gedurende 2 jaar de morbiditeit bij de kinderen. Collegae, zeer bedankt!

Mijn dispuutsgenoot Nico van der Maas (SCILTEC B.V. Beek) dank ik voor zijn zorgvuldige controle en correctie van het Engels in dit boek.

Mijn golfclubgenoten. Ben Hendriks en Vic Seuren dank ik voor de sponsoring van de PREVASK auto in de beginjaren.

Mijn zoon Titus met zijn snelle computervingers dank ik voor zijn hulp bij het programmeren van de PREVASKdatabase in Acces.

Mijn vrouw en kinderen. David, Titus, Hanneke en Laurens en mijn broers, Willem en Jacques, en mijn vriend Rinus Broere voor het aanleveren van en/of meedenken over de stellingen die geen betrekking hadden op het onderwerp van deze dissertatie.

Mijn zwager Jan en mijn zoon Titus, bedankt dat jullie mijn paranimfen wilden zijn! 


\section{De huisartspraktijken die meegewerkt hebben aan het PREVASK-onderzoek}

De praktijken verbonden aant het Netwerk Academische Huisartspraktijken Nijmegen CMRNMP Huisartsenpraktijk Lent, W. vd Bosch, T. Serrarens, H. Schers, E. vd Lisdonk

Huisartsenpraktijk Nijmegen, B. Lagro en mevr. T. Lagro-Janssen, mevr. M. vd Muijsenbergh Huisartsenpraktijk Oosterhout, mevr. E. van Ewijk-vd Wielen, Ch. Verhoeff, H. Beekwilder Huisartsenpraktijk Doesburg, J.C. Bakx, J.E.H. Gelpke, B. Thoonen Huisartsenpraktijk De Heelhoek, Wijchen, J. vd Hoogen en B. van Drenth. Gezondheidscentrum Lindenholt, Nijmegen, Y. vd Vleugel, mevr. M.J. Metz, H. Levelink, mevr. A. Dijkstra, mevr. J. Mooren, mevr. M. Kemper. mevr. M. Meijer, O. Ouwendijk Huisartsenpraktijk Schaijk, J. de Leur, H. Schulte, mevr. M. van Bavel Huisartsenpraktijk De Poort, Beuningen, G. Rutten en A. Haverkort, te Weurt - mevr. N. Rooyackers Lemmens

Huisartsenpraktijk Berghem, W. de Grauw, J.vd Krogt en C.W. Brink.

De praktijken verbonden aan het Registratie Netwerk Huisartsen van de vakgroep huisartsgeneeskunde van de Universiteit Maastricht

Huisartsenpraktijk Stein, SAAM Romeijnders;JP v Proosdij;Gezondheidscentrum "Severen" Maastricht, VA Zwietering

Gezondheidscentrum Heer, Maastricht, FHJA Vissers;MPJM Peeters;mevr AM Muijsken-du Saar;GJ Dinant Gezondheidscentrum Dr. van Kleef Maastricht, LGJ Huijnen;GAHM Castermans;PA Stalenhoef;mevr M Maaskant

Gezondheidscentrum Hoensbroek, M v Nunen;mevr BMMJL Bruls; PM Voorhoeve;mevr H Zwanikken;mevr M Weert;mevr P Pasmans

Huisartsenpraktijk Elsloo, HMJ Boesten;HMJ Jochems

Huisartsenpraktijk Haelen, FGB Smeets;E Deckers

Gezondheidscentrum Geulle, JFM Metsemakers;JWM Muris;PJ Zwietering;RPG Ottenheijm

Gezondheidscentrum Withuis Venlo, PJ Janssen;G de Koning;mevr IA Beekenkamp;HA v Dam;K van

Wersch;mevr AJL v Kessel

Medisch Centrum Putstraat Landgraaf, S van der Eerden;JHM Eussen;mevr CLSM Swerts-Stuurman;mevr CJ Smits

Huisartsenpraktijk 'Nieuw Bergen-lokatie Grote Schuur' , MTJ v Putten;WEM vd Broek

Huisartspraktijk Heerlen, AAM de Wit

Huisartsenpraktijk Heerlen, M Op den Kamp;mevr D Rutgers

Huisartsenpraktijk Ubachsberg, FI Guldemond;mevr ETIM Guldemond-Hecker

Huisartsenpraktijk Voerendaal, PBN Hulshof;RJMG Costongs/M Driessen

Medisch Centrum Eygelshoven, WGE Dijcks;PEW Smeets

Huisartsenpraktijk Brunssum, AJ Drost;CS Hoogervorst;WMH Nieuwdorp

Huisartsenpraktijk Maastricht, AH Wintjens

Medisch Centrum, Merkelbeek, BHJM Otten

Overige huisartspraktijken

Aalten, mevr J.S. Struik; Afferden H.P Jung; Alkmaar, J.J. van Wijland; Alphen, A.H.F.M. Schepens. America, J. van Dongen; Arcen, R Vermunt; Asten, G.J.W. Geboers/Mevr. K. de Vos;Baarle-Hertog, R. Seuntjens; Baarle-Nassau, P.Dekelver Baarlo, GWM Stemkens/JH Hoefnagels; Bakel P.L.B.J. Lucassen/W.F.S.M. Suijs/R.J.M. Clocquet; Barneveld, D.G. de Jong; J.M.B. Hoenderdaal, R. Boomstra; D. Tavenier; Belfeld, mevr. J. Dubelaar-Tijssen/Drs. J. Dubelaar/G. Spitz/mevr. A. Spitz-Meijer; Bemmel, A.H.H. Egging; M.B.M. Peters; Bergen op Zoom, P.A.J. Beysens; H. de Rooij;Beuningen, mevr. drs. R.M. Meijers-Koopma/M. Mazure; Blerick, A.F.H.M. Schuivens; drs.de Mees; Born, W.J.H. Goossens, P. van Galen; Bosschenhoofd, N.M.J. Snieders;Boven Leeuwen, J.S.M. van Leeuwen; Boxmeer, drs. de Jager; Boxtel, T.J.C.M. Doorakkers /J.Janssen;Breda, A.R.B. de Best; R. Böhm; A.H. Bode-Nuis; G.A.F. Saes; Brummen, G. van Geuns; Brunssum, A.G.J.M. Roos; J.P.H. Wanrooij/A.J. de Nooij; Buchten, J.I. Flos/M.W. van Oord;Cuijk, A.H.M. van Heesch; Den Dungen, J. van Laarhoven; Den Haag, D.E. van Wanrooy; Deurne, I.G.C.M. Bierens/ Mevr. S.A.E.M. van Cleef; U.L. Schultz/ M.P. Bakker/ P.G.J.M. Janssen; E.J. Kooijman; J.Th.G. van Uden;Dieren, J.W. Ten Oever/ J.P. Boer; M.Th.W. v.d. Velden; A.R. Simonis/ H.J. Herberts;Diessen, M.C.J. Danen; Doesburg, M. Gulikers; Chr. Trentelman;Doetinchem, A. Vrielink; Drunen, H.M.C.F. Morshuis-Veraa/ R.H.L. Morshuis; D.J. Wassink; P. Engelenburg; Duiven, G.V. Rommers; F.E. Liem/ S.A.J. Sluijmers; Echt, Mevr. M.A.J. Creusen;Ede, M.J.M. de Beer-Buijs/M.J. Rebel;Eerbeek, Dijkstra - van Vliet/B. Simon; Eindhoven, H. Jentjens; O. Schouten; Mevr. S.Ph.M. Schenk; J.H.C. van Hoof; E. Kok; F. van de Pluym/ H. Scholberg; .J.N. Snoeijen; N.P. 
Hoftijzer;Elsendorp, J. Hoevenaars; Elsoo, J. Koppes/ drs. van Stijn; Elst, M.C. Corsten/ R.F. Kleerekooper; J.A. Kruijt; Etten-Leur, W.L.M. Rijnders; Geertruidenberg, H.J. Weltevrede/ N.C.J. Wisse; Geleen, P.C.J.M. Hezemans/ J. van Pelt/J. Dolhain; P. Mekel; J. Sikkes - Mekel; Gendt, G.B.K. Steenhof/M.T.W. Dekkers/ R.M.T.M. v. Kempen/M.E. Elbers; Gennep,T.Q. Nijst/ F.J.G.M. Sinel/ R.H.D. Nypels/ M.K. van den Dool; Grave, G.J.. Olthof/ T.R.K.M. van Summeren/ G.A.C. Veenstra/ K. Walraven-Schils; J.M.G.I. Vos-van de Coer/ W.J.B. de Swart; Grubbenvorst, mevr. M.E.J.M. Baggen/ F.P.A. van de Ven; F. Meeuwis; Gulpen, H.L. Ruijters; Harskamp, F.J.F. Hulsbergen;Heel, A. Massuger; Heerde, E.J. van Apeldoorn; Heerenveen, F.J.L.A. Schilderman; Heerlen, A.O. Koudijs-Koot/J.W.Koudijs; E.A.M. Campman; M.F.J. Bemelmans; Heeze, J.G.H.M. van Otterdijk;J.J.H. van Gestel/ B. van Elk;Helden, F.J. van Kemenade;Helmond, W.J. van Geldrop; C.F.B. Sleyffers; drs. Attalla; W. Heres/ I. Smulders/ W. Blanken/ H. van Hirtum;Helvoirt, G.C.M. de Kroon; Hengelo(Ov), A.A. Kienhuis; H.A.M. van de Cammen; Heyjthuysen, C.A.H. Hameleers/ P.E.G.

Heuts;Hoensbroek, J.P.J. Paas/ P. van Dijk/ R.B.J. Helmers;Hoogeloon, J. van Barneveld/ J. Vissers; Horn, P.A.A. van de Ven;Horst, O.L.P.M. de Groen; T.P.A. te Boekhorst/ P.G.M. Uyen/ K.L.G. Schuurman; Ijsselstein, R.A. Keijzer/ L.A.M. Keijzer-Bors; Kerkrade, A.S. van Dam; P. de Bruyckere; Kilder, A.P. Verberk; Landgraaf, J.J.G. Jongschaap; J.J.P. van Hooren; R.J.A.M. Kuypers; Lieshout, H.B.J. Lindeman/ A.M. Rechters; Lochem, J.W.H. van Huijstee; Lottum, J. Sonke; Maarheze, F.G.G.M. Weijers; Maasbree, J.G.J. Janssen/R. Aendekerk/ van Venrooij; Maastricht, J.P.H.C. Buysrogge; mevr. G. van Pelt/mevr. K. Verstraete/ C. Ruissen; J.J.M. Theunissen; Th.F.W.A. Krebber; G.Wijnands; J.G.H.C. Hamers/ drs.Langenberg/drs.Zonneveld; Made, R. Gaymans/ R.F.M. Jansen/ W.C. Snieders/W.A. van Damme; Malden, P.H. van de Rijt; Margraten, G.W. Priem; Mechelen, H.J.M.H.Huijben; P.P. F.M.Andriessen;Melick, drs. A.Broen; Mill, L.B.J.M. Veelers;Neerkant, P.H. Wout;Nieuw-Bergen, J.J.A.M. Luiken/ G. Bruggeman; Nieuwstadt, R.C.B. Ubachs; Nijkerk, J.J. van Daalen;H.A.A.J. Smorenburg; P.J.A. De Bruijne; J. Oldenburger/ B.J.G. Doornekamp; Nijmegen, mevr. L.G.M. Janssen/ A.A.M. van Erp/ F.B.J. Peters; J.A.M. van Dijk; M.Y. Wong-Schung/mevr.H. Nabuurs; Drs. V. de Jong/ M. Postma; Oirschot, A.M.P. Linsen; Oisterwijk, R.C.A. Rasenberg; Oploo, E.W.A.M. Weijnen/ J.H. van der Horst-Schrier; Ospel, C.M. Hussaarts/ A.P. van Eck; Oss, A.S.J.J. Jenniskens/ M.J.R.M. Buijs/ R.P. Hermans; Ottersum, W.F.W. Jacobs/H.A.C.J. de Waart/ M. Fortuin; Overasselt, J.M. Vorstenbosch; Overloon, P.M.F. Linssen/ mevr. C.H Linssen-Mooy; Panningen, J.M.C. Loozen; Prinsenbeek, I.C.M.Godschalk/ O.J. Veldhuizen/ J.L.M. Koch; Rhenen, H.J. Nederhorst/ H.H.G. de Jong/ N.C.M. Nicolay; Roermond, G.H.M. ten Oever; drs. M. den Heyer/ D.F.W. Mooren/mevr.M.M.D. SmalsOomen/ J.A. Joziasse; H.J. de Vries; J.W.M. van Rooij; Rosmalen, J.A. Houwen; 's Gravenmoer, W.F. Loth; 's Gravenzande, P.D. Visser/ Y.J. Bezuyen/ J.W. Attema;'s Hertogenbosch, M.J. Smulders; drs. Langenberg; A.F.E. Bots; J.H. Aussems; C.J.H. Broekmeulen; Sittard, J.W. Hamers/ A.J.M. Alberts; Mevr. M.T. van Lierop/ W.H.L.J. Dominicus; C.M.E. Liedekerken; Son, H.L. Plasmans; St. Anthonis, C.W.G.J. van de Wert/I. Jaarsma; St. Oedenrode, M.A.C.M. van Osch/mevr. ACM van Mil; Stein, C.J. Vincentie; A. van den Berg; L.O.V. de Wolf; Stramproy, J.J.M. Takken/ G. P.M. Kusters/ D.B.P.M. Snel/mevr. N.M.L. Haselager-Wolfs; Tegelen, Th. Mangnus;Teringen, mevr. J de Kam/ C.A. van Walsum/ B.J.Smit; Tiel, R. van Kimmenade; mevr.drs. Houtman; Tilburg, mevr. A.J. Lindhout-Jansen/ B.F.M. de Kort - de Bont; mevr. T. Hoynck van Papendrecht/M.

Berghege; Ugchelen, F.A.T. van der Heijden; Ulestraten, W.M.F. Ritzen; Veghel, P. Teunis; Velden, J.Jansma/ R.S.M. Schonck; Mevr. T.A. Goddijn-Wessel; Veldhoven, W.D. Haitsma; Venlo, J.J. Hoyng/L.A.P. Verhappen/ Mevr. M. van Deelen-Willems/ M.J.J.S. Crobach /A. van Deelen; H.G.M. Op den Kamp; G.M. Pacilly; Venray, H. Schraven/ M. van Thiel/ F. A. J. Schmeetz/mevr. E. van Thiel-Knoppen/M.W.T. Lucassen; A.J.M. Coenen/ E. de Muinck/ G. van Loon; P.P.M.C.A. Henkes; J.W.T.M. de Vocht; Voorthuizen, E.A. ten Hoor; Vught, P.H. van de Berg; Waalwijk, W. P.M. Weebers/W. Stenvers/mevr. M.E.J. Gerrits; Wageningen, A.G.M. Gradenwitz; T.L. Bijlsma; Wapenveld, J. M. Zwanenburg; Weert, T.L. Berghuis/ J.S.M. Koopmans; M.H.J.M. Rietjens; M.P.J.C. Wolters; H.E.H. Hamelers; Th.J.J. de Leeuw/ G.L.M. Buijs; B.J.S. Koopmans/ Drs. Kessels; Westervoort, J.J. van Dijke; W. v.d. Pan; Wijnandsrade, P.P.M. Hobus; Zaltbommel, mevr. J.A. van Wijgerden; Zetten, mevr. M.J. Buitendijk/P.N. Hilderink/ J. M. de Lange/ P.C.M. van de Weerd; Zevenaar, B.J.G. Zegger 
Curriculum vitae H. J.A.M. Schönberger

Geboren te Venray op 20 februari 1946.

1965: diploma Gymnasium $\beta$ aan het Lyceum voor Jongens "Maria Ïmmaculato Conceptione" te Venray.

1972: diploma geneeskunde Katholieke Universiteit te Nijmegen.

1973: diploma ECFMC (Educational Council For Foreign Medical Graduates)

1972-1973: opleiding tot tropenarts. Eudokia Ziekenhuis te Rotterdam.

1974- 1975: militair dienstplichtig arts, afdeling KNO van het militair hospitaal "Oog en $\mathrm{Al}^{\prime \prime}$ te Utrecht.

1975-2000: gevestigd als apotheekhoudend huisarts te Well (gem. Bergen, Limburgl.

1978-2000: huisarts-opleider bij vakgroep huisartsgeneeskunde van de Radboud Universiteit Nijmegen

1996-1997: onderzoek bij de vakgroep huisartsgeneeskunde te Nijmegen naar het familiale vōórkomen van allergische aandoeningen in de huisartspraktijk.

1985-2000: academisch huisarts, verbonden aan academisch netwerk huisartspraktijken (RegistratieNetwerkHuisartsen) van de vakgroep huisartsgeneeskunde van de Universiteit Maastricht.

1998-2002:Part-fime verbonden als huisarts-onderzoeker aan de vakgroep huisartsgeneeskunde, in welke tijd de PREVASK studie werd uitgevoerd.

2000: diploma huisarts-onderzoeker an de Netherlands School of Primary Care Research (CARE) 



\section{APPENDICES}

\section{N.B. Kortheidshalve zijn de compliantie vragenlijsten en de gezondheidsvragenlijsten (ISAAC-questionnoires 6 maanden, 1 en 2 jaar) niet weergegeven.}

\section{Appendix 1.}

\section{The primary prevention program of asthma in the PREVASC study}

The primary prevention consisted of a comprehensive, non-pharmaceutical approach of asthma, by which lifestyle changes were pursued by means of health educational instructions. The instruction was directed towards asthmatic families. Trained nurses gave the educational advice during home visits before birth (two times) and after birth (one time).

The advised measures to reduce were:

1. Mite allergen exposure from birth and through at least the first two years of life by:

- providing a smooth floor covering in living room, bedroom and nursery;

- thorough cleaning by vacuuming/damp mop;

- washing bed-clothes at 60 degrees Celsius;

- using anti house dust mite covers for parental and crib mattresses, provided without charge;

- providing a new crib mattress;

- ventilating continuously and airing daily during one hour the sleeping rooms.

2. Cat and dog allergen exposure from birth and through at least the first two years of life by:

- not procuring pets;

- in case of pet-owning: re-housing pets and when refused, regularly washing them and keeping them outside the house, starting 3 month before birth.

3. Food allergen exposure during at least the first six months of life by:

- breast-feeding the newborn exclusively;

- when not possible or when supplemental milk feeding was necessary to use of hypoallergenic formula feeding (provided subsidized);

- no feeding with regular formula feeding;

- no introduction of solid foods until after 6 months of life.

4. Tobacco smoking exposure

- no maternal prenatal and postnatal smoking;

- no paternal postnatal smoking during at least the first year of life;

- no smoking by others inside the house during at least the first year of life. 


\section{EXCERPT VOORLICHTINGSPROTOCOL PREVASK INTERVENTIE $1^{E}$ HUISBEZOEK}

\section{VOORLICHTING OVER PREVASK}

U neemt deel aan het onderzoek genaamd Preventie van Astma bij Kinderen. In de brief die u van uw huisarts/van ons heeft ontvangen heeft $\mathrm{u}$ al kunnen lezen wat het onderzoek inhoudt. Graag zou ik in het kort de belangrijkste informatie willen herhalen. $U$ krijgt van mij ook een algemene informatiefolder over het onderzoek, zodat $u$ ook in een latere fase van het onderzoek alles nog eens rustig kunt nalezen. Ook krijgt u van mij dit boekje (120 vragen over CARA).

\section{INSTRUCTIE HUISSTOFMIJTWERENDE MAATREGELEN}

De huisstofmijt en dan met name de "uitwerpselen" van huisstofmijten hebben een grote invloed op het ontstaan van astma. Bekend is dat veel mensen reageren op deze "prikkelende stof". De huisstofmijt komt in ieder huis voor en leeft het prettigst in een vochtige omgeving waar veel huidschilfers te vinden zijn. Hij eet namelijk huidschilfers. Er zijn een aantal maatregelen die u kunt nemen, die het leven van de huisstofmijt zuur maken. Die maatregelen zijn belangrijk omdat de kans op het ontstaan van een huisstofmijtallergie bij uw kindje waarschijnlijk kleiner is als er maar weinig huisstofmijten in zijn omgeving voorkomen. De huisstofmijtwerende maatregelen waarover ik $\mathrm{u}$ voorlichting wil gaan geven hebben betrekking op de volgende dingen:

1. Zorgen dat de huisstofmijt weinig voedsel tot zijn beschikking heeft, waardoor hij zich minder lekker voelt en zich niet zo snel voortplant. Dit bereikt u door heel goed schoon te maken en gladde materialen te gebruiken in huis;

2. Het doden van de huisstofmijt. Dit bereikt $u$ door alles op minimaal 60 graden te wassen in de wasmachine;

3. Zorgen dat de uitwerpselen van de huisstofmijt niet worden ingeademd. Dit bereikt $u$ door speciaal beddengoed te gebruiken, waarover ik u straks meer zal vertellen;

4. De omgeving van de huisstofmijt zó onaangenaam maken voor het beestje dat hij zich er niet prettig bij voelt. Dit laatste kan je doen door de luchtvochtigheid omlaag te brengen. Hierover vertel ik tijdens het volgende huisbezoek meer.

Ik zal u nu wat praktische tips geven over hoe $\mathrm{u}$ de babykamer het beste kunt inrichten, om zo de concentratie huisstofmijten zo laag mogelijk te houden.

Bij de inrichting van de babykamer is het belangrijk om zoveel mogelijk voor gladde materialen te kiezen omdat deze goed schoon te houden zijn. Het gaat dan om de vloerbedekking (linoleum, laminaat) en de meubeltjes (met zo weinig mogelijk "tierlantijnen"). Knuffels dienen uitwasbaar te zijn op 60 graden omdat de huisstofmijt bij deze temperatuur dood gaat (kies hier voor een vulling van katoen of synthetisch materiaal). Ook al staat op de labels van sommige katoenen/synthetische knuffels dat je ze op 30 of 40 graden mag uitwassen, kunnen ze vaak toch ook 60 graden verdragen. De kleuren worden dan alleen iets sneller vaal.

De matras van het babybed is bij voorkeur nieuw, met een vulling van schuim of kunststof (bijv. polyether). Gebruik geen "winterkant" en gebruik een overtrek en lakens van katoen, omdat deze uitwasbaar zijn op 60 graden. Als u kiest voor gordijnen op de babykamer is het van belang dat ook deze uitwasbaar zijn op 60 graden. Is dit niet mogelijk, was ze dan zeer regelmatig uit op een lagere temperatuur. De huisstofmijt gaat dan niet dood, maar de uitwerpselen worden wel uit de gordijnen gewassen.

Overhandig Folder: "voorkomen van astma door preventief saneren"

In deze folder, leest $u$ meer over de inrichting van de babykamer en andere saneringsmaatregelen, waar ik in het tweede bezoek nog uitgebreid op terug zal komen.

In het kader van dit onderzoek mag ik huisstofmijtondoorlaatbaar beddengoed bestellen voor $u$. Uiteraard hoeft $u$ hier niets voor te betalen. Het beddengoed dat ik zal bestellen voor $\mathrm{u}$, is gemaakt van materiaal waar de huisstofmijt niet doorheen kan en waar ook het voedsel (huidschilfers) van de huisstofmijt niet doorheen kan. Om te voorkomen dat jullie kindje in aanraking komt met hoge concentraties huisstofmijten, is het van belang deze materialen te gebruiken. In met name matrassen zitten normaal gesproken namelijk heel veel mijten omdat er veel voedsel te vinden is en omdat het er vochtig is. Omdat jullie kindje waarschijnlijk ook vaak bij jullie in bed zal liggen, krijgen jullie ook voor jullie eigen bed materialen. Hierbij gaat het om een matrashoes (of -hoezen als het gaat om twee eenpersoons matrassen), kussenslopen en een dekbed (of dekbedden). 


\section{INSTRUCTIE ROKEN}

Ik zou graag willen weten of $\mathrm{u}$ of uw man roken?

\section{Zo nee.}

Het is prima dat u en uw man niet roken, want roken vergroot de kans op het ontstaan van astma bij uw baby en heeft natuurlijk ook nadelige gevolgen voor uw eigen gezondheid. Wel wil ik erop wijzen dat het van belang is dat uw baby zo min mogelijk in rokerige omgevingen wordt gebracht. Dit omdat de baby dan toch iedere keer passief zal mee roken, wat de kans op het ontstaan van astma vergroot. Houd hier dus rekening mee met bijvoorbeeld rokende visite en dergelijke. Overhandig: Folder "Astma, zwangerschap en roken".

\section{Zo ja :volg de stappen van de MIS-interventie (stroomdiagram en interventiekaart Hoeveel rookt $u$ ? \\ Wanneer rookt $\mathrm{u}$ uw eerste sigaret? \\ Denkt $\mathrm{u}$ er wel eens aan om te stoppen met roken? \\ Binnen welke termijn?

$$
<1 \text { maand: Gemotiveerd (Zie 1) }
$$$$
>1 \text { maand: Ongemotiveerd (Zie 2) }
$$

\section{Gemotiveerd}

Het is goed dat u binnen één maand wilt stoppen want er zijn tal van nadelige gevolgen bekend van roken gedurende de zwangerschap, zowel voor $\mathrm{u}$ als uw baby. Vooral een slechtere algemene conditie, ademhalingsstoornissen en luchtweginfecties zijn van belang omdat uw kind een verhoogde kans heeft op het ontwikkelen van astma. Ook kunnen vroeggeboorte en problemen bij het geven van borstvoeding door het roken voorkomen. Tenslotte is de kans op een zogenoemde huilbaby groter. In de brochures "Astma, zwangerschap en roken" en de brochure van STIVORO vindt u meer informatie over de nadelige gevolgen van roken.

Overhandig: Folder: "Astma, zwangerschap en roken"; Folder: "Stoppen met roken"; Folder: "Gelieve in deze kinderkamer niet te roken".

\section{Opsporen Barrières}

$\begin{array}{ll}- & \text { Heeft } u \text { al eerder een stoppoging ondernomen? } \\ \text { - } & \text { Waarom is het toen mislukt? }\end{array}$

$O p$ de antwoorden ingaan en verwijzen naar de brochure van STIVORO voor handige tips om rookgewoonten te veranderen.

Als $u$ van plan bent om te gaan stoppen is een goede voorbereiding belangrijk. Het is bekend dat een goede voorbereiding de kans van slagen vergroot. Ook hierover vindt $u$ in de brochure allerlei handige tips en adviezen.

$\mathrm{U}$ gaf zojuist aan dat $\mathrm{u}$ denkt (termijn) wilt stoppen. Als u het prettig vindt kunnen we een datum afspreken.

Zo ja:

Ik kan dan na deze datum contact met u opnemen om te vragen hoe het gaat en u te steunen. Als u dat prettiger vindt, kunt $\mathrm{u}$ ook contact opnemen met mij.

Zo nee:

Vindt u het prettig als ik u over ongeveer een maand opbel, om te vragen of de stoppoging geslaagd is?

\section{Ongemotiveerd}

Als u rookt gedurende de zwangerschap, krijgt uw baby de schadelijke stoffen uit de tabaksrook binnen via de navelstreng. Het is zelfs zo dat het nicotinegehalte van het bloed van uw baby hoger is dan het nicotinegehalte van uw eigen bloed. Door het roken tijdens de zwangerschap stijgt de bloeddruk en daalt het zuurstofgehalte in het bloed van uw baby. Hierdoor gaat de conditie van uw baby achteruit, wat ook met de bevalling een rol speelt.

Roken kan ook leiden tot groeistoornissen. Belangrijk is verder dat de groei van de longen wordt belemmerd door het roken gedurende de zwangerschap. Dit terwijl een goede ontwikkeling van de longen juist voor uw kind zo van belang is omdat uw baby een grotere aanleg heeft voor het ontwikkelen van astma.

Ook als de baby eenmaal geboren is, heeft roken nadelige consequenties. Bekend is dat deze baby's meer verkoudheden en andere luchtweginfecties hebben. Ook hebben meerokende zuigelingen last van een vergrote neusamandel en oorontstekingen. Kinderen met een aanleg voor astma (zoals uw baby) hebben ook veel meer last van piepen en benauwdheid als er gerookt wordt.

Het geven van borstvoeding verloopt moeizamer wanneer u rookt. Zowel de hoeveelheid als de kwaliteit van de borstvoeding is slechter. De kans van slagen van de borstvoeding is dus geringer. Tenslotte is de kans op een zogenaamde huilbaby ook groter wanneer u tijdens en na de zwangerschap blijft roken. 
Dit zijn heel in het kort een aantal nadelige gevolgen voor uw baby als u of anderen blijven roken. Door het rookvrij maken van de omgeving van de baby kan voorkomen worden dat deze gevolgen optreden.

$\mathrm{Nu} \mathrm{u}$ op de hoogte bent van al deze nadelige gevolgen van het roken, bent u dan bereid om te stoppen met roken? Overhandig: Folder: "Astma, zwangerschap en roken"; Folder: "Stoppen met roken"; Folder: "Gelieve in deze kinderkamer niet te roken".

\section{INSTRUCTIE HUISDIEREN}

Heeft $u$ huisdieren?

Zo nee.

Het niet hebben en niet aanschaffen van huisdieren is prima. Huisdieren zijn namelijk zowel direct als indirect een prikkel voor het ontstaan van astma. Direct omdat mensen allergisch kunnen reageren op huisdieren en indirect omdat de huisstofmijt door de extra huidschilfers van huisdieren zich extra eenvoudig kan vermenigvuldigen. Om te voorkomen dat de luchtwegen van uw baby gaan reageren op de huisdieren is het dus heel goed om geen huisdieren te hebben of aan te schaffen.

Zo ja.

Huisdieren zijn zowel direct als indirect een prikkel voor het ontstaan van astma. Direct omdat mensen allergisch kunnen reageren op huisdieren en indirect omdat de huisstofmijt door de extra huidschilfers van huisdieren zich extra eenvoudig kan vermenigvuldigen. Om te voorkomen dat de luchtwegen van uw baby gaan reageren op schilfers van huisdieren is het dus eigenlijk beter om uw huisdieren weg te doen of buiten te laten tot uw baby in ieder geval 1 jaar is.

Als mensen niet gemotiveerd lijken om hun huisdier weg te doen of buiten te laten, kan je aangeven dat er alternatieven zijn.

Alternatieven voor het wegdoen van huisdieren zijn: 1.De huisdieren regelmatig wassen en zeer regelmatig buiten borstelen; 2.Niet op de slaapkamers laten komen; 3.De dieren niet te dicht bij de baby laten komen.

Als je huisdieren in huis hebt, is goed schoonmaken extra belangrijk. Hierover leest u meer in de folder "Voorkomen van astma door preventief saneren".

\section{SAMENVATTING VOORLICHTING}

Ik heb u nu geïnformeerd over het onderzoek in het algemeen, over het stoppen met roken, de inrichting van de babykamer en het hebben van huisdieren. Dit zijn dus allemaal factoren die van invloed zouden kunnen zijn op het ontstaan van astma.

Heeft $u$ nog vragen over alle informatie die ik $u$ nu heb gegeven?

Tijdens het volgende huisbezoek zal ik $u$ wat uitgebreider informeren over maatregelen als luchten en ventileren en over de voeding van het kindje.

\section{AFSLUITING}

Tijdens de zevende of achtste zwangerschapsmaand kom ik weer op huisbezoek. Als er vragen of onduidelijkheden zijn kunt $\mathrm{u}$ gerust bellen. Op het visitekaartje staat het nummer waarop u onze secretaresse kan bereiken.

\section{EXCERPT VOORLICHTINGSPROTOCOL $2^{\mathrm{E}}$ HUISBEZOEK $\left(7-8^{\mathrm{E}}\right.$ MAAND)}

\section{INTRODUCTIE}

De vorige keer hebben we gesproken over maatregelen met betrekking tot de huisstofmijt, roken en huisdieren. Tijdens dit huisbezoek ga ik verder in op het hielprikje, huisstofmijtwerende maatregelen, (eventueel roken en huisdieren), de voeding van de baby, en het babydagboekje.

Allereerst zou ik echter willen vragen of er naar aanleiding van het eerste huisbezoek nog vragen zijn?

\section{HUISSTOFMIJTWERENDE MAATREGELEN}

Tijdens het eerste huisbezoek hebben we besproken dat de huisstofmijt een grote invloed heeft op het ontstaan van astma. Door middel van huisstofmijtwerende maatregelen kunt $u$ het aantal huisstofmijten in uw huis verminderen. We hebben de vorige keer gesproken over het doden van de huisstofmijt door knuffels, gordijnen, beddengoed e.d. te wassen op 60 graden. Daarnaast hebben we gesproken over het belang van goed schoonmaken; hoe gladder de oppervlakken hoe makkelijker ze schoon te houden zijn. Ook hebben we gesproken over het 
huisstofinijtondoorlaatbare beddengoed. Als het goed is hebben jullie alles nu ontvangen. Vandaag zal ik u vertellen hoe $u$ de luchtvochtigheid kunt beïnvioeden.

\section{Vocht bestrijden}

De huisstofmijt voelt zich het beste bij een luchtvochtigheid van boven de $60 \%$. Vandaar dat wij adviseren de luchtvochtigheid tussen de 40 en $50 \%$ te houden. U kunt de luchtvochtigheid in huis naar beneden brengen door goed te ventileren en luchten. Met ventileren wordt bedoeld dat er permanent "iets" bijvoorbeeld een raam of een bovenlicht open staat. Luchten van de kamers waar de baby komt moet éen keer per dag goed gebeuren. Dit kan door de raam of deur helemaal open te zetten, gedurende minimaal een uur.

Waarom nu ventileren en luchten? Vochtigheid in de lucht gaat van warm naar koud en van een hoge concentratie naar een lage concentratie. Dat betekent dat in de winter, wanneer het binnen warmer is dan buiten de vochtigheid door het open raam naar buiten gaat. In de zomer is het buiten vaak warmer dan binnen, maar de concentratie vocht in de buitenlucht is dan veel lager dan de concentratie vocht binnen. Vandaar dat het belangrijk is om ongeacht het weer altijd goed te ventileren en luchten.

Naast het ventileren en luchten is het van groot belang dat $u$ de verwarming aan laat staan als het raam open is. Dit omdat het verschil in temperatuur tussen de binnen- en buitenlucht dan groter is en het vocht sneller naar buiten trekt. In de zomer hoeft u de verwarming natuurlijk niet aan te zetten.

Ook in verband met de luchtvochtigheid is het goed om de temperatuur van de babykamer overdag en s'nachts niet te veel te laten verschillen. Wij adviseren de kamer s'nachts niet meer dan twee graden koeler te laten worden dan overdag.

Ook dient $u$ de verspreiding van vocht in huis tegen te gaan. Dit kan door in huis zo min mogelijk vocht te produceren en geproduceerd vocht via afzuigkap, open ramen of deuren zo snel mogelijk uit het huis te verwijderen. Belangrijk is het om $u$ aan te wennen altijd de afzuigkap aan te zetten als $u$ iets aan het koken bent, ook wanneer $u$ alleen water kookt voor bijvoorbeeld thee (ook bij waterkoker). Naast de keuken is de badkamer naturrlijk een bron van vocht. Tips voor de badkamer zijn bijvoorbeeld dat $u$ de deur gesloten houdt als $u$ aan het douchen bent of in bad zit en als $u$ van de badkamer af gaat het raam open te zetten of een ventilator te laten lopen. Wederom de deur van de badkamer dicht houden! Het vocht kan dan van de badkamer direct naar buiten en zal zich niet zo erg verspreiden door het huis.

\section{BORSTVOEDING}

I $\mathrm{k}$ zou graag willen weten of $\mathrm{u}$ van plan bent uw baby borstvoeding te gaan geven?

Zo ja.

Het is heel goed dat $u$ heeft besloten om borstvoeding te gaan geven. Uit onderzoek is namelijk gebleken dat borstvoeding beschermt tegen het ontstaan van astma. Omdat uw baby een verhoogde kans heeft op het ontstaan van astma is het dus goed om borstvoeding te geven. Moedermelk biedt daarnaast ook bescherming tegen veel infectieziekten.

Belangrijk om te benadrukken is dat het het beste is om gedurende minimaal zes maanden uitsluitend borstvoeding te geven. Dus ook geen bijvoeding in de vorm van groente en fruit. Als u uw baby eerder groente en fruit e.d. geeft is de kans op het ontwikkelen van astma of een allergie groter. De baby heeft in de eerste zes maanden van zijn leven ook geen andere voedingsstoffen nodig dan de moedermelk bevat.

Het kan natuurlijk voorkomen dat $\mathrm{u}$ wel borstvoeding wilt geven maar dat dit op de een of andere manier niet lukt. Wij adviseren $u$ dan om uw baby tot 6 maanden te voeden met anti-allergische flesvoeding. Via ons kunt $u$ antiallergische flesvoeding krijgen. Het gaat hierbij om Nutrilon Pepti.

Nutrilon Pepti is een voeding die normaal gesproken gegeven wordt aan kindjes die allergisch zijn voor koemelkeiwit. Het is dus géén experimentele voeding.

Het verschil tussen hypo-allergene voeding zoals Nutrilon Pepti en gewone flesvoeding is dat het koemelkeiwit in de Pepti in kleine stukjes is 'geknipt', zodat het lichaam van een baby dat eiwit niet meer herkent als koemelkeiwit. De kans dat een kindje allergisch gaat reageren op de Pepti is daardoor bijna uitgesloten. De voedingswaarde van Pepti en andere flesvoeding is hetzelfde, alleen ruikt hij anders en smaakt hij ook anders dan andere flesvoeding. Dit komt door de andere eiwitsamenstelling. $U$ zult de melk zelf vast heel vies vinden, maar babytjes raken zó gewend aan de smaak dat ze het zonder problemen zullen drinken. Door de andere eiwitsamenstelling heeft een kindje dat Pepti krijgt normaal gesproken groene ontlasting. Daar hoeft $u$ zich geen zorgen om te maken, want dit is normaal bij die voeding.

Een nadeel van Nutrilon Pepti is dat het veel duurder is dan gewone flesvoeding (ongeveer 30 tot 45 gulden per blik). Omdat wij vinden dat u geen extra kosten hoeft te maken omdat u meedoet met het onderzoek, kunt u de flesvoeding bij ons bestellen voor 20 gulden per blik. Gewone flesvoeding kost ook ongeveer 20 gulden.

Als u maximaal 2 flesvoedingen per dag geeft, kunt u kosteloos pakjes Pepti bij onze secretaresse bestellen (telefoonnummer op visitekaartje en folders). Als u meer dan 2 flesvoedingen per dag geeft kunt u blikken bestellen, 
wederom door contact op te nemen met onze secretaresse. Het is verstandig goed op tijd te bellen, liefst als u met het op één na laatste blik gaat beginnen. De verzending duurt namelijk ongeveer een week is onze ervaring.

Mocht het onverhoopt gebeuren dat $u$ de voeding te laat ontvangt van ons, dan kunt $u$ zelf een blik of pakjes kopen. Als $u$ het bonnetje bewaart en opstuurt naar ons (enveloppen dagboekje) krijgt u de meerkosten van ons terug. Dit betekent dat $\mathrm{u}$ in elk geval altijd maar 20 gulden zelf hoeft te betalen.

\section{Zo nee.}

Het is jammer dat u denkt uw baby geen borstvoeding te gaan geven. Staat uw besluit helemaal vast? Wat zijn voor u de redenen om geen borstvoeding te geven?

Indien de vrouw vastbesloten is om geen borstvoeding te geven en dit met argumenten kan onderbouwen kun je het hierbij laten. Argumenten van jou zullen nu enkel weerstand op roepen. Indien het besluit nog niet geheel vast staat, of weinig argumenten kunnen worden genoemd kun je beginnen met het onderstaande.

Het is jammer dat $\mathrm{u}$ uw baby geen borstvoeding wilt gaan geven. Borstvoeding is namelijk de beste voeding die $\mathrm{u} u \mathrm{u}$ baby kunt geven. Het bevat alle benodigde voedingsstoffen en biedt daarnaast een goede bescherming tegen allerlei ziekten. Onderzoek heeft aangetoond dat moedermelk beschermt tegen het ontstaan van astma. Omdat uw baby een aanzienlijk grotere kans heeft op het ontstaan van astma is het dus goed om de baby borstvoeding te geven.

Daarnaast beschermt borstvoeding tegen veel infectieziekten als verkoudheid, hoesten etc. Door middel van borstvoeding is uw baby in staat om de eerste zes maanden waarin zijn eigen afweersysteem nog onvoldoende ontwikkeld is, te overbruggen.

Verder vermindert moedermelk de kans op diarree, verstopping, suikerziekte, hersenvliesontsteking en nierinfecties.

Zoals u begrijpt vormt het geven van borstvoeding een goede bescherming tegen tal van ziekten. Mocht $\mathrm{u}$ besluiten om tóch borstvoeding te gaan geven dan is het volgende van belang. Het is het beste om uw baby zo lang mogelijk borstvoeding te geven. Liefst minimaal zes maanden. Uw baby heeft in de eerste zes maanden ook niets anders nodig. Moedermelk bevat alle benodigde voedingsstoffen.

Wanneer $\mathrm{u}$ toch nog onoverkomelijke bezwaren heeft tegen het geven van borstvoeding of geen borstvoeding kunt geven raden wij $u$ aan om uw baby, vanaf de geboorte totdat uw kindje zes maanden is, "speciale" flesvoeding te geven. Hiermee bedoel ik een anti-allergische flesvoeding. Via ons kunt $u$ anti-allergische flesvoeding krijgen. Het gaat hierbij om Nutrilon Pepti.

Nutrilon Pepti is een voeding die normaal gesproken gegeven wordt aan kindjes die allergisch zijn voor koemelkeiwit. Het is dus géén experimentele voeding.

Het verschil tussen hypo-allergene voeding zoals Nutrilon Pepti en gewone flesvoeding is dat het koemelkeiwit in de Pepti in kleine stukjes is 'geknipt', zodat het lichaam van een baby dat eiwit niet meer herkent als koemelkeiwit. De kans dat een kindje allergisch gaat reageren op de Pepti is daardoor bijna uitgesloten. De voedingswaarde van Pepti en andere flesvoeding is hetzelfde, alleen ruikt hij anders en smaakt hij ook anders dan andere flesvoeding. Dit komt door de andere eiwitsamenstelling. $U$ zult de melk zelf vast heel vies vinden, maar babytjes raken zo gewend aan de smaak dat ze het zonder problemen zullen drinken. Door de andere eiwitsamenstelling heeft een kindje dat Pepti krijgt normaal gesproken groene ontlasting. Daar hoeft u zich geen zorgen om te maken, want dit is normaal bij die voeding.

Een nadeel van Nutrilon Pepti is dat het veel duurder is dan gewone flesvoeding (ongeveer 30 tot 45 gulden per blik). Omdat wij vinden dat u geen extra kosten hoeft te maken omdat $u$ meedoet met het onderzoek, kunt $u$ de flesvoeding bij ons bestellen voor 20 gulden per blik. Gewone flesvoeding kost ook ongeveer 20 gulden.

Als u maximaal 2 flesvoedingen per dag geeft, en de rest van de dag dus borstvoeding geeft, kunt u kosteloos pakjes Pepti bij onze secretaresse bestellen (telefoonnummer op visitekaartje en folders). Als u méér dan 2 flesvoedingen per dag geeft kunt u blikken bestellen, wederom door contact op te nemen met onze secretaresse. Het is verstandig goed op tijd te bellen, liefst als $u$ met het op één na laatste blik gaat beginnen. De verzending duurt namelijk ongeveer een week is onze ervaring.

Mocht het onverhoopt gebeuren dat $u$ de voeding te laat ontvangt van ons, dan kunt $u$ zelf een blik of pakjes kopen. Als u het bonnetje bewaart en opstuurt naar ons (enveloppen dagboekje) krijgt u de meerkosten van ons terug. Dit betekent dat $\mathrm{u}$ in elk geval altijd maar 20 gulden zelf hoeft te betalen.

Overhandig brochure "Voorkomen van astma en borstvoeding".

\section{EERSTE HAPJE}

Ongeacht of $u$ kiest voor borstvoeding of voor Nutrilon Pepti, het het beste is om pas als uw kindje zes maanden is bijvoeding te geven in de vorm van groente en fruit. Als u uw baby eerder groente en fruit e.d. geeft is de kans op het ontwikkelen van astma of een allergie groter. 
Op deze kaart staan alle voedingsadviezen nog eens in het kort beschreven. U kunt deze kaart gebruiken om zelf nog eens na te lezen wat nu onze adviezen zijn, maar ook om andere hulpverleners zoals de medewerkers van het consultatieburo en eventueel een kinderarts, kraamverzorgende of andere hulpverlener op de hoogte te brengen van onze adviezen. Op deze manier hoeft u niet telkens weer uit te leggen dat u meedoet met ons onderzoek en wat de adviezen zijn die wij u gegeven hebben. Mochten deze medewerkers nog vragen hebben over onze adviezen, dan kunnen zij contact opnemen met ons, via de telefoonnummers die op de kaart staan.

\section{ROKEN}

Afhankelijk van de fase die in of na het eerste huisbezoek bereikt is, kan verder worden gegaan met de MISinterventie. Zie hiervoor het stroomdiagram, de handleiding en het protocol van huisbezoek 1 .

Geef de folder: "Roken? Niet waar de kleine bij is". Ook niet-rokende ouders krijgen deze folder. Vertel erbij dat het belangrijk is dat het kindje niet blootgesteld wordt aan sigarettenrook. Het advies is dat ouders en bezoek niet roken waar het kindje bij is en dat er goed gelucht wordt in nimtes waar gerookt is.

\section{HUISDIEREN}

Als het gezin huisdieren heeft kan je, afhankelijk van de situatie, eventueel nog ingaan op hetgeen tijdens het eerste huisbezoek besproken is.

\section{SAMENVATTING}

$\mathrm{Ik}$ heb $\mathrm{u}$ nu informatie gegeven over het beïnvloeden van de luchtvochtigheid in huis. Ook hebben we het gehad over het hielprikje, de voeding van de baby, het babydagboekje en de registratie van klachten door de huisarts. (Tenslotte hebben we het gehad over het stoppen met roken en over uw huisdieren).

$\mathrm{Zijn}$ er naar aanleiding van hetgeen ik verteld heb nog vragen?

\section{AFSLUITING}

De volgende keer dat ik bij u op huisbezoek zal komen zal ongeveer 3 weken nadat $u$ bevallen bent zijn. Indien u nog vragen heeft kunt $u$ ons altijd bellen.

\section{EXCERPT VOORLICHTINGSPROTOCOL $3^{\mathrm{E}}$ HUISBEZOEK (1-3 WEKEN NA DE GEBOORTE)}

\section{HUISSTOFMIJTWERENDE MAATREGELEN}

Tijdens de vorige huisbezoeken heb ik uitleg gegeven over de maatregelen die u kunt nemen om de huisstofmijt zoveel mogelijk te verwijderen en zo min mogelijk overlevingskansen te geven. Door het aantal huisstofmijten in huis en met name in de babykamer zoveel mogelijk te verminderen, denken wij dat de kans op het ontstaan van astma en allergie bij uw baby kleiner wordt.

Samenvattend waren de belangrijkste maatregelen die besproken zijn:

1. Het niet of buitenshuis houden van huisdieren, de dieren regelmatig wassen en zeer regelmatig buiten borstelen;

2. Het gebruik van huisstofmijtondoorlaatbaar beddengoed;

3. Ventileren, luchten en verwarmen om de luchtvochtigheid omlaag te brengen, waardoor de huisstofmijt zich niet zo lekker voelt en zich dus niet zo snel zal voortplanten;

4. Heel goed schoonmaken zodat de huisstofmijt weinig voedsel kan vinden en zich dus niet zo snel zal voortplanten;

5. Een gladde inrichting van met name de babykamer.

\section{VOEDING}

Geeft u uw baby borstvoeding?

Zo ja.

De vorige keer hebben we al uitvoerig gesproken over het belang van borstvoeding geven. Met name in jullie geval is dit erg belangrijk omdat jullie kindje een grotere kans heeft op het ontstaan van astma. Het is dus heel goed dat $u$ borstvoeding geeft. Zoals $u$ heeft kunnen lezen in de brochure biedt borstvoeding naast astma ook bescherming tegen luchtweginfecties en hebben borstgevoede baby's minder last van aandoeningen als bronchitis, koemelkeiwitallergie en eczeem (dauwworm).

Het is van belang om te proberen zo lang mogelijk borstvoeding te geven, het liefst langer dan zes maanden. Ook bijvoeding in de vorm van vaste voeding zoals een fruithapje, soepstengel etc. dient u uit te stellen tot uw baby 
minstens zes maanden is. De reden hiervan is dat het afweersysteem van pasgeboren baby's nog niet helemaal werkt zoals dat van een volwassene. De kans op het ontstaan van een voedingsallergie is tijdens deze periode dan ook groter. Tijdens de periode dat de baby borstvoeding krijgt, wordt zijn/haar afweersysteem 'geholpen' door de afweerstoffen van de moeder die in de moedermelk zitten.

Wij gaan ervan uit dat het afweersysteem van een baby na zes maanden zover ontwikkeld is dat de kans op het ontstaan van een allergie voor voeding klein is. Vanaf zes maanden mag $u$ dan ook gerust beginnen met bijvoeding in de vorm van groenten en fruit. Op het consultatieburo kunnen ze $u$ helpen met hoe $u$ het beste kan beginnen met bijvoeding. Mocht $u$ hierover toch nog vragen hebben, bel dan gerust op naar ons.

Het is natuurlijk het beste om zo lang mogelijk borstvoeding te geven. Als u na zes maanden over wilt gaan op flesvoeding mag uw baby, net als andere kindjes, beginnen met opvolgmelk. De opvolgmelk hoeft géén antiallergische voeding te zijn. Uiteraard mag u er wel voor kiezen tóch anti allergische opvolgmelk te geven (bijvoorbeeld Nutrilon Pepti Plus). Voor het onderzoek hoeft het echter niet. Bij ons kunt u géén opvolgmelk kopen. Dus ook als u kiest voor Pepti Plus moet $u$ die zelf in de winkel kopen. U krijgt dit dus niet vergoed van ons.

Mocht het voor u niet mogelijk of wenselijk zijn om gedurende zes maanden borstvoeding te geven, zorg er dan in ieder geval voor dat u Nutrilon Pepti gebruikt. Ik heb de vorige keer al uitgelegd dat $\mathrm{u}$ deze voeding bij ons kunt bestellen voor 20 gulden per blik. Als u maximaal 2 flesvoedingen per dag geeft, kunt u pakjes bestellen bij ons. Deze zijn gratis. Mocht het onverhoopt gebeuren dat $u$ de voeding te laat ontvangt van ons, dan kunt $u$ zelf een blik of pakjes kopen. Als u het bonnetje bewaart en opstuurt naar ons (enveloppen dagboekje) krijgt u de meerkosten van ons terug. Dit betekent dat $\mathrm{u}$ in elk geval altijd maar 20 gulden zelf hoeft te betalen.

\section{Zo nee.}

Het is jammer dat u geen borstvoeding geeft, want zoals ik u de vorige keer ook heb verteld, zijn er duidelijke aanwijzingen dat het geven van borstvoeding de kans op het ontstaan van allergie en astma vermindert.

\section{Gebruikt u de Nutrilon Pepti?}

Het is belangrijk dat $u$ de eerste zes maanden alleen maar Nutrilon Pepti geeft en nog geen vaste voeding. Na ongeveer zes maanden is het afweersysteem van een baby'tje zover ontwikkeld dat de kans op het ontstaan van een allergie voor voeding kleiner is. Vanaf zes maanden mag u dan ook beginnen met bijvoeding. Dit betekent dus dat wij adviseren de baby gedurende de eerste zes maanden niets anders te geven dan Nutrilon Pepti. Op het consultatieburo kunnen ze $\mathrm{u}$ helpen met hoe $\mathrm{u}$ het beste kan beginnen met bijvoeding. Mocht $\mathrm{u}$ hierover toch nog vragen hebben, bel dan gerust op naar ons.

Ik heb de vorige keer al uitgelegd dat u de Nutrilon Pepti bij ons kunt bestellen voor 20 gulden per blik. Mocht het onverhoopt gebeuren dat $\mathrm{u}$ de voeding te laat ontvangt van ons, dan kunt u zelf een blik kopen. Als u het bonnetje bewaart en met uw naam erop geschreven opstuurt naar ons (enveloppen dagboekje) krijgt u de meerkosten van ons terug. Dit betekent dat u in elk geval altijd maar 20 gulden zelf hoeft te betalen.

Uw kindje mag vanaf zes maanden ook, net als andere kindjes, beginnen met opvolgmelk. De opvolgmelk hoeft géén anti-allergische voeding te zijn. Uiteraard mag $\mathrm{u}$ er wel voor kiezen tóch anti-allergische opvolgmelk te geven (bijvoorbeeld Nutrilon Pepti Plus). Voor het onderzoek hoeft het echter niet. Bij ons kunt u géén opvolgmelk kopen. Dus ook als u kiest voor Pepti Plus moet $\mathrm{u}$ die zelf in de winkel kopen. $U$ krijgt dit dus niet vergoed van ons.

\section{ROKEN}

Afhankelijk van de fase die in of na het tweede huisbezoek bereikt is, kan verder worden gegaan met de MISinterventie. Zie hiervoor de handleiding, het stroomdiagram en huisbezoek 1 . Indien de vrouw na de bevalling weer is gestart met roken, bespreek dan met haar de belangen van een rookvrije omgeving voor haar baby. Indien de vrouw geen borstvoeding geeft kun je nu wel ingaan op het stoppen met roken m.b.v nicotine-pleisters. Als de vrouw borstvoeding geeft zijn nicotinepleisters echter niet toegestaan

\section{HUISDIEREN}

Als het gezin huisdieren heeft kan je, afhankelijk van de situatie, eventueel nog ingaan op hetgeen tijdens het eerste huisbezoek besproken is

\section{SAMENVATTING}

Ik heb in het kort de huisstofmijtwerende maatregelen die u kunt nemen voor $u$ herhaald. Verder hebben we uitvoerig gesproken over de beste voeding voor uw baby. (Eventueel: Daarnaast hebben we gesproken over het roken en de huisdieren) Door het opvolgen van onze adviezen kunt $u$ de kans op het ontstaan van astma bij uw baby zoveel mogelijk verminderen.

\section{AFSLUITING}


Appendix 3

Time schedule of the PREVASC intervention and data sampling

\begin{tabular}{|c|c|c|c|c|c|c|}
\hline & $\begin{array}{l}\text { Intervention } \\
\text { /Instruction }\end{array}$ & $\begin{array}{l}\text { Dust sampling } \\
\text { and allergen } \\
\text { measurement }\end{array}$ & $\begin{array}{l}\text { ISAAC } \\
\text { questionnaire } \\
\text { on respiratory } \\
\text { symptoms }\end{array}$ & $I g E$ & $\begin{array}{l}\text { Questionnaires } \\
\text { on compliance }\end{array}$ & $\begin{array}{l}\text { Diary reports } \\
\text { on } \\
\text { respiratory } \\
\text { symptoms }\end{array}$ \\
\hline \multicolumn{7}{|l|}{ Time } \\
\hline $\begin{array}{l}\text { 4-6 month } \\
\text { before birth }\end{array}$ & \begin{tabular}{l}
\multicolumn{1}{c}{$1^{\text {st }}$ visit } \\
-General information \\
-Specific education on \\
avoidance of smoking, \\
and pet allergens
\end{tabular} & $\begin{array}{l}\text { Dust sampling } \\
\text { (living room, } \\
\text { crib and } \\
\text { parental } \\
\text { mattress) } \\
\end{array}$ & & & & \\
\hline $\begin{array}{l}1-2 \text { month } \\
\text { before birth }\end{array}$ & \begin{tabular}{l}
\multicolumn{1}{c}{$2^{\text {nd }}$ visit } \\
Specific education \\
-on avoidance of mite \\
and pet allergens \\
- on food allergens \\
- on passive smoking
\end{tabular} & & & & & \\
\hline $\begin{array}{c}1 \text { month } \\
\text { before birth }\end{array}$ & $\begin{array}{l}\text { Providing anti house } \\
\text { dust mite encasings for } \\
\text { crib and parental } \\
\text { mattress, quilt and } \\
\text { pillow. }\end{array}$ & & & & & \\
\hline \multicolumn{7}{|l|}{ BIRTH } \\
\hline \multicolumn{4}{|l|}{ 3-5 day } & $\operatorname{IgE}^{+}$ & & \\
\hline $0-3 w k s$ & \begin{tabular}{l}
\multicolumn{1}{c|}{$3^{\text {rd }}$ visit } \\
Repeating information \\
on avoidance of mite, \\
pet and food allergens \\
and passive smoking \\
\end{tabular} & & & & & \\
\hline \multicolumn{3}{|l|}{6 month } & ISAAC $^{\ddagger}$ & & Feeding practice & \\
\hline \multicolumn{2}{|l|}{$7-9$ month } & $\begin{array}{l}\text { Dust sampling* } \\
\text { (living room, } \\
\text { crib and } \\
\text { parental } \\
\text { mattress) }\end{array}$ & & & & \\
\hline \multicolumn{2}{|l|}{12 month } & & ISAAC $^{\ddagger}$ & $\operatorname{IgE}^{\dagger}$ & $\begin{array}{l}\text { Smoking } \\
\text { Mite and pet } \\
\text { allergens } \\
\text { measures }\end{array}$ & \\
\hline \multicolumn{2}{|l|}{24 month } & & ISAAC $^{\ddagger}$ & $\operatorname{IgE}^{+}$ & & \\
\hline
\end{tabular}


Geachte (aanstaande) ouder(s),

Onze praktijk doet mee aan een onderzoek van de afdeling huisartsgeneeskunde van de universiteiten van Maastricht en Nijmegen. Wij willen u vragen mee te werken aan dit grootschalig onderzoek naar het voorkómen van het ontstaan van astma bij kinderen. Daarover gaat de onderstaande informatie.

\section{Wat weten we over astma?}

Astma is bij kinderen één van de meest voorkomende ziekten. Tenminste één op de tien kinderen heeft wel eens astma klachten. De klachten ontstaan vaak in de eerste vijf levensjaren. Astma begint in die periode met herhaaldelijk terugkerende perioden van (nachtelijk) hoesten, piepen op de borst en benauwdheid. Huisartsen gebruiken dan vaak het woord bronchitis. Het merendeel van de kinderen houdt klachten op latere leeftijd.

We weten dat astma en bronchitis veel vaker ontstaan bij kinderen waarvan de ouders of broertjes of zusjes astma hebben. Kinderen die geboren worden in een dergelijke familie noemen we daarom erfelijk belast voor astma. Het is bij ons bekend dat klachten van astma bij u of uw gezin, in meerdere of mindere mate vóórkomt of vóórgekomen is. Gelukkig is het niet zo dat, omdat uw baby erfelijk belast is, het $100 \%$ zeker astma zal krijgen. Een kind kan astma krijgen als het als baby vaak in aanraking komt met prikkels die de gevoeligheid van zijn luchtwegen veranderen. Inmiddels kennen wij een aantal van deze prikkels. Dit zijn:

- $\quad$ het roken van de moeder tijdens de zwangerschap

- $\quad$ het roken (van de ouders of anderen) in aanwezigheid van de baby

- $\quad$ het niet geven van borstvoeding

- de aanwezigheid van huisdieren

- $\quad$ het in contact komen van de baby met de huisstofmijt in het eigen bedje of in het bed van de ouders, vooral in het eerste levensjaar. De huisstofmijt is een -voor het oog niet zichtbaarbeestje dat zich vooral ophoudt in matrassen, dekbedden en kussens van het bed van de baby en van uzelf.

Het ligt dus voor de hand te veronderstellen dat, als we ervoor kunnen zorgen dat de baby minder in aanraking komt met deze prikkels, astma gedeeltelijk kan worden voorkómen. Dat is de reden waarom we een preventieprogramma opgesteld hebben, waarin voorlichting wordt gegeven over deze prikkels en hoe deze zijn te vermijden.

\section{Wat willen we weten?}

In ons onderzoek willen we nagaan:

- $\quad$ of door het vermijden van deze prikkels inderdaad astma voorkómen kan worden of dat, als astma toch ontstaat, het verloop minder ernstig is

- $\quad$ of, en in welke mate ouders bereid zijn de preventieve adviezen op te volgen.

- $\quad$ welke kosten daardoor bespaard kunnen worden (bijvoorbeeld kosten van bezoeken aan een arts, van opname in het ziekenhuis, van geneesmiddelen, etc.)

Wij verwachten te kunnen aantonen dat ouders in staat zijn de adviezen m.b.t. preventieve maatregelen op te volgen en dat hierdoor astma bij hun kinderen veel minder vaak ontstaat. Als astma toch ontstaat, verwachten we dat het ziekteverloop minder ernstig is.

\section{Hoe kunnen we dat nu aantonen?}

Om aan te tonen dat astma bij kinderen voorkómen kan worden, zijn ongeveer 400 ouderparen en hun baby's nodig. 200 Van hen krijgen extra preventieve adviezen en de andere 200 krijgen de 'normale' zorg, dat wil zeggen dat zij geen aanvullende adviezen krijgen van de onderzoeksmedewerkers. $U$ bent ingedeeld in de groep die de preventieve adviezen krijgt. We gaan na of de baby's van wie de ouders de preventieve adviezen hebben gekregen en deze opvolgen, minder vaak astma krijgen dan de groep kinderen die 'normaal' behandeld is. De eerste adviezen met betrekking tot het preventieprogramma worden al direct na het vaststellen van de zwangerschap gegeven. Daarom benaderen wij $u$ liefst op dit tijdstip. Het onderzoek gaat als volgt:

U krijgt informatie en adviezen over de maatregelen die u kunt nemen om astma bij uw baby te voorkómen. Deze informatie krijgt u via een speciaal daarvoor opgeleide preventie- verpleegkundige, verspreid over drie huisbezoeken (aan het begin van de zwangerschap, halverwege de zwangerschap en ongeveer een maand na de bevalling). Zij zal u adviseren over: 
Het roken; het gunstige effect van het niet roken tijdens de zwangerschap en het niet roken in aanwezigheid van de baby door $u$ en anderen. De preventieverpleegkundige kan $u$ ook helpen te stoppen met roken.

- Het gebruik van allergeenvrije matras- en kussenhoezen en een trappelzak, die ervoor moeten zorgen dat uw baby niet in aanraking komt met de huisstofmijt. Omdat de baby uiteraard vaker bij u in bed zal liggen is het noodzakelijk dat ook uw bed wordt voorzien van speciale allergeenvrije matras- en kussenhoezen en (een) dekbed(den). De hoezen, het (de) dekbed(den) en de trappelzak, worden door ons gratis verstrekt en hebben een ligcomfort vergelijkbaar met dat van een normale matrashoes, kussensloop, trappelzak en dekbed.

- $\quad$ De wijze waarop de babykamer het beste kan worden ingericht, schoongemaakt en geventileerd.

- Het gunstige effect van het geven van borstvoeding of (indien dat niet mogelijk is) het geven van een speciale soort (allergeenarme) flesvoeding. Deze flesvoeding wordt via ons verstrekt tegen de kostprijs van normale flesvoeding. Het gaat hierbij om een flesvoeding die normaal gesproken gebruikt wordt bij kindjes die een voedselallergie hebben. De flesvoeding die u via ons kunt kopen is dus geen nieuwe of experimentele voeding.

- $\quad$ Het tijdstip waarop de baby het beste vast voedsel kan gaan gebruiken.

- Het houden van huisdieren.

De hierboven genoemde maatregelen zijn adviezen. Als $\mathrm{u}$, om wat voor reden dan ook, een advies niet kunt of wilt uitvoeren dan respecteren wij dat. $U$ kunt gewoon blijven deelnemen aan het onderzoek. Met de preventieverpleegkundige kunt u eventuele moeilijkheden bespreken. De voorlichtingsgesprekken die u tijdens het huisbezoek met de preventieverpleegkundige voert zullen ongeveer 1 tot 2 uur duren, afhankelijk van het moment waarop het bezoek plaatsvindt (bezoek 1, 2 of 3 ).

$\mathrm{Na}$ de drie voorlichtingshuisbezoeken zal de preventieverpleegkundige u nóg drie maal komen bezoeken ( 1 jaar na het eerste huisbezoek en als uw kindje 1 en 2 jaar is). Tijdens deze korte bezoeken zal zij enkele metingen komen doen. Deze meet-huisbezoeken duren ongeveer 15-30 minuten per keer.

Hoe weten we nu of de adviezen werkelijk effect hebben?

- Om een goede indruk te krijgen van de effecten van het preventieprogramma, willen wij alle medische gegevens die zouden kunnen wijzen op een mogelijke ontwikkeling van astma bij uw baby, vastleggen. Zoals u weet krijgen kinderen van 0-5 jaar, of ze nu astma hebben of niet, vaak een aandoening van de luchtwegen. Dit kan bijvoorbeeld een verkoudheid, een oor- of keelontsteking of bronchitis zijn. Wij zouden graag de gegevens over diagnose en behandeling van eventueel optredende ziekten van uw baby gedurende de eerste twee levensjaren gebruiken voor het onderzoek.

- Het ontstaan van allergie willen we vaststellen met behulp van een bepaling in het bloed. Zoals u wellicht weet wordt in Nederland iedere baby in de eerste week na de geboorte via een hielprik onderzocht op de aanwezigheid van een tweetal aangeboren afwijkingen. Bloed uit dezelfde hielprik willen we ook gebruiken om na te gaan of er wellicht sprake is van allergie. Op dat moment hoeft er dus geen extra prik gegeven te worden. De prik wordt na 1 en 2 jaar herhaald; dan wordt een beetje bloed uit de vinger gehaald door de preventieverpleegkundige.

- Van u wordt gevraagd of $\mathrm{u}$ bereid bent onder meer de gezondheidsklachten van uw kindje gedurende 2 jaar bij te houden. U verzamelt deze gegevens in een speciaal daarvoor ontwikkeld babydagboek, dat we u vragen eenmaal per 3 maanden op te sturen.

- Tijdens het onderzoek zal worden nagegaan in welke mate het u gelukt is de adviezen voor preventie op te volgen, welke voor $u$ haalbaar zijn gebleken en welke niet. We zullen u daarover in de 6e maand na de bevalling en na 1 jaar enkele vragen stellen. We zullen u op die tijdstippen en ook als de baby 2 jaar is, tevens vragen naar aanwezige klachten bij uw kind.

- Tijdens de huisbezoeken van de preventieverpleegkundige, worden een drietal metingen verricht; (1) om te zien of, door het gebruiken van de matrashoes en de andere adviezen, de huisstofmijt inderdaad minder voorkomt in uw huis worden een aantal stofmonsters genomen (door middel van opzuigen van stof). Daarin bepalen we dan o.a. de aanwezigheid van de huisstofmijt. Deze meting zal tijdens het eerste huisbezoek uitgevoerd worden en een jaar daarna. (2) De preventieverpleegkundige zal tijdens alle bezoeken de luchtvochtigheid in uw huis meten.

Eventuele risico's van het deelnemen aan het preventieprogramma

Aan het opvolgen van de preventieve adviezen zijn voor $u$ en uw baby geen risico's verbonden. Sterker nog, ons advies te stoppen met roken, bevordert zonder meer de gezondheid van uzelf en uw kind. De overige adviezen, zo wordt aangenomen, brengen eveneens gezondheidsvoordelen met zich mee. Dit geldt natuurlijk voor het advies borstvoeding te geven. Het geven van borstvoeding is immers nog altijd de beste voeding voor uw baby. 
Mogelijke voordelen en alternatieve behandelingen

Het is duidelijk dat het van grote betekenis is als zou blijken dat astma door dit preventie-programma voorkómen kan worden. Dat zou de ouder(s) en het kind veel leed besparen. Het kan ook, zo verwachten wij, leiden tot grote kostenbesparingen in de gezondheidszorg, omdat minder kinderen astma krijgen. Daardoor hoeven bijvoorbeeld minder geneesmiddelen te worden voorgeschreven en ook de huisarts en de specialist hoeven minder geraadpleegd te worden.

Op dit moment zijn er geen andere mogelijkheden om astma te voorkómen.

Ook zou het zo kunnen zijn dat de maatregelen die door u genomen worden, zelfs een gunstige invloed hebben op de klachten van het gezinslid met astma.

\section{Verzekering}

Zoals bij elk wetenschappelijk onderzoek gebruikelijk is, zijn deelnemers aan het onderzoek verzekerd tegen materiële schade (bijvoorbeeld het omstoten van een vaas tijdens een huisbezoek). Vragen hierover kunt $u$ stellen aan de leider van het onderzoek, dokter Schönberger. Hij zal u dan van de regelingen rond de verzekering op de hoogte brengen.

\section{Vrijwillige deelname}

Vanzelfsprekend bent $u$ niet verplicht aan het onderzoek deel te nemen. Ook kunt $u$ op ieder moment stoppen. Wij hopen natuurlijk dat dit zo weinig mogelijk gebeurt. Als u besluit niet aan het onderzoek deel te nemen, zal dat zeker geen invloed hebben op de behandeling die $i k u$, als huisarts geef. $U$ bent niet verplicht een verklaring voor uw beslissing af te leggen.

\section{Vragen}

Mocht $\mathrm{u}$ nu vragen hebben dan kunt $\mathrm{u}$ contact opnemen met mij of met een van de medewerkers aan het onderzoek (tel 043-3882324). Vanzelfsprekend kunt $u$ hen ook tijdens de periode van het onderzoek vragen stellen. $\mathrm{Zij}$ zullen $\mathrm{u}$ informeren over het verloop van het onderzoek.

Vertrouwlijkheid van uw gegevens en die van uw baby

Alle gegevens die tijdens het onderzoek over $u$ en uw baby verzameld worden, zijn vertrouwelijk. Anderen dan de behandelend arts of de onderzoekers kunnen de gegevens wel bekijken, maar uw naam blijft voor hen onbekend. De resultaten van het onderzoek kunnen terecht komen in wetenschappelijke publicaties, maar ook dan blijft uw naam uiteraard onbekend.

\section{Overige informatie}

Het onderzoek is gesubsidieerd door het Astmafonds en door het Praeventiefonds.

Aan het onderzoek zijn voor u geen extra kosten verbonden.

Tijdens het onderzoek blijf ik de behandelend arts. Dokter Schönberger heeft de leiding over het onderzoek.

De huisarts,

De huisarts-onderzoeker,

H.J.A.M. Schönberger. 
Geachte (aanstaande) ouder(s),

Onze praktijk doet mee aan een onderzoek van de universiteiten van Maastricht en Nijmegen. De afdelingen huisartsgeneeskunde van deze universiteiten doen onderzoek naar de oorzaken van ziekten en de juiste behandeling ervan.

Wij willen $\mathrm{u}$ vragen mee te werken aan een onderzoek naar het ontstaan van astma bij kinderen.

Astma is bij kinderen één van de meest voorkomende ziekten. Het ontstaat vaak in de eerste vijf levensjaren. Astma begint veelal met herhaaldelijk terugkerende perioden van (nachte-lijk) hoesten, piepen op de borst en benauwdheid. Huisartsen gebruiken dan vaak het woord bronchitis. Het merendeel van de kinderen houdt deze klachten op latere leeftijd.

We weten dat allergie, astma en bronchitis vaker ontstaan bij kinderen waarvan de ouders of broertjes of zusjes astma hebben. Kinderen die geboren worden in een dergelijke familie noemen we daarom erfelijk belast voor astma. Het is bij ons bekend dat astma bij $\mathrm{u}$ of in uw gezin in meerdere of mindere mate vóórkomt of vóórgekomen is.

\section{Doel van het onderzoek}

We willen onderzoeken bij welke kinderen astma ontstaat en wat daarvan de oorzaak is. Daarvoor is het nodig te weten óf en hoe vaak bij de erfelijk belaste kinderen allergie, bronchitis en astma ontstaan in de loop van de jaren en welke factoren daarbij een rol spelen.

\section{Het PREVASK onderzoek}

Voor dit onderzoek zijn ongeveer 200 ouderparen en hun baby's nodig.

Ieder kind maakt in de eerste vijf levensjaren, of het nu astma heeft of niet, een groot aantal aandoeningen van de luchtwegen door. Dit kan bijvoorbeeld een verkoudheid, een oor- of keelontsteking of een bronchitis zijn. Soms zult u mij daarvoor raadplegen. Ik leg dan de klachten, de diagnose en behandeling, zoals gebruikelijk, vast.

\section{Het onderzoek gaat als volgt}

Allereerst willen we de, op de vorige bladzijde vermelde, ziektegegevens van uw kind die door mij zijn genoteerd gedurende een periode van twee jaar, met uw toestemming, gebruiken.

Ook willen we vaststellen of zich bij uw kind een allergie ontwikkelt. Hiermee starten we direct na de geboorte met behulp van een bepaling in het bloed. Zoals $u$ weet wordt in Nederland iedere baby in de eerste week na de geboorte via een hielprik onderzocht op de aanwezigheid van een tweetal aangeboren aandoeningen. Bloed uit dezelfde hielprik willen we ook gebruiken om na te gaan of er wellicht sprake is van allergie. Op dat moment hoeft er dus niet extra geprikt te worden. De prik wordt na één en twee jaar herhaald; dan wordt een beetje bloed uit de vinger gehaald door een onderzoeksmedewerker.

Allergie ontstaat ook bij kinderen die veel in aanraking komen met de huisstofmijt. We willen daarom onderzoeken in weike mate de huisstofmijt in uw huis voorkomt. We doen dat door op een aantal plekken stofmonsters te nemen door met een stofzuiger wat stof op te zuigen. Deze metingen zullen bij $u$ thuis plaatsvinden rond de volgende tijdstippen: als bekend is dat u mee doet met het onderzoek, 1 jaar daarna en als uw kindje 1 en 2 jaar is.

Vervolgens vragen wij $\mathrm{u}$ of $\mathrm{u}$ in de eerste twee levensjaren bereid bent, onder meer de gezondheidsklachten van uw kindje bij te houden. U verzamelt deze gegevens in een speciaal daarvoor ontwikkeld babyboek dat wij $u$ zullen geven. Wij vragen $u$ deze gegevens regelmatig naar ons op te sturen.

Tenslotte wordt u gevraagd een aantal vragenlijsten in te vullen over dan aanwezige klachten bij uw kind en factoren die mogelijk een rol spelen bij het ontstaan van astma. Deze vragenlijsten worden verspreid aan $\mathbf{u}$ aangeboden, en wel direct nadat $u$ heeft aangegeven deel te willen nemen aan het onderzoek, en als uw kindje 6 maanden, 1 en 2 jaar is.

Eventuele risico's van het onderzoek

Aan het onderzoek zijn voor u en uw baby geen risico's verbonden.

\section{Mogelijke voordelen van het onderzoek}


Door deel te nemen aan dit onderzoek kunt u een belangrijke bijdrage leveren aan de kennis omtrent de ontstaanswijze van astma. Daaruit leren we hoe we astma kunnen voorkomen. Dit is van groot belang aangezien astma steeds meer voorkomt en er op het moment nog geen mogelijkheden zijn tot preventie van astma. Uiteraard zullen we u informeren over de bevindingen aan het einde van het onderzoek na twee jaar. Het gaat hierbij om de uitslagen van de metingen die in uw huis, en bij uw kindje gedaan zijn en om de algemene bevindingen van het onderzoek.

\title{
Verzekering
}

Zoals bij elk wetenschappelijk onderzoek gebruikelijk is, zijn deelnemers aan het onderzoek verzekerd tegen materiële schade (bijvoorbeeld het omstoten van een vaas tijdens een huisbezoek). Vragen hierover kunt $u$ stellen aan de leider van het onderzoek, dokter Schönberger (telefoonnummer: 043-3882324).

\section{Vrijwillige deelname}

Vanzelfsprekend bent $u$ niet verplicht aan het onderzoek deel te nemen. Ook kunt $u$ op ieder moment stoppen. Wij hopen natuurlijk dat dit zo weinig mogelijk gebeurt.

Als $u$ weigert zal dat zeker geen invloed hebben op de behandeling die ik u geef. U bent niet verplicht een verklaring voor uw beslissing af te leggen. Wij stellen het echter op prijs als $u$ de reden, waarom u niet (meer) mee wilt doen, wilt vermelden.

\section{Vragen}

Mocht $u$ nu vragen hebben dan kunt $u$ contact opnemen met mij of met één van de medewerkers aan het onderzoek. Vanzelfsprekend kunt $u$ ons ook tijdens de periode van het onderzoek vragen stellen.

\section{Vertrouwelijkheid van uw gegevens en die van uw baby}

Alle gegevens die tijdens het onderzoek over $u$ en uw baby verzameld worden, zijn vertrouwelijk. Anderen dan de behandelend arts of de onderzoekers kunnen de gegevens wel bekijken, maar uw naam blijft voor hen onbekend. De resultaten van het onderzoek kunnen terecht komen in wetenschappelijke publicaties, maar ook dan blijft uw naam uiteraard onbekend.

\section{Overige informatie}

Het onderzoek wordt gesubsidieerd door het Astmafonds en het Praeventiefonds.

Aan het onderzoek zijn voor u geen kosten verbonden.

Tijdens het onderzoek blijf ik de behandelend arts. Dokter Schönberger heeft de leiding over het onderzoek.

De huisarts,

De huisarts-onderzoeker,

\author{
H.J.A.M, Schönberger.
}


Voor criteria zie de toelichting handleiding registratie (s.v.p. hokje aankruisen indien van tocpassing)

Naam baby: geb.datum: huisarts:

Datum contact: nieuwe episode vervolgcontact/aktie

Soort contact (s.v.p. bij ieder contact noteren) $\begin{array}{llll}\text { visite } & \square & \text { consult } & \square\end{array}$ telefonisch consult

Symptomen/klachten (altiid vermelden, ook indien tevens een diagnose wordt geregistreerd) koorts $>=38.5$ verkoudheid (rhinitis) piepen (wheezing)

hoesten

kortademigheid

voedingsproblemen

onderzoeksbevindingen piepen met inspanning piepen zonder inspanning overdag

's nachts

bij inspanning in rust bij inspanning darmkolieken( krampjes) en/of aanvallen van ontroostbaar huilen diarree spugen piepende expir. rhonchi (verlengd expirium)

Diagnosen: (voor criteria zie de toelichting handleiding registratie)

Otitis media serosa (glue ear)

Otitis media acuta

Pseudocroup

Angina tonsillaris

Acute bronchitis

Pneumonie

Bronchiolitis

Astma

Constitutioneel eczeem/Dauwwrm

Koemelkeiwitallergie

Diagnostische akties (geen uitslagen vermelden)

Phadiatop

\section{RAST}

Huidtest

$\mathrm{X}$ thorax

Lab. (soort bepaling vermelden) anders, nl.

Verstrekte medicatie, ook herhalingsrecepten! (voor criteria zie de toelichting handleiding registratie)

Merknaam:

Dosering (hoeveelheid/dag):

Concentratie (sterkte: $\mathrm{mg} / \mathrm{ml} \mathrm{e.d.):}$
Toedieningsvorm:

Hoeveelheid (stuks, ml.e.d.):




\section{Voeding}

Borstvoeding

Hypo-allergene voeding

Borstvoeding en hypo-allergene voeding

Anders namelijk

( bijvoobeeld "normale flesvoeding)

\section{WEEK}

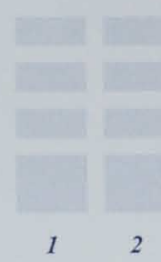

Algemene klachten

Koorts( temp 38.5 of hoger)

$0=$ geen koorts, $1=$ wel koorts

Huilen ( 3 uur of meer per dag)

$0=$ minder, $1=$ meer

\section{Luchtwegklachten}

\section{Verkouden *}

Hoesten *

De baby hoest overdag*

De baby hoest 's nachts*

De baby hoest bij inspanning*

De baby hoest in rust*

Volzitten met slijm* ( de baby heeft een zagende ademhaling, u hoort slijmgeruisen)

Piepen * ( de baby maakt een piepend geluid vooral bij uitademing)

De baby piept overdag *

De baby piept 's nachts*

De baby piept bij inspanning *

De baby piept in rust*

${ }^{*} 0=$ niet, $1=$ enigszins, $2=$ veel

\section{Heesheid}

\section{Kortademig}

\section{Diagnosen}

\section{Bronchitis*}

Astma

Valse croup

$$
\begin{aligned}
& \text { Dagverblijf } \\
& \text { Week } 1 \\
& \text { Week } 2 \\
& \text { Week....etc }
\end{aligned}
$$

